LIGIA MARIA CANTARINO DA COSTA

AVALIAÇÃO DO SISTEMA DE VIGILÂNCIA EPIDEMIOLÓGICA DA INFLUENZA NO BRASIL, 2010-2013

Brasília - DF, 2015 
Ficha catalográfica elaborada automaticamente, com os dados fornecidos pelo(a) autor(a)

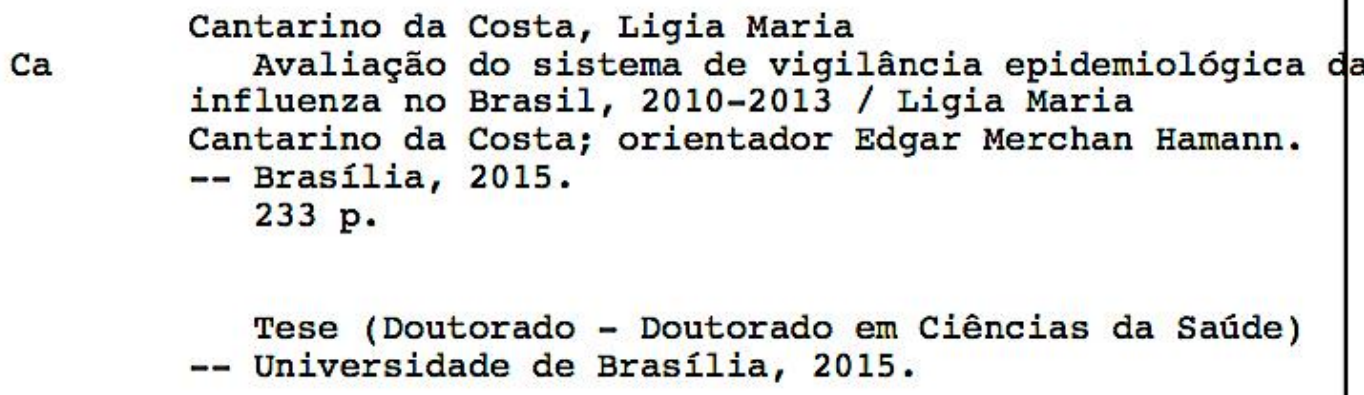

1. Influenza. 2. Vigilância epidemiológica. 3 . Avaliação em sistemas de saúde. 4. Gripe. I. Merchan Hamann, Edgar, orient. II. Título. 


\author{
UNIVERSIDADE DE BRASÍLIA \\ FACULDADE DE CIÊNCIAS DA SAÚDE \\ PROGRAMA DE PÓS-GRADUAÇÃO EM CIÊNCIAS DA SAÚDE
}

LIGIA MARIA CANTARINO DA COSTA

AVALIAÇÃO DO SISTEMA DE VIGILÂNCIA EPIDEMIOLÓGICA DA INFLUENZA NO BRASIL, 2010-2013.

Tese apresentada como requisito parcial para obtenção do Título de Doutor em Ciências da Saúde pelo Programa de Pós-Graduação em Ciências da Saúde da Universidade de Brasília.

Orientador:

Professor Dr. Edgar Merchan Hamann

$$
\text { Brasília - DF }
$$




\title{
AVALIAÇÃO DO SISTEMA DE VIGILÂNCIA EPIDEMIOLÓGICA DA INFLUENZA NO BRASIL, 2010-2013
}

\begin{abstract}
Tese apresentada como requisito parcial para obtenção do Título de Doutor em Ciências da Saúde pelo Programa de Pós-Graduação em Ciências da Saúde da Universidade de Brasília.
\end{abstract}

BANCA EXAMINADORA

Professor Dr. Edgar Merchan Hamann - Presidente Faculdade de Ciências da Saúde - Universidade de Brasília

Dr. Wyller Alencar de Mello

Instituto Evandro Chagas - Secretaria de Vigilância em Saúde - Ministério da Saúde

Professora Dra . Helena Eri Shimizu

Faculdade de Ciências da Saúde - Universidade de Brasília

Professor Dr. Pedro Luiz Tauil

Faculdade de Medicina - Universidade de Brasília

Professor Dr. Mauro Niskier Sanchez

Faculdade de Ciências da Saúde - Universidade de Brasília

Professor Dr. Wildo Navegantes de Araújo - suplente

Faculdade de Ceilândia - Universidade de Brasília 
Para José Renato, Laura e Suzana 


\section{AGRADECIMENTOS}

Ao Professor Dr. Edgar Merchan Hamann, com o reconhecimento pela compreensão das minhas limitações e percalços, agradeço pela orientação segura, tranquila e amiga.

Aos membros da banca de qualificação, os doutores José Ricardo Pio Marins, Maria Margarita Urdaneta Gutierrez, Pedro Sadi Monteiro e Leonor Maria Pacheco Santos, pelas importantes críticas e sugestões.

Aos colegas, professores e funcionários do Programa de Pós Graduação em Ciências da Saúde da Faculdade de Ciências da Saúde, Universidade de Brasília, pelas experiências e conhecimentos compartilhados.

Ao Professor Dr. Wildo Navegantes de Araújo, do Núcleo de Medicina Tropical da UnB, pela cordial, amiga e importante colaboração no trabalho.

Aos doutores Marilda Agudo Mendonça Teixeira de Siqueira, Wyller Alencar de Mello e Terezinha Maria de Paiva, responsáveis, respectivamente, pelos laboratórios de referência de influenza da Fiocruz, Rio de Janeiro; do Instituto Evandro Chagas, Pará; e do Instituto Adolfo Lutz, São Paulo, extensivo a seus braços fortes, Fernando do Couto Motta, Mirleide Cordeiro dos Santos e Margarete Aparecida Benega, pelos muitos ensinamentos.

Ao Grupo Técnico de Influenza da Secretaria de Vigilância em Saúde do Ministério da Saúde, pelas informações prestadas.

Ao Ronaldo de Jesus, da Coordenação Geral de Laboratórios de Saúde Pública do Ministério da Saúde, pela cordialidade nas informações sobre o Sistema Gerenciador de Ambiente Laboratorial.

À Faculdade de Agronomia e Medicina Veterinária da Universidade de Brasília, pelo apoio ao meu afastamento oficial.

À Ana Lourdes Arrais de Alencar Mota, do Laboratório de Epidemiologia Veterinária da UnB pela ajuda com a base de dados.

À Simone Perecmanis, pela amizade, incentivo permanente e conversas regadas a chá gelado. 
À Norma Vollmer Labarthe e Flávya Mendes-de-Almeida, amigas com quem, mesmo de longe, pude contar com apoio e estímulo.

À Denise Macedo Mancini, pela leitura cuidadosa e contribuições ao trabalho e, principalmente, pelas palavras amigas e pelos nossos cafés com letras quando, debalde, rimos de nós mesmas.

À minha família - a quem agradeço em nome dos meus primos-irmãos Gilson, Eduardo, Cristina, Taís e Marilena Cantarino - presença importante em muitos momentos.

A meus irmãos Noélia, José Geraldo e Maria Auxiliadora Cantarino da Costa e meus cunhados Marcos Lourenço de Almeida e Caitriona Kavanagh, por estarem sempre ao meu lado, fraternal e incondicionalmente.

A meus pais, Antônio Rodrigues da Costa e Lygia Cantarino Rodrigues da Costa, in memorian, pela presença amorosa constante em minha vida.

A José Renato Junqueira Borges, meu companheiro de caminhada nesta jornada terrena e sua/nossa filha Suzana Prista Borges.

À Laura Costa Borges, minha filha, pela luminosa presença em minha vida.

E a tantas outras pessoas que cruzam nossos caminhos, e que contribuem, de perto ou de longe, das mais diversas formas com nossas vidas. 
Nada é permanente, exceto a mudança.

Heráclito 


\section{RESUMO}

Influenza é virose respiratória de alta transmissibilidade e de impacto na população mundial. A Organização Mundial da Saúde estima que epidemias anuais resultem em cerca de 3 a 5 milhões de casos de doença grave e de 250 mil a 500 mil mortes em todo o mundo. $O$ objetivo geral do estudo foi avaliar a o sistema de vigilância epidemiológica de influenza no Brasil. Eram os objetivos específicos: descrever a estrutura sanitária brasileira frente a episódios pandêmicos de influenza; descrever a implantação e estruturação da vigilância de influenza no Brasil; discutir princípios éticos na vigilância de influenza; descrever os dados e a qualidade do seu registro nos bancos de dados do sistema de vigilância epidemiológica da influenza; descrever os atributos do sistema de vigilância epidemiológica de influenza. Foi realizada revisão de literatura e, para avaliar os atributos qualitativos, quantitativos, utilidade do sistema e desempenho da definição de caso foi utilizada a metodologia do Updated Guidelines for Evaluating Public Health Systems do Centers for Disease Control and Prevention (CDC). A população de estudo correspondeu aos casos registrados de síndrome gripal no Sistema de Informação Epidemiológica da Gripe (Sivep-Gripe), de 2010 a 2013, com base de dados secundários, não nominais. O sistema de vigilância deve ser melhorado em relação à qualidade dos dados, clareza metodológica e completitude. Foi considerado parcialmente útil, simples, de fácil entendimento, oportuno e flexível. No entanto, possui baixa aceitabilidade, baixo valor preditivo positivo e representatividade insatisfatória. $O$ estudo demonstrou que há necessidade de reflexão ética sobre as práticas em vigilância em saúde, observando a interdependência entre vigilância e pesquisa em saúde. É evidenciada a importância da vigilância da influenza de avaliações constantes, para identificar e corrigir problemas e melhorar o desempenho do sistema de vigilância, num processo contínuo de aperfeiçoamento.

Palavras-chave: Influenza; Vigilância Epidemiológica; Avaliação em Saúde 


\begin{abstract}
Influenza is a highly transmissible viral respiratory infection with significant impact on world population. The World Health Organization estimates that current epidemics result in approximately 3 to 5 million cases of severe illness and 250 thousand to 500 thousand deaths worldwide. The overall objective of the study was to evaluate the epidemiological surveillance system of influenza in Brazil. The specific objectives were: to describe the Brazilian health structure against the pandemic episodes of influenza; to describe the implementation and structuring of influenza surveillance in Brazil; to discuss ethical principles in influenza surveillance; to describe the data and the quality of the records in the databases of the influenza epidemiological surveillance system; to describe the attributes of the influenza epidemiological surveillance system. Literature review was performed and in order to assess the qualitative and quantitative attributes, the system usefulness and the performance of the case definition the methodology used was based on the Updated Guidelines for Evaluating Public Health of Systems Centers of the Disease Control and Prevention (CDC). The population of the study corresponded to recorded cases of flu-like illness in Brazil's Influenza Epidemiological Information System (Sivep-Gripe), from 2010 to 2013, with secondary databases and without patient names. The surveillance system should be improved in relation to data quality, methodological clarity and completeness. It was considered partially useful, simple, of easy comprehension, timely and flexible. However, it has low acceptability, low positive predictive value and unsatisfactory representation. The study demonstrated that there is a need for ethical reflection on health surveillance practices, noting the interdependence between surveillance and health research. It is evidenced the importance of influenza surveillance and that ongoing assessments should be conducted to identify and correct problems and to improve the performance of the surveillance system in a continuous process of improvement.
\end{abstract}

Keywords: Influenza, Epidemiological Surveillance, Health Assessment 


\section{LISTA DE FIGURAS}

Artigo 2 - Influenza no Brasil: caminhos da vigilância

Figura 1- Fluxograma da Vigilância da Influenza

Artigo 5 - Estudo dos atributos do sistema de vigilância epidemiológica da influenza no Brasil, 2010-2013

Figura 1 - Fluxograma da vigilância sentinela de influenza (síndrome gripal)

Figura 2 - Distribuição dos vírus respiratórios identificados nas unidades

sentinelas de Síndrome Gripal, por semana epidemiológica de início dos sintomas. Brasil, SE 1/2010 a SE 22/2013

Figura 3 - Observações sobre a qualidade da amostra para

imunofluorescência. Sivep-Gripe, Brasil, 2010-2013 


\section{LISTA DE QUADROS}

Artigo 1 - Pandemias de influenza e a estrutura sanitária brasileira: breve histórico e caracterização dos cenários

Quadro 1 - Estrutura sanitária brasileira frente à história dos eventos de 56 influenza

Artigo 4 - Avaliação da qualidade dos registros do Sistema de Informação de Vigilância Epidemiológica da Gripe, Brasil, 2010-2013

Quadro 1 - Critérios de avaliação da qualidade dos dados nas dimensões clareza metodológica, completitude e inconsistência do Sivep-Gripe. Brasil, 2010-2013

\section{Artigo 5 - Estudo dos atributos do sistema de vigilância} epidemiológica da influenza no Brasil, 2010-2013

Quadro 1 - Instrumento auxiliar de avaliação do sistema de vigilância epidemiológica da influenza sazonal

Quadro 2 - Parâmetro populacional para implantação da vigilância de síndrome gripal

Quadro 3 - Contingência comparativa dos dados de vigilância e de laboratório para estudo da definição de caso de influenza

Quadro 4 - Distribuição de Unidades Sentinelas de síndrome gripal por Região Metropolitana de capital estadual, em municípios com mais de 300 mil habitantes

Quadro 5 - Distribuição de Unidades Sentinelas de síndrome gripal em municípios da Região Sul com mais de 300 mil habitantes 


\section{LISTA DE TABELAS}

Artigo 4 - Avaliação da qualidade dos registros do Sistema de Informação de Vigilância Epidemiológica da Gripe, Brasil, 2010-2013

Tabela 1 - Resumo do número e percentual de campos incompletos ou 114 ignorados das variáveis do Sivep-Gripe. Brasil, 2010-2013

Tabela 2 - Número e percentual dos campos incompletos ou ignorados 115 relativos à vacinação dos pacientes que tiveram amostras coletadas no Sivep-Gripe. Brasil, 2010-2013

Tabela 3 - Número e percentual do preenchimento dos campos relativos ao 116 resultado da imunofluorescência no Sivep-Gripe. Brasil, 2010-2013

Tabela 4 - Número e percentual de inconsistências no Sivep-Gripe. Brasil, 2010-2013

\section{Artigo 5 - Estudo dos atributos do sistema de vigilância epidemiológica da influenza no Brasil, 2010-2013}

Tabela 1 - Vírus respiratórios identificados nas unidades sentinelas, por região e faixa etária. Sivep-Gripe, Brasil, 2010-2013

Tabela 2 - Distribuição das amostras coletadas nas unidades sentinelas para síndrome gripal por faixa etária e sexo. Sivep-Gripe, Brasil, 2010-2013

Tabela 3 - Frequência da informação "Qualidade do material” por região. Sivep-Gripe, Brasil, 2010-2013

Tabela 4 - Número e percentual de amostras coletadas nas unidades sentinelas de influenza. Sivep-Gripe, Brasil, 2010-2013

Tabela 5 - Resultados da imunofluorescência indireta para vírus respiratórios. Sivep-Gripe, Brasil, 2010-2013

Tabela 6 - Distribuição do número de US por município, estado, região, extensão territorial, população e densidade demográfica

Tabela 7 - Oportunidade da coleta de amostra e do resultado laboratorial: 
mediana em dias, por estado. Sivep-Gripe, Brasil, 2010-2013*

Tabela 8 - Frequência da informação dos sintomas. Sivep-Gripe, Brasil, 2010-2013

Tabela 9 - Desempenho da definição de caso de síndrome gripal. SivepGripe, Brasil, 2010-2013 


\section{LISTA DE ABREVIATURAS E SIGLAS}

ACE

ANF

Anvisa

BVS

Capes

CC

CDC

CEP

CGDT

CGLAB

CID

CIEVS

Cioms

CNES

CNS

CRIE

Ct

Datasus

DBF

Episus

ESPII
American College of Epidemiology

Aspirado de Nasofaringe

Agência Nacional de Vigilância Sanitária

Biblioteca Virtual em Saúde

Coordenação de Aperfeiçoamento de Pessoal de Nível Superior

Centros Colaboradores

Centers for Disease Control and Prevention / Centros de Controle e Prevenção de Doenças dos Estados Unidos.

Comitê de Ética de Pesquisa

Coordenação-Geral de Doenças Transmissíveis

Coordenação Geral de Laboratórios de Saúde Pública

Classificação Internacional de Doenças

Centro de Informações Estratégicas e Resposta em Vigilância em Saúde

Conselho Internacional de Organizações de Ciências Médicas

Cadastro Nacional de Estabelecimentos de Saúde

Conselho Nacional de Saúde

Centros de Referência para Imunobiológicos Especiais

Cycle Threshold

Departamento de Informática do SUS Sistema Único de Saúde

Data Base File

Programa de Treinamento em Epidemiologia Aplicada aos Serviços do Sistema Único de Saúde

Emergência em Saúde Pública de Importância Nacional e Internacional 
FAO Organização das Nações Unidas para Alimentação e Agricultura

Fiocruz Fundação Oswaldo Cruz

FluNet Plataforma de compartilhamento de dados do GISRS

GAL Sistema Gerenciador de Ambiente Laboratorial

GEI Grupo Executivo Interministerial

GEI-ESPII Grupo Executivo Interministerial de Emergência em Saúde Pública de Importância Nacional e Internacional

GISN Global Influenza Surveillance Network / Rede Global de Vigilância da Influenza

GISRS Global Influenza Surveillance and Response System-/-Sistema Global de Vigilância e Resposta da Influenza

GROG Groupe Regional d'Observation de la Grippe / Grupo de Observação da Gripe

HIPAA Health Insurance Portability and Accountability Act of 1996

IA Influenza Aviária

IAL Instituto Adolfo Lutz

IBGE Instituto Brasileiro de Geografia e Estatística

IEC Instituto Evandro Chagas

IFI Imunofluorescência indireta

ILI Influenza-like illness

Lacen Laboratório Central de Saúde Pública

Lanagro Laboratório Nacional Agropecuário

LR Laboratórios de Referência

MAPA Ministério da Agricultura, Pecuária e Abastecimento

MDCK Madin-Darby canine kidney cells

Medline Medical Literature Analysis and Retrieval System Online /

Sistema Online de Busca e Análise de Literatura Médica 


$\begin{array}{ll}\text { MS } & \text { Ministério da Saúde } \\ \text { NCBI } & \text { National Center for Biotechnology Information } \\ \text { NIC } & \text { National Influenza Centres / Centros Nacionais de Influenza } \\ \text { OFFLU } & \text { OIE/FAO Network of Expertise on Animal Influenza } \\ \text { OIE } & \text { World Organisation for Animal Health / Organização Mundial de } \\ & \text { Saúde Animal } \\ \text { OMS } & \text { Organização Mundial da Saúde } \\ \text { OPAS } & \text { Organização Pan-Americana da Saúde } \\ \text { Panaftosa } & \text { Centro Panamericano de Febre Aftosa } \\ \text { PCR } & \text { Reação em cadeia da polimerase } \\ \text { PNS } & \text { Pesquisa Nacional de Saúde } \\ \text { Rede CIEVS } & \text { Rede Nacional de Alerta e Resposta às Emergências em Saúde } \\ \text { RM } & \text { Regiões Metropolitanas } \\ \text { RSI } & \text { Regulamento Sanitário Internacional } \\ \text { SC } & \text { Swab Combinado } \\ \text { SciELO } & \text { Scientific Electronic Library Online } \\ \text { SE } & \text { Semana Epidemiológica } \\ \text { SG } & \text { Síndrome Gripal } \\ \text { SIH } & \text { Sistema de Informações Hospitalares } \\ \text { SIM } & \text { Sistema de Informação de Mortalidade } \\ \text { Sinan } & \text { Sistema de Informação de Agravos de Notificação } \\ \text { SIS } & \text { Sistemas de Informação em Saúde } \\ \text { SisBraVet } & \text { Sistema Brasileiro de Vigilância e Emergências Veterinárias } \\ \text { Sislab } & \text { Sistema Nacional de Laboratórios de Saúde Pública } \\ \text { Sivep-Gripe } & \text { Sistema de Informação de Vigilância Epidemiológica da Gripe } \\ & \end{array}$


Sistema Nacional de Informação Zoossanitária

SNVE

Sistema Nacional de Vigilância Epidemiológica

SRAG

Síndrome Respiratória Aguda Grave

SUS

Sistema Único de Saúde

SVS

Secretaria de Vigilância em Saúde

TCLE

Termo de Consentimento Livre e Esclarecido

UnB

Universidade de Brasília

US

Unidade Sentinela

UTI

Unidade de Terapia Intensiva

UVRI

Unidade Técnica de Vigilância das Doenças de Transmissão Respiratórias e Imunopreveníveis

VigiGripe Grupo de Observação da Gripe

VPP Valor preditivo positivo

VRS Vírus respiratório sincicial

WAHID World Animal Health Information Database

WAHIS World Animal Health Information System 


\section{SUMÁRIO}

1 INTRODUÇÃO

1.1 INFLUENZA 22

1.2 VIGILÂNCIA EM SAÚDE E AVALIAÇÃO 23

1.3 SISTEMAS DE INFORMAÇÃO 25

2 OBJETIVOS

2.1 OBJETIVO GERAL $\quad 27$

2.2 OBJETIVOS ESPECÍFICOS

3 MÉTODOS 28

3.1 REVISÃO DE LITERATURA 28

3.2 AVALIAÇÃO DO SISTEMA DE VIGILÂNCIA DA INFLUENZA 28

3.3 ASPECTOS ÉTICOS 30

4 RESULTADOS 31

4.1 PRIMEIRO ARTIGO - "PANDEMIAS DE INFLUENZA E A 32

ESTRUTURA SANITÁRIA BRASILEIRA: BREVE HISTÓRICO E CARACTERIZAÇÃO DOS CENÁRIOS"

4.1.1 Resumo 32

4.1.2 Introdução 32

4.1.3 Aspectos históricos $\quad 34$

4.1.4 Aspectos virológicos 36

4.1.5 Pandemias de influenza 38

4.1.5.1 Pandemia de 1889 - $1890 \quad 40$

4.1.5.2 Pandemia de 1918 - 1920: Gripe Espanhola 41

4.1.5.3 Pandemia de 1957 - 1958: Gripe Asiática 44

4.1.5.4 Pandemia de 1968 - 1969: Gripe de Hong Kong 45

4.1.5.5 Gripe Russa: 1977 - 1978

4.1.5.6 Gripe Aviária: 2003 - 2004

4.1.5.7 Pandemia de 2009: gripe A(H1N1)pdm09 49

4.1.6 Aspectos da influenza em animais 52

4.1.7 Considerações finais $\quad 54$

Referências $\quad 58$ 
4.2 SEGUNDO ARTIGO - "INFLUENZA NO BRASIL: CAMINHOS DA

VIGILÂNCIA"

4.2.1 Resumo

67

4.2.2 Introdução 68

4.2.3 Vigilância global $\quad 69$

4.2.4 A vigilância de influenza humana no Brasil 70

4.2.4.1 A vigilância em 2009: ano pandêmico 73

4.2.4.2 A atual vigilância de influenza no Brasil 73

4.2.4.3 O diagnóstico laboratorial na vigilância $\quad 76$

4.2.4.4 A rede laboratorial $\quad 77$

4.2.5 A vacinação como medida preventiva 78

4.2.6 Sistemas de informação 79

4.2.7 Aspectos da vigilância de influenza em animais 79

4.2.8 Considerações finais 82

Referências

4.3 TERCEIRO ARTIGO - "PENSAR A ÉTICA NA VIGILÂNCIA DE 91

INFLUENZA?"

4.3.1 Resumo 91

4.3.2 Introdução 92

4.3.3 Das práticas, orientações e normas de vigilância

4.3.4 Dos direitos 98

4.3.5 Dos princípios bioéticos 99

4.3.6 Considerações finais 101

Referências 103

4.4 QUARTO ARTIGO - "AVALIAÇÃO DA QUALIDADE DOS 106 REGISTROS DO SISTEMA DE INFORMAÇÃO DE VIGILÂNCIA EPIDEMIOLÓGICA DA GRIPE, BRASIL, 2010-2013"

$\begin{array}{ll}\text { 4.4.1 Resumo } & 106\end{array}$

$\begin{array}{ll}\text { 4.4.2 Introdução } & 107\end{array}$

4.4.3 Material e método 109

4.4.4 Resultados 111

4.4.4.1 Clareza metodológica 112

4.4.4.2 Completitude 113 
4.4.5 Discussão 117

Referências 123

4.5 QUINTO ARTIGO - "ESTUDO DOS ATRIBUTOS DO SISTEMA DE 127 VIGILÂNCIA EPIDEMIOLÓGICA DA INFLUENZA NO BRASIL, 20102013"

\subsubsection{Resumo}

\subsubsection{Métodos}

4.5.4.1 Propósito e utilidade da vigilância 136

$\begin{array}{ll}\text { 4.5.4.2 Definição de caso } & 136\end{array}$

4.5.4.3 Componentes e operacionalização do sistema 136

4.5.4.4 Informações relevantes geradas à vigilância 137

4.5.4.5 Utilidade 144

4.5.4.6 Estudo dos atributos qualitativos $\quad 145$

4.5.4.6.1 Simplicidade $\quad 145$

4.5.4.6.2 Flexibilidade $\quad 146$

4.5.4.6.3 Aceitabilidade $\quad 146$

4.5.4.7 Estudo dos atributos quantitativos $\quad 150$

4.5.4.7.1 Valor Preditivo Positivo 150

4.5.4.7.2 Representatividade $\quad 150$

$\begin{array}{ll}\text { 4.5.4.7.3 Oportunidade } & 157\end{array}$

4.5.4.7.4 Sensibilidade $\quad 157$

4.5.4.8 Desempenho da definição de caso 159

4.5.5 Discussão 162

Referências $\quad 170$

5 CONSIDERAÇÕES FINAIS 175

$\begin{array}{ll}\text { Referências } & 180\end{array}$

APÊNDICES

$\begin{array}{ll}\text { ANEXOS } & 185\end{array}$ 


\section{INTRODUÇÃO}

\subsection{INFLUENZA}

A influenza ou gripe é uma das principais causas de morbidade e mortalidade em todo o mundo. É causada pelo vírus influenza e tem alto poder de transmissibilidade e está globalmente distribuída.

A transmissão pessoa-pessoa ocorre principalmente por aerossóis ou contato direto com secreções. Possui curto período de incubação e os principais sintomas são febre, tosse, dor de garganta, dor de cabeça, mal-estar. Pessoas com maior risco de complicações da infecção por influenza são os jovens, idosos, aquelas com certas condições de saúde preexistentes. Crianças, idosos, indivíduos com doenças crônicas, imunocomprometidos e gestantes têm potencial risco para a doença. Nas estações de outono e inverno são registrados maiores números de casos, demarcando sazonalidade $(1,2)$.

A virose tem incidência anual estimada de $5 \%$ a $10 \%$ em adultos e de $20 \%$ a $30 \%$ em crianças. Doenças consequentes desse agravo podem resultar em hospitalização e morte, principalmente entre os grupos de alto risco (os muito jovens, idosos ou doentes crônicos). Calcula-se que as epidemias resultem em aproximadamente 3 a 5 milhões de casos de doença grave e de 250 mil a 500 mil mortes anuais em todo o mundo (3).

A gripe consta na Pesquisa Nacional de Saúde (PNS) de 2013 (4) como um dos motivos que impediram $17,8 \%$ das pessoas a realizar suas atividades rotineiras. A distribuição dos casos de gripe ou resfriado, segundo grupo etário, foi de $39,8 \%$ na para o de 0 a 17 anos de idade e $6,9 \%$ para o de 60 anos ou mais.

Os países devem melhorar a vigilância para entender melhor circulação do vírus influenza e a sazonalidade para determinar a composição da vacina e o melhor momento para a vacinação, como recomendado pela Organização Mundial da Saúde (OMS). As regiões com circulação diferenciada do vírus, como as tropicais, devem ter especial atenção em relação à adequação da vacina e ao calendário 
vacinal. Pesquisas são fundamentais para avaliar a carga da doença - morbidade, mortalidade, hospitalização -, bem como o ônus econômico da gripe.

\subsection{VIGILÂNCIA EM SAÚDE E AVALIAÇÃO}

O Sistema Nacional de Vigilância Epidemiológica (SNVE) foi instituído pela Lei 6.259/1975 (5) e regulamentado pelo Decreto 78.231/1976 (6). Com a criação do Sistema Único de Saúde (SUS) e a publicação da Lei 8.080/1990 (7), regulamentada pelo Decreto 7.508/2011 (8), vigilância epidemiológica foi definida como "um conjunto de ações que proporciona o conhecimento, a detecção ou prevenção de qualquer mudança nos fatores determinantes e condicionantes de saúde individual ou coletiva, com a finalidade de recomendar e adotar as medidas de prevenção e controle das doenças ou agravos".

O propósito da vigilância epidemiológica é "fornecer orientação técnica permanente para os profissionais de saúde, que têm a responsabilidade de decidir sobre a execução de ações de controle de doenças e agravos, bem como dos fatores que a condicionam, numa área geográfica ou população definida" (5). Sua operacionalização deve ser desenvolvida de forma contínua tendo como funções: coleta, processamento, análise e interpretação de dados; recomendação das medidas de prevenção e controle; promoção das ações de prevenção e controle indicadas; avaliação da eficácia e efetividade das medidas adotadas; divulgação de informações pertinentes (9). Desse modo, a vigilância epidemiológica se configura como importante instrumento para o planejamento, organização e operacionalização dos serviços de saúde, além subsidiar as atividades técnicas.

A preocupação do Estado com a proteção da saúde da população é antiga e com frequência envolve questões econômicas e de segurança interna e externa. Diante do processo de globalização de mercado que afeta a saúde pública, as doenças infecciosas voltam, sob a nova abordagem de emergentes e reemergentes, a partir de 1990, a constituir preocupação do Estado, com a busca de instrumentos adequados ao seu controle. Com tal propósito, torna-se imperiosa a perfeita delimitação do conceito de controle a ser adotado e a identificação e aperfeiçoamento dos instrumentos a serem utilizados com essa finalidade, entre os 
quais poderíamos apontar: as tecnologias médicas (vacinas e antibióticos, entre outras) e a vigilância de doenças infecciosas, oferecendo subsídios para a fundamentação técnica das estratégias aplicadas nas ações de controle (10).

Vigilância em saúde pública é a contínua e sistemática coleta, análise, interpretação e disseminação de dados relativos a um evento sanitário. É um conjunto de ações em saúde pública com objetivo de reduzir morbidade, mortalidade e melhorar a saúde. Os dados registrados e disseminados por um sistema de vigilância podem e devem ser usados para planejamento e avaliação de programas, além de formulação de hipóteses para pesquisa em saúde pública $(11,12)$.

São etapas importantes para avaliação de um sistema de vigilância: a descrição do evento de saúde sob vigilância, a enumeração dos objetivos do sistema e sua operacionalização para prevenção e controle da doença ou agravo. Essas três etapas sozinhas são, frequentemente, suficientes para indicar como o sistema pode ser melhorado (13).

Cada sistema de vigilância possui características ou atributos que contribuem diretamente para a sua capacidade de cumprir seus objetivos específicos. A combinação desses atributos é que determina os pontos fortes e fracos do sistema. Os atributos devem ser equilibrados e são utilizados para executar essas avaliações. $\mathrm{Na}$ descrição de um sistema de vigilância, quatro atributos quantitativos devem ser verificados: sensibilidade, valor preditivo positivo, representatividade e oportunidade. Os três atributos qualitativos são: simplicidade, flexibilidade e aceitabilidade (13).

O atributo sensibilidade é a capacidade do sistema de detectar os casos verdadeiros do evento. O valor preditivo positivo (VPP) representa a proporção dos casos suspeitos ou notificados e que são confirmados como doentes ao final da investigação epidemiológica. Representatividade indica a cobertura, ou seja, descreve a ocorrência de um evento adverso à saúde, ao longo do tempo, segundo os atributos da população e a distribuição espacial dos casos. $O$ atributo oportunidade reflete a agilidade do processo desde a captação dos dados, passando pela confirmação até a obtenção de relatórios. Pode ser definida como a quantidade de tempo decorrido no cumprimento das etapas de vigilância, desde a identificação do agravo, sua notificação até a disseminação das informações. A simplicidade indica se sua estrutura e operação são de fácil compreensão e implementação e pouco dispendiosos. A flexibilidade é a habilidade de adaptação do sistema frente a novas necessidades em resposta às mudanças na natureza do evento, alterações 
das estratégias de prevenção e controle ou na importância de um evento adverso à saúde. $O$ atributo aceitabilidade indica que o sistema é aceito pelos profissionais de saúde e das instituições que conduzem o sistema, permitindo que as informações geradas sejam consistentes e regulares $(14,15,12)$.

\subsection{SISTEMAS DE INFORMAÇÃO}

"Sistemas de informação em saúde compreendem o conjunto de subsistemas de informações de natureza demográfica, epidemiológica, administrativa e gerencial necessárias ao estudo e gestão dos bens e serviços de saúde" conforme conceituam Duarte (16) e colaboradores. Esses autores ressaltam que a existência de sistemas de informação desenvolvidos aponta uma maior estruturação da vigilância em saúde e, possivelmente, maior organização dos serviços de atenção e qualidade no atendimento aos usuários.

Para acompanhar as estratégias de vigilância deste agravo são utilizadas informações de diferentes Sistemas de Informação em Saúde (SIS). Os dados da vigilância são coletados por meio de formulários padronizados, e inseridos nos sistemas de informação on-line: Sistema de Informação de Vigilância Epidemiológica da Gripe (Sivep-Gripe) e Sistema de Informação de Agravos de Notificação (Sinan Influenza). Outros sistemas, como o Sistema de Informações Hospitalares $(\mathrm{SIH}$ SUS) e o Sistema de Informações sobre Mortalidade (SIM) também se configuram como importantes fontes para seu acompanhamento $(2,17,18)$. O Sistema Gerenciador de Ambiente Laboratorial (GAL) constitui ferramenta facilitadora para a disponibilidade dos resultados laboratoriais, o que colabora na divulgação da informação sobre os agravos alvo de vigilância (19).

O Sivep-Gripe foi desenvolvido para dar suporte às ações da vigilância de influenza, principalmente voltadas para identificação dos principais vírus respiratórios circulantes. Os dados da vigilância são coletados por meio de formulários padronizados e inseridos on-line, via internet. A alimentação do sistema é realizada no nível local, nas Unidades Sentinelas (US), e pelos laboratórios de referência regionais e nacional que entram com dados relativos aos resultados dos exames como a caracterização antigênica do vírus da influenza. O Sivep-Gripe 
registra os dados da vigilância sentinela de casos de síndrome gripal e de Síndrome Respiratória Aguda Grave (SRAG) com coleta de amostra para exame laboratorial, o agregado total do número de atendimentos das US e o total de atendimentos por síndrome gripal $(18,20,21)$.

O Sinan agrega informações das mais diversas doenças e agravos de notificação obrigatória e que vem sendo sucessivamente atualizado. É um sistema complexo. Nele, existe um módulo, de arquitetura baseada na internet, para a vigilância de influenza conhecida como Sinan Influenza. É um sistema importante de acompanhamento da morbidade e dos casos graves de influenza (SRAG). Entretanto, apresenta limitações como o fato de não dispor dos seguintes recursos: versão desktop para instalação do sistema em municípios sem estrutura de internet; mecanismo de gestão local nas bases de dados pelas secretarias municipais e estaduais de saúde; e mecanismo de exportação das bases de dados (22).

Os SIS favorecem a circulação ágil e gerenciamento da informação entre as instâncias governamentais do Sistema de Saúde, nos níveis municipal, estadual e federal. À medida que a tecnologia da informação avança de forma acelerada, com o constante lançamento de produtos, plataformas e recursos que possibilitam novas rotinas de trabalho, os SIS também precisam se modernizar para acompanhar essas demandas e desafios. São instrumentos importantes de vigilância em saúde pública. 


\section{OBJETIVOS}

\subsection{OBJETIVO GERAL}

Avaliar o sistema de vigilância epidemiológica de influenza nos anos de 2010 a 2013.

\subsection{OBJETIVOS ESPECÍFICOS}

1. Descrever a estrutura sanitária brasileira frente a episódios pandêmicos de influenza.

2. Descrever a implantação e estruturação da vigilância de influenza no Brasil.

3. Discutir princípios éticos na vigilância de influenza

4. Avaliar os dados e a qualidade do seu registro nos bancos de dados do sistema de vigilância epidemiológica da influenza.

5. Avaliar os atributos e a utilidade do sistema de vigilância epidemiológica de influenza nos anos de 2010 a 2013. 


\section{MÉTODOS}

\subsection{REVISÃO DE LITERATURA}

A revisão narrativa da literatura foi realizada pela consulta bibliográfica e eletrônica no acervo da Biblioteca Central da Universidade de Brasília (UnB) e nas bases de periódicos científicos: Periódicos da Coordenação de Aperfeiçoamento de Pessoal de Nível Superior (Capes), Biblioteca Virtual em Saúde (BVS), Scientific Electronic Library Online (SciELO), National Center for Biotechnology Information (NCBI), Web of Science ${ }^{T M}$ e serviço do U.S. National Library of Medicine (Medline). Também foram pesquisados sítios de organismos internacionais e nacionais de saúde: Organização Mundial da Saúde (OMS), Organização Mundial de Saúde Animal (OIE), Organização Pan-americana de Saúde (OPAS), Centers for Disease Control and Prevention (CDC) e Ministério da Saúde (MS).

Foram utilizados os descritores: influenza, vigilância epidemiológica, saúde pública, epidemia, sistemas de saúde, animais. A revisão incluiu artigos científicos originais, outros tipos de produção acadêmica, documentos oficiais (legislação, manuais, notas técnicas), bem como livros, incluindo os elaborados por historiadores como aqueles de cunho jornalístico. As mesmas palavras-chave foram pesquisadas em português e em inglês.

\subsection{AVALIAÇÃO DO SISTEMA DE VIGILÂNCIA DE INFLUENZA}

O estudo foi aplicado à vigilância epidemiológica de influenza no âmbito nacional. A população de estudo correspondeu aos casos registrados de síndrome gripal no Sistema de Informação Epidemiológica da Gripe (Sivep-Gripe), de 2010 a 2013.

Foram utilizados como fontes bancos de dados secundários, não nominais, sem qualquer identificação dos indivíduos, proveniente do Sistema de Vigilância Epidemiológica da Gripe (Sivep-Gripe) dos anos 2010 a 2013.

A requisição formal dos dados à Secretaria de Vigilância em Saúde (SVS) do Ministério da Saúde (MS) foi com base na Lei de Acesso à Informação (Lei 
12.527/2011) (23) e na Portaria/MS 1.583/2012 (24). Os arquivos foram oficialmente fornecidos, em mídia removível, pela Unidade Técnica de Vigilância das Doenças de Transmissão Respiratórias e Imunopreveníveis (UVRI) da Coordenação Geral de Doenças Transmissíveis (CGDT) da SVS/MS. Os arquivos originais de extensão Data Base File (DBF) foram convertidos em planilhas do software Microsoft Excel $^{\circledR} 2010$.

As planilhas do Sivep-Gripe obtidas para este trabalho continham os registros referentes às observações de Síndrome Gripal (SG), que tiveram coleta de amostras, dos anos de 2010, 2011, 2012 e 2013. Os bancos obtidos não apresentavam os dados agregados dos atendimentos das Unidades Sentinelas (US) para vigilância da influenza, que indicariam a proporção de casos de SG por faixa etária (Anexo F).

A pesquisa avaliativa de sistemas de vigilância em saúde pública utilizou a metodologia preconizada no documento Updated Guidelines for Evaluating Public Health Surveillance Systems (12) do Centers for Disease Control and Prevention (CDC), Departamento de Saúde e Serviços Humanos dos Estados Unidos. Foi feito estudo dos atributos qualitativos: simplicidade, flexibilidade, qualidade dos dados e aceitabilidade; e os quantitativos: sensibilidade, valor preditivo positivo, representatividade e oportunidade do sistema de vigilância da influenza. A utilidade do sistema foi avaliada considerando o atendimento aos objetivos propostos nos guias e manuais da vigilância da influenza, e o desempenho da definição de caso de síndrome gripal adotada pelo cálculo da prevalência dos sintomas em relação ao número total de casos positivos.

A descrição do sistema de vigilância de influenza - do propósito, operação e objetivos - foi realizada segundo levantamento dos dados disponíveis sobre a vigilância epidemiológica da influenza obtidos junto aos sistemas Sivep-Gripe, por pesquisa bibliográfica, consulta à legislação, documentos de trabalho e materiais diversos, como as Notas Técnicas e Informes Epidemiológicos da Secretaria de Vigilância em Saúde do Ministério da Saúde.

Para as análises descritivas foram utilizados os softwares Epi Info ${ }^{\mathrm{TM}} 7.1 .4 .0 \mathrm{e}$ Microsoft Excel ${ }^{\circledR} 2010$. 


\subsection{ASPECTOS ÉTICOS}

O trabalho seguiu os preceitos de ética em pesquisa científica em conformidade com a Resolução do Conselho Nacional de Saúde (CNS) nำ466, de 12 de dezembro de 2012 (25), que trata das diretrizes e normas regulamentadoras de pesquisas envolvendo seres humanos. Embora o estudo tenha utilizado bases fornecidas de forma não nominais, sem nenhuma menção de nomes ou identificação dos indivíduos, o projeto foi submetido ao Comitê de Ética da Faculdade de Ciências da Saúde da UnB (CEP/FS/UnB) e aprovado pelo Parecer 563.033/2014 em 12 de março de 2014 (Anexo A). 


\section{RESULTADOS}

Os resultados foram apresentados sob a forma de cinco artigos científicos.

O primeiro, "Pandemias de influenza e a estrutura sanitária brasileira: breve histórico e caracterização dos cenários", trata de revisão histórica da virose e relata a organização sanitária brasileira frente aos eventos de influenza. Esse artigo responde ao primeiro objetivo específico e foi submetido para publicação e encontrase em fase final de avaliação.

O segundo artigo, "Influenza no Brasil: caminhos da vigilância" descreve a implantação e a estruturação da vigilância de influenza no Brasil. Esse artigo atende ao segundo objetivo específico. Aqui apresentado em português, foi submetido e aceito para publicação, em inglês, no periódico The Journal of Infection in Developing Countries com sede na Itália (Anexos B e C).

O terceiro artigo, "Pensar a ética na vigilância de influenza?", corresponde ao terceiro objetivo específico e traz uma reflexão sobre aspectos éticos nas atividades práticas da vigilância da influenza. Foi submetido e aceito para publicação na Revista Bioética, do Conselho Federal de Medicina, com sede em Brasília (Anexo D).

O quarto artigo, "Avaliação da qualidade dos registros do Sistema de Informação de Vigilância Epidemiológica da Gripe, Brasil, 2010-2013", versa sobre a descrição dos dados e a qualidade dos registros do Sivep-Gripe, e refere-se ao quarto objetivo específico. Foi submetido para publicação e está em processo de análise.

O quinto artigo, "Avaliação dos atributos do Sistema de Vigilância Epidemiológica da Influenza no Brasil, 2010-2013", discorre sobre o resultado do estudo dos atributos do sistema e responde ao quinto objetivo específico e será submetida para publicação. 


\subsection{PRIMEIRO ARTIGO - "PANDEMIAS DE INFLUENZA E A ESTRUTURA SANITÁRIA BRASILEIRA: BREVE HISTÓRICO E CARACTERIZAÇÃO DOS CENÁRIOS"}

Ligia Cantarino

Faculdade de Agronomia e Medicina Veterinária, Universidade de Brasília, Brasília, Brasil

Edgar Merchan-Hamann

Faculdade de Ciências da Saúde, Universidade de Brasília, Brasília, Brasil

\subsubsection{Resumo}

A influenza e sua capacidade de gerar ondas epidêmicas e pandêmicas são registradas mundialmente. São feitas anotações das principais características virológicas, clínicas e epidemiológicas, incluindo sua mortalidade e letalidade, e o contexto da sua ocorrência em caráter pandêmico. A estrutura sanitária brasileira frente à história das pandemias é caracterizada de forma breve. Aspectos da vigilância em animais também são abordados, face à possibilidade de propagação do vírus da influenza para a população humana. A abordagem histórica contribui para alertar sobre a importância da influenza quanto virose respiratória de caráter zoonótico, alta capacidade de transmissão e distribuição global e a necessidade crescente de resposta articulada de governos.

\section{Palavras-chave}

Influenza humana, pandemias, vigilância em saúde, saúde pública.

\subsubsection{Introdução}

A influenza ou gripe talvez seja a infecção que causou mais doenças e mortes até a atualidade. Doença aguda do sistema respiratório, causada pelo vírus influenza, tem alta capacidade de transmissão e distribuição global.

A transmissão do vírus da influenza entre humanos está bem estabelecida e ocorre pela via respiratória por meio de secreções como aerossóis, gotículas ou por contato direto da mucosa (1). O vírus influenza, de característica zoonótica, afeta 
muitas espécies de aves e mamíferos. Algumas vezes a transmissão ultrapassa as barreiras entre as diferentes espécies e pode criar cenário promissor para geração de uma cepa com potencial pandêmico. A cada ano a influenza é causa significativa de doença e óbitos humanos e produz importante impacto na saúde e produção animal. É uma contínua ameaça à saúde pública veterinária e humana $(1,2)$.

Apesar dos sintomas semelhantes com outros vírus que acometem o trato respiratório, a febre súbita - que dura cerca de três dias, acompanhada de dor muscular e prostração - é característica de infecção pelo vírus da influenza. As epidemias são imprevisíveis e afetam um grande número de pessoas. O cenário de uma epidemia dependerá entre outros aspectos das medidas de prevenção e controle. Essas epidemias são comumente evidenciadas por um aumento nas internações hospitalares por broncopneumonias, associadas a infecções bacterianas secundárias e com um excesso de mortes, principalmente em idosos e pessoas que sofrem de insuficiência cardíaca crônica e doença pulmonar (3).

As manifestações clínicas da doença aparecem após período de incubação de um a três dias. A maioria das pessoas com infecção sintomática de influenza pode ter a doença sem complicações, com início súbito de febre, tosse, dor de cabeça, dor de garganta, coriza, congestão nasal e dores musculares que se resolvem entre três e cinco dias, embora a tosse e fadiga possam persistir por mais tempo. Crianças com gripe podem apresentar diarreia e dor abdominal, somados aos sintomas respiratórios. Problemas gastrointestinais foram observados em adultos com infecção pelo vírus influenza durante a pandemia de 2009. Os sinais e sintomas podem variar conforme a idade e as condições clínicas. A faixa etária tem grande influência sobre o risco individual de influenza, com incidência maior nos jovens e letalidade mais expressiva nos idosos e em indivíduos que possuem condições clínicas, ou comorbidades, que possam colocá-los em risco para complicações da influenza. Essas complicações incluem exacerbação das condições crônicas e outras complicações graves como infecção bacteriana, miocardite, pericardite, bronquiolite, encefalite $(4,5)$.

É difícil quantificar com exatidão os óbitos causados pelo vírus da influenza, pois a doença nem sempre é registrada como causa primária ou contribuinte, devido à ausência de diagnóstico laboratorial (6). Acrescenta-se, ainda, o sub-registro do número de casos, dado que o nexo causal com a influenza nem sempre é feito por 
falta de suspeição clínica e ou ausência de diagnóstico laboratorial diante de doença respiratória grave. Desse modo, os coeficientes de mortalidade e letalidade por influenza são afetados por erros no numerador, para a obtenção do indicador da mortalidade, e do denominador, para o cálculo da letalidade.

É importante ressaltar que no Brasil, em relação à influenza, é de notificação compulsória a ocorrência de surto ou de óbitos, e de casos de influenza humana produzida por novo subtipo viral. A influenza sazonal não é doença de notificação compulsória $(7,8)$.

Ondas epidêmicas de influenza são registradas mundialmente e, se por um lado a doença paira como motivo de apreensão nas populações devido à ocorrência de pandemias, por outro, é considerada moléstia comum, na ocorrência endêmica sazonal. A população está familiarizada com a doença de forma quase que permanente. Apesar disso, quando acontece de modo epidêmico, recrudesce 0 temor da doença, decorrente do aumento registrado da virulência e patogenicidade, com os consequentes incrementos na morbidade e letalidade. É a banalização versus a doença grave, como aponta Silveira (9) em relação à gripe espanhola de 1918.

O objetivo deste artigo é descrever aspectos relevantes das características da epidemiologia da influenza e da sua bioecologia. Busca-se, também, rever a história das pandemias de influenza, contribuindo, assim, para alertar sobre sua importância e a necessidade de uma resposta articulada de governos mediante os gestores do sistema de saúde nos níveis federal, estadual e municipal para a vigilância, prevenção e controle da enfermidade.

\subsubsection{Aspectos históricos}

A doença é antiga e o nome influenza teria origem diversa: ou em decorrência dos costumes antigos de se atribuir fenômenos físicos à influência astrológica; ou pela nominação de "influenza del freddo" ou "influência do frio", na Itália, em 1504, na vigência de uma epidemia. Já o termo gripe, que significa "fantasia súbita" ou "desafeição passageira", teria sido registrado em carta ao filósofo francês Voltaire 
em $1743(9,10,11)$. Seja como influenza ou gripe, a doença inflige a humanidade desde a pré-história (8).

No estudo da história das doenças, uma das primeiras dificuldades está na definição da enfermidade, que tem seu conceito alterado em função da sociedade e da época. No Reino Unido, termos como catarro epidêmico, febre catarral ou destempero eram empregados desde o século XVIII, e o termo influenza foi reconhecido pelo Royal College of Physicians após a pandemia de $1918(9,11)$.

Há registros históricos com evidências de doenças sugestivas de influenza. A primeira descrição que sugere tratar-se de influenza é atribuída a Hipócrates, por volta do século V a.C. em Creta, Grécia (12). Documentos antigos apontam a possibilidade de surtos ou epidemias de influenza de maior ou menor intensidade, porém esses episódios têm evidência circunstancial e constam como relatos em escrituras religiosas, registros militares ou crônicas de época (13).

Ao longo da história, numerosos surtos de gripe podem ser identificados, embora o registro se torne cada vez menos seguro conforme sua antiguidade. Referências à influenza podem ser encontradas em publicações científicas desde 1650. Há evidências de possíveis pandemias desde 1590 e alusão a ocorrências anteriores (3).

No entanto, há suposições de que doenças documentadas em épocas anteriores ao isolamento do vírus, em 1933, com base nos aspectos clínicos e epidemiológicos tenha sido de fato gripe, e não doenças causadas por diferentes agentes infecciosos conhecidos ou extintos. Essas suspeitas devem ser consideradas provisórias e improváveis, uma vez que são estudadas à luz do conhecimento atual e não da época do registro da evidência. Além das dificuldades relativas aos conceitos de doença e definição de caso clínico, o registro histórico pode estar comprometido pela perda importante de informações sobre o curso da epidemia ou pandemia, por relatórios incompletos, de qualidade variável e sem possibilidade de averiguação pelos critérios virológicos modernos (13).

Apesar das objeções e resistência aos relatos de epidemias ou pandemias de influenza na literatura antiga, pesquisadores têm tentado identificar suas ocorrências durante todo o período histórico $(3,13)$. Há relatos de surtos e epidemias de gripe nos séculos XIV e XV. A primeira descrição médica com interessantes observações 
é atribuída ao médico Molineux (14), na Irlanda e Inglaterra, entre 1688 e 1693. São encontradas referências de epidemias de gripe no século XVII na América do Norte e na Europa. A partir do início do século XVIII, os dados sobre a doença aumentaram em quantidade e qualidade, pois cronistas e médicos registraram informações e comentários sobre o número de pessoas infectadas, se epidemia ou pandemia, os países envolvidos e as possíveis origens das cepas virais. As escritas médicas e os relatórios de encontros científicos constituem fontes ricas para estudos das doenças em tempos antigos, como o registro feito em 1892 na London Epidemiological Society de um surto sugestivo de influenza em porcos. Nessa ocasião, na Inglaterra, ocorria uma epidemia generalizada em humanos, em associação temporal e geográfica com múltiplas epizootias e relatos de casos de doenças semelhantes à influenza em cavalos, cães e gatos (15).

A literatura aponta a ocorrência de epidemias de influenza nos séculos XVIII e XIX. Após a pandemia de 1889-1890, os registros têm sido mais confiáveis e revisados e, a partir de 1957, com a disponibilidade de análise dos vírus, o status de pandemia é cientificamente comprovado (3).

As primeiras referências sobre influenza no Brasil são verificadas no primeiro século após a colonização e aumentaram partir dos séculos XVIII e XIX. ${ }^{9}$ Os primeiros relatos sugestivos de epidemias de gripe no Brasil datam de 1552, nos estados de Pernambuco e Bahia, e 1559 no Rio de Janeiro e Espírito Santo. A partir daí, outros episódios da doença no território brasileiro foram observados na literatura médica, como a epidemia descrita como febre catarral, em 1835, no Rio de Janeiro, chamada vulgarmente de grippe, influencia ou malmatello. $(16,17,18)$

Desde a colonização do Brasil, as doenças e as epidemias representaram fator relevante na diminuição da população indígena brasileira $(19,20)$. E, dentre as epidemias que dizimaram a população indígena brasileira, a gripe desempenhou papel importante face à maior susceptibilidade imunológica (21).

\subsubsection{Aspectos virológicos}

O vírus da influenza - Myxovirus influenzae -, pertencente à família Orthomyxoviridae, contém um genoma RNA segmentado e fita simples. Cerca de 
$75 \%$ de todos os patógenos humanos emergentes são vírus de RNA, muitos dos quais são transmitidos por via mucosa ou respiratória (1). Pode ser classificado como tipos A, B, ou C e seus isolamentos ocorreram nos anos de 1933, 1940 e 1947, respectivamente (6). O vírus do tipo A pode infectar humanos e animais e está implicado em episódios epidêmicos e pandêmicos; o vírus do tipo $B$ que infecta apenas humanos está ligado a surtos moderados; e o vírus C, mais estável, acomete humanos e suínos, causa doença subclínica, sem potencialidade epidêmica.

São características dos vírus influenza a alta transmissibilidade e a capacidade de mutação, principalmente do vírus $\mathrm{A}$ e $\mathrm{B}$, que se configuram como preocupação para a saúde pública pela maior morbidade e mortalidade. Os vírus do tipo B são classificados como linhagem Yamagata ou linhagem Victoria $(6,22)$.

Os vírus do tipo $A$ da influenza são classificados conforme duas proteínas virais de superfície - hemaglutinina (HA) e neuraminidase (NA) - que possibilitam o transporte do vírus nas células do hospedeiro (23). Essas glicoproteínas estão relacionadas aos fatores de virulência, mecanismos de escape à resposta celular e de escape à imunidade natural do hospedeiro (6).

A hemaglutinina tem como função a fixação e fusão do vírus na célula do hospedeiro. São 18 subtipos diferentes $(\mathrm{H} 1$ a $\mathrm{H} 18)$, dos quais 16 circulam em aves aquáticas e dois ( $\mathrm{H} 17$ e H18) foram isolados de morcegos (24). Os subtipos de neuraminidase ( $\mathrm{N} 1$ a $\mathrm{N} 11$ ) possuem papel relevante na liberação das partículas virais após a replicação do vírus, assim como a propagação do vírus a partir de um hospedeiro para outro (25). Em humanos, a infecção normalmente ocorre pelos subtipos virais $\mathrm{H} 1, \mathrm{H} 2$ ou $\mathrm{H} 3$ e N1 ou N2 (5).

O vírus da influenza do tipo A apresenta diversidade antigênica devido aos diferentes subtipos de hemaglutinina e de neuraminidase. Múltiplas combinações de subtipos HA-NA são possíveis e podem ter origem na infecção mista e rearranjos, e gerar novas variantes virais, que podem ser selecionadas sob pressões evolutivas como exposição a novas espécies de hospedeiros, imunidade e drogas antivirais (26).

A alta capacidade de adaptação e mutação do vírus da influenza é devida, principalmente, à variação antigênica das duas glicoproteínas da superfície viral, HA 
e NA. A variação antigênica ocorre por dois mecanismos: drift e shift. $\mathrm{O}$ drift antigênico é uma variação menor, que ocorre devido a mutações pontuais do genoma viral, causando erros na transcrição durante a replicação do vírus com alterações moleculares. Essa alteração gera variantes virais capazes de escapar da imunidade estimulada por infecção prévia ou vacinação. O segundo mecanismo de variação, shift antigênico, ocorre apenas entre os vírus da influenza do tipo $A$, por um reagrupamento entre vírus humano e vírus que infectam outras espécies animais, originando uma nova cepa viral. A recombinação genética resulta em alterações importantes na antigenicidade e patogenicidade. A variação antigênica viral torna um indivíduo susceptível a novas cepas, apesar de infecção anterior pelo vírus da gripe ou por vacinação $(6,5)$.

A nomenclatura completa do vírus influenza segue padrão universal a qual considera o tipo viral, o hospedeiro de origem, o local geográfico do primeiro isolamento, o número de registro da amostra no laboratório, e o ano do isolamento. A informação referente ao hospedeiro é suprimida no caso de origem humana. Para o vírus da influenza do tipo $A$, a descrição antigênica, entre parênteses, segue a designação da cepa e inclui as informações dos subtipos de hemaglutinina e neuraminidase (27).

\subsubsection{Pandemias de influenza}

O potencial pandêmico faz com que a influenza seja destaque entre outras doenças infecciosas (6). Muitos são os estudos que apontam a ocorrência de possíveis e comprovados eventos de influenza na história, como os de 1889, 1918, 1957, 1968, 1977 e 2009 (12,1). Os mais importantes foram a Gripe Espanhola, entre 1918 e 1920; a Gripe Asiática, entre 1957 e 1960; e a de Hong Kong, entre 1968 e 1969. Nos anos 1977 e 1978, a Gripe Russa afetou principalmente crianças e adolescentes. Até a Gripe Russa, cada nova cepa pandêmica substituía a anterior. A partir de 1977, subtipos de vírus influenza A (H1N1) e (H3N2) passaram a cocircular com cepas do vírus influenza B (linhagens Victoria e Yamagata). A cocirculação de múltiplos subtipos de vírus da gripe constitui uma oportunidade para 
recombinação genética durante infecção mista de um indivíduo com dois subtipos de vírus influenza $A$ ou duas linhagens de vírus $B(28,29,30)$.

Interessante observar que as pandemias de influenza ocorreram em épocas próximas a períodos de conflitos bélicos: Primeira Guerra Mundial (1914-1918), Guerra da Coreia (1950-1953), Guerra do Vietnã (1964-1973) e a ocupação soviética do Afeganistão (1979-1989). Ocasiões com grande movimentação de pessoas o que aumenta a possibilidade de transmissão de doenças.

Entre os anos 2003 e 2004, foi registrada a influenza aviária de alta patogenicidade - A (H5N1) - com transmissão ao ser humano, causando surtos com alta letalidade na região asiática (1).

A identificação de um novo vírus da influenza do tipo A pandêmico desencadeou a Emergência de Saúde Pública de Importância Internacional (ESPII), decretada pela OMS em abril de 2009. A dispersão global do vírus nessa pandemia colocou no centro das atenções a capacidade de resposta dos serviços de vigilância epidemiológica de influenza em todo o mundo (31).

A título de comparação, constata-se que a mais grave pandemia de influenza, a Gripe Espanhola, marcou na história um número de óbitos estimado entre 20 a 50 milhões de pessoas no mundo todo $(10,12,32)$ - mais que o dobro de mortes em quatro anos da Primeira Guerra Mundial, e um terço das decorrentes da peste, em seis séculos (33). Já a estimativa global de óbitos para a pandemia de 2009 foi menor: entre 151.700 e 575.400 mortes (34).

A vigilância é base essencial para o monitoramento e avaliação de qualquer processo de doença, sendo especialmente crítico quando surgem novos agentes (35). Assim, a pandemia de influenza de 2009 testou a capacidade dos países para detectar, avaliar, notificar e relatar um evento como preconizado pelo Regulamento Sanitário Internacional (RSI) (36) - acordo sanitário internacional adotado em 1951, modificado em 1969, 1973, 1981 e com ampla e importante revisão em 2005.

Deste modo, é interessante rever a estrutura sanitária brasileira frente à história das pandemias e a necessidade crescente de resposta articulada de governos nacionais e decisões internacionais. 


\subsubsection{Pandemia de 1889 - 1890}

A pandemia de influenza de 1889 e 1890 foi a última do século XIX e a primeira da "era bacteriológica" $(9,37)$.

Embora o vírus causador dessa pandemia não tenha sido identificado, pesquisas realizadas em soros coletados e preservados de indivíduos que viveram neste período sugerem ter sido o vírus influenza $\mathrm{A}$, subtipo $\mathrm{H} 2$ ou $\mathrm{H} 3$. O padrão de mortalidade característico, de um maior número de óbitos entre pessoas idosas e muito jovens, foi observado pela primeira vez (12). A pandemia teve início em São Petersburgo, na Rússia, e em poucos meses se disseminou pela Europa, Ásia e América. A gripe que acometia a Europa, onde foi chamada de Morbus maximus epidemicus, teria chegado ao Brasil, no porto de Salvador, em um navio vindo de Hamburgo, na Alemanha, e se espalhou pelo país $(17,18)$.

No final do período imperial - pouco antes da promulgação da República em 15 de novembro de 1889 - o Brasil enfrentava sérios problemas de saúde pública, mesmo com os investimentos de D. Pedro II em pesquisas científicas, principalmente para as doenças tropicais. Cólera, peste, febre amarela, febre tifoide, varíola, tuberculose, doenças venéreas e as endemias rurais (malária, doença de Chagas, ancilostomose) eram registradas num país sem uma estrutura sanitária definida para controle das enfermidades $(17,18)$.

Como estrutura de serviço de saúde, havia sido criado o Conselho Superior de Saúde, em 1886, em substituição à extinta Junta Central de Higiene e ao Instituto Vacínico do Império. O Conselho compreendia a Inspetoria Geral de Higiene e a Inspetoria de Saúde dos Portos. A primeira era responsável pela higiene terrestre, principalmente na Capital, e a segunda, pelas condições de higiene dos portos, num contexto econômico agroexportador. Mesmo com as medidas de ampliação dos serviços de saúde, esses continuavam com sua administração centrada nos municípios e ligados à capital do Império (38). Em 24 de fevereiro de 1891, foi promulgada a Constituição da República dos Estados Unidos do Brasil, segunda do país e primeira no sistema republicano de governo, que preconizava a descentralização administrativa do Estado, incluindo a saúde. 
Nesse período ocorre a criação de novas escolas médicas e de importantes centros brasileiros de pesquisas: no estado de São Paulo, o Instituto Adolfo Lutz (IAL/SP), em 1892; o Instituto Butantã, em 1899; e o Instituto Pasteur, em 1903; no Rio de Janeiro, em 1899, o de Manguinhos, hoje Fundação Oswaldo Cruz.

Até 1910, os setores governamentais eram mobilizados quando em situação de crise sanitária em decorrência de surtos epidêmicos (18). As atividades de saúde pública eram, nessa época, de caráter emergencial e temporário. Os serviços eram limitados à manutenção geral da salubridade, com ênfase para as medidas de inspeção e fiscalização dos portos, habitações populares e comércio de alimentos e bebidas alcoólicas. A assistência primária à saúde era relegada às entidades filantrópicas, sem responsabilidade do setor público (38).

\subsubsection{Pandemia de 1918 - 1920: Gripe Espanhola}

Em 1918 a imprensa brasileira noticiava sobre a Primeira Guerra Mundial. A atenção da população estava dividida entre o estado de guerra entre Brasil e Alemanha; o envio de uma Missão Médica Brasileira para colaborar no atendimento às vítimas da guerra; e os eventos em consequência da Revolução Russa de 1917; enquanto pequenas notas informavam sobre uma forte gripe que se alastrava na Europa $(18,39,40)$.

A epidemia de gripe espanhola chegou ao Brasil em setembro de 1918, nos navios que atracavam nos portos brasileiros vindos da Europa. É atribuído ao navio inglês Demerara - que saiu de Liverpool na Inglaterra, com escala em Lisboa, e atracou nos portos de Recife, Salvador e Rio de Janeiro - ter trazido essa virose que se disseminou por todo o país. Sem saber como tratar o problema, as autoridades sanitárias e a imprensa colocaram em dúvida a ocorrência da doença no Brasil. Essa situação evidenciaria a fragilidade das políticas de saúde brasileira $(10,17,18,41)$.

A origem da gripe espanhola permanece incerta. É possível que tenha surgido na China ou em campos militares no interior dos Estados Unidos da América $(3,6)$. $\mathrm{Na}$ Europa, os primeiros registros foram feitos em abril de 1918, em tropas francesas possivelmente relacionados a chineses contratados como auxiliares (33). O 
transporte de tropas e de trabalhadores entre os EUA, Europa e outras partes do mundo durante a Primeira Guerra Mundial certamente contribuiu para sua propagação, além de ter mascarado sua verdadeira origem (42). O nome "espanhola" é atribuído ao fato de que a Espanha, neutra na guerra, reconheceu a gripe como problema e divulgava informações sobre a doença $(17,18,43,44)$. Entre os meses de setembro e novembro de 1918, a epidemia assolou o Brasil: caos sanitário, desordem social e crise política - um reflexo das inúmeras mortes por complicações da gripe, como a de Rodrigues Alves, em janeiro de 1919, que, reeleito presidente da República, não chegou a ser empossado $(10,40)$.

Essa pandemia foi marcada pela extrema abrangência, morbidade agravada, mortalidade e letalidade provocada pelo vírus da influenza do tipo $A(H 1 N 1)$. A mortalidade foi de 1 a 2\% em indivíduos de 20 a 39 anos, grupo etário em que a gripe normalmente não configura causa de óbito. Alta letalidade foi verificada em adultos jovens e crianças, principalmente em menores de um ano. Gestantes também apresentaram alto risco. Embora de difícil avaliação, fatores epidemiológicos, sociais e microbiológicos têm sido estudados na tentativa de explicar sua elevada gravidade. Estudos apontam que o impacto desta pandemia teria sido resultado da grande virulência agravada por uma superinfecção bacteriana numa época em que antibióticos não estavam disponíveis (12). É possível que entre as causas dessa alta letalidade encontre-se também o caos sanitário e a escassez de alimentos, decorrentes da Primeira Guerra Mundial (18).

Estudos apontam que a influenza teria vitimado cerca de 38 milhões de pessoas na Europa e na América e que, em um mês, morreram de gripe, por dia, 4 mil pessoas em Londres; mais de 4 mil em Viena; e que, em Paris, houve dias com registro de 3 mil óbitos (16). Embora em muitas partes do mundo não existam dados, estima-se que essa pandemia tenha infectado $50 \%$ da população mundial, $25 \%$ tenham sofrido uma infecção clínica e a mortalidade total tenha sido entre 40 e 50 milhões; o número de 20 milhões de mortes, citado com frequência, é visivelmente muito baixo (3).

O número de casos relativos à gripe espanhola no Brasil também foi subinformado devido à gravidade da situação da epidemia e por muitos óbitos não terem sido notificados às autoridades sanitárias. Famílias inteiras desapareceram de bairros tradicionais onde imigrantes, chegando por navios, aportavam. Os números 
de doentes e mortos são estimados e variáveis. Em São Paulo e Rio de Janeiro, as maiores cidades brasileiras na época, estima-se que morreram 35.240 pessoas pelo menos, devido à gripe, número esse abaixo da realidade (17). Mesmo com os esforços do serviço de Demographia Official, "a balburdia do Pandemonio de 1918" não permitiu que se tivesse uma estatística da mortalidade causada pela hespanhola (16). A Diretoria de Saúde avaliou que 600 mil pessoas foram acometidas de gripe e que a mortalidade foi menor que $2 \%$, números estes considerados otimistas pelo Dr. Moncorvo Filho (16), que acreditava terem sido afetados 2/3 da população - 800 mil indivíduos, portanto. A gripe teria atingido aproximadamente $65 \%$ da população brasileira. Em todo o país, em torno de 300 mil pessoas morreram em decorrência da influenza, embora muitos casos e óbitos não chegaram a ser registrados $(18,44)$.

As autoridades sanitárias recomendavam observar a higiene pessoal e coletiva, evitar aglomerações e espaços confinados $(39,40,41)$. Sugeriam o uso de desinfetantes para as vias respiratórias superiores e, mesmo sem saber o valor terapêutico para a gripe e seus efeitos adversos, passaram a distribuir quinino (41), profilático da malária, sem efeito terapêutico para gripe. Conforme o conhecimento da época, o controle de epidemias, especialmente as bacterianas, era feito com quarentenas, isolamento, extermínio de animais portadores ou vetores, restrição à liberdade de movimento, medidas que se mostraram incapazes de conter a pandemia de gripe (33).

O desconhecimento sobre a enfermidade levou à adoção, nos portos brasileiros, de uma "profilaxia indeterminada, isto é, visando tudo quanto pudesse ser motivo de transmissão mórbida" $(16,39)$. A medida foi determinada, em 3 de outubro de 1918, pela Diretoria Geral de Saúde Pública, que fazia parte da estrutura do Ministério de Justiça e Negócios Interiores (44).

As faltas de conhecimento científico e de técnicas apropriadas impediram que o Estado brasileiro reagisse de modo efetivo no controle da epidemia. No entanto, os serviços sanitários estavam sendo estruturados inclusive pela pressão de um movimento iniciado em 1918, liderado por médicos e intelectuais chamado "Liga PróSaneamento do Brasil”. A centralização dos setores de saúde tem início com os serviços da Quinina Oficial e o de Profilaxia Rural, subordinados à Inspetoria de Serviços de Profilaxia, conforme os Decretos 13.000 (45) e 13.001 (46), ambos de 1ํㅜㄴ 
de maio de 1918. O Departamento Nacional de Saúde Pública, órgão equivalente ao atual Ministério da Saúde (MS), somente foi criado em janeiro de 1920.

A imprensa brasileira teve seu papel no contexto pandêmico: antes de ser verificada a existência de casos da gripe em território nacional, as notícias eram ignoradas ou tratadas com descaso (44) e, durante a epidemia, os jornais noticiavam a desorganização dos serviços de saúde públicos e privados, caos social, medo, inclusive com registros de suicídios $(18,39,40)$.

\subsubsection{Pandemia de 1957 - 1958: Gripe Asiática}

A pandemia de Gripe Asiática começou em fevereiro de 1957 na China e se difundiu em duas ondas com alta morbidade e letalidade que, mesmo sendo menor que a de 1918, levou a óbito cerca de quatro milhões de pessoas $(3,37,47)$. Em 4 de maio de 1957, a OMS recebeu as primeiras notificações de casos e, em 17 de maio, anunciou a ocorrência da gripe no Oriente, prevendo uma epidemia com ampla extensão geográfica. Amostras do novo vírus foram encaminhadas aos laboratórios, para produção de vacinas (48).

A gripe asiática afetou entre $40 \%$ e $50 \%$ das pessoas no mundo, sendo que, destas, $25 \%$ a $30 \%$ apresentaram a forma clínica típica da doença, benigna, e a maior parte dos óbitos foi por pneumonia bacteriana secundária, predominantemente em pessoas muito jovens ou muito idosas. A mortalidade estimada foi de 1 em 4.000 (3). A incidência foi maior de $50 \%$ na faixa etária de 5 a 19 anos (6).

O agente causal dessa pandemia, o vírus influenza A/Cingapura/1/57(H2N2), com as glicoproteínas hemaglutinina e neuraminidase diferentes de todos os tipos anteriores (49), substituiu o influenza $A(\mathrm{H} 1 \mathrm{~N} 1)$ que circulava no mundo desde a pandemia de 1918-1920 (45). O isolamento desse vírus ocorreu, pela primeira vez, no Japão em maio de 1957; no Reino Unido e nos Estados Unidos, em meados do mesmo ano. O pico de incidência ocorreu no mês de outubro de 1957, tanto no Reino Unido como nos Estados Unidos. A disseminação entre os países foi rápida, principalmente pelas rotas marítimas, e em aproximadamente seis meses tinha se alastrado no mundo inteiro $(3,6)$. É provável que a disseminação do vírus tenha 
ocorrido principalmente por duas rotas: ao longo da ferrovia transiberiana para a então União Soviética e, por mar, de Hong Kong a Cingapura e Japão (42).

No Brasil, os primeiros casos foram registrados em julho e, na segunda quinzena de agosto de 1957, um surto foi identificado em Uruguaiana, no Rio Grande do Sul, tendo sido identificado e isolado o mesmo vírus da pandemia. ${ }^{48,50}$ No final de agosto, o IAL/SP isolou o vírus em São Paulo; no início de setembro, sua presença foi identificada no Rio de Janeiro, pelo Instituto Oswaldo Cruz e pelo Instituto de Microbiologia da Universidade do Brasil - hoje, Universidade Federal do Rio de Janeiro. Ainda em setembro daquele ano, o vírus foi identificado e isolado em Belo Horizonte (Instituto Ezequiel Dias), Salvador (Instituto Biológico) e Belém (Instituto Evandro Chagas) (48).

Um estudo sobre a gripe asiática em Porto Alegre, realizado entre 15 de agosto e 31 de outubro de 1957, indicou que um terço da população foi infectado, principalmente indivíduos oriundos de coletividades de baixa renda. Alta incidência foi observada em crianças. Nesse estudo, cujo levantamento domiciliar apontou que $34 \%$ dos habitantes da cidade adoeceram com gripe asiática, o inquérito sorológico revelou que o vírus infectou $54 \%$, demonstrando-se que $20 \%$ da população fizeram infecção subclínica, assintomática (50).

Com o desmembramento do antigo Ministério da Saúde e Educação e a criação do MS pela Lei 1.920/1953 (51), esse órgão passou a ser responsável pelas atividades do Departamento Nacional de Saúde. O MS era mantido informado pela OMS sobre a pandemia de gripe e tomou medidas como a abertura especial de crédito para a organização da luta contra a gripe; a criação e nomeação de uma "Comissão de estudos sobre a gripe e planejamento de seu combate" (Comissão de Gripe do MS), que trabalhava na organização de reuniões com médicos, no planejamento da campanha e determinação de instruções; a criação de uma cadeia de laboratórios regionais para identificação do vírus nas capitais dos principais estados e estímulo à produção da vacina específica (48).

Ao vírus $A(H 2 N 2)$, que circulou até 1968, seguiu-se a variante $A(H 3 N 2)$, agente viral da "Gripe de Hong Kong" (52). 
A Gripe de Hong-Kong foi responsável por cerca de um milhão de óbitos. O vírus influenza $A(H 3 N 2)$ pandêmico foi isolado em Hong Kong em julho de 1968. Foi observada uma incidência de $40 \%$ na faixa etária de 10 a 14 anos (6), com maior hospitalização e mortalidade entre idosos, jovens e indivíduos com riscos definidos como doença cardiopulmonar (12).

$\mathrm{O}$ vírus $\mathrm{A} / \mathrm{Hong} \mathrm{Kong} / 1 / 68$, causador da pandemia, foi identificado no território nacional e isolado em janeiro de 1969 pelo IAL/SP (52).

O Brasil estava sob regime militar desde o golpe de estado em 31 de março de 1964, situação encontrada na maioria dos países da América Latina, configurando um ciclo de ditaduras militares na região. Durante esse período, foram estabelecidas pelo Decreto-Lei 200/1967 (53) as competências do MS: a formulação e coordenação da "política nacional de saúde; responsabilidade pelas atividades médicas e paramédicas; ação preventiva em geral; vigilância sanitária de fronteiras e de portos marítimos, fluviais e aeroportos; controle de drogas, medicamentos e alimentos; pesquisa médico-sanitária".

\subsubsection{Gripe Russa: 1977 - 1978}

A epidemia causada por um vírus influenza do tipo $A(H 1 N 1)$ de origem suína teria iniciado em outubro de 1977 na Rússia e, em fevereiro de 1978, estava disseminada no mundo. Pessoas com menos de 20 anos foram as mais atingidas, registrando-se alta morbidade e mortalidade nesse grupo etário (47). Nesse período, pela primeira vez, houve indicação de cepa viral brasileira (A/Brazil/11/78 - H1N1) para composição da vacina (52).

No Brasil, havia sido publicada a Lei 6.229/1975 (54), que organizava o Sistema Nacional de Saúde e estabelecia as principais competências das distintas esferas de governo. O documento legal, além do caráter centralizador do governo federal, mostrava a dicotomia entre as ações coletivas, de competência do MS, e as individuais, competência do Ministério da Previdência e Assistência Social, não existindo assim um comando único em cada esfera de governo (55).

As ações de vigilância epidemiológica, o Programa Nacional de Imunizações e a notificação compulsória de doenças foram estabelecidos pela Lei 6.259/1975 (56). Essa lei instituiu para o MS a obrigatoriedade de elaboração periódica de uma 
relação de doenças de notificação compulsória, para cada estado, e incluiu um item para casos de agravo inusitado à saúde, além das doenças constantes no RSI. Nesse período foram implementados programas nacionais para controle de doenças específicas.

Entre os anos de 1976 e 1988 ocorreu o movimento da Reforma Sanitária pela democratização da saúde. Com a promulgação da Constituição de 1988, a saúde passa a ser direito de todos e dever do Estado e é criado o Sistema Único de Saúde (SUS). A estruturação do SUS foi estabelecida com a publicação da Lei 8.080/1990 (57), que dispõe sobre a organização e o funcionamento dos serviços de saúde em todo o país. Essa lei foi regulamentada vinte e um anos depois pelo Decreto 7.508/2011 (58). Nesse contexto, a organização do SUS é de rede regionalizada, hierarquizada e descentralizada dos serviços de saúde, com atribuições a cada nível de governo, inclusive as ações de vigilância, controle e atenção à saúde.

\subsubsection{Gripe Aviária: 2003 - 2004}

Em 1997, na Ásia, foi registrada a transmissão, de aves para humanos, do vírus influenza $A(H 5 N 1)$, de alta patogenicidade. O vírus se espalhou pela Europa, Ásia, e África. A partir de 2003, passam a ser a registrados em diversos países asiáticos e africanos surtos de influenza aviária (IA) em humanos, com casos graves e alta letalidade. A preocupação mundial em relação a uma possível pandemia faz com que os países elaborem planos detalhados de preparação e contenção. $O$ mundo entra em estado de alerta para o problema. O vírus, embora de alta virulência, apresenta, até agora, baixa transmissibilidade (1).

O surgimento de focos IA de alta patogenicidade no mundo se deu no mesmo período - início dos anos 2000 - em que o Brasil se firmava como grande produtor e exportador de carne de frango. Para fazer frente ao problema o Ministério da Agricultura, Pecuária e Abastecimento (MAPA) instituiu programa oficial de vigilância para o vírus de IA. A vigilância foi reforçada e até o momento não há registro do vírus aviário de alta patogenicidade. No entanto, a situação requer monitoramento permanente, pois trabalhos evidenciam respostas sorológicas positivas e isolamento 
de cepas de IA de baixa patogenicidade em aves domésticas e silvestres no Brasil. Os resultados de estudo de monitoramento realizado pelo MAPA de 2004 a 2007 demonstraram reação sorológica positiva em aves de produção comercial em Rondônia; isolamento do vírus IA (subtipo H3) em aves capturadas em sítios migratórios no Pará e Pernambuco; e identificação de subtipos H2, H3 e H4 em aves de subsistência nos estados do Amazonas, Pará, Pernambuco, Rio Grande do Sul e Santa Catarina (59).

No ano 2000, ocorreu a implantação nacional da vigilância da influenza com os seguintes objetivos: "monitorar as cepas dos vírus de influenza que circulam nas regiões brasileiras; avaliar o impacto da vacinação contra a doença; acompanhar a tendência da morbimortalidade associada à doença; responder a situações inusitadas; detectar e oferecer resposta rápida à circulação de novos subtipos que poderiam estar relacionados à pandemia de influenza; produzir e disseminar informações epidemiológicas". A vigilância passiva foi estabelecida com base nas redes de unidades de saúde sentinela e de laboratórios (60).

Em 2003, foi constituído Comitê Técnico para a elaboração do Plano de Preparação para a Pandemia de Influenza no Brasil pela Portaria SVS/MS 36/2003 (61). Os principais pontos a serem abordados pelo Comitê eram o fortalecimento da vigilância epidemiológica, da rede de laboratórios do país e da Rede Nacional de Alerta e Resposta às Emergências em Saúde (Rede CIEVS); investimento no Butantã para a fabricação de vacina contra gripe; manutenção da rede de alerta para o surgimento de novos vírus influenza; e capacitação de recursos humanos das vigilâncias epidemiológicas dos estados.

O Decreto de 24 de outubro de 2005, da Presidência da República, instituiu o Grupo Executivo Interministerial (GEI), com a finalidade de acompanhar e propor medidas emergenciais necessárias para a implementação do Plano de Contingência Brasileiro para a Pandemia de Influenza, visando a sua prevenção e controle no território nacional. O GEI foi composto por representantes de 16 órgãos da Presidência da República e Ministérios e a primeira versão do plano foi apresentada em novembro daquele ano. O Decreto de 2005 foi revogado pelo Decreto de 6 de dezembro de 2010, que instituiu o Grupo Executivo Interministerial de Emergência em Saúde Pública de Importância Nacional e Internacional (GEI-ESPII). A finalidade 
do novo Grupo foi acompanhar e propor medidas de emergência em saúde pública de importância nacional e internacional, preconizadas no RSI de 2005.

A epidemia de influenza aviária surgiu durante o processo de revisão do RSI.

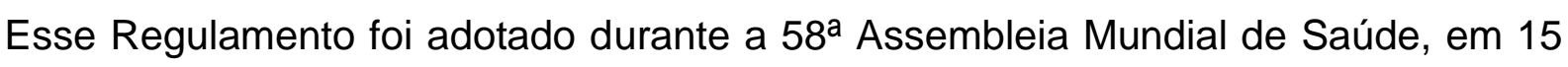
de junho de 2005, e passou a vigorar internacionalmente em 15 de junho de 2007. O RSI (2005) passou a ser incorporado ao ordenamento jurídico brasileiro pelo Decreto Legislativo 395/2009 (63).

\subsubsection{Pandemia de 2009: gripe $A(H 1 N 1) p d m 09$}

Devido à alta mobilidade do mundo atual, a propagação da influenza pandêmica (H1N1) em 2009 ocorreu de forma extremamente rápida. Em 25 de abril daquele ano, em resposta a casos de um novo subtipo de influenza $A(H 1 N 1)$ no México e nos Estados Unidos, a OMS declarou uma Emergência de Importância Internacional de Saúde Pública (64), conforme preconizado pelo RSI de 2005.

A OMS anunciou pandemia (64) fase 4 (transmissão de humano para humano) em 27 de abril, fase 5 (transmissão sustentada) em 29 de abril, e fase 6 (disseminação internacional) em 11 de junho de 2009, em resposta à evidência de grandes surtos em países de diferentes regiões geográficas. Quando a fase 6 da pandemia foi declarada, 30.000 casos já haviam sido notificados em 74 países. A influenza de 2009 tornou-se a primeira pandemia após a adoção do RSI de 2005 e durou 472 dias, até 10 de agosto de 2010, quando a OMS declarou o fim da pandemia (65).

A resposta nacional à emergência internacional começou logo após as primeiras notícias do novo subtipo da influenza e, em 24 de abril de 2009, o MS divulgou um alerta de emergência para os serviços de saúde e a população, com informações sobre a situação epidemiológica nacional e internacional. Em 25 de abril de 2009, o MS criou o Gabinete Permanente de Emergência de Saúde Pública, no Centro de Informações Estratégicas e Resposta em Vigilância em Saúde (CIEVS), no edifício sede do MS - formado por participantes de diversos setores envolvidos na resposta - para discutir, avaliar e adotar estratégias de prevenção e 
controle e divulgação de informações sobre a situação epidemiológica, no Brasil e no mundo, para a comunidade de saúde e a população geral $(65,66,67)$.

O Gabinete de Emergência era mantido em estado permanente com reuniões diárias para acompanhamento da situação epidemiológica no mundo e no Brasil. Informações e orientações eram direcionadas aos serviços e profissionais de saúde, à imprensa e à população. Eram realizadas teleconferências para orientações e trocas de informações com as coordenações de vigilância epidemiológica e assessorias de comunicação das secretarias de saúde dos estados, da Rede CIEVS, rede de laboratórios e, também, com países membros do Mercado Comum do Sul (Mercosul) e da União das Nações Sul-Americanas (Unasul) (66).

A resposta sanitária frente à pandemia seguiu o disposto no Plano Brasileiro de Preparação para uma Pandemia de Influenza (68). Houve investimento nas ações de vigilância para a rápida detecção de casos suspeitos a partir da rede instalada de vigilância de influenza com agilização dos fluxos de envio de amostras e liberação dos resultados laboratoriais. Foi estabelecido um Protocolo de Notificação e Investigação Imediata e criado aplicativo on-line do Sistema de Informação de Agravos de Notificação (Sinan) para otimizar as notificações. Houve, também, intensificação das medidas sanitárias em portos, aeroportos e fronteiras, assim como recomendações de alerta aos viajantes. O atendimento médico dispensado aos casos e contatos foi descrita em protocolo específico de procedimentos. Houve grande mobilização para o enfrentamento da pandemia, com produção de informação e difusão nos veículos de comunicação; estruturação das redes de saúde; obtenção de insumos e tratamentos, além de investimento na ampliação da capacidade nacional para produção da vacina específica $(65,66)$.

A pandemia de influenza de 2009 foi considerada doença de moderada severidade, com similaridade à influenza sazonal, inclusive na sintomatologia, com tosse, febre elevada e dor de garganta. Os jovens foram os mais afetados, constituindo, principalmente, os casos graves e fatais. Esse fato é o que marca a diferença da influenza sazonal, em que os mais atingidos normalmente são pessoas com mais de 65 anos. Foi observada, em pequena proporção, falência respiratória grave em pacientes com condições médicas de risco para a doença, assim como aumento na incidência de complicações em gestantes (1). 
O vírus da influenza do tipo $\mathrm{A}(\mathrm{H} 1 \mathrm{~N} 1)$ foi identificado pela primeira vez no Brasil, pelo IAL/SP em maio de 2009, no início do inverno do hemisfério sul, quando normalmente a atividade viral é aumentada. Os padrões de morbidade e de mortalidade por influenza pandêmica no Brasil foram semelhantes aos observados em outros países. Em meados de julho, o MS reconheceu oficialmente a ocorrência de casos autóctones (69). Desde o início de julho, evidências apontavam o aumento de mortalidade por pneumonia e influenza entre os indivíduos de 20 a 59 anos de idade. No final de novembro de 2009 foi detectada a maioria das mortes relacionadas com a primeira onda de pandemia, principalmente nos grupos etários de 5 a 19 e de 20 a 59 anos (70).

A influenza pandêmica $A(H 1 N 1) p d m 09$ de 2009, no Brasil, foi confirmada em 44.544 casos e causou 2.051 mortes. A taxa de mortalidade foi de 1,1 para cada 100 mil habitantes. As taxas de incidência da doença foram maiores em crianças abaixo de dois anos de idade e em pessoas entre 20 e 29 anos de idade. As maiores taxas de mortalidade foram observadas em pessoas com idade entre 50 e 59 anos e de 30 a 39 anos e em crianças menores de dois anos. Cerca de 75\% das mortes ocorreram em indivíduos com doenças crônicas subjacentes $(30,60)$.

A existência de sistema nacional de vigilância epidemiológica estruturado, com agentes de vigilância nos níveis estadual e municipal, e um programa de vigilância sentinela específico para influenza, facilitou o monitoramento da pandemia de gripe no Brasil (60). O CIEVS e a Rede CIEVS do MS - que desde 2006 estavam organizados em polos estratégicos distribuídos pelo país - contribuíram nas ações de vigilância do evento, que exigiu resposta imediata e coordenada internacionalmente (71).

Apesar das fragilidades na vigilância para doenças semelhantes à gripe, implantada em 60 postos sentinela em 2000, o sistema demonstrou o aumento da proporção de infecções pelo vírus influenza $A(H 1 N 1)$ em 2009 , em comparação com outros vírus respiratórios durante a pandemia (68).

Em todos os estados e no Distrito Federal, a confirmação da gripe sazonal era realizada por meio de teste rápido e imunofluorescência indireta (IFI) nos Laboratórios Centrais de Saúde Pública (Lacen), como preconizado pela Rede Nacional de Vigilância da Influenza, coordenada pelo MS. Três laboratórios de referência, credenciados pela junto à OMS como Centros de Referência para 
Influenza (National Influenza Center - NIC) - o Laboratório de Virologia do Instituto Evandro Chagas, no Pará (IEC/PA); o Laboratório de Vírus Respiratórios do Instituto Adolfo Lutz, em São Paulo (IAL/SP); e o Laboratório de Vírus Respiratório e Sarampo da Fundação Oswaldo Cruz, no Rio de Janeiro (Fiocruz/RJ) - realizavam PCR em tempo real como rotina para a vigilância da influenza. A identificação rápida de infecção pelo vírus da influenza pandêmico permitiu a rápida implantação de vigilância nacional, com confirmação laboratorial, para casos de infecção respiratória aguda grave e de mortes (64).

A propagação da pandemia de influenza $A(H 1 N 1)$ em 2009 destacou a necessidade de sistema de vigilância oportuno e eficaz para detectar vírus emergentes com potencial pandêmico bem como de plataformas padrão para o compartilhamento de dados e divulgação.

\subsubsection{Aspectos da influenza em animais}

O vírus da influenza possui característica zoonótica. O vírus do tipo $A$ da influenza foi isolado a partir de várias espécies animais - focas, baleias, cavalos e porcos - como, por exemplo, os vírus H1N1 de suínos e H3N8 de cavalos. Tendo aves aquáticas como reservatório primário, o vírus influenza é capaz de infectar uma ampla variedade de aves e mamíferos, incluindo os seres humanos. Epizootias ocasionais podem levar a pandemias com graves consequências para a população humana $(6,24)$. Casos de influenza canina e felina associados a surtos em equinos e humanos têm sido descritos por séculos. Outros mamíferos têm sido envolvidos na circulação do vírus da influenza, no entanto, seu possível papel na geração de pandemias ou na manutenção e evolução viral é pouco compreendido e passível de investigação (13).

O vírus influenza $A(H 1 N 1)$ que causou a pandemia de 2009, além de afetar humanos, foi descrito em animais domésticos e não domésticos, como cães, gatos, furões, suínos e várias espécies de animais selvagens. Há registro de caso confirmado de infecção em pandas gigantes na China (72) e em suínos em Santa Catarina, sul do Brasil (73). Vírus influenza da espécie aviária, como $A(H 5 N 1)$ e $A(H 7 N 9)$, têm, ocasionalmente, causado doença em humanos. Embora a 
transmissão eficiente desses vírus entre humanos não tenha sido identificada, a elevada mortalidade dos casos de infecção humana por esses vírus ressalta a importância desses patógenos para a saúde pública (74).

Essa capacidade do vírus influenza de circular em aves migratórias, notadamente, e em outros animais de diversas espécies, traduz o risco real e permanente de transmissão interespécies e de adaptação ao homem. As grandes pandemias, que resultaram em milhões de mortes - como na Gripe Espanhola, Asiática e de Hong Kong -, ocorreram em decorrência de variações antigênicas (75, 76).

O vírus da influenza do tipo A ultrapassa a barreira entre espécies, o que permite que 0 vírus alterne entre hospedeiros e possa infectar várias espécies de aves e mamíferos. A imprevisibilidade da evolução do vírus e o movimento interespécies gera contínuo desafio para a saúde pública. Suínos e aves são os hospedeiros que representam maior risco para saúde humana. No entanto, vírus da influenza equina já foram identificados em doenças respiratórias em cães, suínos e em pessoas por exposição ocupacional (26).

Estudos sobre o vírus influenza em animais, seu papel na transmissão e na manutenção da circulação viral e a interface com a doença em humanos são importantes. Para tanto, a OMS mantém, desde 1963, um centro de coordenação (Ecology of Influenza in Animals) em Memphis, nos Estados Unidos da América, para pesquisas com a finalidade de embasar as práticas de vigilância, e conta com a participação de organismos internacionais como a Organização Mundial de Saúde Animal (OIE) e Organização das Nações Unidas para Alimentação e Agricultura (FAO) (74).

A vigilância da influenza em animais de produção é fundamental e no Brasil é exercida pelo MAPA. Maior atenção é dada à $\mathrm{IA}$, pois além das questões relativas à transmissão para humanos com casos graves e fatais, a produção avícola brasileira é economicamente relevante. Além da IA, são ainda de notificação obrigatória ao MAPA, com registro nos informes mensais, casos confirmados de gripe equina (cavalos, asininos e muares) e influenza suína, conforme a Instrução Normativa MAPA 50/2013 (77). As influenzas aviária e equina estão na relação de doenças de notificação obrigatória da OIE. A influenza suína, no entanto, não é de notificação (78). 


\subsubsection{Considerações finais}

Nos últimos anos, a influenza tem sido pauta de preocupação mundial pela sua circulação em vários países, causando doença em homens e animais. As epidemias e pandemias de influenza humana estimularam a criação de sistema de vigilância internacional que tem sido permanentemente aperfeiçoado.

Em 120 anos, de 1889 a 2009, foram registrados seis grandes eventos de influenza humana e, com eles, lições aprendidas. Acompanhando o curso das doenças e o domínio científico, as formas de lidar com o processo saúde-doença vão delineando as estruturas dos serviços de atenção e prevenção. Um resumo da estrutura sanitária brasileira frente à história dos eventos de influenza pode ser verificado no Quadro 1. A organização do setor saúde no Brasil é um processo em construção, nos diferentes momentos ou períodos históricos, que se reflete na vigilância da influenza.

Muito se evoluiu em relação à influenza ao longo dos anos: novas técnicas para diagnóstico, conhecimento maior das características virais, ferramentas epidemiológicas ágeis para estudo da distribuição da doença e suas tendências, além da importância da doença no cenário econômico, político e social. Mesmo com o acompanhamento hoje realizado em tempo real, ainda é preciso reforçar aspectos referentes à qualidade da coleta de dados, sua consolidação e divulgação da informação para a população e servidores da saúde, uma vez que informação favorece conscientização e gera ação. A vigilância do vírus da influenza, mesmo sendo capaz de cumprir seus objetivos, pode e deve ser mais fortalecida.

Após a pandemia de 2009, a reorganização da vigilância veio como uma necessidade de reforço e ampliação das ações. Por mecanismo de repasse financeiro - Portaria MS/GM 2.693/2011 (79) - houve revisão de critérios de seleção e incentivo, por adesão, para implantação e manutenção de Unidades Sentinelas, numa estratégia ampliada de vigilância de influenza: vigilância sentinela de síndrome gripal e de síndrome respiratória aguda grave; vigilância universal de síndrome respiratória aguda grave complementada pelo monitoramento da hospitalização e mortalidade por pneumonias; e pela investigação de surtos, óbitos e eventos incomuns suspeitos para influenza. Entre os avanços obtidos pós-pandemia está o 
emprego de técnicas de biologia molecular em tempo real como rotina para diagnóstico de influenza nos Lacen, até então concentrado nos Laboratórios de Referência.

A SVS havia sido estabelecida como ponto focal nacional para o RSI junto à OMS, pela Portaria GM/MS 1.865/2006 (80). A partir da internalização do RSI (2005) em 2009, normativas legais foram instituídas como medidas para o controle internacional de doenças. Entre elas, o Decreto 7.616/2011 (81), que dispõe sobre a declaração de Emergência em Saúde Pública de Importância Nacional e institui a Força Nacional do SUS e a Portaria GM/MS 104/2011 (82), que define as terminologias adotadas em legislação nacional, conforme o RSI.

Certamente a pandemia de 2009 e os investimentos governamentais colaboraram para a conscientização da necessidade do fortalecimento da vigilância da influenza, inclusive para atendimento ao RSI de 2005. Mesmo assim, é preciso incentivar a organização dos serviços e motivar servidores para a melhoria das atividades, de modo a acentuar as características do sistema, como a representatividade, a aceitabilidade e as oportunidades de cada etapa da vigilância (notificação, tomada de amostras, diagnóstico, encerramento do caso, informação).

Um fluxo formal de compartilhamento de informações entre os órgãos envolvidos na vigilância animal, humana e ambiental contribuiria para a ampliação da visão sobre o problema. $O$ trabalho de educação continuada e a divulgação de informações aumentariam a percepção da necessidade de intensificação da vigilância de casos de influenza em animais, incluindo estudo laboratorial para identificação viral. Esses conhecimentos são fundamentais para estudo de programas de vigilância abrangente. É relevante considerar a velocidade cada vez maior com que se dissemina o vírus, em função da rapidez e volume do tráfego internacional, e a importância da vigilância global em tempo real.

É preciso que haja uma melhor articulação estratégica das possíveis respostas do Estado, numa visão multidisciplinar e intersetorial, para a vigilância dessa complexa virose, que é uma prioridade na política pública internacional de saúde. 
Quadro 1 - Estrutura sanitária brasileira frente à história dos eventos de influenza (continua)

\begin{tabular}{|c|c|c|}
\hline Evento & Vírus & Estrutura brasileira \\
\hline $\begin{array}{c}\text { Pandemia de } \\
1889-1890\end{array}$ & $\begin{array}{l}\text { Pesquisas sugerem } \\
\text { ter sido o vírus } \\
\text { influenza } A \text {, subtipo } \\
\text { H2 ou H3. }\end{array}$ & $\begin{array}{l}\text { Conselho Superior de Saúde, criado em 1886, em } \\
\text { substituição à extinta Junta Central de Higiene e ao Instituto } \\
\text { Vacínico do Império. O Conselho compreendia a Inspetoria } \\
\text { Geral de Higiene e a Inspetoria de Saúde dos Portos. } \\
\text { Os setores governamentais eram mobilizados em situação } \\
\text { de crise sanitária em decorrência de surtos epidêmicos. } \\
\text { As atividades de saúde pública eram de caráter } \\
\text { emergencial e temporário. } \\
\text { Os serviços eram restritos à manutenção geral da } \\
\text { salubridade, com ênfase para as medidas de fiscalização } \\
\text { dos portos, habitações populares e comércio de alimentos e } \\
\text { bebidas alcoólicas. } \\
\text { A assistência à saúde era relegada às entidades } \\
\text { filantrópicas, sem responsabilidade do setor público. }\end{array}$ \\
\hline $\begin{array}{c}\text { Pandemia de } \\
1918 \text { - 1920: a } \\
\text { Gripe } \\
\text { Espanhola }\end{array}$ & $\begin{array}{l}\text { Vírus influenza } \\
\text { A(H1N1) }\end{array}$ & $\begin{array}{l}\text { A falta de conhecimento e de recursos práticos impediu que } \\
\text { o estado brasileiro reagisse de modo efetivo no controle da } \\
\text { epidemia. } \\
\text { Os serviços sanitários estavam sendo estruturados inclusive } \\
\text { pela pressão do movimento "Liga Pró-Saneamento do } \\
\text { Brasil". } \\
\text { A centralização dos setores de saúde tem início com os } \\
\text { serviços da Quinina Oficial e o de Profilaxia Rural, } \\
\text { subordinados à Inspetoria de Serviços de Profilaxia. } \\
\text { O Departamento Nacional de Saúde Pública, órgão } \\
\text { equivalente ao atual Ministério da Saúde, foi criado em } \\
\text { janeiro de } 1920 \text {. }\end{array}$ \\
\hline $\begin{array}{l}\text { Pandemia de } \\
\text { 1957 - 1958: a } \\
\text { Gripe Asiática }\end{array}$ & $\begin{array}{l}\text { Vírus influenza } \\
\text { A(H2N2) }\end{array}$ & $\begin{array}{l}\text { Com a criação do Ministério da Saúde em 1953, esse órgão } \\
\text { passou a ser responsável pelas atividades do } \\
\text { Departamento Nacional de Saúde. } \\
\text { O Ministério da Saúde era mantido informado pela OMS } \\
\text { sobre a pandemia de gripe e tomou medidas como: a } \\
\text { abertura especial de crédito; a criação e nomeação de uma } \\
\text { "Comissão de estudos sobre a gripe e planejamento de seu } \\
\text { combate" que trabalhava na organização de reuniões com } \\
\text { médicos, no planejamento da campanha e determinação de } \\
\text { instruçães; criação de uma cadeia de laboratórios regionais } \\
\text { e estímulo à produção da vacina específica. }\end{array}$ \\
\hline
\end{tabular}


Quadro 1 - Estrutura sanitária brasileira frente à história dos eventos de influenza (continuação)

\begin{tabular}{|c|c|c|}
\hline Evento & Vírus & Estrutura brasileira \\
\hline $\begin{array}{c}\text { Pandemia de } \\
\text { 1968 - 1969: a } \\
\text { Gripe de Hong } \\
\text { Kong }\end{array}$ & $\begin{array}{l}\text { Vírus influenza } \\
\text { A(H3N2) }\end{array}$ & $\begin{array}{l}\text { Como competência do Ministério da Saúde foi estabelecida } \\
\text { a formulação e coordenação da política nacional de saúde; } \\
\text { responsabilidade pelas atividades médicas e paramédicas; } \\
\text { ação preventiva em geral; vigilância sanitária de fronteiras e } \\
\text { de portos marítimos, fluviais e aeroportos; controle de } \\
\text { drogas e medicamentos e alimentos; pesquisa médico- } \\
\text { sanitária. }\end{array}$ \\
\hline $\begin{array}{c}\text { 1977 - 1978: a } \\
\text { Gripe Russa }\end{array}$ & $\begin{array}{l}\text { Vírus influenza } \\
\text { A(H1N1) }\end{array}$ & $\begin{array}{l}\text { Organização do Sistema Nacional de Saúde e } \\
\text { estabelecimento das principais competências das distintas } \\
\text { esferas de governo. } \\
\text { O caráter centralizador do governo federal mostrava a } \\
\text { dicotomia entre as ações coletivas, de competência do } \\
\text { Ministério da Saúde, e as individuais, de atribuição do } \\
\text { Ministério da Previdência e Assistência Social. } \\
\text { Não existia comando único em cada esfera de governo, o } \\
\text { que veio a ocorrer a partir de } 1988 \text { com a criação do } \\
\text { Sistema Único de Saúde (SUS). }\end{array}$ \\
\hline $\begin{array}{l}2003-2004: \text { a } \\
\text { Gripe Aviária }\end{array}$ & $\begin{array}{l}\text { Vírus influenza } \\
\mathrm{A}(\mathrm{H} 5 \mathrm{~N} 1)\end{array}$ & $\begin{array}{l}\text { Surgimento de focos influenza aviária de alta } \\
\text { patogenicidade no mundo se deu no momento em que o } \\
\text { Brasil se consolidava como um grande produtor e } \\
\text { exportador mundial de carne de frango. } \\
\text { O Ministério da Agricultura, Pecuária e Abastecimento } \\
\text { organizou programa oficial de vigilância para influenza } \\
\text { aviária. } \\
\text { Comitê Técnico é criado, em 2003, para elaborar o Plano de } \\
\text { Preparação para a Pandemia de Influenza. } \\
\text { Em 2005, Decreto Presidencial cria o Grupo Executivo } \\
\text { Interministerial (GEI) para acompanhar e propor medidas } \\
\text { emergenciais à implementação do Plano de Contingência } \\
\text { Brasileiro para a Pandemia de Influenza. }\end{array}$ \\
\hline $\begin{array}{c}\text { Pandemia de } \\
2009\end{array}$ & $\begin{array}{l}\text { Vírus influenza } \\
\mathrm{A}(\mathrm{H} 1 \mathrm{~N} 1) \text { pdm09 }\end{array}$ & $\begin{array}{l}\text { Programa de Vigilância de Influenza em atividade desde } \\
2000 . \\
\text { Centro de Informações e Respostas Estratégicas em } \\
\text { Vigilância em Saúde (Cievs) - implantado em } 2006 \text {-e } \\
\text { Rede Nacional de Alerta e Resposta às Emergências em } \\
\text { Saúde Pública (Rede Cievs) com cerca de } 20 \text { unidades em } \\
\text { funcionamento no final de } 2008 \text {. } \\
\text { A resposta nacional à emergência internacional foi imediata. } \\
\text { O Ministério da Saúde divulgou alerta de emergência para } \\
\text { os serviços de saúde e a população. } \\
\text { O Ministério da Saúde criou um Gabinete Permanente de } \\
\text { Emergência para discutir, avaliar e adotar estratégias de } \\
\text { prevenção e controle e divulgação de informações sobre a } \\
\text { situação epidemiológica no Brasil e no mundo. }\end{array}$ \\
\hline
\end{tabular}




\section{Referências}

1 Zambon M. Influenza and other emerging respiratory viruses. Medicine $2014 ; 42(1): 45-51$.

2 Jerigan DB, Cox NJ. Human influenza: one health, one world. In: Webster, RG. et al. Ed. Textbook of influenza. 2.ed. Oxford: Wiley Blackwell; 2013: 3-19.

3 Potter CW. A history of influenza. J Appl Microbiol 2001; 91(4):572-9.

4 Uyeki TM. Preventing and controlling influenza with available interventions. N Engl J Med 2014; 370(9):789-91.

5 WHO. World Health Organization. Vaccines against influenza WHO position paper. Wkly Epidemiol Rec 2012; 87(47): 461-76.

6 Cox NJ, Subbarao K. Global epidemiology of influenza: past and present. Annu Rev Med 2000; 51:407-21.

7 Brasil. Ministério da Saúde. Gabinete do Ministro. Portaria n 1.271, de 6 de junho de 2014. Define a Lista Nacional de Notificação Compulsória de doenças, agravos e eventos de saúde pública nos serviços de saúde públicos e privados em todo o território nacional, nos termos do anexo, e dá outras providências. Diário Oficial da União, Brasília, no 108, p.6769, 9 jun. 2014. Seção 1.

8 Brasil. Ministério da Saúde. Secretaria de Vigilância em Saúde. Influenza. In: Guia de Vigilância em Saúde. 1ª edição. Versão eletrônica, vol. único. Brasília: Ministério da Saúde; 2014.

9 Silveira, AJT. A medicina e a influenza espanhola de 1918. Tempo 2005; (19):91-105.

10 Bueno E. À sua saúde: a vigilância sanitária na história do Brasil. Brasília: Ministério da Saúde: Agência Nacional de Vigilância Sanitária; 2005. 208p.

11 Delacy $M$. The conceptualization of influenza in eighteenth-century Britain: specificity and contagion. Bull Hist Med 1993;67(1):75-117. 
12 Monto AS, Webster RG. Human pandemic: history and lessons learned. In: Webster, RG et al. (ed). Textbook of influenza. 2. ed. Oxford: Wiley Blackwell; 2013.

13 Morens DM, Taubenberger, JK. Pandemic influenza: certain incertainties. Rev Med Virol 2011; 21(5):262-284.

14 Molineux T. Dr. Molineux's historical account of the late general coughs and colds; with some observations on other epidemic distemper. Philos Trans R Soc London 1694; 18:105-11.

15 Morens D, Taubenberger JK. A possible outbreak of swine influenza, 1892. Lancet Infect Dis 2014; 14(2): 169-172.

16 Moncorvo Filho A. O pandemônio de 1918 - subsídio ao histórico da epidemia de gripe que em 1918 assolou o território do Brasil. Rio de Janeiro: Departamento da Creança; 1924. Disponível em: http://www2.dbd.pucrio.br/pergamum/docdigital/MoncorvoFilho/Rolo1/9_O_pandemonio_de_ 1918.pdf. Acesso em: 15 Mai. 2014.

17 Bertolli Filho C. A gripe espanhola em São Paulo, 1918: epidemia e sociedade. São Paulo: Paz e Terra; 2003.

18 Abrão JS. Banalização da morte na cidade calada: a hespanhola em Porto Alegre, 1918. 2.ed. Porto Alegre: EDIPUCS; 2009.

19 Ribeiro D. Os índios e a civilização. A integração das populações indígenas no Brasil moderno. São Paulo: Cia das Letras; 1996.

20 Almeida CS, Nötzold ALV. O impacto da colonização e imigração no Brasil Meridional: contágios, doenças e ecologia humana dos povos indígenas. Tempos Acadêmicos; 2008(6):1-18.

21 Scliar M. O Brasil e suas epidemias. Revista Carta Capital. Disponível em: http://www.cartacapital.com.br/cultura/o-brasil-e-suas-epidemias. Acesso em: 1 Dez. 2014. 28 fev. 2011.

22 Pica N, Palese P. Toward a universal influenza virus vaccine: prospects and challenges. Annu Rev Med 2013; 64:189-202. 
23 Morens DM, Taubenberger JK, Fauci AS. The persistent legacy of the 1918 influenza virus. N Engl J Med 2009; 361(3):225-9.

24 Edinger TO, Pohl MO, Stertz S. Entry of influenza A virus: host factors and antiviral targets. J Gen Virol 2014; 95(2):263-77.

25 Nayak D et al. Structure, disassembly, assembly, and budding of influenza viruses. In: Webster RG et al. Ed. Textbook of influenza. 2. ed. Oxford: Wiley Blackwell; 2013. p.37-56.

26 Taubenberger JK, Morens DM. Influenza viruses: breaking all the rules. mBio 2013;4(4):1-6. [e00365-13]

27 WHO. World Health Organization. A revision of the system of nomenclature for influenza viruses: A WHO memorandum. Bull World Health Organ1980; 58(4):585-91.

$28 \mathrm{Xu} X$ et al. Reassortment and evolution of current human influenza A and B viruses. Virus Res 2004; 103(1-2):55-60.

29 Ellis JS et al. Influenza AH1N2 Viruses, United Kingdom, 2001-02 Influenza Season. Emerg Infect Dis 2003; 9(3):304-10.

30 Brasil. Ministério da Saúde. Secretaria de Vigilância em Saúde. Influenza pandêmica (H1N1) 2009 - análise da situação epidemiológica e da resposta no ano de 2009. Boletim Eletrônico Epidemiológico 2010; 10(2):1-21.

31 Reis $\mathrm{PO}$ et al. Monitoramento da síndrome gripal em adultos nas capitais do Brasil e no Distrito Federal por meio de inquérito telefônico. Rev Bras Epidemiol 2011; 14(1)supl: 115-24.

32 Taubenberger J, Morens D. 1918 influenza: the mother of all pandemics. Emerging Infectious Diseases 2006;12(1):15-22.

33 Sequeira A. A pneumónica. Arch Med Intern 2001;1(1):49-55.

34 Dawood FS et al. Estimated global mortality associated with the first 12 months of 2009 pandemic influenza A H1N1 virus circulation: a modelling study. Lancet Infect Dis 2012; 12(9): 687-95. 
35 Briand S, Mounts A, Chamberland M. Challenges of global surveillance during an influenza pandemic. Global Influenza Programme. [Internet] [11p.] Geneva: World Health Organization; april 2011. [cited 2014 dez 10]. Disponível em:

http://www.who.int/influenza/surveillance_monitoring/Challenges_global _surveillance.pdf.

36 WHO. World Health Organization. International health regulations (2005). 2nd ed. Geneva: WHO Press. 2008. [Internet] 74p. [citado 2015 Mar 13] Disponível em: http://www.who.int/ihr/publications/9789241596664/en/.

37 Shope RE. Influenza: history, epidemiology and speculation. Public Health Rep 1958; 73(2):165-79.

38 Escorel S, Teixeira LA. História das políticas de saúde no Brasil de 1822 a 1963: do império ao desenvolvimentismo populista. In: Giovanella L, Lobato LV et al. (Org). Políticas e sistemas de saúde no Brasil. [2ª reimpressão]. Rio de Janeiro: Editora Fiocruz; 2011. p.333-84.

39 Bertucci LM. Influenza, a medicina enferma: ciência e prática de cura na época da gripe espanhola em São Paulo. Campinas: Editora da Unicamp; 2004. 448p.

40 Souza CMC. A gripe espanhola na Bahia: saúde, política e medicina em tempos de epidemia. Rio de Janeiro: Editora Fiocruz; Salvador: Editora Edufba; 2009.

41 Santos RA. Representações sociais da peste e da gripe espanhola. In: Nascimento DR, Carvalho DM (Orgs). Uma história brasileira das doenças. Brasília: Paralelo 15; 2004. p.126-44.

42 Hampson AW. Surveillance for pandemic influenza. J Infect Dis 1997;176(Suppl 1):8-13.

43 Kolata G. Gripe: a história da pandemia de 1918. Rio de Janeiro: Record; 2002. 381p.

44 Goulart AC. Revisitando a espanhola: a gripe pandêmica de 1918 no 
Rio de Janeiro. Hist Cienc Saude Manguinhos 2005; 12(1):101-142.

45 Brasil. Decreto no 13.000, de 1 de maio de 1918. Crêa o serviço da quinina official, prophylatico da malaria, inicial ao dos medicamentos do Estado, necessarios ao saneamento do Brasil. Diário Oficial da União, Rio de Janeiro, 3 mai. 1918. Seção 1. [Coleção de Leis do Brasil, v.2, p.533, col.1].

46 Brasil. Decreto oㅜ 13.001, de 1 de maio de 1918. Dispõe sobre organização das commissões de medicos e auxiliares para o serviço de prophylaxia rural. Diário Oficial da União, Rio de Janeiro, p.6237, 3 mai. 1918. Seção 1.

47 Garcia-Garcia J, Ramos C. La influenza, un problema vigente de salud pública. Salud Publica Mex 2006;48(3):244-267.

48 Bruno-Lobo M. Gripe asiática. Rio de Janeiro: Instituto de Previdência e Assistência dos Servidores do Estado; 1959. Coleção Ipase, v 21, 123p.

49 Kawaoka Y, Krauss S, Webster RG. Avian-to-Human Transmission of the PB1 Gene of Influenza A Viruses in the 1957 and 1968 Pandemics. J Virol 1989; 63(11): 4603-4608.

50 Silva NN. Dados epidemiológicos e sorológicos sobre a incidência da gripe asiática em Porto Alegre. O Hospital 1958: 53(6):137-141. [Republicado em Boletim da Saúde 2009; 23(1):103-7.

51 Brasil. Lei oํ 1.920, de 25 de julho de 1953. Cria o Ministério da Saúde e dá outras providências. Diário Oficial da União, Rio de janeiro, p. 13193, 29 jul. 1953. Seção 1.

52 Paiva TM, Ishida MA, Carvalhanas Pinto TRMP, Barbosa HA. Influenza: Desafio em Saúde Pública. Bol. epidemiol. paul. 2004; 1(7):14-17.

53 Brasil. Decreto-Lei ํㅡ 200, de 25 de fevereiro de 1967. Dispõe sobre a organização da Administração Federal, estabelece diretrizes para a Reforma Administrativa e dá outras providências. Diário Oficial da União, Brasília, p.4, 27 fev. 1967. Seção 1 - Suplemento. 
54 Brasil. Lei no 6.229, de 17 de julho de 1975. Dispõe sobre a organização do Sistema Nacional de Saúde. Diário Oficial da União, Brasília, p. 8921, 18 jul. 1975. Seção 1.

55 Andrade LOM, Pontes RJS, Martins Junior T. A descentralização no marco da Reforma Sanitária no Brasil. Rev Panam Salud Publica 2000; 8(1-2):85-91.

56 Brasil. Lei o 6.259, de 30 de outubro de 1975. Dispõe sobre a organização das ações de Vigilância Epidemiológica, sobre o Programa Nacional de Imunizações, estabelece normas relativas à notificação compulsória de doenças, e dá outras providências. Diário Oficial da União, Brasília, 31 out 1975.

57 Brasil. Lei № 8.080, de 19 de setembro de 1990. Dispõe sobre as condições para a promoção, proteção e recuperação da saúde, a organização e o funcionamento dos serviços correspondentes e dá outras providências. Diário Oficial da União, Brasília, № 182, p.1805518059, 20 set. 1990, Seção 1.

58 Brasil. Decreto № 7.508, de 28 de junho de 2011. Regulamenta a Lei no 8.080, de 19 de setembro de 1990, para dispor sobre a organização do Sistema Único de Saúde - SUS, o planejamento da saúde, a assistência à saúde e a articulação interfederativa, e dá outras providências. Diário Oficial da União, Brasília, no123, p.1-3, 29 jun. 2011. Seção 1.

59 Mota MA, Lima FS, Oliveira PFN, Guimarães M.P. Ações de vigilância para influenza aviária desenvolvida no Brasil, no período de 2004 e 2007. Arq Bras Med Vet Zootec 2013; 65(5):1265-73.

60 Brasil. Ministério da Saúde. Secretaria de Vigilância em Saúde. Departamento de Vigilância Epidemiológica. Influenza. In: Guia de Vigilância Epidemiológica. 7.ed. Caderno 1. Brasília: Ministério da Saúde; 2009.

61 Brasil. Ministério da Saúde. Secretaria de Vigilância em Saúde. Portaria № 36, de 22 de dezembro de 2003. Institui o Comitê Técnico para elaboração do Plano de Preparação para a Pandemia de Influenza no 
Brasil e dá outras providências. Brasília: Diário Oficial da União, ㄲo 249, 23 Dez 2003, p.82. Seção 1.

62 Brasil. Decreto de 24 de outubro de 2005. Institui Grupo Executivo Interministerial com a finalidade de acompanhar e propor as medidas emergenciais necessárias para a implementação do Plano de Contingência Brasileiro para a Pandemia de Influenza, visando a sua prevenção e controle no território nacional. Diário Oficial da União, Brasília, no 205, p.2-32, 5 out. 2005. Seção 1.

63 Brasil. Decreto Legislativo no 395, de 9 de 2009. Aprova o texto revisado do Regulamento Sanitário Internacional, acordado na 58 ${ }^{\underline{a}}$ Assembleia Geral da Organização Mundial da Saúde, em 23 de maio de 2005. Diário Oficial da União, Brasília, p. 11, 10 jul. 2009. Seção 1.

64 WHO. World Health Organization. New influenza $A(H 1 N 1)$ virus infections: global surveillance summary, May 2009. Wkly Epidemiol Rec 2009; 84(20):173-84.

65 Domingues CMAS, Oliveira WK. Uptake of pandemic influenza (H1N1)2009 vaccines in Brazil, 2010. Vaccine; 2012; 30(32):4744-4751.

66 Temporão JG. O enfrentamento do Brasil diante do risco de uma pandemia de influenza pelo vírus $\mathrm{A}(\mathrm{H} 1 \mathrm{~N} 1)$. Epidemiol Serv Saúde. 2009; 18(3): 201-204.

67 Brasil. Ministério da Saúde. Secretaria de Vigilância em Saúde. Gabinete Permanente de Emergências de Saúde Pública. Emergência de Saúde Pública de Importância Internacional - ESPII. Ocorrências de casos humanos de infecção por Influenza A (H1N1). Informe do dia 30.04 .09 , às $16 \mathrm{~h} 30$.

68 Brasil. Ministério da Saúde. Secretaria de Vigilância em Saúde. Plano de preparação brasileiro para o enfrentamento de uma pandemia de influenza. Série B. Textos Básicos de Saúde. 1aㅡ Edição. Brasília: Ministério de Saúde; 2005. 224 p. 
69 Oliveira WK et al. Pandemic H1N1 influenza in Brazil: Analysis of the first 34,506 notified cases of influenza-like illness with severe acute respiratory infection (SARI). Euro Surveill 2009; 14(43):ii:19382.

70 Oliveira JFM et al. Ecological study on mortality from influenza and pneumonia before and after influenza vaccination in the Northeast and South of Brazil. Cad Saúde Pública 2013; 29(12) 2535-45.

71 Dimech GS. A experiência do Centro de Informações Estratégicas e Respostas em Vigilância em Saúde (CIEVS/SVS/MS). In: Organização Pan-Americana da Saúde. Sala de Situação em Saúde: compartilhando as experiências do Brasil. Organização Pan-Americana da Saúde. Brasília: Organização Pan-Americana da Saúde, Ministério da Saúde; 2010.

72 Li D et al. Influenza A(H1N1)pdm09 virus infection in giant pandas, China. Emerg Infect Dis 2014;20(3):480-3.

73 Schaefer R. et al. Isolation and characterization of a pandemic H1N1 influenza virus in pigs in Brazil. Pesquisa Vet Brasil 2011; v.31(9): 761-7.

74 WHO. World Health Organization. Global Influenza Surveillance and Response System (GISRS). Disponível em: http://www.who.int/influenza/gisrs_laboratory/en. Acesso em: 5 nov. 2014.

75 Forleo-Neto E, Halker E, Santos VJ, Paiva TM, Toniolo-Neto J. Influenza. Rev Soc Bras Med Trop. 2003; 36(2): 267-274.

76 Almeida FJ, Berezin EN, Farhat Ck, Cintra OA, Stein RT, Burnset DAR et al. Consenso para o tratamento e profilaxia da influenza (Gripe) no Brasil. Sociedade brasileira de pediatria. [citado 2015 set 15]. Disponível em: <http://www.sbp.com.br/PDFs/conseso_influenza.pdf>.

77 Brasil. Ministério da Agricultura, Agropecuária e Abastecimento. Instrução Normativa ${ }^{\circ} 50$, de 24 de setembro de 2013. [Altera lista de doenças passíveis da aplicação de medidas de defesa sanitária animal]. Diário Oficial da União, Brasília, p. 47, 25 set. 2013. Seção 1. 
78 OIE. World Organization for Animal Health. OIE listed disease, 2014. [cited 2014 nov 15]. Disponível em: http://www.oie.int/animal-health-inthe-world/oie-listed-diseases-2014.

79 Brasil. Ministério da Saúde. Gabinete do Ministro. Portaria no 2.693, de 17 de novembro de 2011. Estabelece mecanismo de repasse financeiro do Fundo Nacional de Saúde aos Fundos de Saúde do Distrito Federal e Municípios, por meio do Piso Variável de Vigilância e Promoção da Saúde, para implantação, implementação e fortalecimento da Vigilância Epidemiológica da Influenza. Diário Oficial da União, Brasília, p.81-82, 18 nov. 2011. Seção 1. Republicada no DOU. Brasília, p.37-38, 26 abr. 2012. Seção 1.

80 Brasil. Ministério da Saúde. Gabinete do Ministro. Portaria oํ 1.865, de 10 de agosto de 2006. Estabelece a Secretaria de Vigilância em Saúde como Ponto Focal Nacional para o Regulamento Sanitário Internacional (2005) junto à Organização Mundial da Saúde. Diário Oficial da União, Brasília, no 154, p.46, 11 ago. 2006. Seção 1.

81 Brasil. Decreto № 7.616, de 17 de novembro de 2011. Dispõe sobre a declaração de Emergência em Saúde Pública de Importância Nacional ESPIN e institui a Força Nacional do Sistema Único de Saúde - FNSUS. Diário Oficial da União, Brasília, no 221, p.14-15, 18 nov. 2011. Seção 1.

82 Brasil. Ministério da Saúde. Gabinete do Ministro. Portaria ํㅡ 104, de 25 de janeiro de 2011. Define as terminologias adotadas em legislação nacional, conforme o disposto no Regulamento Sanitário Internacional 2005 (RSI 2005), a relação de doenças, agravos e eventos em saúde pública de notificação compulsória em todo o território nacional e estabelece fluxo, critérios, responsabilidades e atribuições aos profissionais e serviços de saúde. Diário Oficial da União, Brasília, oㅡ 18, p. 37-38, 26 de jan. 2011. Seção 1. 


\title{
4.2 SEGUNDO ARTIGO - "INFLUENZA NO BRASIL: CAMINHOS DA VIGILÂNCIA"
}

Ligia Cantarino

\author{
Faculdade de Agronomia e Medicina Veterinária, Universidade de Brasília, Brasília, Brasil \\ Edgar Merchan-Hamann \\ Faculdade de Ciências da Saúde, Universidade de Brasília, Brasília, Brasil
}

\subsubsection{Resumo}

A influenza é uma virose de interesse mundial e que tem exigido atenção das autoridades sanitárias. Desde 1947 a Organização Mundial da Saúde monitora, por meio de uma rede mundial de laboratórios, a circulação viral para definição da vacina anual como medida preventiva. Neste trabalho é feita uma apresentação da estruturação da vigilância da influenza no Brasil, destacando-se a vigilância virológica, o papel dos laboratórios de diagnóstico e como tem sido a ampliação de suas ações para melhorar a detecção e resposta rápida. O modelo instituído corresponde à vigilância sentinela complementada pela notificação universal de Síndrome Respiratória Aguda Grave; pela investigação de surtos, óbitos e eventos incomuns; e pelo monitoramento de hospitalização e mortalidade numa vigilância ampliada. Nesta revisão são abordados aspectos da vigilância de influenza em animais e a necessidade de integração entre órgãos e de partilha de informações originadas nos diversos sistemas de vigilância.

Palavras-chave: influenza; vigilância epidemiológica; saúde pública.

\section{Abstract}

Influenza is a viral disease of global concern that has demanded the attention of the health authorities. Since 1947, as a preventive measure, the World Health Organization monitors, through a worldwide network of laboratories, the viral circulation to define the annual vaccine. This article presents the structuring of surveillance of influenza in Brazil, highlighting the virological surveillance and the role of diagnostic laboratories, as well as the expansion of its actions to improve detection and rapid response. The model set corresponds to the sentinel surveillance 
complemented by the universal notification of Severe Acute Respiratory Syndrome, by investigating outbreaks, death and unusual events, and by monitoring hospitalization and mortality in an expanded surveillance. In this review, we address aspects of influenza surveillance in animals and the need for integration between agencies and the sharing of information arising in many surveillance systems.

Keywords: influenza; epidemiological surveillance; public health.

\subsubsection{Introdução}

A influenza ou gripe é uma doença respiratória de distribuição mundial, causada pelos vírus influenza, Myxovirus influenzae. Pertencentes à família Orthomyxoviridae são classificados como vírus $\mathrm{A}, \mathrm{B}$, ou $\mathrm{C}$. As variações antigênicas virais constituem importante mecanismo de escape imunológico e favorecem o aporte de novos hospedeiros suscetíveis. Esses fatores, aliados à alta transmissibilidade e aos potenciais zoonótico e pandêmico, tornam o desafio de prevenção e controle um problema crescente e de importância reconhecida em saúde pública $(1,2)$.

A história registrou a virose como uma doença multifacetada. Enfermidade comum, de curso benigno, com sazonalidade conhecida, pode se apresentar com quadros clínicos graves e fatais. As pandemias ocorridas no passado - como a gripe espanhola (1918-20), asiática (1957-60) e de Hong-Kong (1968-72) - foram caracterizadas por causar milhões de mortes. No episódio da pandemia de 2009, o vírus $\mathrm{H} 1 \mathrm{~N} 1$ espalhou-se rapidamente em humanos, com altas taxas de morbidade $(3,4,5)$.

Em função do potencial pandêmico e da possível gravidade das manifestações clínicas, a influenza apresenta distintos problemas na perspectiva de saúde pública, que requerem atenções específicas de vigilância e controle (6). A vigilância desse agravo é preconizada mundialmente (7).

A importância da doença frente às ameaças de pandemia impulsionou esta revisão narrativa na qual apresentamos o caminho da estruturação da vigilância da 
influenza humana no Brasil, com uma breve abordagem de aspectos da vigilância em animais.

\subsubsection{Vigilância global}

A Organização Mundial da Saúde (OMS) monitora, desde 1947, a atividade do vírus da influenza por meio de uma rede de laboratórios para identificação viral denominada, inicialmente, de Rede Global de Vigilância da Influenza (GISN-Global Influenza Surveillance Network). Em 2011, o nome dessa rede foi alterado para Sistema Global de Vigilância e Resposta à Influenza (GISRS-Global Influenza Surveillance and Response System). Sua atribuição é acompanhar a evolução dos vírus influenza e fornecer informações que subsidiam a OMS nas recomendações relativas ao diagnóstico laboratorial, vacinas, susceptibilidade ao antiviral e avaliação de risco, além de constituir um mecanismo de alerta global para o surgimento de vírus com potencial pandêmico $(2,8)$.

Os objetivos da vigilância virológica de influenza são: identificar a circulação viral - tipos e subtipos - e suas relações com os padrões regionais e globais; descrever características antigênicas e genéticas; monitorar a sensibilidade antiviral; conhecer a relação entre a cepa do vírus e sua gravidade; e fornecer informação e amostras virais para seleção de vírus candidatos para a produção de vacinas (7).

O GISRS está constituído por seis Centros Colaboradores (CC) da OMS e 141 instituições de diagnóstico viral, em 111 Estados Membros da OMS. Os laboratórios de diagnóstico são reconhecidos como Centros Nacionais de Influenza (NIC - National Influenza Center) (8). A organização desse sistema laboratorial incumbe os NICs de cada país como responsáveis pela coleta de amostras de espécimes clínicos, isolamento e envio de amostras virais de interesse para os CC. Esses, além das caracterizações antigênicas e genéticas virais, têm como funções oferecer treinamento, elaborar manuais de técnicas laboratoriais, de qualidade e de avaliação para abordagem padronizada em toda a rede. Para padronização e uniformização das técnicas, os protocolos e os reagentes comuns são disponibilizados pela OMS, por meio do Centers for Disease Control (CDC), aos $\operatorname{NICs}(2)$. 
O Brasil faz parte do GISRS pela atuação de três laboratórios credenciados, junto à OMS, como NIC: o Laboratório de Virologia do Instituto Evandro Chagas, no Pará (IEC/PA); o Laboratório de Vírus Respiratórios do Instituto Adolfo Lutz, em São Paulo (IAL/SP); e o Laboratório de Vírus Respiratório e Sarampo da Fundação Oswaldo Cruz, no Rio de Janeiro (Fiocruz/RJ). Os dois primeiros laboratórios são reconhecidos, pelo Sistema Nacional de Laboratórios de Saúde Pública (Sislab), como referência regional, e o último, como referência nacional para influenza no Brasil $(9,10)$.

Soma-se à vigilância viral, um sistema mundial padronizado e em aprimoramento desde 1950 para acompanhar a influenza, com objetivos específicos: descrever a sazonalidade da influenza em cada país; sinalizar o início da estação de influenza; e estabelecer e monitorar as tendências de Síndrome Gripal (SG) e Síndrome Respiratória Aguda Grave (SRAG). Essas informações são importantes por fornecerem dados sobre a carga da doença e o impacto da influenza em relação a outras doenças, auxiliar na identificação, monitoramento dos grupos de alto risco e das alterações anuais de gravidade e definir prioridades para utilização dos recursos (7).

\subsubsection{A vigilância de influenza humana no Brasil}

No Brasil, a vigilância de influenza começou na década de 1990, com a identificação dos vírus circulantes em alguns locais do País e em situações de surtos (11). Com base na vigilância sentinela da circulação viral desenvolvida em Paris, França, e iniciada em outubro de 1984 pelo Groupe Regional d'Observation de la Grippe - GROG (12), foi criado no Brasil, em 1995, o Grupo de Observação da Gripe - GROG formado por alguns serviços de saúde, públicos e privados, das regiões Sul e Sudeste. O objetivo era sistematizar as informações acerca da circulação dos vírus respiratórios no Brasil, em particular do vírus influenza. Em 2000, O GROG passou a se chamar Projeto VigiGripe, como parte do Projeto VigiVírus. Esse grupo estava vinculado à Universidade Federal de São Paulo, em trabalho conjunto com a Seção de Vírus Entéricos e Respiratórios do IAL $(11,13,14)$. A vigilância epidemiológica da influenza foi implantada nacionalmente no ano 2000 , 
estabelecida com base em Unidades Sentinela (US) e no uso de dados indiretos de morbidade e mortalidade associados (9). Nessa época, a vigilância epidemiológica era exercida pelo Centro Nacional de Epidemiologia (Cenepi), que estruturou equipe técnica de forma articulada com as Secretarias Estaduais de Saúde e com os laboratórios de vírus respiratórios do IAL/SP, IEC/PA e Fiocruz/RJ, já credenciados como referências pela OMS (11). Assim, foi adotado um conjunto de ações específicas e continuadas para conhecer o comportamento da influenza e possibilitar a adoção de medidas de intervenção pertinentes, oportunas e eficazes $(9,10)$.

A vigilância implantada teve por objetivos o monitoramento da circulação das cepas do vírus influenza e das tendências de morbimortalidade; a avaliação do impacto da vacinação; a resposta a situações inusitadas, além da produção de informações sobre a doença. Para seleção de ao menos uma US por Estado, adotaram-se critérios específicos: o interesse real da unidade na participação do trabalho; sua condição como centro de atendimento com demanda de consultas de clínica geral e/ou pediatria; a presença de equipe e estrutura mínima; localização preferencialmente próxima ao laboratório; e ter bom desempenho gerencial. As US deveriam registrar a proporção de atendimentos por SG em relação ao total atendido e encaminhar cinco amostras biológicas de secreção respiratória por semana a um dos Laboratórios Centrais de Saúde Pública (Lacen) (9).

A vigilância de influenza tem sido capaz de identificar os vírus respiratórios circulantes, e sua sazonalidade e população de maior risco. Em estudo sobre a vigilância brasileira de influenza realizado de 2000 a 2010 (10), foram registrados nas US o total de atendimentos de 29.318 .698 pacientes, sendo 3.291 .946 (11\%) por influenza like ilness (ILI). Desses, em 37.120 (1\%) foram coletadas amostras de secreção de nasofaringe para pesquisa de vírus respiratórios. Foram positivos 6421 (17\%) sendo 1690 (26\%) positivos para o vírus influenza A; 567 (9\%) influenza B; 277 (4\%) parainfluenza 1; 571 (9\%) parainfluenza 2; 589 (9\%) parainfluenza 3, 742 (12\%) adenovírus; e 1985 (31\%) para vírus respiratório sincicial.

O fortalecimento da vigilância de influenza foi impulsionado pelo surgimento, em 2003, na região asiática e em alguns países europeus, de surtos de influenza aviária (IA) de alta patogenicidade (A/H5N1), com casos graves e alta letalidade em pessoas $(1,2,15)$. A situação gerou preocupação mundial e, no Brasil, mobilizou diversos órgãos para discussão de estratégias que levaram ao Plano Brasileiro de 
Preparação para uma Pandemia de Influenza, apresentado e discutido em seminário internacional, no Rio de Janeiro, em novembro de 2005. Esse esforço coletivo inseriu a influenza na pauta da política nacional de saúde pública (11).

Com a aprovação da revisão do Regulamento Sanitário Internacional (RSI), pela Assembleia Mundial de Saúde, em 2005, os países signatários igualmente reviram suas estruturas e processos de monitoramento, vigilância e resposta às Emergências de Saúde Pública de Importância Internacional, comprometidos em desenvolver capacidades para responder a essas emergências $(2,14)$.

A influenza humana - no que se refere à notificação de surto ou de óbitos passou a fazer parte da relação das doenças de notificação compulsória nacional em julho de 2005 (16). A inclusão da influenza humana por novo subtipo (pandêmico) ocorreu em fevereiro de 2006 (17). A Portaria GM/MS no 104, de 25 de janeiro de 2011, além de definir as terminologias em conformidade com o RSI 2005, alterou a nomenclatura para influenza humana por novo subtipo como de notificação compulsória e imediata e, classificou influenza humana como doença de notificação compulsória em unidades sentinelas (18). Na norma vigente, Portaria GM/MS no 1.271 , de 6 de junho de 2014, consta na relação como Influenza humana produzida por novo subtipo viral (19).

A regulamentação das Diretrizes Operacionais dos Pactos Pela Vida e de Gestão, pela Portaria GM/MS no 699, de 30 de março de 2006, também contribuiu para fortalecer a vigilância da influenza. Prerrogativas de repasse de verbas federais foram pactuadas para o fortalecimento da capacidade de resposta à influenza, entre outras doenças emergentes e endemias. A meta nacional, para 2006, estabeleceu a implantação de US e do Sistema de Informação Epidemiológica da Gripe (SivepGripe) em $100 \%$ das capitais. O indicador de monitoramento e avaliação definido foi a Taxa de Participação no Sistema: número de semanas epidemiológicas informadas, dividido pelo total de semanas epidemiológicas do período, multiplicado por 100. Com os investimentos financeiros direcionados a capacitações, treinamentos e supervisões, e a aquisições de insumos e equipamentos laboratoriais e de informática, a vigilância da influenza foi gradativamente sendo implantada e ampliada em todo o País (20). 


\subsubsection{A vigilância em 2009: ano pandêmico}

Quando a pandemia de 2009 foi declarada, em abril, a vigilância nacional de influenza contava com um programa estruturado em 60 US, o que facilitou o monitoramento das ações preconizadas e, mesmo com fragilidades - problemas com o sistema de informação e com a divulgação das informações -, demonstrou o aumento da proporção de infecções pelo vírus A/H1N1 2009, entre outros vírus respiratórios (21).

No decorrer da pandemia, com a transmissão sustentada no País, declarada em 16 de agosto de 2009, apenas os casos de SRAG constituíam objeto de vigilância, com notificação, internação e investigação laboratorial, conforme orientação da OMS. Houve, então, alteração da vigilância executada, que passou da notificação universal para a notificação dos casos de SRAG e dos óbitos com confirmação laboratorial de infecção por influenza pandêmica (6). Essa estratégia colaborou para a posterior inclusão da vigilância sentinela de SRAG.

O encerramento da pandemia foi declarado em 10 de agosto de 2010, pela OMS. A atividade da doença no mundo retomara aos níveis sazonais. No Brasil, as regiões Sul e Sudeste foram as mais afetadas (66,2 e 9,7 casos/100.000 hab., respectivamente) e a taxa de incidência de SRAG por influenza pandêmica foi de 14,5 casos/100.000 hab. Os grupos etários mais atingidos foram o das crianças até dois anos (22 casos/100.000 hab.) e o de jovens entre 20 e 29 anos (16 casos/100.000 hab.) (6). Com a situação epidemiológica da influenza estabilizada, a experiência gestora adquirida com a condução do evento pandêmico, a sensibilização da população para as questões sanitárias, e as recomendações da OMS, observou-se a conscientização governamental para a necessidade de rever e adequar a estratégia da vigilância.

\subsubsection{A atual vigilância de influenza no Brasil}

Para reforçar e ampliar a vigilância da influenza foi estabelecido mecanismo de repasse financeiro, por adesão, do Fundo Nacional de Saúde aos Fundos de 
Saúde do Distrito Federal e Municípios, pela Portaria GM/MS № 2.693, de 17 de novembro de 2011 (22). Nesse instrumento, buscando a representatividade mínima da circulação viral em todos os Estados brasileiros, tanto em casos graves quanto leves, foram definidos como sítios sentinelas as capitais e municípios de maior porte das regiões metropolitanas, e revisados os critérios de seleção das US. Esse incentivo financeiro de custeio para implantação e manutenção de ações e serviços públicos estratégicos de vigilância em saúde foi regulamentado pela Portaria GM/MS № 183, de 30 de janeiro de 2014 (23), que também estabeleceu os critérios de financiamento, monitoramento e de avaliação.

Diferentes estratégias são utilizadas numa vigilância ampliada de influenza: vigilância sentinela de SG e de SRAG; vigilância universal de SRAG complementada pelo monitoramento de hospitalização e de mortalidade por pneumonias segundo a Classificação Internacional de Doenças e Problemas Relacionados à Saúde (CID 10) de J09 ao J18; e investigação de surtos, óbitos e eventos incomuns suspeitos para influenza (Figura 1). As definições de caso consideradas são: para SG, indivíduo com febre, mesmo que referida, acompanhada de tosse ou dor de garganta e início dos sintomas nos últimos sete dias; para SRAG, indivíduo hospitalizado com febre, mesmo que referida, acompanhada de tosse ou dor de garganta e que apresente dispneia, e ainda sinais de saturação de oxigênio menor que $95 \%$ ou desconforto respiratório ou aumento da frequência respiratória (6). 


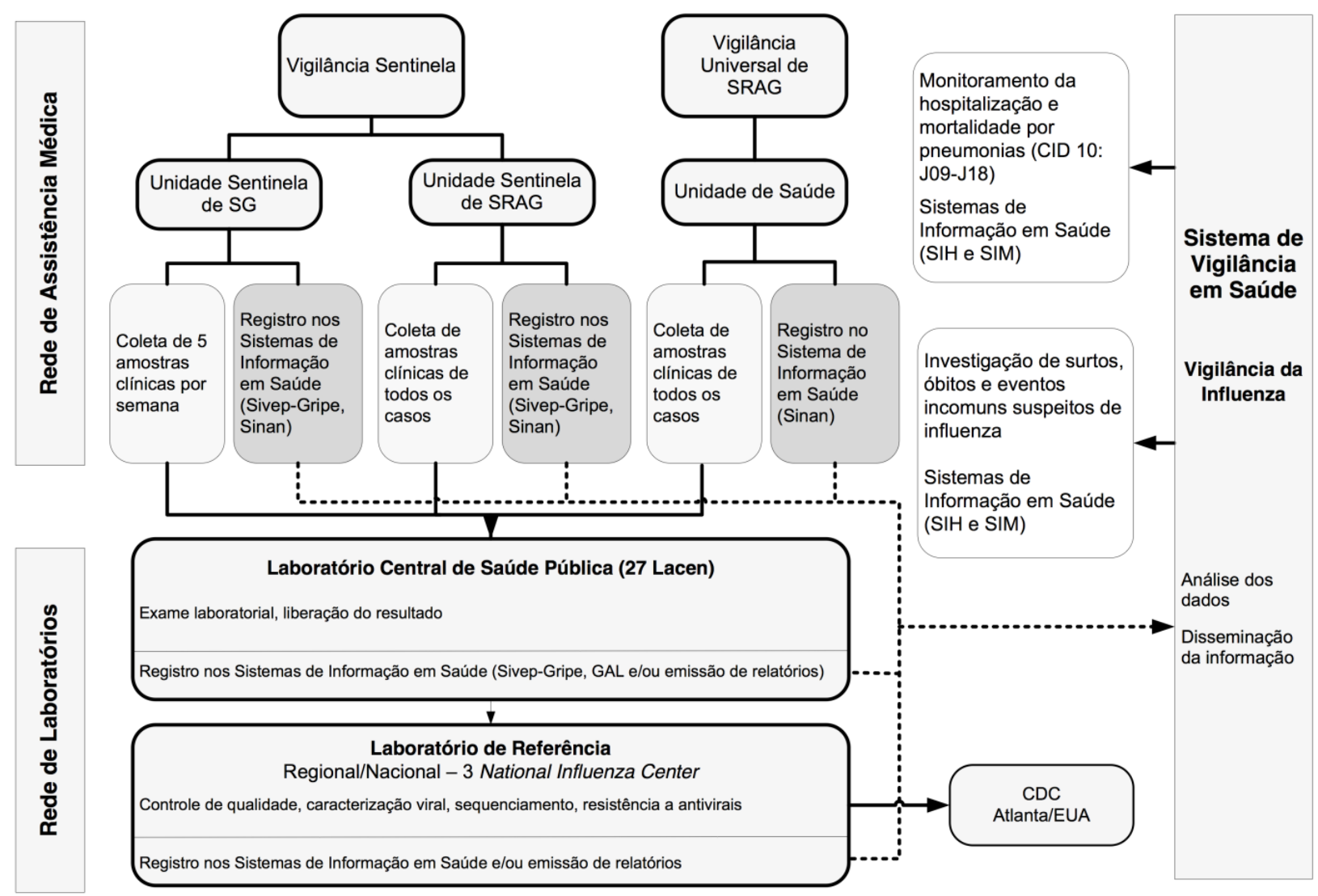

Figura 1 - Fluxograma da Vigilância da Influenza

As US fazem os registros dos atendimentos por SG, com dados agregados, por semana epidemiológica (proporção de casos suspeitos de $S G$ em relação ao total de atendimentos), e se comprometem a coletar cinco amostras clínicas por semana, de modo a atingir o mínimo de $80 \%$ de coleta de material da meta semanal e registrar no Sivep-Gripe, oportunamente, o agregado semanal, por sexo e faixa etária dos atendimentos de SG, e o total de atendimentos da US em, no mínimo, 90\% das semanas epidemiológicas do ano. A Portaria GM/MS 2.693, de 17 de novembro de 2011, preconizava esse protocolo e, ainda, que a vigilância sentinela de SRAG fosse realizada em Unidade de Terapia Intensiva (UTI), com monitoramento da vigilância agregada por semana epidemiológica, pelo CID 10: J09 a J18. Os dados das internações inseridos semanalmente, de forma agregada, no Sivep-Gripe, são de 90\% das semanas epidemiológicas do ano, no mínimo. São coletadas e enviadas amostras aos Lacen de, no mínimo, 80\% dos casos de SRAG notificados. O registro da notificação universal (e imediata) de SRAG é feito no 
módulo Influenza do Sistema de Informação de Agravos de Notificação (Sinan), com registro da investigação de surtos, óbitos e eventos incomuns suspeitos para influenza no componente específico para surtos (Sinan-NET), e o monitoramento de hospitalização e mortalidade pelo CID-10: J09 ao J18, nos Sistemas de Informação de Internação Hospitalar (SIH) e de Mortalidade (SIM), respectivamente (22).

O número de US aumentou em todo o País com a estratégia de repasse financeiro adotada em 2011. Em 2009, estavam ativas 60 US e, em março de 2014, havia 221. Apesar do aumento do número de US, elas não estão distribuídas de forma equilibrada em todas as regiões do País: a região Norte tinha 22 de SG e 11 de SRAG; a Nordeste, 28 de SG e 17 de SRAG; a Sudeste, 36 de SG e 10 de SRAG; a Sul, 40 de SG e 41 de SRAG e a Centro Oeste com 11 de SG e 5 de SRAG (24).

\subsubsection{O diagnóstico laboratorial na vigilância}

O diagnóstico de influenza no Brasil segue as metodologias recomendadas pela OMS, com os espécimes clínicos sendo testados para influenza A e B por imunofluorescência indireta (IFI), e por técnicas de biologia molecular - clássica ou em tempo real - como a reação em cadeia da polimerase. As amostras positivas são selecionadas para isolamento do vírus e caracterização genética e antigênica conforme o protocolo padrão do CDC. O isolamento do vírus influenza (em ovos embrionados de galinha ou em células derivadas de epitélio de rim canino - MDCK Madin-Darby canine kidney cells) é um procedimento laboratorial que também é empregado (6).

O diagnóstico depende da qualidade da amostra clínica coletada, do transporte e do armazenamento adequados, e segue orientações de biossegurança. O espécime clínico pode ser obtido por swab nasal, nasofaríngeo, oral, combinado (nasal + oral), aspirado nasofaríngeo, lavado nasal, brônquico ou traqueal. As amostras devem ser coletadas, preferencialmente, do terceiro ao quinto dia após o início dos sintomas (fase aguda da doença) $(9,25)$, sendo aceitas, atualmente, até o sétimo dia (6). 


\subsubsection{A rede laboratorial}

Para estruturar a vigilância da influenza foi preciso a organização de uma rede de diagnóstico laboratorial, infraestrutura obrigatória para a eficiência da vigilância. A Rede Nacional de Diagnóstico de Influenza faz parte do Sislab, como uma das sub-redes específicas que compõem a Rede Nacional de Vigilância Epidemiológica, atuando sob coordenação dos Lacen e dos três laboratórios credenciados como NICs pela OMS.

As amostras clínicas dos casos de SG e SRAG são encaminhadas para análise nos Lacen de cada Estado, para pesquisa de vírus respiratórios: influenza $A$ e B; parainfluenza 1, 2 e 3; adenovírus e vírus sincicial. Todas as amostras com resultados inconclusivos, $10 \%$ das negativas e todas as positivas para influenza $A$ são encaminhadas para um dos três NICs para testes de controle de qualidade e, as positivas, para caracterização viral, sequenciamento e testes de resistência a antivirais (10).

Atualmente, as análises laboratoriais contam com metodologias de biologia molecular como a técnica de reação em cadeia da polimerase de transcrição reversa (RT-PCR) em tempo real. Os laboratórios que utilizam essa metodologia encaminham para análises complementares, nos Laboratório de Referência (LR) todas as amostras (100\%) com resultado positivo para influenza A sem identificação do subtipo ou inconclusivas (independentes do Cycle Threshold - Ct), e as amostras positivas com $\mathrm{Ct} \leq 30$ conforme a sazonalidade. Para SG, são encaminhadas $20 \%$ das amostras positivas para influenza; amostras positivas de trabalhadores de avicultura e suinocultura e de surtos. Para SRAG, no período sazonal, deverão ser encaminhadas $20 \%$ das amostras positivas para influenza e, fora do período, todas as amostras positivas. Devem seguir para os LR amostras de casos de SRAG em pessoas com idade entre 2 e 65 anos; e de pacientes internados por mais de 10 dias e em uso de fosfato de oseltamivir. Amostras de pacientes que foram a óbito por SRAG com idade entre 2 e 65 anos, com histórico de vacinação recente contra influenza, e que fizeram uso do fosfato de oseltamivir até dois dias após o início dos sintomas também devem ser remetidas para os LR. Nos Lacen que não fazem diagnóstico molecular, o material clínico deve ser processado pela técnica de IFI e o 
laboratório deve enviar para o LR $100 \%$ das amostras que forem positivas para influenza e $100 \%$ das inconclusivas (6).

Após a confirmação diagnóstica ser estabelecida por um dos três LR, amostras dos vírus detectados são encaminhadas ao CDC para análises complementares. Os resultados da pesquisa dos vírus circulantes são discutidos em Reunião de Peritos da OMS para subsidiar a formulação da vacina (10).

\subsubsection{A vacinação como medida preventiva}

A imunização contra influenza é reconhecida como importante estratégia de controle. Utilizada mundialmente desde 1945, sua composição muda periodicamente como reflexo do acompanhamento viral. Desde 1977 a vacina trivalente apresenta cepas vacinais dos vírus influenza A/H3N2, A/H1N1 e B. A partir de 2004, com a cocirculação das linhagens Victoria e Yamagata do vírus influenza $B$, foi iniciado estudo para uso da composição tetravalente (26). Em novembro de 2014, no Brasil, foi aprovado pela Agência Nacional de Vigilância Sanitária (Anvisa) o registro da vacina influenza tetravalente (fragmentada, inativada) (27), que será composta por dois tipos de cepas do vírus influenza $B$, adicionalmente às cepas influenza $A$.

A vigilância virológica global foi fator importante para que a OMS, em setembro de 1998, adotasse recomendação específica para a composição da vacina anual contra influenza para os países do Hemisfério Sul. Desde então, a recomendação da composição da vacina é realizada duas vezes por ano: em fevereiro, para o Hemisfério Norte (de novembro a abril) e, em setembro, para o Hemisfério Sul (maio a outubro). Para as regiões equatoriais, são considerados os dados epidemiológicos para indicação da composição mais apropriada - a de fevereiro ou a de setembro (28).

No Brasil, a implantação da vacinação contra influenza precedeu as ações de vigilância epidemiológica (11) e foi incluída, em 1999, no Programa Nacional de Imunizações, em campanhas nacionais anuais direcionadas a indivíduos com mais de 65 anos $(11,13)$, como proteção aos grupos de maior risco para as complicações da influenza, ou seja, os idosos e os doentes crônicos.

No ano 2000, a idade foi reduzida para indivíduos acima de 60 anos. Gradativamente foram sendo incorporados outros grupos prioritários e, para a campanha de 2014, com público alvo de cerca de 49,6 milhões de pessoas, a 
indicação era para indivíduos com 60 anos ou mais de idade, trabalhadores de saúde, povos indígenas, crianças de 6 meses a menores de 5 anos de idade, gestantes, puérperas (até 45 dias após o parto), portadores de doenças crônicas não transmissíveis e outras condições clínicas especiais, população privada de liberdade e os funcionários do sistema prisional. A vacina está disponível nos Centros de Referência para Imunobiológicos Especiais (CRIE) para pessoas com condições clínicas especiais, mediante prescrição médica (29).

\subsubsection{Sistemas de informação}

Para acompanhar as estratégias de vigilância desse agravo são utilizadas informações on-line em diferentes Sistemas de Informação em Saúde: no SivepGripe, dados da vigilância sentinela e no Sinan, da vigilância universal de SRAG (6), além do SIH-SUS e SIM, para morbidade agravada, mortalidade e letalidade. O sistema Gerenciador de Ambiente Laboratorial (GAL) também se configura como ferramenta de monitoramento e controle de exames laboratoriais, essencial à gestão e ao acompanhamento dos programas (30). Relevante também é a FluNet, plataforma internacional com base na web, do GISRS, para compartilhamento de dados e comunicação desde 1996 (8).

\subsubsection{Aspectos da vigilância de influenza em animais}

Em 1963 a OMS desenvolveu um programa informal para coordenar estudos sobre a relevância da influenza em animais na doença em humanos, que contribuíram para o estabelecimento da evidência da transmissão entre as espécies. A importância dos estudos levou à designação de um Centro Colaborador específico para a pesquisa em ecologia de influenza em animais, em Memphis, nos Estados Unidos da América (EUA), que permanece até os dias de hoje (8).

Em 2005, a Organização Mundial de Saúde Animal (OIE) e a Organização das Nações Unidas para Alimentação e Agricultura (FAO) estabeleceram a OFFLU (OIE/FAO Network of Expertise on Animal Influenza), uma rede global de informação sobre a influenza em animais, disponível na Internet em http://www.offlu.net. A OFFLU promove cooperação entre especialistas em saúde animal e humana, além 
de apoiar e coordenar esforços mundiais para prevenir, detectar e controlar influenza em animais $(31,32)$.

Estudos na interface homem-animal têm sido importantes tanto para se conhecer o papel de animais na cadeia de transmissão do vírus, como para as atividades de vigilância, principalmente as relativas a IA de alta patogenicidade. $O$ vírus influenza A se mantém em muitas espécies de mamíferos e aves. Estudos filogenéticos têm demonstrado linhagens virais espécie-específicas, que causam infecção altamente contagiosa em animais e com significativo impacto econômico. $\mathrm{Na}$ perspectiva da saúde humana, maior risco provém dos suínos e aves, pelo seu papel como fontes de novos vírus da gripe capazes de causar pandemias. Os suínos podem se infectar com vírus de origem aviária e humana tendo, portanto, maior capacidade de promover rearranjos virais (33).

A influenza em aves domésticas apresenta sinais clínicos evidentes (problemas neurológicos e respiratórios, dificuldade de locomoção, edema na crista e nas patas e depressão), e alta letalidade (33). Em suínos, no entanto, a doença se manifesta com quadro clínico que tende a ser leve ou subclínico, com alta transmissibilidade, alta morbidade e baixa mortalidade. Tal fato pode favorecer a circulação viral sem detecção e, portanto, as medidas de controle podem não ser implementadas para interromper a transmissão e disseminação. Esse fato pode colaborar para a manutenção da circulação de diferentes cepas virais e, com isso, oportunidades para rearranjos (34).

Nos equinos a doença é causada por dois subtipos virais - H7N7 e H3N8 que também podem cruzar barreiras das espécies e já foram identificados em doenças respiratórias em cães, suínos e em pessoas por exposição ocupacional (33).

O vírus influenza pandêmico de 2009 foi descrito em animais domésticos e não domésticos, como em pandas gigantes na China (35) e em suínos no Brasil $(36,37)$ e em outros países como Austrália, Índia, Sri Lanka, Colômbia e Camarões (38).

Muitas pesquisas apontam a importância do conhecimento da influenza animal para a doença em humanos. No entanto, apesar de vasta produção científica sobre ecologia e propriedades moleculares dos vírus influenza em animais, não há um sistema de vigilância internacional abrangente $(32,39)$. 
A vigilância da influenza em animais de produção é fundamental e, no Brasil, é exercida pelo Ministério da Agricultura, Pecuária e Abastecimento (MAPA). Maior atenção é dada à $I A$, pois além das questões relativas à transmissão para humanos com casos graves e fatais, a produção avícola brasileira é economicamente relevante e o País é um dos maiores produtores e exportadores mundiais de carne de frango. Esse perfil avícola se consolidou no início dos anos 2000 (40), período em que se verificaram surtos de IA de alta patogenicidade $(1,2,15,41)$.

O MAPA instituiu programa nacional com realização de vigilância passiva com o atendimento a todas as suspeitas de IA e vigilância ativa em sítios de aves migratórias, plantéis avícolas comerciais e de subsistência, com envio de material para diagnóstico laboratorial. Esse diagnóstico segue as normativas da OIE, tanto para a coleta e transporte de amostras (sangue, swabs de traqueia e de cloaca) como para as metodologias empregadas, e é realizado na rede oficial do MAPA sendo o Laboratório Nacional Agropecuário (Lanagro) de Campinas, São Paulo, de referência para doenças avícolas (42). Até o momento no Brasil não foi identificado vírus de IA de alta patogenicidade, no entanto cepas de baixa patogenicidade foram descritas em vários estudos como os de Mota et al. (2013) (40), Rajão et al. (2013) (36), Araujo et al. (2014) (43) entre outros.

A OIE mantém uma lista de doenças de notificação obrigatória atualizada anualmente. Nessa lista constam a IA e a gripe equina, mas não a influenza suína (44). Além da IA, são de notificação obrigatória ao MAPA, com registro nos informes mensais, casos confirmados de gripe equina (cavalos, asininos e muares) e influenza suína, conforme a Instrução Normativa MAPA no 50, de 24 de setembro de 2013 (45).

A vacina contra influenza para aves é proibida no Brasil (42). Não há recomendação para vacinação de suínos conforme o Programa Nacional de Sanidade Suídea, instituído pela Instrução Normativa MAPA no 47, de 18 de junho de 2004 (46), embora exista vacina comercial disponível. O Programa Nacional de Sanidade dos Equídeos instituído pela Instrução Normativa MAPA № 17, de 8 de maio de 2008 não referenda a vacinação (47). No entanto, a Instrução de Serviço MAPA ํo 17, de 16 de novembro de 2001 (48), refere-se à vacinação como medida sanitária na ocorrência de surtos de gripe equina. $A$ indicação é de primo vacinação com duas doses com intervalo de quatro a seis semanas e reforço a cada seis 
meses. Potros devem ser vacinados a partir dos quatro meses e animais de competições em intervalos de três a quatro meses (49).

Informações da vigilância veterinária são registradas no Sistema Nacional de Informação Zoossanitária (SIZ) que faz parte do Sistema Brasileiro de Vigilância e Emergências Veterinárias (SisBraVet). O Departamento de Saúde Animal do MAPA é responsável pela manutenção e gerenciamento do SIZ com base na relação de doenças de notificação obrigatória no Brasil e da OIE. No sítio na internet da OIE são disponibilizados os dados do Sistema Mundial de Informação Zoosanitária (WAHIS-World Animal Health Information System) por meio do Banco Mundial de Informações de Saúde Animal (WAHID-World Animal Health Information Database). Outra ferramenta de acompanhamento é o Sistema Continental de Vigilância Epidemiológica (SivCont), desenvolvido em 2004 pelo Centro Panamericano de Febre Aftosa (Panaftosa), para registro e análise de dados e informações de eventos de vigilância sindrômica no qual, no final de 2010, foi incluído a síndrome respiratória e neurológica das aves (50).

O MAPA acompanha a situação epidemiológica da influenza aviária no mundo e tem intensificado as medidas e exigências sanitárias em pontos de entrada no País para a proteção e conservação do status sanitário dos plantéis avícolas brasileiros (51). No entanto, são poucos os conhecimentos sobre os vírus influenza circulantes em animais no Brasil, particularmente em suínos - uma infecção que parece ter se tornada endêmica nos rebanhos nacionais após a introdução do vírus pandêmico (37).

\subsubsection{Considerações finais}

Em que pese a intenção de abordar a estruturação da vigilância brasileira de influenza, estudos de efetividade, desempenho do sistema, qualificação dos sistemas de informação, integração das vigilâncias nas vertentes da saúde humana e animal são temas que requerem aprofundamento de análise. A revisão realizada manteve o foco nas intervenções da rede oficial de vigilância de influenza - humana ou animal - pela característica de ações continuadas e sistemáticas, como requer a vigilância epidemiológica, evitando abarcar valiosos trabalhos de pesquisas 
conduzidos por grupos de estudos de instituições de ensino e pesquisa sobre o tema. A abordagem à rede oficial de vigilância de influenza em animais, apesar de breve, igualmente não desconhece a necessária e relevante importância dos setores nela envolvidos.

O investimento no fortalecimento da vigilância de influenza humana e animal no País merece destaque. Diferenças de estratégias devem ser consideradas: para animais a vigilância é passiva, enquanto que a base da vigilância epidemiológica de influenza humana segue o modelo sentinela.

Desde 2000, a estrutura vem sendo burilada conforme as configurações epidemiológicas e políticas, e o sistema tem se mostrado capaz de demonstrar a presença e a circulação viral, mesmo com limitações. O número de US e de amostras coletadas é pequeno frente à composição da população brasileira e sua distribuição geográfica. A positividade dos resultados, em torno de 17\%, pode ocorrer tanto por reflexo da seleção de pacientes (definição de caso), dos procedimentos adequados na coleta, armazenamento e envio para o laboratório, bem como pela técnica do diagnóstico. Esses elementos se configuram como pontos críticos para a vigilância e devem ser trabalhados nas supervisões e avaliações de serviço. Há que se melhorar a vigilância, principalmente, no que se refere à representatividade, oportunidade e positividade dos exames, de modo a refinar o conhecimento do impacto da virose e aumentar a capacidade de resposta dos serviços de saúde pública.

Nelson \& Vincent (2015) (38) chamam atenção para os vieses - de amostra, de tempo, de espaço - da vigilância de influenza em humanos e suínos, uma vez que o desequilíbrio das atividades de vigilância prejudica o entendimento da ecologia viral. Os autores afirmam a necessidade de se intensificar a vigilância de influenza em suínos, principalmente nos países que possuem grandes populações desses animais, e com reduzida vigilância como, por exemplo, Brasil, Vietnã e Rússia. Pode-se extrapolar a questão dos vieses para outras espécies animais.

O Brasil, grande produtor de suínos e aves, precisa melhorar a vigilância e a intercomunicação entre os órgãos governamentais envolvidos. Pelas características da doença em suínos e para conferir maior representatividade na pesquisa de circulação dos vírus, deveriam ser considerados, para coleta de material, tanto animais clinicamente doentes como saudáveis, como sugere Henningson et al (34). 
Cabe reforçar que o necessário investimento na rede laboratorial de diagnóstico, no que concerne à provisão de insumos, quadro de profissionais e técnicos, infraestrutura adequada e pertinente, é fundamental para possibilitar o estabelecimento de novas metodologias, sensíveis e efetivas. Investimento em recursos humanos nos diferentes níveis de participação é fator inquestionável, pelo inegável diferencial que proporciona às atividades de saúde.

Devido a sua alta infectividade e disseminação, a influenza é um problema sanitário complexo que exige aplicação de medidas excepcionais de emergência, mesmo quando o evento for de baixa letalidade. A prevenção e o controle da influenza são impossíveis sem o acompanhamento permanente dos vírus influenza humano e animal. A circulação do vírus em animais pode representar risco tanto para a saúde pública quanto para a saúde animal.

É preciso fomentar estudos e a vigilância em animais e, para tanto, os instrumentos normativos da saúde humana e animal devem ter mais objetividade e consonância, numa abordagem única de saúde. É imprescindível estreitar a interface e o compartilhamento de informações e otimizar recursos entre os órgãos governamentais, instituir fluxos de informação e construir plataformas amigáveis e ambiência tecnológica (merging, layers de sistemas de informação geográfica), de modo a proporcionar subsídios para a tomada de decisões conjuntas.

Para manter o alerta em relação à influenza é fundamental que se invista também em educação sanitária - grande tarefa dos órgãos de saúde pública - na produção de informação sobre a doença para a população e para os profissionais de saúde, numa educação continuada. A influenza representa um permanente desafio para as autoridades veterinárias e de saúde pública no mundo todo. 


\section{Referências}

1 Zambon M. Influenza and other emerging respiratory viruses. Medicine 2014; 42(1):45-51.

2 Jerigan DB, Cox NJ. Human influenza: one health, one world. In: Webster, RG. et al. Ed. Textbook of influenza. 2.ed. Oxford: Wiley Blackwell; 2013:3-19.

3 Cox NJ, Subbarao K. Global epidemiology of influenza: past and present. Annu Rev Med 2000; 51:407-21.

4 Monto AS, Webster RG. Human pandemic: history and lessons learned. In: Webster RG et al. (ed). Textbook of influenza. 2. ed. Oxford: Wiley Blackwell; 2013.

5 Potter CW. A history of influenza. J Appl Microbiol 2001;91(4):572-9.

6 Brasil. Secretaria de Vigilância em Saúde. Departamento de Vigilância Epidemiológica. Influenza. In: Guia de Vigilância em Saúde. 1.ed., p. 13-39. Brasília: Ministério da Saúde; 2014.

7 World Health Organization (WHO). Global epidemiological surveillance standards for influenza. Switzerland: WHO Press; 2013: 84.

8 World Health Organization (WHO). Global Influenza Surveillance and Response System (GISRS). Disponível em: http://www.who.int/influenza/gisrs_laboratory/en. Acesso em: 5 nov. 2014.

9 Barros FR et al. O desafio da influenza: epidemiologia e organização da vigilância no Brasil. Boletim Eletrônico Epidemiológico, 19(1):197-225, 2004.

10 Freitas FTM. Sentinel surveillance of influenza and other respiratory viruses, Brazil, 2000-2010. Braz J Infect Dis, 2013; 17(1):62-68.

11 Luna EJ. Vigilância epidemiológica da influenza no Brasil - onde estamos? In: Kfouri, RÁ \& Berezin, EN (Ed.). Atualização em vírus respiratórios. 1. ed. São Paulo: Guinom Propaganda \& Comunicação; 2011: p. 15-20.

12 Dab W et al. A new influenza surveillance system in France - The lle-de-France GROG.2. Validity of indicators (1984-1989). Eur J Epidemiol, 2001; 7(6):579-587. 
13 Forleo-Neto E, Halker E, Santos VJ, Paiva TM, Toniolo-Neto J. Influenza. Rev Soc Bras Med Trop. 2003; 36(2):267-274.

14 Carmo EH. O regulamento sanitário internacional e as oportunidades para fortalecimento do sistema de vigilância em saúde. Recife: Portal DSS Nordeste; 30 abr. 2013. Disponível em: <http://dssbr.org/site/opinioes/o-regulamentosanitario-internacional-e-as-oportunidades-para-fortalecimento-do-sistema-devigilancia-em-saude>. Acesso em: 29 ago. 2014.

15 Perdue ML, Swayne DE. Public health risk from avian influenza viruses. Avian Dis, 2005; 49(3):317-327.

16 Brasil. Ministério da Saúde. Secretaria de Vigilância em Saúde. Portaria no 33, de 14 de julho de 2005. Inclui doenças à relação de notificação compulsória, define agravos de notificação imediata e a relação dos resultados laboratoriais que devem ser notificados pelos Laboratórios de Referência Nacional ou Regional. Disponível em: http://bvsms.saude.gov.br/bvs/saudelegis/svs/2005/prt0033_14_07_2005.html

17 Brasil. Ministério da Saúde. Secretaria de Vigilância em Saúde. Portaria nํ5, de 21 de fevereiro de 2006. Inclui doenças na relação nacional de notificação compulsória, define doenças de notificação imediata, relação dos resultados laboratoriais que devem ser notificados pelos Laboratórios de Referência Nacional ou Regional e normas para notificação de casos. Disponível em: http://bvsms.saude.gov.br/bvs/saudelegis/svs/2006/prt0005_21_02_2006_comp. html

18 Brasil. Ministério da Saúde. Gabinete do Ministro. Portaria no 104, de 25 de janeiro de 2011. Define as terminologias adotadas em legislação nacional, conforme o disposto no Regulamento Sanitário Internacional 2005 (RSI 2005), a relação de doenças, agravos e eventos em saúde pública de notificação compulsória em todo o território nacional e estabelece fluxo, critérios, responsabilidades e atribuições aos profissionais e serviços de saúde. Disponível em: http://bvsms.saude.gov.br/bvs/saudelegis/gm/2011/prt0104_25_01_2011.html.

19 Brasil. Ministério da Saúde. Gabinete do Ministro. Portaria ํo 1.271, de 6 de junho de 2014. Define a Lista Nacional de Notificação Compulsória de doenças, 
agravos e eventos de saúde pública nos serviços de saúde públicos e privados em todo o território nacional, nos termos do anexo, e dá outras providências. Disponível em: http://bvsms.saude.gov.br/bvs/saudelegis/gm/2014/prt1271_06_06_2014.html

20 Brasil. Ministério da Saúde. Portaria no 699, de 30 de março de 2006. Regulamenta as Diretrizes Operacionais dos Pactos Pela Vida e de Gestão. Diário Oficial da União, Brasília, 3 abr. 2006. p.49-67. Seção 1.

21 Oliveira WK et al. Pandemic H1N1 influenza in Brazil: Analysis of the first 34,506 notified cases of influenza-like illness with severe acute respiratory infection (SARI). Euro Surveill 2009;14(43):ii:19382.

22 Brasil. Ministério da Saúde. Gabinete do Ministro. Portaria no 2.693, de 17 de novembro de 2011. Estabelece mecanismo de repasse financeiro do Fundo Nacional de Saúde aos Fundos de Saúde do Distrito Federal e Municípios, por meio do Piso Variável de Vigilância e Promoção da Saúde, para implantação, implementação e fortalecimento da Vigilância Epidemiológica da Influenza. Diário Oficial da União, Brasília, p.81-82, 18 nov. 2011. Seção 1. Republicada no DOU. Brasília, 26 abr. 2012. p.37-38. Seção 1.

23 Brasil. Ministério da Saúde. Gabinete do Ministro. Portaria no 183, de 30 de janeiro de 2014. Regulamenta o incentivo financeiro de custeio para implantação e manutenção de ações e serviços públicos estratégicos de vigilância em saúde, previsto no art. 18, inciso I, da Portaria oํ 1.378/GM/MS, de 9 de julho de 2013, com a definição dos critérios de financiamento, monitoramento e avaliação. Diário Oficial da União, Brasília, 31 jan. 2014. p. 59, Seção 1.

24 Brasil. Ministério da Saúde. Secretaria de Vigilância em Saúde. Influenza: monitoramento até a semana epidemiológica 5 de 2014. Brasília, DF: Ministério da Saúde, 2014.

25 WHO. World Health Organization. WHO global influenza surveillance network: manual for the laboratory diagnosis and virological surveillance of influenza. Geneva: WHO Press: 137 p. 2011.

26 Keitel, W. A.; Neuzil, K. M.; Treanor, J. Immunogenicity, efficacy of inactivated/live virus seasonal and pandemic vaccines. In: Webster, R. G. e. a. 
(Ed.). Textbook of influenza 2.ed. Oxford: Wiley Blackwell, 2013. cap. 20, p.313326.

27 Brasil. Agência Nacional de Vigilância Sanitária. Resolução-RE no 4319 de 31 de outubro de 2014. Brasília, DF: Diário Oficial da União de 03/11/2014.

28 WHO. World Health Organization. Recommendation for the composition of influenza virus vaccines for use in 1999. Wkly Epidemiol Rec, 1998; 73(40): 305308.

29 Brasil. Ministério da Saúde. Secretaria de Vigilância em Saúde. CoordenaçãoGeral do Programa Nacional de Imunizações. Campanha Nacional de Vacinação Contra a influenza 2014. Informe Técnico. Brasília: Ministério da Saúde, 2014.

30 Jesus, R et al. Sistema Gerenciador de Ambiente Laboratorial: relato de experiência de uma ferramenta transformadora para a gestão laboratorial e vigilância em saúde. Epidemiol. Serv. Saúde, 2013; 22(3):525-529.

31 Edwards, S. OFFLU network on avian influenza. Emerg Infect Diseases. 2006;12(8):1287-1288.

32 Vincent, A et al. Review of influenza A virus in swine worldwide: a call for increased surveillance and research. Zoonoses Public Health, 2014; 61(1):4-17.

33 Alexander, DJ; Brown, IH. Recent zoonoses caused by influenza A viruses. Rev Sci Tech OIE, 2000; 19(1):197-225.

34 Henningson, JN et al. Comparative virulence of wild-type H1N1pdm09 influenza A isolates in swine. Vet Microbiol, 2015; 176(1-2):40-49.

$35 \mathrm{Li} D$ et al. Influenza $\mathrm{A}(\mathrm{H} 1 \mathrm{~N} 1)$ pdm09 virus infection in giant pandas, China. Emerg Infect Dis 2014; 20(3):480-3.

36 Rajão DS et al. Genetic characterization of influenza virus circulating in Brazilian pigs during 2009 and 2010 reveals a high prevalence of the pandemic H1N1 subtype. Influenza Other Respir Viruses, 2013; 7(5):783-790.

37 Schaefer $R$ et al. Isolation and characterization of a pandemic H1N1 influenza virus in pigs in Brazil. Pesqui Vet Bras, 2011; 31(9):761-767.

38 Nelson Ml; Vincent AL. Reverse zoonosis of influenza to swine: new perspectives on the human-animal interface. Trends Microbiol, 2015; 23(3): 142-153. 
39 Webster, RG. The importance of animal influenza for human disease. Vaccine, 2002; 20: S16-S20.

40 Mota, MA et al. Ações de vigilância para influenza aviária desenvolvida no Brasil, no período de 2004 e 2007. Arq Bras Med Vet Zootec., 2013; 65(5): 1265-1273.

41 WHO. World Health Organization. Evolution of H5N1 Avian Influenza Viruses in Asia. Emerg Infect Diseases, 2005; 11(10): 1515-1521.

42 Brasil.Ministério da Agricultura, Pecuária e Abastecimento. Secretaria de Defesa Agropecuária. Departamento de Saúde Animal. Plano de contingência para influenza aviária e doença de Newcastle. 2013 a. 59p. Disponível em:<http://www.agricultura.gov.br/arq_editor/file/PNSA/Plano\%20de\%20Conting \%C3\%AAncia\%20-\%20Vers\%C3\%A30\%201_4.pdf>. Acesso em: 11 out. 2014.

43 Araujo J et al. Avian Influenza Virus (H11N9) in Migratory Shorebirds Wintering in the Amazon Region, Brazil. Plos One, 2014; 9(10): e110141.

44 World Organization for Animal Health (OIE). OIE listed disease, 2014. Disponível em: <http://www.oie.int/animal-health-in-the-world/oie-listed-diseases-2014>. Acesso em: 15 out. 2014.

45 Brasil. Ministério da Agricultura, Pecuária e Abastecimento. Instrução Normativa № 50, de 24 de Setembro de 2013. Estabelece a relação das doenças de notificação obrigatória ao serviço veterinário oficial. Diário Oficial da União de 25/09/2013, p. 47. Seção 1, Página 47.

46 Brasil. Ministério da Agricultura, Pecuária e Abastecimento. Secretaria de Defesa Agropecuária. Instrução Normativa № 47, de 18 de junho de 2004. Aprova o Regulamento Técnico de Programa Nacional de Sanidade Suídea - PNSS, na forma do anexo a esta Instrução Normativa. Diário Oficial da União de 23/06/2004, Seção 1, Página 64. Disponível em:

http://extranet.agricultura.gov.br/sislegisconsulta/consultarLegislacao.do?operacao=visualizar\&id $=7938$

47 Brasil. Ministério da Agricultura, Pecuária e Abastecimento. Secretaria de Defesa Agropecuária. Instrução Normativa ํㅜ 17, de 8 de maio de 2008. Institui o Programa Nacional de Sanidade dos Eqüídeos - PNSE, no âmbito do Ministério da Agricultura, Pecuária e Abastecimento. Diário Oficial da União de 09/05/2008, 
Seção 1, Página 27. http://extranet.agricultura.gov.br/sislegisconsulta/consultarLegislacao.do?operacao=visualizar\&id=18609

48 Brasil. Ministério da Agricultura, Pecuária e Abastecimento. Secretaria de Defesa Agropecuária. Departamento de Defesa Animal. Instrução de Serviço no 17, de 16 de novembro de 2001. Brasília, 2001.

49 Brasil. Ministério da Agricultura, Pecuária e Abastecimento. Sanidade Animal. Calendário de vacinação. 2014. Disponível em:

$<$ http://www.agricultura.gov.br/animal/sanidade-animal/calendario-devacinacao>. Acesso em: 15 Set 2014.

50 Brasil. Ministério da Agricultura, Pecuária e Abastecimento. Secretaria de Defesa Agropecuária. Manual do Sistema Nacional de Informação Zoossanitária - SIZ. $2^{\underline{a}}$ ed. Brasília: Ministério da Agricultura; 2013. 40p. Disponível em:<http://www.agricultura.gov.br/arq_editor/file/Manual\%20SIZ/Manual_SIZ_09 _12_2013.pdf>. Acesso em: 11 out. 2014.40 p. 2013.

51 Brasil. Ministério da Agricultura, Pecuária e Abastecimento. Mapa monitora situação da gripe aviária pelo mundo. Assessoria de Comunicação Social. Notícias. 11/02/2015. Gripe Aviária. Disponível em: http://www.agricultura.gov.br/comunicacao/noticias/2015/02/mapa-monitorasituacao-da-gripe-aviaria-pelo-mundo. Acesso 4 de Mar 2015. 


\subsection{TERCEIRO ARTIGO - "PENSAR A ÉTICA NA VIGILÂNCIA DA INFLUENZA?" \\ Ligia Cantarino \\ Faculdade de Agronomia e Medicina Veterinária, Universidade de Brasília, Brasília, Brasil \\ Edgar Merchan-Hamann \\ Faculdade de Ciências da Saúde, Universidade de Brasília, Brasília, Brasil}

\subsubsection{Resumo}

A vigilância epidemiológica, importante na indicação e execução de políticas de saúde pública e nas tomadas de decisão, constitui um elo entre os serviços de saúde e a pesquisa. Nesse contexto, as questões éticas presentes nas práticas diárias de vigilância demandam processos reflexivos aprofundados e discussões específicas mais qualificadas. Para a elaboração deste ensaio reflexivo, tomaram-se algumas indagações éticas relacionadas à vigilância da influenza, confrontando-as com uma gama de conceitos bioéticos, de direitos humanos, de direito à saúde, de saúde pública e de ética. As reflexões propostas enfocam os princípios da bioética, relacionando-os às características das ações de vigilância direcionadas aos participantes da pesquisa de circulação de vírus respiratórios.

Palavras-chave: Ética. Bioética. Vigilância epidemiológica. Influenza humana.

\section{Resumen - Pensar la ética en la vigilancia de la gripe?}

La vigilancia epidemiológica, importante en la indicación e implementación de políticas de salud pública y toma de decisión, constituye una conexión entre los servicios de salud y la investigación. En este contexto, las cuestiones éticas presentes en las prácticas diarias de vigilancia requieren procesos reflexivos profundos y discusiones específicas más calificadas. Para el presente ensayo de reflexión se consideran algunas indagaciones éticas relacionadas con la vigilancia ejercida a la influenza, abordándolas frente a una gama de conceptos bioéticos, de derechos humanos, del derecho a la salud, de salud pública y de ética. Las reflexiones propuestas abordan los principios de la bioética relacionándolos con las 
características de las acciones de vigilancia dirigidas a los participantes de la pesquisa de circulación de virus respiratorios.

Palabras-clave: Ética. Bioética. Vigilancia epidemiológica. Gripe humana.

\section{Abstract - To think ethics in influenza surveillance?}

Epidemiological surveillance, important in the indication and implementation of public health policies and decision-making, constitutes a link between health services and research. In this context, the ethical issues found in daily surveillance practices require in-depth reflective processes and specific qualified discussions. For this reflection essay, some ethical questions related to the surveillance carried out for influenza were considered, holding them up against a range of bioethical concepts, including human rights, right to health, public health and ethics. The reflections proposed address the principles of bioethics, relating them to the characteristics of surveillance actions directed to the participants of the survey on respiratory viruses circulation.

\subsubsection{Introdução}

A influenza, ou gripe, é uma doença viral aguda do sistema respiratório, de rápida disseminação e distribuição global. Um indivíduo pode contrair gripe várias vezes ao longo de sua vida, e sua maior gravidade verifica-se nos grupos de risco, como idosos, crianças, imunodeprimidos, cardiopatas e pneumopatas. $\mathrm{Na}$ perspectiva de saúde pública, essa virose constitui-se em diferentes problemas que requerem cuidados específicos de vigilância e controle, haja vista a gravidade de suas manifestações clínicas e de seu potencial pandêmico e zoonótico (1-3).

A influenza causa preocupação às autoridades sanitárias mundiais por suas repercussões na morbimortalidade, sua similaridade com pneumonias atípicas de elevado poder de transmissão e gravidade, bem como pela probabilidade de aparecimento e disseminação de cepas com potencial pandêmico (4). Por causa dessas características, a virose é alvo, desde 1947, de programa mundial de 
vigilância, atualmente denominado Sistema Global de Vigilância e Resposta à Influenza (Global Influenza Surveillance and Response System - GISRS), criado pela Organização Mundial da Saúde (OMS) (5).

No ano 2000, o governo brasileiro, por intermédio do Ministério da Saúde (MS), introduziu a vigilância da influenza em âmbito nacional. A vigilância está calcada em unidades-sentinela e no monitoramento de dados indiretos de morbidade e mortalidade associados à influenza. São considerados os registros dos atendimentos por síndrome gripal e a circulação dos vírus, que são os agentes etiológicos de infecções agudas do sistema respiratório. A vigilância de vírus respiratórios tem como objetivo conhecer as cepas em circulação no Brasil, responder a situações inusitadas, avaliar o impacto da vacinação, acompanhar a tendência da morbimortalidade, além de produzir e disseminar informações epidemiológicas com vistas ao fortalecimento da vigilância por meio da elaboração de planos de contingência para o enfrentamento de situações pandêmicas (1).

A vigilância epidemiológica tem papel importante na indicação e execução de políticas de saúde pública e nas tomadas de decisão. Em um conceito ampliado, a vigilância epidemiológica funciona como elo entre os serviços de saúde e a pesquisa (6). Já o papel da pesquisa na vigilância em saúde é fundamental para a construção do conhecimento e elucidação de situações sanitárias. A pesquisa em saúde pública e a investigação em serviços de saúde estão imbricadas e, embora tenham diferentes abordagens em relação à pesquisa acadêmica tradicional, os aspectos éticos em comum devem ser considerados.

A necessidade de vigilância da influenza é indiscutível. No entanto, algumas questões éticas demandam reflexão. $O$ objetivo deste artigo é fazer uma reflexão sobre aspectos da ação permanente de vigilância de vírus respiratórios, parte fundamental da vigilância da influenza sob o olhar da bioética.

\subsubsection{Das práticas, orientações e normas de vigilância}

O Brasil pertence à rede mundial de vigilância da influenza com a participação de três laboratórios credenciados pela OMS, como centros nacionais de referência para influenza (National Influenza Center - NIC). As informações geradas por essa 
rede são analisadas e discutidas anualmente em reunião na sede da OMS, que, entre outras tomadas de decisão, indica as composições das vacinas a serem empregadas no ano seguinte.

Para situar a vigilância da influenza no contexto mais abrangente das atividades da vigilância à saúde, convém esclarecer que há formas diferentes de monitorar os eventos. $O$ enfoque tradicional, centrado na doença e conhecido como vigilância universal, fundamenta-se na notificação compulsória e é chamado de vigilância passiva. No entanto, abordagens alternativas têm sido preconizadas nos últimos anos, focalizando outros momentos do evento, ou dos ciclos biológicos, o que implica a promoção de ações diversificadas, denominadas vigilância ativa. Nessa abordagem, incluem-se as estratégias de vigilância-sentinela.

Na vigilância-sentinela da influenza, são tomadas amostras de pacientes com sintomatologia de síndrome gripal que buscaram atendimento médico nas unidades de saúde, mesmo que a queixa principal desses pacientes não se relacione com a síndrome. Preconiza-se uma amostragem por conveniência, e as unidades de saúde devem coletar amostras de cinco pacientes por semana, todas as semanas do ano. Assim, amostras são tomadas após triagem e rápida entrevista com os cidadãos presentes na sala de espera, desde que eles confirmem serem portadores de sinais clínicos compatíveis com síndrome gripal. As amostras são, em ordem de preferência: 1) aspirado de nasofaringe, ou 2) swab combinado (nasal e oral), obtido até cinco dias do início do aparecimento dos sintomas (fase aguda da doença) ${ }^{1}$. Essas amostras são encaminhadas para os laboratórios da rede de vigilância da influenza, e não para diagnóstico atrelado ao atendimento do paciente.

Quanto à forma de abordagem e aos cuidados ou aspectos éticos relativos aos pacientes, sujeitos participantes da pesquisa viral, encontra-se referência sobre o tema no "Guia de vigilância epidemiológica" do MS (1) (página 23), expressa pela afirmação de que a notificação tem de ser sigilosa, só podendo ser divulgada fora do âmbito médico-sanitário em caso de risco para a comunidade, respeitando-se o direito de anonimato dos cidadãos. Na Portaria MS 2.693/2011 (7), que trata do repasse de recursos para introdução, execução e fortalecimento da vigilância epidemiológica da influenza, não há alusão aos aspectos éticos.

$\mathrm{Na}$ prática da vigilância do agravo, documentos normativos não são observados em sua integralidade, a exemplo da orientação aos pacientes sobre as 
amostras de biológicas, fluxo laboratorial e resultados. A Portaria 788/2002, expedida pela Secretaria de Assistência à Saúde (SAS) do MS, preconiza que entre as principais funções de um posto de coleta estão o atendimento e orientação de pacientes para a coleta, identificação e recebimento de materiais biológicos, bem como o armazenamento adequado dos fluidos biológicos para posterior transporte, liberação e entrega de laudo ${ }^{8}$. Nesse sentido, a Portaria SAS 787/2002, além de estabelecer parâmetros básicos e normas técnicas para a organização da rede de laboratórios clínicos, recomenda a identificação correta das amostras, sistema de transporte eficiente e em acondicionamento adequado, bem como fluxo claro de encaminhamento de laudos de exames para os postos de coleta e/ou unidade de origem dos pacientes, de forma segura e confiável, visando garantir que o paciente tenha acesso ao resultado oportunamente (9).

Também reforça esse cuidado a Resolução 302/2005 da Diretoria Colegiada da Agência Nacional de Vigilância Sanitária (Anvisa), destinada à regulamentação técnica para o funcionamento de laboratórios clínicos, e aplicável a todos os serviços públicos ou privados que realizam atividades laboratoriais na área de análises clínicas, patologia clínica e citologia. De acordo com essa normativa, a unidade de coleta de amostras e o laboratório devem atender aos processos operacionais previstos e, entre outras atribuições, devem disponibilizar ao paciente ou responsável instruções escritas e ou verbais, em linguagem acessível, orientando sobre o preparo e coleta de amostras tendo como objetivo o entendimento do paciente (10). Além disso, a resolução determina que o paciente ambulatorial ou seu responsável deve receber um comprovante de atendimento contendo número de registro, nome completo do paciente, data do atendimento, data prevista de entrega do laudo, relação de exames solicitados e dados para contato com o laboratório.

No entanto, a despeito da existência dessas normativas orientadoras, persiste a situação em que o paciente não sabe qual laboratório processará sua amostra, não recebe comprovante para acompanhamento da análise laboratorial de sua amostra biológica, e tampouco recebe o resultado da análise. Uma vez realizada a coleta da amostra clínica, é dever do serviço público (ou privado) garantir a identificação, o acondicionamento e envio adequado e oportuno dessa amostra para análise laboratorial. Do mesmo modo, devem-se assegurar o processamento da amostra no prazo estabelecido e a entrega dos resultados laboratoriais aos 
pacientes de forma individualizada (para cada paciente, um laudo). Na prática da vigilância, o que se observa é que os resultados das análises laboratoriais são divulgados, de modo agregado, por semana epidemiológica, no "Boletim Epidemiológico de Influenza", disponível no site da Secretaria de Vigilância em Saúde do MS.

Nas atividades de vigilância da influenza, no momento da coleta na unidade de saúde, o consentimento ou assentimento para a investigação viral é informado oralmente pelo paciente, após receber breve explicação. Não existe o assentimento livre e esclarecido, assim como não há assinatura formalizada de um documento análogo ao termo de consentimento livre e esclarecido (TCLE), como no caso das pesquisas científicas, ou uma gravação da manifestação de aceite. Também inexiste qualquer outra evidência inequívoca de que a informação foi correta e oportunamente repassada pelo profissional de saúde e entendida pelo paciente. E, como se sabe, para que haja um consentimento esclarecido a informação revelada deve ser compreendida, não sendo suficiente que a pessoa seja mera receptora (11). Não há aqui uma sugestão de formalização documental, mas sim o questionamento quanto à informação e à comunicação adequada aos sujeitos da pesquisa. Procedimentos formais, mero cumprimento de determinações burocráticas desprovidas de reflexão e escolha consciente (12) não contribuem para o respeito aos direitos do cidadão participante da pesquisa.

$\mathrm{Na}$ pesquisa em vigilância, mesmo com base em um entendimento diferenciado, à luz da Resolução 466/2012 (13) do Conselho Nacional de Saúde (CNS), que dispõe sobre as diretrizes e normas regulamentadoras de pesquisas envolvendo seres humanos, os pacientes participantes da investigação viral, sujeitos da pesquisa, podem ser considerados vulneráveis. Ou ainda, os pacientes podem ser reputados como vulnerados, dada sua condição de vida, inclusive seu estado de saúde (14). Afinal, esses pacientes buscaram uma unidade de saúde para atendimento médico não necessariamente por problemas respiratórios, e, na triagem, foram interpelados por um profissional de saúde com vista à realização de coleta de material para exame pelo fato de aquele serviço médico pertencer à redesentinela para influenza.

Embora em seus efeitos individuais e sociais a pesquisa de vírus respiratórios seja altamente relevante e benéfica, uma vez que trará proveito direto ou indireto, 
imediato ou posterior, auferido pelo participante elou sua comunidade em decorrência de sua participação na pesquisa, os participantes devem ser esclarecidos sobre a natureza da pesquisa, seus objetivos, métodos, benefícios previstos, potenciais riscos e o incômodo que esta possa lhes acarretar, na medida de sua compreensão e respeitados em suas singularidades, conforme preconiza a Resolução CNS 466/2012 (13).

Não se propõe aqui a utilização da Resolução CNS 466/2012 (13) para subsidiar aspectos acerca da ética na vigilância epidemiológica da influenza. A pesquisa biomédica acadêmica tem características diferentes da investigação ou pesquisa em vigilância em saúde; no entanto, faz-se necessário observar as práticas de vigilância. É notório que a tomada de decisões em epidemiologia envolve ao mesmo tempo conhecimentos técnicos e a reflexão sobre questões importantes para o serviço de saúde pública. Do mesmo modo, as relações entre ética e epidemiologia desdobram-se entre compromisso político e prática nos serviços de saúde, passando pela produção de conhecimentos. Além do compromisso político ou da relevância social dos conhecimentos e intervenções, é fundamental destacar a necessidade de eleger prioridades para indivíduos na sociedade. A isso se somam as questões relativas à ética nas pesquisas envolvendo seres humanos e aos conceitos de risco e vulnerabilidade, que levantam a questão do consentimento informado e do retorno dos resultados à sociedade (12) - retorno esse aqui discutido tanto como resultado individual quanto como benefício da pesquisa à coletividade.

Embora os princípios individuais não se apliquem à saúde pública nem às pesquisas epidemiológicas, é importante a observação de normas e condutas que considerem as particularidades dos grupos e populações. Nas pesquisas epidemiológicas, mesmo com o compromisso de aquisição e aplicação de conhecimentos científicos para a manutenção e restauração da saúde pública, os direitos individuais devem ser respeitados (15).

Definir critérios e parâmetros para condutas éticas na pesquisa epidemiológica é preocupação constante dos estudiosos e pesquisadores da área, cujos temas de discussão constam de documentos internacionais dirigidos a epidemiologistas, como os seguintes exemplos, mencionados por Coughlin (16): as "International Ethical Guidelines for Epidemiological Studies", elaboradas pelo Conselho Internacional de Organizações de Ciências Médicas (Cioms) em 
colaboração com a OMS, e editadas em 1991; as "Ethics Guidelines", do American College of Epidemiology (ACE), publicadas no ano 2000; e as orientações da "HIPAA privacy rule and public health Guidance", de 2003, do Centers for Diseases Control and Prevention (CDC).

\subsubsection{Dos direitos}

Considerando que a estratégia da vigilância deve fundamentar-se no conceito de cidadão como sujeito de direitos, é vital estabelecer instrumentos que protejam a saúde do indivíduo integrado ao seu grupo populacional, reconhecido como igual em seus direitos, mesmo quando defende posições ou valores socioculturais diferenciados. É assaz relevante que a ética esteja estreitamente vinculada às práticas de saúde pública, uma vez que os aspectos éticos estão circunscritos apenas ao âmbito técnico, legal ou administrativo. As interferências éticas, sejam diretas ou indiretas, podem afetar as pessoas em suas tomadas de decisão (17).

De acordo com documento da OMS (18) que discute soluções para a influenza pandêmica, os direitos humanos são garantias legais universais destinadas a proteger os indivíduos e grupos contra ações que afrontam as liberdades fundamentais ou a dignidade humana. Uma das características mais importantes desse documento, o consenso internacional acerca das garantias que indivíduos e povos devem usufruir no âmbito da saúde foi ratificado pelos governos dos países signatários, que, dessa forma, se comprometem em aplicar as normas internacionais em contexto local. Assim, tanto por força de lei na dimensão nacional quanto em decorrência de consenso moral entre os países, os direitos humanos não podem ser renegados ou retirados.

O direito à saúde é exigência primária do direito à vida (19). Em grande medida, a construção do direito à saúde decorre da crescente urbanização que sobreveio à industrialização a partir do século XIX, bem como do fato - definido por lei - de a saúde ter passado a ser responsabilidade do Estado (20). Do mesmo modo, a vigilância epidemiológica é função do Estado, devendo constituir prérequisito na elaboração de programas de saúde e instrumento de avaliação do impacto de sua execução. Os sistemas de vigilância de doenças ou agravos devem 
ser objeto de avaliações frequentes e além de adaptações às mudanças necessárias, de forma a garantir bom desempenho, com qualidade, eficácia, eficiência e efetividade de suas ações. Só assim será possível evidenciar a situação epidemiológica do problema, as tendências, o impacto das medidas de controle, bem como propor novas ações. O sistema de vigilância epidemiológica mantém-se eficiente quando seu funcionamento é aferido regularmente, com vistas a ajustes oportunos (21).

Cabe, portanto, avaliar a pesquisa epidemiológica em função do bem coletivo, mas com olhar de respeito pelos direitos do indivíduo. O avanço da saúde pública tem se pautado pela incorporação de atribuições e responsabilidades, por parte do Estado, com base na consideração de que os direitos coletivos, e mesmo os direitos sociais difusos, se definem como condição inexorável da cidadania. As ações de controle sanitário têm origem no conjunto de medidas que as sociedades estabelecem no decorrer do tempo, com o intuito de impedir ou diminuir riscos e danos à saúde da população. As relações entre saúde pública e direitos humanos

permeiam os aspectos políticos, programas e práticas da saúde pública. É indispensável, portanto, buscar o equilíbrio entre o bem coletivo e os direitos individuais (22).

\subsubsection{Dos princípios bioéticos}

A bioética pode ser definida como ética voltada para a sobrevivência humana, uma vez que abrange temas sociais e ambientais, além dos conflitos biomédicos e biotecnológicos (23). O campo constitui-se em disciplina comprometida não só com a moral na área da saúde e da doença dos seres humanos e dos animais, mas também com a reflexão e discussão dos conflitos éticos por ela apontados, e que sempre estiveram presentes ao longo da história da sociedade humana (24).

A Declaração Universal sobre Bioética e Direitos Humanos (25) significou uma nova fase para o campo da bioética, que abandonou os estreitos limites da clínica e da pesquisa para consolidar-se como disciplina sob o marco dos direitos humanos. $O$ documento traz inúmeros princípios: a dignidade humana e os direitos humanos; benefício e dano; autonomia e responsabilidade individual; consentimento; 
indivíduos sem capacidade de consentir; respeito pela vulnerabilidade humana e pela integridade individual; privacidade e confidencialidade; igualdade, justiça e equidade; não discriminação e não estigmatização; respeito pela diversidade cultural e pelo pluralismo; solidariedade e cooperação; responsabilidade social e saúde; compartilhamento de benefícios; proteção das gerações futuras; proteção do meio ambiente, da biosfera e da biodiversidade.

No Brasil, a motivação ética é vista por princípios semelhantes entre si: a) respeito pelas pessoas, seja na obtenção de um TCLE, seja na confidencialidade e na proteção dos que são incapazes de tomar decisões; b) beneficência ou não causar dano (não maleficência), maximizando benefícios e reduzindo riscos; c) justiça distributiva, com balanço favorável do risco-benefício e seleção equitativa de pacientes, aspectos decorrentes de desenhos adequados ao estudo e da qualificação dos pesquisadores e equipe. Essa motivação foi discutida em estudo de Novaes e colaboradores (26), e seus princípios são regulamentados pela Resolução 466/2012 (13) do Conselho Nacional de Saúde.

Os desafios bioéticos com enfoque na saúde coletiva merecem reflexão crítica em temas essenciais como: saúde global e bioética global, justiça social e equidade em saúde, fatores de vulnerabilidade nos países mais desfavorecidos, respeito pela autonomia cultural dos povos, responsabilidade face à solidariedade e cooperação entre as nações, o universalismo versus relativismo ético face à dignidade humana (27).

Considerando as transformações vivenciadas pela sociedade, há que pensar em bioética orientada pelo respeito e incentivo à liberdade individual na tomada de decisão, somados aos princípios da solidariedade, justiça, equidade e responsabilidade, reforçando a necessidade de proteção dos menos favorecidos ou vulneráveis. É preciso pensar em um fazer bioético capaz de auxiliar na busca de soluções equilibradas entre liberdades individuais e interesses coletivos (28).

Os princípios bioéticos devem ser observados até mesmo na interdependência entre vigilância e pesquisa em saúde. As interfaces presentes nas atividades de vigilância da influenza devem ser minuciosas, de modo a orientar e pontuar a tomada de decisão quanto às ações de serviço, que devem priorizar o respeito ao cidadão. A ética da vida deve nortear as ações de vigilância, uma vez 
que elas se voltam para o coletivo, com o propósito de garantir, por parte do Estado, direitos dos cidadãos.

\subsubsection{Considerações finais}

Este ensaio traz algumas reflexões a partir da perspectiva da ética na vigilância da influenza. O que se observa é que os serviços e os profissionais de saúde não têm manifestado interesse explícito por mudanças no sistema, ao mesmo tempo em que os pacientes participantes não se mostram preocupados com a obtenção dos resultados diagnósticos nem com o andamento da pesquisa.

As considerações acerca do redimensionamento das ações de vigilância incluíram, como ponto de partida, o fato de constituírem dever de Estado e de atingirem a coletividade. Em parte, essas reflexões ocorreram no período de descentralização da vigilância e no momento em que se percebeu que a vigilância tradicional - passiva, baseada na notificação compulsória - era insuficiente e, com frequência, pouco oportuna (6). Tal fato reforçou a necessidade de inovar as formas de vigilância mediante a introdução de estratégias de vigilância-sentinela ativa, impactando o próprio conceito de vigilância. Ao mesmo tempo, vem-se enfatizando o papel da pesquisa tanto de forma induzida e pontual (ad hoc), para elucidação de eventos relevantes à vigilância em saúde, quanto de modo seriado e permanente, a fim de acompanhar estrategicamente a evolução de agravos e práticas ou hábitos de risco. Tais investigações podem ser realizadas, quer pelo próprio serviço de saúde, quer por entidades acadêmicas e institutos de pesquisa. $\mathrm{Na}$ pesquisa epidemiológica, em geral, há importantes considerações éticas $(15,16)$. É assaz relevante ponderar que a interface e a profunda ligação entre a pesquisa epidemiológica e as práticas de vigilância implicam novos desafios no enfrentamento dos aspectos éticos, e, dada sua relevância social e política, deve-se levar em conta sua relação com o cuidado ou a assistência em saúde.

Questões relacionadas à ética muitas vezes passam despercebidas pelos serviços e profissionais de vigilância em saúde; consequentemente, não são contempladas em seus programas e protocolos. Aspectos éticos na condução da 
vigilância da influenza são importantes e devem ser observados, como qualquer outro fator necessário para essa gestão.

São de interesse para estudo mais aprofundado as condutas adotadas no momento da tomada de amostras, as explicações oportunas e necessárias sobre o uso do material biológico obtido, bem como o dever e o direito relacionados ao resultado das análises laboratoriais. Outras questões relativas aos planos de contingência também devem ser verificadas na perspectiva da ética, como as medidas de restrição da liberdade (quarentenas), o uso de medicamentos antivirais e de vacinas (racionar ou racionalizar?), o acesso ao sistema de saúde e a seus recursos físicos, o risco e o desgaste impostos aos profissionais de saúde e suas responsabilidades, além da comunicação do risco e o papel da imprensa.

É necessário que direitos e responsabilidades sejam discutidos a partir do enfoque educativo, nos espaços de educação continuada (29) e nos treinamentos em serviço e supervisões técnicas. Na produção do conhecimento epidemiológico, as questões éticas em pesquisas envolvendo seres humanos, bem como o significado social do risco e da vulnerabilidade, são importantes aspectos de reflexão para o norteamento das práticas de vigilância epidemiológica.

Aqui foram retratados alguns pontos acerca da vigilância-sentinela da influenza como um exercício de reflexão. As preocupações éticas são indispensáveis nas práticas corriqueiras da vigilância. Como direitos de todo cidadão-paciente, a obtenção de informações claras sobre o encaminhamento laboratorial da amostra no momento da coleta e a comunicação adequada dos resultados dos exames são exemplos de situações que precisam ser revistas no âmbito dos serviços de saúde. Além disso, há que levar em conta a criação e adesão a rotinas pautadas pela ética na relação com aqueles que participam dos estudos. Tais preocupações deveriam estar previstas nas orientações e guias de vigilância e em regulamentos éticos voltados para a pesquisa em vigilância de saúde pública. 


\section{Referências}

1. Brasil. Ministério da Saúde. Secretaria de Vigilância em Saúde. Departamento de Vigilância Epidemiológica. Guia de vigilância epidemiológica. 7ª̣ ed. Brasília: Ministério da Saúde; 2009. (Série A. Normas e Manuais Técnicos).

2. Jerigan D, Cox NJ. Human influenza: one health, one world. In: Webster RG, Monto AS, Braciale TJ, Lamb RA, editors. Textbook of influenza. $2^{\underline{a}}$ ed. Oxford, UK: Wiley Blackwell; 2013. p. 3-19.

3. Zambon M. Influenza and other emerging respiratory viruses. Medicine. $2014 ; 42(1): 45-51$.

4. Barros FR, Daufenbach LZ, Vicente MG, Soares MS, Siqueira M, Carmo EH. O desafio da influenza: epidemiologia e organização da vigilância no Brasil. Bol Eletr Epidemiol. [Internet]. 2004 [acesso 20 fev 2014];4(1):2-6. Disponível: http://bvsms.saude.gov.br/bvs/periodicos/boletim_eletronico_epi_ano04_n01.pdf

5. World Health Organization. Global Influenza Surveillance and Response System (GISRS). [Internet]. 2014 [acesso 20 fev 2014]. Disponível: http://www.who.int/influenza/gisrs_laboratory/en

6. Hamann EM, Laguardia J. Reflections on epidemiological surveillance: beyond notifiable diseases. Inf Epidemiol SUS. [Internet]. 2000 set;9(3):211-9.

7. Brasil. Ministério da Saúde. Portaria no 2.693, de 17 de novembro de 2011, republicada em 26 de abril de 2012. Estabelece mecanismo de repasse financeiro do Fundo Nacional de Saúde aos Fundos de Saúde do Distrito Federal e Municípios, por meio do Piso Variável de Vigilância e Promoção da Saúde, para implantação, implementação e fortalecimento da Vigilância Epidemiológica da Influenza. Diário Oficial da União. Brasília, nº 81, p. 37-8, 26 abr. 2012. Seção 1.

8. Brasil. Ministério da Saúde. Secretaria de Assistência à Saúde. Portaria no 788, de 23 de outubro de 2002. Institui Manual de Apoio aos Gestores do Sistema Único de Saúde - SUS, para a organização dos Postos de Coleta da Rede de Laboratórios Clínicos. Diário Oficial da União. Brasília, no 207, p. 156-8, 24 out. 2002. Seção 1. 
9. Brasil. Ministério da Saúde. Secretaria de Assistência à Saúde. Portaria no 787, de 23 de outubro de 2002. Institui Manual de Apoio aos Gestores do SUS para organização da Rede de Laboratórios Clínicos. Diário Oficial da União. Brasília, no 207, p. 142-56, 24 out. 2002. Seção 1.

10. Brasil. Ministério da Saúde. Agência Nacional de Vigilância Sanitária. Resolução № 302, de 13 de outubro de 2005. Dispõe sobre Regulamento Técnico para funcionamento de Laboratórios Clínicos. [Internet]. 2005 [acesso 20 maio 2014]. Disponível:http://bvsms.saude.gov.br/bvs/saudelegis/anvisa/2005/res0302_13_1 0_2005.html

11. Fortes PAC. Reflexões sobre a bioética e o consentimento esclarecido. Bioética. 1994;2(2):129-35. p.131.

12. Barata RB. Ética e epidemiologia. Hist Cienc Saúde-Manguinhos. [Internet]. 2005 set-dez [acesso 1ํ ago 2015];12(3):735-53. Disponível: http://www.scielo.br/pdf/hcsm/v12n3/06.pdf

13. Brasil. Ministério da Saúde. Conselho Nacional de Saúde. Resolução nํ466, de 12 de dezembro de 2012. Aprova as diretrizes e normas regulamentadoras de pesquisas envolvendo seres humanos. Diário Oficial da União. Brasília, № 112, p. 59-62, 13 jun. 2013. Seção 1.

14. Schramm FR. A saúde é um direito ou um dever? Autocrítica da saúde pública. Rev Bras Bioét. 2006;2(2):187-200.

15. Barata RB. Ethics in epidemiological research. Ciênc Saúde Coletiva. 2008 marabr;13(2):453-8.

16. Coughlin SS. Ethical issues in epidemiologic research and public health practice. Emerg Themes Epidemiol. [Internet]. 2006 out [acesso 1 ago 2015];3:16. DOI: 10.1186/1742-7622-3-16

17. Fortes PAC. Vigilância sanitária, ética e construção da cidadania. In: De Seta MH, Pepe VLE, Oliveira GO, organizadores. Gestão e vigilância sanitária: modos atuais do pensar e fazer. Rio de Janeiro: Fiocruz; 2006. p. 61-9.

18. World Health Organization. Ethical considerations in developing a public health response to pandemic influenza. [Internet]. Geneva: WHO Press, 2007 [acesso 
20 maio 2014]. Disponível: http://www.who.int/csr/resources/publications/ WHO_CDS_EPR_GIP_2007_2c.pdf

19. Garrafa V, Oselka G, Diniz D. Saúde pública, bioética e equidade. Bioética. 1997;5(1):27-33.

20. Dallari SG. A bioética e a saúde pública. In: Ferreira SI, Costa GO, Garrafa V, coordenadores. Iniciação à bioética. Brasília: Conselho Federal de Medicina; 1998. p.205-16.

21. Teixeira MG, Junior, JBR, Costa MCN. Vigilância epidemiológica. In: Rouquayrol MZ, organizador. Epidemiologia \& saúde. 6ª ed. Rio de Janeiro: Medsi; 2003. p. 313-43.

22. Mann J. Saúde pública e direitos humanos. Physis. 1996; 6(1-2):135-45.

23. Potter VR. Bioethics: bridge to the future. Englewood Cliffs, NJ: Prentice-Hall; 1971.

24. Diniz D, Guilhem D. O que é bioética. São Paulo: Brasiliense; 2002. (Primeiros Passos).

25. Organização das Nações Unidas para a Educação, a Ciência e a Cultura. Declaração Universal sobre Bioética e Direitos Humanos. [Internet]. Paris: Unesco; 2006 [acesso 15 fev 2014]. Disponível: http://unesdoc.unesco.org/images/0014/001461/146180por.pdf

26. Novaes MRCG, Guilhem D, Lolas F. Dez anos de experiência do Comitê de Ética em Pesquisa da Secretaria de Saúde do Distrito Federal, Brasil. Acta Bioeth. 2008;14(2):185-92.

27. Meireles ACP. Venenos de Deus, remédios do diabo - uma análise bioética da obra de Mia Couto. Rev Bras Bioét. 2009;5(1-4):9-23. p.23.

28. Fortes PAC. A bioética em um mundo em transformação. Rev. bioét. (Impr.). 2011;19(2):319-27.

29. Vidal SV, Motta LCS, Gomes AP, Siqueira-Batista R. Problemas bioéticos na Estratégia Saúde da Família: reflexões necessárias. Rev. bioét. (Impr.). 2014;22(2):347-57. 


\title{
4.4 QUARTO ARTIGO - "AVALIAÇÃO DA QUALIDADE DOS REGISTROS DO SISTEMA DE INFORMAÇÃO DE VIGILÂNCIA EPIDEMIOLÓGICA DA GRIPE, BRASIL, 2010-2013"
}

\author{
Ligia Cantarino \\ Faculdade de Agronomia e Medicina Veterinária, Universidade de Brasília, Brasília, Brasil \\ Edgar Merchan-Hamann \\ Faculdade de Ciências da Saúde, Universidade de Brasília, Brasília, Brasil
}

Title: Quality assessment of records of the Information System of Epidemiological Surveillance of Influenza, Brazil, 2010-2013

Título resumido: Avaliação da qualidade de registros do Sivep-Gripe

Running head: Quality assessment of records of the Sivep-Gripe

\subsubsection{Resumo}

O estudo de avaliação em saúde desenvolvido teve como objetivo examinar a qualidade da informação dos registros de síndrome gripal do Sistema de Informação de Vigilância Epidemiológica da Gripe (Sivep-Gripe), no período de 2010 a 2013, em âmbito nacional. A qualidade dos dados foi avaliada nas seguintes dimensões: clareza metodológica, completitude e inconsistências. Entre os resultados do estudo, podemos destacar que a clareza metodológica foi avaliada como ruim; a completitude dos campos teve boa avaliação para variáveis obrigatórias e essenciais, embora considerada baixa para alguns campos de relevância para a vigilância, como os resultados laboratoriais e situação vacinal. O grau de inconsistência observado foi baixo em relação a datas e tempo entre coleta da amostra, início de sintomas e realização do exame. No entanto, foi considerado alto para a definição de caso. O estudo aponta para a necessidade de avaliações sistemáticas para qualificação dos dados e fortalecimento da vigilância do agravo.

Palavras-chave: Influenza, Vigilância Epidemiológica, Sistemas de Informação em Saúde, Avaliação, Sivep-Gripe 


\section{Abstract}

The health assessment study carried out aimed to examine the quality of information of records of flu-like illness of the Information System of Epidemiological Surveillance of Influenza (Sivep-Gripe), from 2010 to 2013, at a national level. The quality of the data was assessed in the following dimensions: methodological clarity, completeness and inconsistencies. From the results of the study, we can highlight that the methodological clarity was assessed as poor; the completeness of the fields was good for mandatory and essential variables, although considered low for some relevant fields for surveillance, such as laboratory results and vaccination status. The degree of inconsistency was low for dates, and time between sample collection, early symptoms and testing. However, it was considered high for case definition. The study points to the need of systematic assessments for qualification of data and strengthening of the surveillance of the disease.

Key words: Influenza, Epidemiological Surveillance, Health Information Systems, Assessment, Sivep-Gripe

\subsubsection{Introdução}

A influenza ou gripe é doença aguda do sistema respiratório. É causada pelo vírus influenza que tem alta capacidade de transmissão e distribuição global. Mundialmente, a influenza é alvo de atenção permanente dos serviços de saúde pública pelo impacto da doença na forma epidêmica sazonal e ocasionais pandemias $(1,2)$.

A influenza é transmitida pessoa-pessoa através de gotículas de saliva (aerossóis) produzidas ao falar, tossir ou espirrar. O vírus também pode ser transmitido pelas secreções do doente, principalmente pelas mãos em contato direto com as mucosas oral, nasal e ocular. Afeta pessoas de todos os grupos, embora crianças, idosos, indivíduos com doenças crônicas, imunocomprometidos e gestantes possuem risco particular para a doença. Com um período de incubação 
curto - de um a três dias - os indivíduos infectados podem eliminar o vírus desde um dia antes até de cinco a seis dias após o início dos sintomas, sendo capaz de infectar muitos susceptíveis. Os sintomas de infecção incluem febre, tosse, malestar, dor de cabeça, congestão nasal, dor de garganta e mialgia. A atividade da influenza mostra um padrão sazonal, com pico de ocorrência durante o outono e inverno (3-5).

A vigilância epidemiológica sentinela da influenza, implantada no Brasil no ano 2000, foi estruturada com Unidades Sentinela (US) distribuídas em todos os estados, com ao menos uma US implantada nas capitais. A vigilância utiliza dados indiretos de morbidade e mortalidade associados, e os objetivos são: monitorar as cepas dos vírus influenza circulantes; avaliar o impacto da vacinação contra a doença; acompanhar a tendência da morbimortalidade associada à doença; responder a situações inusitadas; produzir informações sobre a doença; detectar e oferecer resposta rápida à circulação de novos subtipos que poderiam estar relacionados à pandemia de influenza; identificar grupos e fatores de risco para influenza; e estudar a resistência dos antivirais (5-7).

A influenza sazonal (casos de síndrome gripal) não é de notificação obrigatória, mesmo sendo objeto de vigilância sentinela. É de notificação a suspeita de surto e óbito por influenza sazonal e influenza humana produzida por novo subtipo viral (8). Os dados da vigilância de influenza são coletados por meio de formulários padronizados e inseridos on-line no Sistema de Informação de Vigilância da Gripe (Sivep-Gripe) e no Sistema de Informação de Agravos de Notificação (Sinan) $(5,9)$. Esses sistemas constituem instrumentos importantes à gestão e monitoramento do agravo.

Em 2010, início do período deste estudo, o Guia de Vigilância (7) então vigente assim definia a SG: "indivíduo com doença aguda (com duração máxima de 5 dias), apresentando febre (ainda que referida) e pelo menos um sintoma respiratório (tosse ou dor de garganta), na ausência de outros diagnósticos". Para o diagnóstico laboratorial, as amostras eram encaminhadas ao Laboratório Central de Saúde Pública (Lacen) de cada estado e submetidas ao exame de imunofluorescência indireta (IFI), que tem por base um painel de anticorpos que permite a detecção dos principais vírus respiratórios (influenza A e B; parainfluenza 1, 2 e 3; vírus respiratório sincicial e adenovírus). Os exames de isolamento viral e 
os que envolviam técnicas de biologia molecular, de caracterização antigênica e genômica eram realizados pelos laboratórios de referência (LR) para o agravo, nas instituições: Fundação Oswaldo Cruz/RJ, Instituto Evandro Chagas/PA e Instituto Adolfo Lutz/SP (7).

Para a vigilância sentinela de síndrome gripal, era preconizada a coleta de cinco amostras de secreção de nasofaringe e ou orofaringe, por semana epidemiológica (SE), nas US. As US deveriam realizar, no mínimo, $80 \%$ de notificação e coleta de material para análise laboratorial nos Lacen e digitar, de maneira oportuna, os dados no Sivep-Gripe; informar a proporção de atendimentos por SG em relação ao total de atendimentos no serviço, semanalmente; notificar os casos de SG em, no mínimo, 80\% das SE no ano (5). Nas US, o Sivep-Gripe é alimentado com dados de acordo com 0 formulário padrão Ficha de Encaminhamento de Amostras para Pesquisa de Vírus Respiratórios (Influenza Sazonal) (Anexo E).

Os sistemas de vigilância de doenças ou agravos necessitam ser avaliados periodicamente e, frente às necessidades, devem sofrer adequações de modo a obter bom desempenho $(10,11)$. A qualidade da informação dos SIS é uma das características importantes a serem observadas e diz respeito tanto à qualidade do dado produzido, como o uso continuado do dado e a facilidade operacional (coleta, análise e infraestrutura). Avaliações da qualidade dos dados dos SIS brasileiros não possuem periodicidade estratégica pelos órgãos do MS $(12,13)$.

O objetivo deste estudo foi avaliar a qualidade do registro dos dados no sistema de vigilância epidemiológica da influenza, o Sivep-Gripe.

\subsubsection{Material e método}

O banco de dados foi obtido após requisição formal à Secretaria de Vigilância em Saúde (SVS) do MS com base na Lei de Acesso à Informação (14) e na Portaria GM/MS 1.583/2012 (15). Os arquivos foram oficialmente fornecidos, em mídia removível, em arquivos originais de extensão Data Base File (DBF) e convertidos em planilhas do software Microsoft Excel ${ }^{\circledR} 2010$. 
O presente trabalho abrange a vigilância epidemiológica de influenza em âmbito nacional. A população de estudo correspondeu aos casos de SG que tiveram coleta de amostras nas US e foram registrados no Sivep-Gripe, da SE 1 de 2010 a SE 22 de 2013. O banco de dados estava estruturado em consonância com ficha padronizada para registro individual de caso de síndrome gripal que realizou coleta de amostra (Anexo E). O banco utilizado era composto de dados secundários, não nominais, sem qualquer identificação dos indivíduos. Os bancos obtidos não apresentavam os dados agregados dos atendimentos das US para vigilância da influenza que são colhidos por meio de formulário específico (Anexo F) .

A avaliação de sistemas de vigilância em saúde pública utilizou a metodologia preconizada no documento Updated Guidelines for Evaluating Public Health Surveillance Systems (16) do Centers for Disease Control and Prevention (CDC).

$\mathrm{Na}$ análise descritiva a avaliação da qualidade foi verificada em três dimensões $(12,17,18)$ - clareza metodológica, completitude $(19,20)$ e inconsistências (21). A forma de avaliação e interpretação dos parâmetros estudados está apresentada no Quadro 1. Foram calculadas as frequências simples de cada categoria com sua representação percentual. Para as análises descritivas foram utilizados os softwares Epi InfoTM 7.1.4.0 e Microsoft Exce|®2010.

O trabalho seguiu os preceitos de ética em pesquisa científica em conformidade com a Resolução do Conselho Nacional de Saúde (CNS) 466/2012 (22), que estabelece as diretrizes e normas regulamentadoras de pesquisa envolvendo seres humanos. Embora o estudo tenha utilizado bases anônimas, o projeto foi submetido e aprovado pelo Comitê de Ética da Faculdade de Ciências da Saúde da UnB (CEP/FS/UnB) sob o registro CAAE 27907114.8.0000.0030 (Anexo A). 


\begin{tabular}{|c|c|c|c|}
\hline Dimensões & Parâmetros verificados & Pontuação & Interpretação \\
\hline Clareza metodológica & $\begin{array}{l}\text { Diz respeito às instruções constantes } \\
\text { nos manuais e orientações de } \\
\text { preenchimento, dicionário de dados. } \\
\text { Análise descritiva e grau de } \\
\text { concordância dos documentos } \\
\text { (resumo descritivo, manual de } \\
\text { preenchimento, dicionário de dados) } \\
\text { que acompanham a base de dados - } \\
\text { Sivep-Gripe. }\end{array}$ & $\begin{array}{l}\text { Julgamento } \\
\text { subjetivo: } \\
\text { precisão das } \\
\text { informações }\end{array}$ & Boa ou Ruim \\
\hline \multirow{4}{*}{ Completitude } & \multirow{4}{*}{$\begin{array}{l}\text { Percentual de informação ignorada, } \\
\text { campos em branco e os com o código } \\
\text { especificado no dicionário de dados. }\end{array}$} & 0 a $25 \%$ & Boa \\
\hline & & 25,1 a $50 \%$ & Regular \\
\hline & & 50,1 a $75 \%$ & Baixa \\
\hline & & 75,1 a $100 \%$ & Muito baixa \\
\hline \multirow[b]{3}{*}{ Inconsistências } & \multirow{3}{*}{$\begin{array}{l}\text { Bloco } 1 \text { - Datas/tempo } \\
\text { - Data de coleta de amostras anterior } \\
\text { à data de início dos sintomas. } \\
\text { - Data da coleta > } 15 \text { dias da data dos } \\
\text { primeiros sintomas. } \\
\text { - Data da realização do exame } \\
\text { anterior a data da coleta de amostra. } \\
\text { - Data do exame > } 15 \text { dias da coleta } \\
\text { da amostra. } \\
\text { Bloco } 2 \text { - Cumprimento da definição de } \\
\text { caso, observação da presença dos } \\
\text { sintomas de febre, tosse ou dor de } \\
\text { garganta. }\end{array}$} & $<10 \%$ & Baixa \\
\hline & & 10 a $30 \%$ & Regular \\
\hline & & $>30 \%$ & Alta \\
\hline
\end{tabular}

Quadro 1 - Critérios de avaliação da qualidade dos dados nas dimensões clareza metodológica, completitude e inconsistência do Sivep-Gripe. Brasil, 2010-2013

\subsubsection{Resultados}

As planilhas obtidas do Sivep-Gripe continham 30.089 registros referentes às observações de SG de $1^{\circ}$ de janeiro de 2010 (SE 1/2010) até $1^{\circ}$ de junho de 2013 (SE 23/2013). Não constavam os registros dos dados agregados das US. 


\subsubsection{Clareza metodológica}

Verificou-se falta de clareza metodológica, pois foram constatadas diferenças entre o Dicionário de Dados e a base de dados, além da ausência de algumas informações e descrições importantes como, por exemplo, a classificação de Campo Chave.

No Dicionário de Dados do Sivep-Gripe os campos estão classificados em três tipos: i) Obrigatório: é aquele cuja ausência de dado impossibilita a inclusão do registro no sistema; ii) Essencial: é aquele que, apesar de não ser obrigatório, registra dado necessário à investigação do caso ou ao cálculo de indicador epidemiológico ou operacional; e iii) Interno: é aquele que, apesar de não constar na ficha, é preenchido automaticamente pelo sistema, não aparece no display da tela, mas persiste no banco de dados. Estão descritas 61 variáveis sendo 10 campos obrigatórios, 15 essenciais e 3 internos. Não possuem classificação 33 campos.

Não há descrição e característica de Campo Chave. No entanto, essa é a classificação das variáveis de registro da amostra no Lacen e no Laboratório de Referência (LR), respectivamente. Alguns campos não possuem classificação, embora sejam importantes para a vigilância do agravo, como "Natureza do Espécime", "Qualidade do Material", "Observação Imunofluorescência" e os campos referentes aos resultados laboratoriais.

No Dicionário de Dados, a opção de preenchimento para ausência da informação ou "não informação" é "9-Ignorada", mas o sistema permite deixar campos sem preenchimento.

Para o campo "País (se residente fora do Brasil)", classificado como essencial, consta no Dicionário ter na categoria uma tabela com código e nomes dos países; no entanto, no sistema só há a opção "1" referente ao Brasil.

Em relação aos campos acerca da situação vacinal dos pacientes, o campo "Vacinado contra influenza?" é automaticamente preenchido pelo sistema com a opção "Não". Os campos "Mês da última vacina" e "Ano da última vacina" são habilitados caso o campo "Vacinado contra Influenza?" seja igual a "1-Sim". No Dicionário e no banco não há a opção "9-Ignorado" para essas variáveis, porém o sistema permite que mês e ano fiquem sem informação. 
O campo essencial "Outros sintomas" é descrito no Dicionário para listar outros sinais e sintomas apresentados pelo paciente. No entanto, no banco, constam as opções "1-Sim" e "2-Não", sem possibilitar descrição.

"Natureza da Investigação" é descrito como campo automaticamente preenchido pelo sistema como "1-Caso Esporádico", e poderia ser ainda "2-Surto" e "3-Epidemia". No entanto, no banco constam apenas as opções 1 e 9, configurando uma não conformidade importante. Cerca de $1 \%$ dos registros estavam preenchidos como 9 ou constavam sem informação ou em branco e, 96,6\% como caso esporádico.

Os sete campos para inclusão dos resultados laboratoriais da imunofluorescência para influenza A, influenza B, parainfluenza 1, 2 e 3, adenovírus e vírus respiratório sincicial, no Dicionário de Dados, trazem as opções: "1-Positivo", "2-Negativo", "3-Inconclusivo", "4-Não Realizado" e "9-Ignorado". No entanto, no banco, as opções disponíveis são 1, 2, 3, 4. Não há a opção "9-Ignorado" no banco de dados e os campos automaticamente eram preenchidos pelo sistema como 2"Negativo".

\subsubsection{Completitude}

A análise de completitude foi considerada boa, com média de preenchimento de cerca de $86 \%$ para as variáveis obrigatórias e de $93 \%$ para os campos essenciais (Tabela 1).

De acordo com o Dicionário de Dados, dez campos são considerados obrigatórios. Desses, não foram considerados os campos: "Nome", pois o banco obtido não continha nenhuma identificação dos indivíduos; "Idade" e "Idade/Tipo" pelo fato de serem preenchidos automaticamente pelo sistema a partir da digitação da "data do nascimento do paciente".

Dos quinze campos classificados como essenciais, o sistema não possui alternativa "9-Ignorado", sendo que para os campos dos sintomas as alternativas são: "1-Sim" e "2-Não". O campo "Município de residência do paciente", contava com 4 registros sem informação (4/30.089). Para "Data da realização do exame" imunofluorescência, de 30.089 registros, 144 estavam em branco e poucos (12) 
apresentavam erros de digitação na entrada do dado, constando anos como 1953 , 1954, 2022, 2111, 2103, 2031, 2017, 2031.

Tabela 1 - Resumo do número e percentual de campos incompletos ou ignorados das variáveis do Sivep-Gripe. Brasil, 2010-2013

\begin{tabular}{|c|c|c|c|c|c|c|c|c|c|}
\hline \multirow{3}{*}{ Variável / Campo } & \multicolumn{8}{|c|}{ Ano } & \multirow{3}{*}{$\begin{array}{c}\text { Média } \\
\text { Percentua }\end{array}$} \\
\hline & \multicolumn{2}{|c|}{$\begin{array}{c}2010 \\
N=7.971 \\
\end{array}$} & \multicolumn{2}{|c|}{$\begin{array}{c}2011 \\
N=9.215 \\
\end{array}$} & \multicolumn{2}{|c|}{$\begin{array}{c}2012 \\
N=10.479\end{array}$} & \multicolumn{2}{|c|}{$\begin{array}{c}2013 \\
\mathrm{~N}=2.424 \\
\end{array}$} & \\
\hline & $\mathrm{n}$ & $\%$ & $\mathrm{n}$ & $\%$ & $\mathrm{n}$ & $\%$ & $\mathrm{n}$ & $\%$ & \\
\hline \multicolumn{10}{|l|}{ Obrigatórias } \\
\hline Unidade Sentinela & 99 & 1,2 & 0 & 0,0 & 0 & 0,0 & 0 & 0,0 & 0,3 \\
\hline Laboratório & 2 & 0,03 & 0 & 0,0 & 0 & 0,0 & 0 & 0,0 & 0,1 \\
\hline Sexo do paciente & 19 & 0,2 & 57 & 0,6 & 50 & 0,5 & 14 & 0,6 & 0,5 \\
\hline Data do resultado (cultura) & 7.971 & 100,0 & 9.215 & 100,0 & 10.479 & 100,0 & 2.424 & 100,0 & 100,0 \\
\hline Média Percentual & & 14,5 & & 14,4 & & 14,4 & & 14,4 & 14,4 \\
\hline \multicolumn{10}{|l|}{ Essenciais } \\
\hline $\begin{array}{l}\text { Município de residência do } \\
\text { paciente }\end{array}$ & 0 & 0,0 & 4 & 0,04 & 0 & 0,0 & 0 & 0,0 & 0,04 \\
\hline $\begin{array}{l}\text { Data da realização do exame } \\
\text { (imunofluorescência) }\end{array}$ & 44 & 0,6 & 60 & 0,7 & 39 & 0,4 & 9 & 0,4 & 0,5 \\
\hline $\begin{array}{l}\text { Data da realização do exame } \\
\text { (cultura) }\end{array}$ & 7.971 & 100,0 & 9.215 & 100,0 & 10.479 & 100,0 & 2.424 & 100,0 & 100,0 \\
\hline Média Percentual & & 6,7 & & 6,7 & & 6,7 & & 6,7 & 6,7 \\
\hline
\end{tabular}

Entre os campos obrigatórios analisados, 57\% (4/7) apresentaram problemas no preenchimento. Chama atenção o fato de "Data do resultado (cultura)" estar totalmente em branco em todos os anos. Já as variáveis "Data de nascimento", "Data do início dos sintomas" e "Data da coleta da amostra" estavam integralmente preenchidas.

Em 20\% (3/15) das variáveis essenciais foi identificado problemas no preenchimento. "País de residência do paciente", "UF de residência do paciente" e as de registro dos sinais e sintomas - febre, tosse, dor de garganta, dores musculares, dor de cabeça, artralgia, coriza, dor de ouvido, obstrução nasal e outros sintomas - foi feito em sua totalidade.

O percentual de campos incompletos relativos à situação vacinal do paciente aumentou ao longo do período estudado, sendo a completitude muito baixa. Em 
relação ao mês da última vacina estavam sem informação $93,4 \%$ dos registros sendo 85,9\% em 2010; 92,5\% em 2011; 96,6\% em 2012 e 98,4\% em 2013. Constavam sem preenchimento do ano da última vacina $93,2 \%$ dos campos com 84,7\% em 2010; 91,2\% em 2011; 97,7\% em 2012 e 99,2\% em 2013. Dos 30.089 pacientes que tiveram amostras coletadas no período, 3.894 (cerca de 13\%) constavam ser vacinados contra influenza. Desses, 53\%, em média, não apresentaram as informações de mês e ano da última vacina contra gripe (Tabela 2).

Tabela 2 - Número e percentual dos campos incompletos ou ignorados relativos à vacinação dos pacientes que tiveram amostras coletadas no Sivep-Gripe. Brasil, 2010-2013

\begin{tabular}{|c|c|c|c|c|c|c|c|c|c|}
\hline \multirow{3}{*}{ Variável } & \multicolumn{8}{|c|}{ Vacinados contra influenza ao ano } & \multirow{3}{*}{$\begin{array}{c}\text { Média } \\
\text { Percentual }\end{array}$} \\
\hline & \multicolumn{2}{|c|}{$\begin{array}{c}2010 \\
N=1.568\end{array}$} & \multicolumn{2}{|c|}{$\begin{array}{c}2011 \\
N=1.313\end{array}$} & \multicolumn{2}{|c|}{$\begin{array}{c}2012 \\
N=881\end{array}$} & \multicolumn{2}{|c|}{$\begin{array}{c}2013 \\
N=132\end{array}$} & \\
\hline & $\mathrm{n}$ & $\%$ & $\mathrm{n}$ & $\%$ & $\mathrm{n}$ & $\%$ & $\mathrm{n}$ & $\%$ & \\
\hline $\begin{array}{l}\text { Mês da última } \\
\text { vacina }\end{array}$ & 445 & 28,4 & 621 & 47,3 & 529 & 60,0 & 94 & 71,2 & 51,7 \\
\hline $\begin{array}{l}\text { Ano da última } \\
\text { vacina }\end{array}$ & 351 & 22,4 & 504 & 38,4 & 644 & 73,1 & 113 & 85,6 & 54,9 \\
\hline Média Percentual & & 25,4 & & 42,8 & & 66,6 & & 78,4 & 53,3 \\
\hline
\end{tabular}

Todos os 18 campos relacionados aos resultados dos testes de cultura e caracterização viral, executados nos Laboratórios de Referência (NIC), estavam sem preenchimento em todos os anos.

O preenchimento dos campos referentes ao resultado da imunofluorescência está apresentado na Tabela 3. Embora presente no Dicionário de Dados, a opção "9-ignorado" para os resultados da IFI, não consta no banco. O número de valores perdidos (missing) ou informação ignorada foi considerado muito baixo $(0,3 \%)$, o que classifica o sistema por boa completitude. A maioria dos resultados laboratoriais foi negativa, em média $87,8 \%$, porém essa opção era automaticamente preenchida pelo sistema. Das 30.089 amostras coletadas nas US, 15,4\% das amostras foram positivas para um dos vírus respiratórios; e cerca de $20 \%$ tiveram resultado inconclusivo e $7 \%$ não foram processadas laboratorialmente. 
Tabela 3 - Número e percentual do preenchimento dos campos relativos ao resultado da imunofluorescência no Sivep-Gripe. Brasil, 2010-2013

\begin{tabular}{lcccccccccc}
\hline $\begin{array}{c}\text { Resultado } \\
\text { IFI }\end{array}$ & $\begin{array}{c}\text { Missing } \\
\text { Ou sem } \\
\text { informação }\end{array}$ & \multicolumn{2}{c}{$\begin{array}{c}\text { Opção 1 } \\
\text { Positivo }\end{array}$} & \multicolumn{2}{c}{$\begin{array}{c}\text { Opção 2 } \\
\text { Negativo }\end{array}$} & \multicolumn{2}{c}{$\begin{array}{c}\text { Opção 3 } \\
\text { Inconclusivo }\end{array}$} & \multicolumn{2}{c}{$\begin{array}{c}\text { Opção 4 } \\
\text { Não realizado }\end{array}$} \\
\cline { 2 - 13 } & $\mathrm{n}$ & $\%$ & $\mathrm{n}$ & $\%$ & $\mathrm{n}$ & $\%$ & $\mathrm{n}$ & $\%$ & $\mathrm{n}$ & $\%$ \\
\hline IFI - Flu A & 99 & 0,3 & 1085 & 3,6 & 25937 & 86,2 & 908 & 3,0 & 2060 & 6,8 \\
IFI - Flu B & 99 & 0,3 & 525 & 1,7 & 26510 & 88,1 & 901 & 3,0 & 2054 & 6,8 \\
IFI_Para1 & 99 & 0,3 & 203 & 0,7 & 26917 & 89,5 & 887 & 2,9 & 1983 & 6,6 \\
IFI_Para2 & 102 & 0,3 & 136 & 0,5 & 26983 & 89,7 & 888 & 3,0 & 1980 & 6,6 \\
IFI_Para3 & 106 & 0,4 & 329 & 1,1 & 26778 & 89,0 & 891 & 3,0 & 1985 & 6,6 \\
IFI_Adeno & 115 & 0,4 & 684 & 2,3 & 26423 & 87,8 & 887 & 2,9 & 1980 & 6,6 \\
VRS & 117 & 0,4 & 1661 & 5,5 & 25445 & 84,6 & 888 & 3,0 & 1978 & 6,6 \\
\hline
\end{tabular}

$\mathrm{N}=30.089$

Flu A = Influenza A; Flu B = Influenza B; Para 1 = Parainfluenza A; Para 2 = Parainfluenza 2; Para 3 = Parainfluenza 3; Adeno = Adenovírus; VRS = Vírus Respiratório Sincicial

\subsubsection{Inconsistências}

Em relação à dimensão inconsistência, a avaliação dos parâmetros adotados foi aferida em dois blocos (Tabela 4). No bloco 1, a inconsistência foi avaliada como baixa $(4,4 \%)$ em relação às datas, embora tenha sido considerado regular $(13,5 \%)$ o parâmetro referente a realização do exame de imunofluorescência com mais de quinze dias após a coleta.

No bloco 2, o grau de inconsistência frente à definição de caso foi avaliado como alta, com média percentual de $31,2 \%$. Febre, tosse e dor de garganta não estavam presentes, respectivamente, em cerca de $20 \%, 16 \%$ e $57 \%$ dos pacientes que tiveram amostras coletadas para análise laboratorial. 
Tabela 4 - Número e percentual de inconsistências no Sivep-Gripe. Brasil, 20102013

\begin{tabular}{|c|c|c|c|c|c|c|c|c|c|}
\hline \multirow{3}{*}{ Inconsistências } & \multicolumn{8}{|c|}{ Ano } & \multirow{3}{*}{$\begin{array}{l}\text { Média } \\
\text { Percentual }\end{array}$} \\
\hline & \multicolumn{2}{|c|}{$\begin{array}{c}2010 \\
N=7971\end{array}$} & \multicolumn{2}{|c|}{$\begin{array}{c}2011 \\
N=9215\end{array}$} & \multicolumn{2}{|c|}{$\begin{array}{c}2012 \\
N=10479\end{array}$} & \multicolumn{2}{|c|}{$\begin{array}{c}2013 \\
N=2424\end{array}$} & \\
\hline & $\mathbf{n}$ & $\%$ & $\mathbf{n}$ & $\%$ & $\mathbf{n}$ & $\%$ & $\mathbf{n}$ & $\%$ & \\
\hline \multicolumn{10}{|l|}{ Bloco 1 - Datas/intervalo de tempo } \\
\hline $\begin{array}{l}\text { Data coleta anterior a data dos } \\
\text { primeiros sintomas }\end{array}$ & 66 & 0,8 & 60 & 0,7 & 39 & 0,4 & 13 & 0,5 & 0,6 \\
\hline $\begin{array}{l}\text { Data coleta }>15 \text { dias da data dos } \\
\text { primeiros sintomas }\end{array}$ & 158 & 2,0 & 188 & 2,0 & 196 & 1,9 & 34 & 1,4 & 1,8 \\
\hline $\begin{array}{l}\text { Data do exame anterior da data da } \\
\text { coleta da amostra }\end{array}$ & 138 & 1,7 & 163 & 1,8 & 134 & 1,3 & 45 & 1,9 & 1,7 \\
\hline $\begin{array}{l}\text { Data do exame }>15 \text { dias da coleta } \\
\text { da amostra }\end{array}$ & 990 & 12,4 & 1654 & 17,9 & 1553 & 14,8 & 210 & 8,7 & 13,5 \\
\hline \multicolumn{10}{|l|}{$\begin{array}{c}\text { Bloco } 2 \text { - Definição de } \\
\text { Caso/Sintomas }\end{array}$} \\
\hline Febre & 1.771 & 22,2 & 2.152 & 23,4 & 2.093 & 20,0 & 388 & 16,0 & 20,4 \\
\hline Tosse & 1.238 & 15,5 & 1.592 & 17,3 & 1.617 & 15,4 & 407 & 16,8 & 16,3 \\
\hline Dor de garganta & 4.688 & 58,8 & 5.228 & 56,7 & 5.959 & 56,9 & 1.340 & 55,3 & 56,9 \\
\hline
\end{tabular}

\subsubsection{Discussão}

A chave dos sistemas de vigilância são os SIS e a qualidade dos dados é relevante para um sistema robusto de vigilância. Os recursos de informática contribuem para a qualidade dos SIS, desde o registro até a coleta, processamento dos dados e oportuna disponibilização da informação. Essas informações são subsídios base para tomada de decisão de políticas, planejamento, monitoramento e avaliação de programas de saúde, além de constituírem elementos fundamentais para estudos epidemiológicos (23). Os dados da vigilância de influenza são coletados por meio dos formulários padronizados e inseridos on-line no Sivep-Gripe. Esse fato, por um lado, favorece a coleta de dados e, por outro, requer das US estrutura de informática, mecanismo de transmissão dos dados (internet) e recursos humanos capacitados de forma permanente. 
A clareza metodológica é aferida pela comparação do banco de dados e dos documentos que acompanham o sistema. No caso, o Dicionário de Dados, pois o Sivep-Gripe não possui manual de preenchimento. Fato que se constitui em uma crítica importante já que esse sistema está ativo desde a implantação da vigilância de influenza, no ano 2000.

Há necessidade de se revisar e reclassificar os campos/variáveis com base na relevância para o agravo. Por exemplo, apesar de indicar a presença de existência de "Campo Chave", no Dicionário não há a respectiva classificação e descrição. Da mesma forma é preciso, também, rever as opções e a forma de preenchimento dos campos. O preenchimento automático pode representar um componente de viés. Os campos destinados para preenchimento dos resultados laboratoriais da imunofluorescência indireta, que não são classificados como obrigatórios nem essenciais, são automaticamente preenchidos como "negativos". O campo referente à situação vacinal era automaticamente preenchido como "não" vacinado. Esse fato pode se constituir em margem de erro de informação pela dificuldade na obtenção de resposta fidedigna, embora seu preenchimento, conforme o Dicionário de Dados, deva ser feito após o profissional de saúde se informar "se o paciente foi vacinado contra influenza, após verificar a documentação/caderneta. Caso o paciente não tiver a caderneta, direcionar a pergunta para ele ou responsável e preencher o campo com o código correspondente a resposta". Embora seja um dado importante para a vigilância, é uma variável que pode traduzir um viés de informação e de memória.

O sistema permitia deixar campos em brancos, vazios, que pode gerar dúvidas se ausência da informação é por falta de atenção na inclusão do registro ou por dificuldade na obtenção da informação. A "informação ignorada" corresponde, em sua maioria, a campos sem informação e não propriamente a informação desconhecida por parte do informante $(17,24)$.

A completitude é medida de forma simples e direta pela porcentagem de campos ignorados, não preenchidos ou em branco. Assim, dados de alta qualidade apresentarão baixas porcentagens de campos sem informação (16). A completitude do Sivep-Gripe, em relação aos campos obrigatórios e essenciais, foi classificada como boa. No entanto, é importante ressaltar que variáveis importantes para a vigilância sentinela da influenza não estavam classificadas como obrigatórias nem 
como essenciais. Numa vigilância que tem por base a identificação dos principais vírus respiratórios circulantes, pressupõe-se que as informações laboratoriais sejam relevantes. Os campos para resultados dos exames de IFI não foram classificados. Embora tenham apresentado boa completitude, vale atentar para o preenchimento automático do campo com a opção de resultado negativo, fato este que pode representar viés importante no dado. O percentual de informação ignorada para esse quesito foi considerado muito baixo - somente 0,3\% - sendo relevante observar que aproximadamente de $87 \%$ dos resultados foi preenchido como negativo, $20 \%$ inconclusivos e apenas $15 \%$ positivo para vírus respiratórios. Esses resultados indicam a necessidade de revisar os procedimentos de cada etapa do fluxo da vigilância, desde a seleção dos pacientes para a tomada de amostra até a digitação do resultado laboratorial no sistema.

Os campos relativos ao exame de cultivo viral realizado nos NICs - o obrigatório "Data do resultado (cultura)" e o essencial "Data da realização do exame (cultura)" - estão completamente sem informação, em branco. Cabe ressaltar, no entanto, que esses exames são complementares e realizados em uma parcela das amostras, para caracterização antigênica e genética do vírus e, assim, fornecer a informação à OMS para subsidiar definição da composição da vacina contra influenza. Esses campos deveriam ser reclassificados.

Dos 30.089 registros de pacientes que tiveram amostra coletada no período, somente em cerca de $13 \%$ havia informação referente à situação vacinal. Houve aumento gradual do não preenchimento dos registros relativos ao mês e ano da vacinação, ou seja, a cada ano menor atenção vem sendo dada à observação desse quesito. Esse fato pode interferir no acompanhamento das medidas, pois se perde a chance de estudos referentes à efetividade da vacina.

Embora o grau de inconsistência tenha sido considerado baixo para o bloco 1, o que é positivo, deve ser dada atenção à questão de o material biológico ter sido coletado há mais de 15 dias da data dos primeiros sintomas. O Guia de Vigilância Epidemiológica (7) preconiza que para diagnóstico de influenza a coleta de amostras de secreções respiratórias deve ser realizada, preferencialmente, no $3^{\circ}$ dia ou, no máximo, até o $7^{\circ}$ dia após o início dos sintomas, pois o número de células infectadas que podem ser obtidas por aspiração ou swabs decresce durante o curso da 
infecção. Mesmo dobrando o tempo estipulado, foram encontrados registros de pacientes que não deveriam ter tido amostras coletadas.

Como os testes de IFI eram realizados nos Lacen de cada estado e um dos critérios para seleção das US era o envio semanal de amostras de espécimes clínicos de pacientes com síndrome gripal, assumimos que 15 dias seria um prazo razoável para analisar o parâmetro tempo entre a coleta e a realização do exame de imunofluorescência, que foi avaliado como regular. Essa é uma questão que deve ser revisada junto aos partícipes da vigilância, pois envolvem condições de armazenamento do material biológico, fluxo de transporte de amostras entre US e Lacen e o processamento laboratorial. A qualidade da amostra é uma preocupação, pois interfere diretamente no diagnóstico laboratorial. As células epiteliais infectadas são muito lábeis e sujeitas a problemas no armazenamento ou demora no processamento. Existe orientação para que o espécime clínico seja mantido em refrigeração ( $4^{\circ}$ a $\left.8^{\circ} \mathrm{C}\right)$ e transportado da US ao laboratório no mesmo dia da coleta, acondicionado em caixa isotérmica (7).

A informação de inconsistências relativas à definição de caso, no bloco 2, é mais impactante, pois indica a não observação da descrição preconizada e, certamente, o não enquadramento correto interfere nos resultados e na vigilância como um todo. Resultado semelhante de qualidade insatisfatória dos dados no aspecto de cumprimento da definição de caso de síndrome gripal foi relatado em trabalho de 2007 (25). Esses autores chamaram atenção de que a definição de caso "febre + tosse" apresentou maior sensibilidade (70\%), e apontaram entre outras recomendações, o aprimoramento da definição de caso e da qualidade das amostras coletadas. Importante reforçar a atualização permanente dos profissionais de saúde que atuam nas US sobre a importância do seu envolvimento e participação. Cabe como motivação o retorno das informações produzidas para as US, desde os resultados laboratoriais, boletins e relatórios, para que esses profissionais se vejam atuantes como elo da cadeia de vigilância.

A avaliação é uma ferramenta que deve ser aplicada para acompanhamento, implementação e melhoria (26) de um programa, atividade, serviços ou política. Em 1969, Langmuir (27) já dizia que uma boa vigilância exige mais do que a epidemiologia descritiva e o diagnóstico preciso. Para o autor, o objetivo da vigilância deve ser a prestação de informações suficientemente precisas e atuais 
para guiar a aplicação eficaz das medidas de controle. Para tanto, a qualidade dos dados é fundamental para gerar informações robustas que possam garantir adoção de medidas de proteção à saúde pública.

A qualidade da informação é considerada um conceito multidimensional em saúde pública. Representa ou reflete um aspecto ou elementos dos dados. De acordo com a perspectiva da cadeia de informações, podem ser utilizadas três macro dimensões: processo, dado e usuário, para agrupar um conjunto de dimensões conceituais da qualidade de dados. A avaliação de qualidade de dados pode ser trabalhada no aspecto do processo da coleta dos dados, aqui entendido como a geração, montagem, descrição e manutenção de dados, antes do armazenamento nos SIS, da utilização dos dados e do fluxo das informações $(12,28)$.

Deste modo, o monitoramento e avaliação da qualidade dos dados devem se tornar uma prática nos serviços de saúde. A rotina da avaliação deve ser vista como práxis positiva, na identificação de pontos frágeis, para que se possam introduzir alterações de melhoria e não apenas para apontar fragilidades e deficiências. A avaliação não deve ser vista como instrumento de controle ou castigo e sim, exercício de reflexão da prática, parte de um processo de aperfeiçoamento, e indicativo estratégico de fornecimento de subsídios para a tomada de decisão política-institucional.

Para tanto, é importante a capacitação dos profissionais de saúde, com visitas técnicas continuadas aos serviços que capturam e trabalham os dados de influenza. Essas são algumas iniciativas que podem contribuir para promover a valorização e o uso adequado da informação e para o fortalecimento das ações de vigilância, como sugerido por Malhão e colaboradores (29). Para informação de qualidade é clara e evidente a importância de investimentos em supervisões, capacitações para os recursos humanos responsáveis pela coleta, produção e análise dos dados. Profissionais de saúde não recebem ou recebem instruções insuficientes e orientações sobre como coletar os dados, principalmente de forma padronizada (23).

Recomenda-se revisão dos conceitos e definições constantes nos documentos técnicos da vigilância da influenza (dicionário de dados); das variáveis, bem como sua classificação de em obrigatórias e ou essenciais; elaboração de manual de preenchimento do Sivep-Gripe; e adoção de estratégias para melhorar o 
preenchimento adequado das variáveis. A revisão dos campos ou variáveis necessários para registro na ficha de notificação e no sistema de vigilância deve ser feita de tal modo que a informação produzida seja mais eficiente e efetiva. A quantidade e qualidade dos campos são fundamentais na captação de dados para o objeto de estudo. O número grande de campos, por exemplo, sobrecarrega o banco, dificulta o preenchimento e gera lacunas e falhas que fragilizam o sistema. Os campos devem estar sempre sendo revistos para que a coleta de dados seja cada vez mais precisa.

Mesmo que nova versão do Sivep-Gripe tenha entrado em funcionamento a partir de maio de 2013, quando foram retiradas algumas variáveis e incluídas outras, é recomendável revisar a classificação dos campos obrigatórios e essenciais. É importante verificar a existência de campos que, mesmo interessantes ou relevantes, não possuem factibilidade no preenchimento por não serem práticos no âmbito da US, por falta de conscientização ou de conhecimento dos profissionais de saúde em relação à importância do dado para vigilância. A informação deve ser relevante, de boa qualidade e fidedigna.

A questão da avaliação e do cuidado com a qualidade dos dados tem sido recomendada em estudos internacionais (28) e, mesmo de iniciativa pontual, em trabalhos brasileiros de avaliação de sistemas de vigilância em saúde pública (21,25,30-33). É importante que os técnicos envolvidos na vigilância da influenza e os gestores dos programas de vigilância em saúde instituam a avaliação sistemática como uma das diretrizes de política estratégica de vigilância em saúde pública. 


\section{Referências}

1. Zambon M. Influenza and other emerging respiratory viruses. Medicine 2014; 42(1):45-51.

2. Jerigan DB, Cox NJ. Human influenza: one health, one world. In: Webster RG, Monto AS, Braciale TJ, Lamb RA, eds. Textbook of Influenza. Second edition. Oxford: Wiley \& Sons Ltd; 2013:3-19.

3. Cox NJ, Subbarao K. Global epidemiology of influenza: Past and present. Annu Rev Med 2000; 51:407-21.

4. Forleo-Neto E, Halker E, Santos VJ, Paiva TM, Toniolo-Neto J. Influenza. Rev Soc Bras Med Trop 2003; 36(2):267-74.

5. Ministério da Saúde. Secretaria de Vigilância em Saúde. Guia de Vigilância em Saúde. [1ํㅡㄹ ed. Versão eletrônica]. Brasília: Ministério da Saúde; 2014.

6. Ministério da Saúde. Secretaria de Vigilância em Saúde. Influenza. In: Ministério da Saúde. Guia de Vigilância Epidemiológica. 5ªe ed. Brasília: Funasa; 2002:493500 .

7. Ministério da Saúde. Guia de vigilância epidemiológica. $7^{\mathrm{a}}$ ed. Brasília: Ministério da Saúde; 2009.

8. Ministério da Saúde. Portaria oㅡ 1.271, de 6 de junho de 2014. Define a Lista Nacional de Notificação Compulsória de doenças, agravos e eventos de saúde pública nos serviços de saúde públicos e privados em todo o território nacional, nos termos do anexo, e dá outras providências. Brasília: Diário Oficial da União; 2014, 9 jun.

9. Ministério da Saúde. Secretaria de Vigilância em Saúde. Doenças infecciosas e parasitárias: guia de bolso. 8ํㅡㄹ ed. Brasília: Ministério da Saúde; 2010.

10. Waldman EA. Usos da vigilância e da monitorização em saúde pública. Inf. Epidemiol. Sus 1998; 7(3):7-26.

11. Teixeira MG, Risi Junior JB, Costa MCN. Vigilância epidemiológica. In: Rouquayrol MZ, Almeida Filho N, eds. Epidemiologia \& Saúde. 6ª ed. Rio de Janeiro: Medsi; 2003:313-43. 
12. Lima CRA, Schramm JMA, Coeli CM, Silva MEM. Revisão das dimensões de qualidade dos dados e métodos aplicados na avaliação dos sistemas de informação em saúde. Cad Saude Publica 2009; 25(10):2095-109.

13. Lima CRA, Schramm JMA, Coeli CM. Gerenciamento da qualidade da informação: uma abordagem para o setor saúde. Cad de Saúde Colet 2010; 18(1):19-31.

14. Brasil. Lei $n-12.527$, de 18 de novembro de 2011. Regula o acesso a informações previsto no inciso XXXIII do art. $5^{\circ}$, no inciso II do $\S 3^{\circ}$ do art. $37 \mathrm{e}$ no $\S 2^{\circ}$ do art. 216 da Constituição Federal; altera a Lei ํo 8.112, de 11 de dezembro de 1990; revoga a Lei oㅜ 11.111, de 5 de maio de 2005, e dispositivos da Lei no 8.159 , de 8 de janeiro de 1991; e dá outras providências. Brasília: Diário Oficial da União, 2011; 18 de nov.

15. Brasil. Ministério da Saúde. Portaria no 1.583 de 19 de Julho de 2012. Dispõe, no âmbito do Ministério da Saúde e entidades a ele vinculadas, sobre a execução da Lei no 12.527, de 18 de novembro de 2011, que versa sobre a lei de Acesso à Informação, e do Decreto oㅜ 7.724, de 16 de maio de 2012, que a regulamenta. Brasília: Diário Oficial da União 2012; 20 jul.

16. Centers for Disease Control and Prevention. Updated guidelines for evaluating public health surveillance systems: Recommendations from the guidelines working group. (CDC) MMWR 2001; 50(RR-13):1-36.

17. Romero $D E$, Cunha $C B$. Avaliação da qualidade das variáveis epidemiológicas e demográficas do Sistema de Informações sobre Nascidos Vivos, 2002. Cad Saude Publica 2007; 23(3):701-14.

18. Romero $D$, Cunha $C B$. Avaliação da qualidade das variávies sócio-econômicas e demográficas dos óbitos de crianças menores de um ano registrados no Sistema de Informações sobre Mortalidade do Brasil (1996/2001). Cad Saúde Pública 2006; 22(3):673-84.

19. Ministério da Saúde. Sinan Relatórios: manual de operação. Versão do produto: 4.7. $1^{\mathrm{a}}$ ed. Brasília: Ministério da Saúde; 2014. 
20. Abath MB, Lima MLLT, Lima PS, Silva MCM, Lima MLC. Avaliação da completitude, da consistência e da duplicidade de registros de violência do Sinan em Recife, Pernambuco, 2009-2012. Epidemiol Serv Saúde 2014; 23(1):131-42.

21. Souza VMM, Brant JL, Arsky MLS, Araújo WN. Avaliação do sistema nacional de vigilância epidemiológica da leptospirose - Brazil, 2007. Cad Saúde Colet 2010; 18(1):95-105.

22. Conselho Nacional de Saúde. Resolução № 466 de 12 de dezembro de 2012. Aprovar as diretrizes e normas regulamentadoras de pesquisa envolvendo seres humanos. Brasília: Diário Oficial da União 2013; 13 jun.

23. Jorge MHPM, Laurenti R, Gotlieb SLD. Avaliação dos sistemas de informação em saúde no Brasil. Cad Saúde Colet 2010; 18(1):7-18.

24. Cruz MM, Toledo LM, Santos EM. O sistema de informação de AIDS do Município do Rio de Janeiro: suas limitações e potencialidades enquanto instrumento da vigilância epidemiológica. Cad Saúde Pública 2003; 19(1):81-9.

25. Freitas D, Daufenbach L, Barros F, Hatch D. Avaliação do sistema de vigilância epidemiológica da influenza no Brasil, 2000 a 2004. Anais do 43ํㅡㄹ Congresso da Sociedade Brasileira de Medicina Tropical. Rev Soc Bras Med Trop 2007;40(suppl):209.

26. Champagne F, Contandriopoulos AP, Brousselle A, Hartz Z, Denis JL. A avaliação no campo da saúde: conceitos e métodos. In: Brousselle $A$ et al orgs. Avaliação: conceitos e métodos. Rio de Janeiro: Fiocruz; 2011:41-60.

27. Langmuir AD, Housworth J. A critical evaluation of influenza surveillance. Bull World Health Organ 1969; 41:393-8.

28. Chen H, Hailey D, Wang N, Yu P. A review of data quality assessment methods for public health information systems. Int J Environ Res Public Health 2014; 11(5):5170-207.

29. Malhão TA, Oliveira GP, Codennoti SB, Moherdaui F. Avaliação da completitude do Sistema de Informação de Agravos de Notificação da Tuberculose, Brasil, 2001-2006. Epidemiol. Serv. Saúde 2010; 19(3):245-56.

30. Santos ED, Garrett DO. Avaliação do sistema de vigilância de hantavírus no Brasil. Epidemiol. Serv. Saúde 2005; 14(1):15-31. 
31. Barbosa JR, Barrado JCS, Zara ALSA, Siqueira Júnior JB. Avaliação da qualidade dos dados, valor preditivo positivo, oportunidade e representatividade do sistema de vigilância epidemiológica da dengue no Brasil, 2005 a 2009. Epidemiol. Serv. Saúde 2015; 24(1):49-58.

32. Mota DM, Freitas DRC, Araújo WN. Avaliação do sistema de vigilância sanitária do sangue em âmbito federal, Brasil, 2007. Cien Saude Colet 2012; 17(1):191202.

33. Rossetto EV, Dimech GS, Braz RM, Ladislau JLB, Araújo WN. Avaliação do sistema de informações hospitalares como instrumento para vigilância da malária na Amazônia Legal. Brasil, 1998-2005. Rev Epidemiol Control Infect 2013; 3(2):50-5. 


\title{
4.5 QUINTO ARTIGO - "AVALIAÇÃO DOS ATRIBUTOS DO SISTEMA DE VIGILÂNCIA EPIDEMIOLÓGICA DA INFLUENZA NO BRASIL, 2010-2013”
}

\section{EVALUATION OF THE ATTRIBUTES OF THE INFLUENZA EPIDEMIOLOGICAL SURVEILLANCE SYSTEM IN BRAZIL, 2010-2013}

\author{
Ligia Cantarino \\ Faculdade de Agronomia e Medicina Veterinária, Universidade de Brasília, Brasília, Brasil \\ Edgar Merchan-Hamann \\ Faculdade de Ciências da Saúde, Universidade de Brasília, Brasília, Brasil
}

\subsubsection{Resumo}

Introdução: Influenza ou gripe é virose de distribuição mundial, de alta transmissibilidade, e no Brasil é objeto de vigilância desde o ano 2000. Objetivo: Avaliar os atributos do sistema de vigilância epidemiológica da influenza sazonal no Brasil, de 2010 a 2013. Método: Foi empregada a metodologia do Updated Guidelines for Evaluating Public Health Systems do Centers for Disease Control and Prevention (CDC) para avaliar os atributos qualitativos, quantitativos, utilidade do sistema e desempenho da definição de caso. Resultados: Dos 30.089 registros de pacientes que tiveram amostra coletadas, cerca de $21 \%$ não atendiam à definição de caso de síndrome gripal e 15\% foram positivas para vírus respiratórios. Os vírus que mais circularam no período foram o respiratório sincicial e o influenza A. Cerca de $7 \%$ das amostras coletadas não foram processadas laboratorialmente, $21 \%$ tiveram resultado inconclusivo, 2\% estavam sem informação. Exames de crianças tiveram maior positividade (33\%), enquanto a menor porcentagem de resultados positivos foi entre os idosos. Os sintomas mais frequentes foram tosse (84\%), febre $(79 \%)$ e coriza (76\%). Febre, tosse e dor de garganta apresentaram sensibilidade de $40 \%$ para os vírus influenza. Febre e tosse, isoladamente, possuem maior sensibilidade (85\%). Conclusão: Foi descrito o sistema de vigilância que foi considerado parcialmente útil, simples, de fácil entendimento e oportuno e flexível. No entanto, possui baixa aceitabilidade, baixo valor preditivo positivo e representatividade insatisfatória.

Palavras-chave: Influenza, Vigilância Epidemiológica, Sistemas de Informação em Saúde, Avaliação em Saúde, Sivep-Gripe 


\section{Abstract}

Introduction: Influenza or flu is a highly transmissible viral disease of worldwide distribution. In Brazil, it has been under surveillance since 2000. Objective: To evaluate the attributes of the epidemiological surveillance system of seasonal influenza in Brazil, from 2010 to 2013. Method: The methodology used was according to the Updated Guidelines for Evaluating Public Health methodology of Systems Centers for Disease Control and Prevention (CDC) in order to assess the qualitative and quantitative attributes, the system usefulness and the performance of the case definition. Results: Out of the 30,089 records of patients, who had their sample collected, about $21 \%$ did not meet the case definition flu-like illness and $15 \%$ were positive for respiratory viruses. The most circulated viruses over the period were the respiratory syncytial and influenza A. About $7 \%$ of the collected samples were not laboratory processed, $21 \%$ had inconclusive results, $2 \%$ had no information. Children tests had greater positivity (33\%), while the lowest percentage of positive results was among the elderly. The most frequent symptoms were cough (84\%), fever (79\%) and runny nose (76\%). Fever, cough and sore throat showed sensitivity of $40 \%$ for influenza viruses. Fever and coughing, alone, have a higher sensitivity (85\%). The surveillance system was described and it was considered partially useful, simple, of easy comprehension, timely and flexible. However, it has low acceptability, low positive predictive value and unsatisfactory representation.

Key words: Influenza, Epidemiological Surveillance, Health Information Systems, Health Assessment, Sivep-Gripe 


\subsubsection{Introdução}

A influenza ou gripe é causada pelo vírus influenza e tem distribuição mundial. Doença aguda do sistema respiratório é foco de atenção por apresentar rápida transmissão pessoa-pessoa; morbimortalidade agravada para grupos de risco como idosos, crianças e portadores de comorbidades; e por seu impacto em surtos, epidemias e potencial pandêmico $(1,2)$.

A vigilância sentinela da influenza no Brasil teve início no ano 2000. Foi estabelecida com uso de dados indiretos de morbidade e mortalidade associados e tem como principal objetivo o monitoramento das cepas dos vírus influenza circulantes no território brasileiro $(1,3)$. A ocorrência de surtos e óbitos por influenza entrou na relação das doenças de notificação compulsória em julho de 2005 (4). No entanto, por ser de interesse para a saúde pública, a notificação de casos de Síndrome Gripal (SG) ou influenza sazonal, e de Síndrome Respiratória Aguda Grave (SRAG) foram incluídas na Portaria MS/1.984/2014, que definiu a lista nacional de doenças e agravos de notificação compulsória a serem monitorados por meio da estratégia de vigilância sentinela (4).

Nas Unidades Sentinelas (US), distribuídas em todos os estados, são realizadas coletas de amostras clínicas de pacientes com quadro de SG; são preenchidas fichas padronizadas da vigilância; e os dados são lançados no Sistema de Informação Epidemiológica da Gripe (Sivep-Gripe) (1).

Para implantação, implementação e fortalecimento da vigilância epidemiológica da influenza foi estabelecido mecanismo de repasse financeiro pela Portaria MS/2.693/2011 (5) (Anexo H), republicada em 2012. Essa Portaria definiu os sítios sentinelas para a vigilância de SG; e as unidades de saúde de urgência/emergência para todas as faixas etárias. Caberia às US coletar cinco amostras clínicas por semana, todas as semanas do ano, e alimentar o Sivep-Gripe semanalmente com a informação da proporção de atendimentos de $S G$ em relação ao total de atendimentos realizados. A Portaria estabeleceu a proporção populacional para vigilância de SG: uma relação de uma US para 500 mil habitantes nas capitais e uma US em municípios com população maior que 300 mil habitantes da Região Sul e das regiões metropolitanas de capitais nas demais regiões. A 
Portaria MS/183/2014 (6) revogou a anterior e passou a regulamentar o incentivo financeiro para ações e serviços públicos estratégicos de vigilância em saúde, com a definição dos critérios de financiamento, monitoramento e avaliação, mas manteve os mesmos critérios proporcionais entre número de US e população.

A Secretaria de Vigilância em Saúde (SVS) do Ministério da Saúde (MS), atualmente, em 2015, trabalha com um conceito ampliado de vigilância de influenza. Para esse agravo são empregadas diferentes estratégias: vigilância sentinela de SG e de síndrome respiratória aguda grave (SRAG); vigilância universal de SRAG; monitoramento de hospitalização e de mortalidade por pneumonias (códigos da Classificação Internacional de Doenças (CID) versão №10: J09 ao J18); e investigação de surtos, óbitos e eventos incomuns suspeitos para influenza $(1,8)$. 0 fluxograma da vigilância da gripe pode ser verificado na Figura 1.

A vigilância é base essencial para o monitoramento e avaliação de qualquer processo de doença e é especialmente crítica quando surgem novos agentes capazes de causar doença (8). A ampliação das estratégias e práticas de vigilância epidemiológica são necessárias para uma resposta rápida e efetiva, diante de situações emergenciais, e depende da capacidade do sistema em identificar e acompanhar as situações corriqueiras (9). 


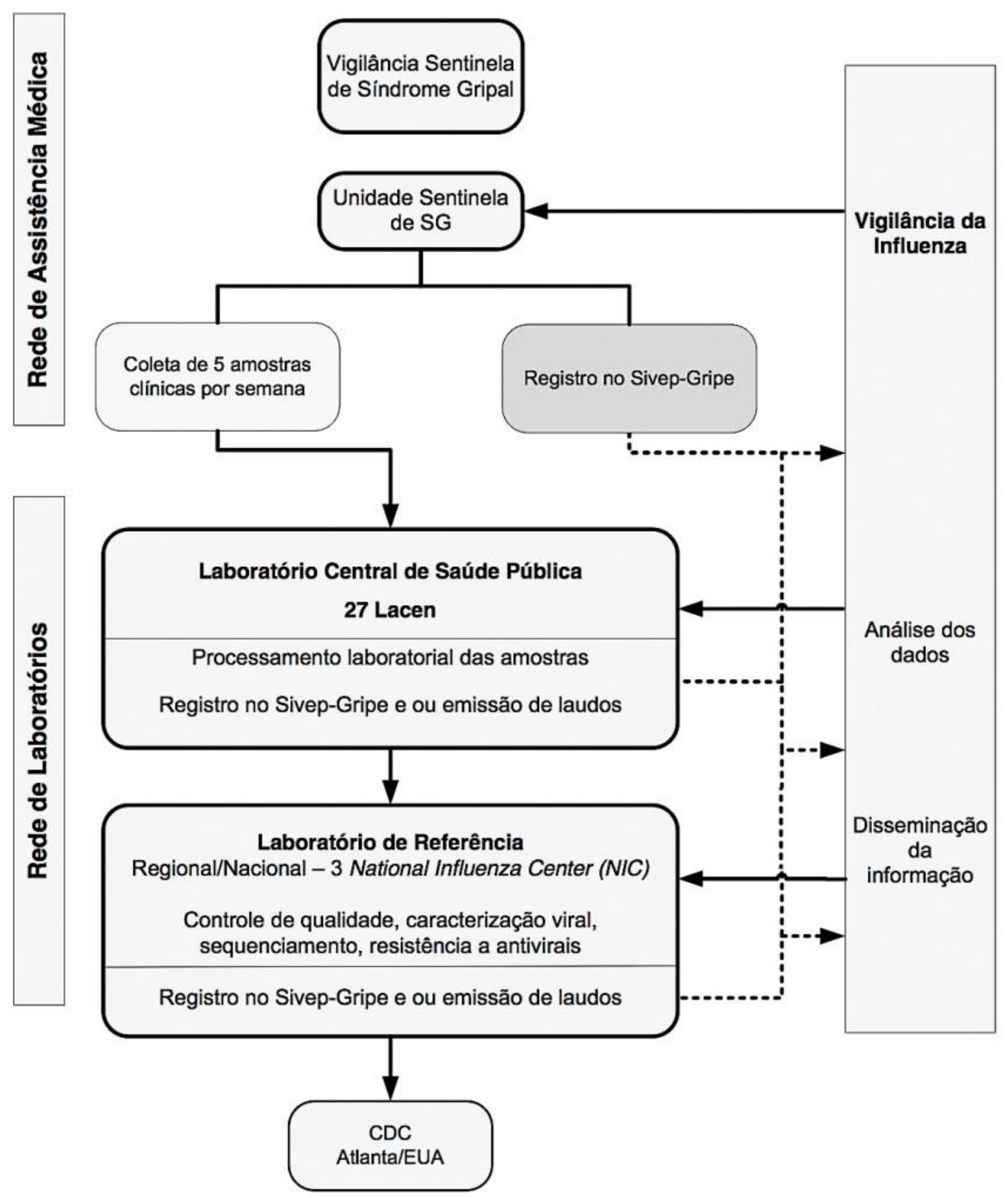

Figura 1 - Fluxograma da vigilância sentinela de influenza (síndrome gripal) 
A vigilância epidemiológica como função de Estado deve ser pré-requisito para a elaboração de políticas e programas de saúde, bem como de instrumento para avalição do impacto de sua implementação. Os sistemas de vigilância de doenças ou agravos devem ser avaliados periodicamente e, frente às necessidades, devem sofrer adequações de modo a obter bom desempenho, expresso pelos seus diversos atributos (10).

As avaliações do sistema de vigilância epidemiológica, ou de vigilância em saúde pública, devem ter o propósito de assegurar que problemas relevantes estejam sendo monitorados de forma eficiente e efetiva, e que as fragilidades detectadas possam ser objeto de recomendações para superação, de modo a melhorar a qualidade do sistema (11-13). Se necessário, o sistema deve ser alterado, para garantir seu bom desempenho e para adequá-lo periodicamente às modificações da estrutura, grau de desenvolvimento e complexidade tecnológica do sistema nacional de saúde (12).

O propósito deste estudo foi avaliar os atributos do sistema de vigilância epidemiológica da influenza sazonal no Brasil, de 2010 a 2013.

\subsubsection{Métodos}

Foram considerados como fonte os registros de síndrome gripal no SivepGripe nos anos de 2010 a 2013, em âmbito nacional. Os bancos de dados secundários, não nominais, foram oficialmente fornecidos, em mídia removível, pela SVS/MS em arquivos Data Base File (DBF) e convertidos em planilhas do software Microsoft Excel ${ }^{\circledR} 2010$.

A avaliação foi realizada segundo metodologia do Updated Guidelines for Evaluating Public Health Systems (13) do Centers for Disease Control and Prevention (CDC). O estudo abordou os atributos qualitativos (simplicidade, flexibilidade e aceitabilidade) e quantitativos (valor preditivo positivo, oportunidade e representatividade). Os parâmetros adotados para a avaliação estão apresentados no Quadro 1. 


\begin{tabular}{|c|c|c|}
\hline Atributo/Propriedade & Forma de verificação/Critérios & $\begin{array}{l}\text { Parâmetros/ } \\
\text { Classificação }\end{array}$ \\
\hline Simplicidade & $\begin{array}{l}\text { Análise do fluxo estabelecido e } \\
\text { número de níveis de transferência } \\
\text { dos dados }\end{array}$ & Simples ou complexo \\
\hline Flexibilidade & $\begin{array}{l}\text { Respostas e adaptações do sistema } \\
\text { às alterações na vigilância ou no } \\
\text { diagnóstico laboratorial. } \\
\text { Classificação subjetiva. }\end{array}$ & Flexível ou não flexível \\
\hline \multirow[t]{2}{*}{ Aceitabilidade } & $\begin{array}{l}\text { Observado de modo indireto pelo } \\
\text { grau de preenchimento dos } \\
\text { registros na ficha de investigação } \\
\text { epidemiológica individual. }\end{array}$ & $\begin{array}{c}<50 \%=\text { Baixa } \\
50 \% \text { a } 85 \%=\text { Regular } \\
>85 \%=\text { Boa }\end{array}$ \\
\hline & $\begin{array}{l}\text { Percentual de amostras coletadas } \\
\text { nas US }\end{array}$ & $\begin{array}{l}<80 \%=\text { Baixa } \\
\geq 80 \%=\text { Boa }\end{array}$ \\
\hline $\begin{array}{l}\text { Valor preditivo } \\
\text { positivo }\end{array}$ & $\begin{array}{l}\text { Proporção dos casos considerados } \\
\text { positivos (com resultado positivo no } \\
\text { exame de imunofluorescência } \\
\text { indireta para vírus respiratórios) em } \\
\text { relação ao total de casos } \\
\text { registrados de síndrome gripal que } \\
\text { tiveram amostra coletadas para } \\
\text { exame laboratorial. }\end{array}$ & $\begin{array}{l}>80 \%=\text { Satisfatório } \\
50 \text { a } 80 \%=\text { Regular } \\
<50 \%=\text { Insatisfatório }\end{array}$ \\
\hline Representatividade & $\begin{array}{l}\text { Adequação do número de US por } \\
\text { população. } \\
\text { - } 1 \text { US para cada } 500 \text { mil hab. nas } \\
\text { capitais estaduais } \\
\text { - } 1 \text { US para cada município de } \\
\text { Região Metropolitana de Capital } \\
\text { estadual com mais de } 300 \text { mil hab. } \\
\text { - } 1 \text { US nos municípios da Região } \\
\text { Sul com mais de } 300 \text { mil hab. }\end{array}$ & $\begin{array}{l}>80 \%=\text { Satisfatória } \\
50 \text { a } 80 \%=\text { Regular } \\
<50 \%=\text { Insatisfatória }\end{array}$ \\
\hline \multirow{2}{*}{ Oportunidade } & $\begin{array}{l}\text { Oportunidade da coleta de amostra: } \\
\text { tempo em dias entre a data dos } \\
\text { primeiros sintomas e a data da } \\
\text { coleta de amostra }\end{array}$ & $\begin{array}{l}3 \text { a } 5 \text { dias = Oportuna } \\
>7 \text { dias = Não oportuna }\end{array}$ \\
\hline & $\begin{array}{l}\text { Oportunidade do resultado } \\
\text { laboratorial: tempo em dias entre a } \\
\text { data da coleta de amostra e a data } \\
\text { do diagnóstico laboratorial }\end{array}$ & $\begin{array}{c}7 \text { dias = Oportuna } \\
>8 \text { dias = Não oportuna }\end{array}$ \\
\hline
\end{tabular}

Quadro 1 - Instrumento auxiliar de avaliação do sistema de vigilância epidemiológica da influenza sazonal 
Para avaliação da representatividade foi verificada pela adequação do número de US conforme população municipal considerando a Portaria MS/2.693/2011(5) (Quadro 2).

\begin{tabular}{|c|c|}
\hline População & US de SG \\
\hline População até 1 milhão & 1 a * $^{*}$ \\
\hline de 1 a 2 milhões & 3 a 4 \\
\hline de 2 a 3 milhões & 5 a 6 \\
\hline de 3 a 4 milhões & 7 a 8 \\
\hline de 4 a 5 milhões & 9 a 10 \\
\hline de 5 a 6 milhões & 11 a 12 \\
\hline de 6 a 7 milhões & 13 a 14 \\
\hline de 7 a 8 milhões & 15 a 16 \\
\hline de 8 a 9 milhões & 16 a 17 \\
\hline de 9 a 10 milhões & 18 a 19 \\
\hline de 10 a 11 milhões & 20 a 21 \\
\hline 11 milhões e mais & 22 a 23 \\
\hline
\end{tabular}

Quadro 2 - Parâmetro populacional para implantação da vigilância de síndrome gripal

\footnotetext{
${ }^{*}$ A cada intervalo populacional de 500.000 habitantes deve-se implantar 1 unidade de vigilância da SG.

Adaptado do Anexo II da Portaria MS/2.693/2011
}

A utilidade do sistema foi avaliada considerando o atendimento aos objetivos propostos nos guias e manuais da vigilância da influenza (1,7). A classificação foi escalonada em útil, com 100\% dos objetivos alcançados; parcialmente útil; e inútil, se nenhum dos objetivos fosse atingido.

Para a análise do desempenho da definição de caso de SG foi considerado o indivíduo com febre (aferida ou referida), acompanhada de tosse ou dor de garganta, na ausência de outros diagnósticos, com no máximo cinco dias do início dos sintomas. Foi estabelecido, como confirmado, caso de SG com resultado positivo pela reação de IFI; e, como boa sensibilidade - bom desempenho -, o valor maior ou igual a $80 \%$. Foi analisado pelo cálculo da prevalência dos sintomas em relação ao número total de casos positivos em conformidade com o Quadro 3. 


\begin{tabular}{|c|c|c|c|}
\hline \multirow{3}{*}{ 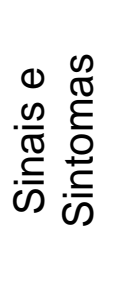 } & & $\begin{array}{c}\text { Diagnóstico } \\
\text { laboratorial positivo }\end{array}$ & $\begin{array}{c}\text { Diagnóstico laboratorial } \\
\text { negativo }\end{array}$ \\
\hline & Presente & $\begin{array}{c}\text { Verdadeiro Positivo } \\
\text { (a) }\end{array}$ & $\begin{array}{l}\text { Falso Positivo } \\
\text { (b) }\end{array}$ \\
\hline & Ausente & $\begin{array}{c}\text { Falso Negativo } \\
\text { (c) }\end{array}$ & $\begin{array}{l}\text { Verdadeiro Negativo } \\
\text { (d) }\end{array}$ \\
\hline
\end{tabular}

Quadro 3 - Contingência comparativa dos dados de vigilância e de laboratório para estudo da definição de caso de influenza

Considerando desta forma, a sensibilidade (capacidade de detectar caso verdadeiro de gripe tendo como referência a definição de caso de síndrome gripal) foi calculada como: Sensibilidade $=a /(a+c) \times 100 \%$.

A especificidade (capacidade de indicar corretamente a ausência de um caso de gripe, tendo como referência a definição de caso de síndrome gripal) foi obtida como: Especificidade $=d /(b+d) \times 100 \%$.

O valor preditivo positivo (probabilidade de que um resultado positivo indica verdadeiramente caso de gripe tendo como referência a definição de caso de síndrome gripal) foi derivado como: Valor Preditivo Positivo $=a /(a+b) \times 100 \%$.

A descrição e análise do sistema de vigilância de influenza, do propósito, operação e objetivos foi realizada segundo levantamento dos dados disponíveis sobre a vigilância epidemiológica da influenza, obtidos por busca no sistema SivepGripe, pesquisa bibliográfica, consulta à legislação, documentos de trabalho e materiais diversos, como as Notas Técnicas e Informes Epidemiológicos da SVS/MS.

Para as análises descritivas foram utilizados os softwares Epi Info ${ }^{T M} 7.1 .4 .0 \mathrm{e}$ Microsoft Excel ${ }^{\circledR} 2010$.

Mesmo com a utilização de dados secundários, sem identificação dos indivíduos, o projeto foi submetido e aprovado pelo Comitê de Ética da Faculdade de Ciências da Saúde da UnB, sob o registro CAAE 27907114.8.0000.0030.

\subsubsection{Resultados}




\title{
4.5.4.1 Propósito e utilidade da vigilância
}

Os objetivos do sistema de vigilância da influenza descritos nos Guias de Vigilância $(8,15)$ da SVS/MS, para o período em estudo, eram: monitorar as cepas dos vírus influenza que circulam nas regiões brasileiras; avaliar o impacto da vacinação contra a doença; acompanhar a tendência da morbidade e da mortalidade associadas à doença; responder a situações inusitadas; detectar e oferecer resposta rápida à circulação de novos subtipos que poderiam estar relacionados à pandemia de influenza; e produzir e disseminar informações epidemiológicas.

\subsubsection{Definição de caso}

No atual Guia de Vigilância em Saúde (1) para a vigilância sentinela de influenza, a definição de caso para SG é indivíduo com febre, mesmo que referida, acompanhada de tosse ou dor de garganta e início dos sintomas nos últimos sete dias. No início do período deste estudo, constava como definição de caso de SG (7):

\begin{abstract}
Suspeito - indivíduo com doença aguda (com duração máxima de 5 dias), apresentando febre (ainda que referida) e pelo menos um sintoma respiratório (tosse ou dor de garganta), na ausência de outros diagnósticos. Abrange as seguintes infecções respiratórias agudas, com seus respectivos CID: J00 (todos)-Nasofaringite aguda (resfriado comum); J02.9Faringite aguda não especificada; J03.9-Amigdalite aguda não especificada; J04.0-Laringite aguda; J04.1-Traqueíte aguda; J04.2-Laringotraqueite aguda; J06 (todos)-Infecção aguda das vias aéreas superiores e não especificadas; J10 (todos)-Influenza devido a vírus influenza identificado; e J11 (todos)-Influenza devida a vírus influenza não identificado.

Confirmado - quando for confirmado, através de exame laboratorial, o vírus da influenza; ou confirmação por vínculo epidemiológico.

Descartado - quando o resultado do exame for negativo, em amostra adequadamente colhida e transportada, ou quando for identificado laboratorialmente outro agente etiológico, que não o vírus da influenza.
\end{abstract}

Documentos oficiais, como o protocolo de tratamento de influenza, informes técnicos e manuais, apresentavam diferenças na definição de caso (Apêndice A).

\subsubsection{Componentes e operacionalização do sistema}


São componentes da vigilância da influenza as redes de US e de laboratórios que monitoram a circulação das cepas virais e a morbidade por infecção respiratória aguda, em sua demanda de atendimento (14), além das equipes técnicas das vigilâncias epidemiológicas das três esferas de governo (municipal, estadual, federal). As US eram então selecionadas conforme critérios de demanda, como possuir centro de atendimento de consultas de clínica geral e/ou pediatria; apresentar equipe e estrutura mínima; estar localizada próxima ao laboratório; ter bom desempenho gerencial e interesse na participação da vigilância. (3)

A rede laboratorial oficial é formada pelos 27 Laboratórios Centrais de Saúde Pública (Lacen) e por Laboratórios de Referência (LR) definidos pela Coordenação Geral de Laboratórios de Saúde Pública (CGLAB) da SVS/MS. Como LR estão designados o Laboratório de Virologia do Instituto Evandro Chagas, no Pará (IEC/PA); o Laboratório de Vírus Respiratórios do Instituto Adolfo Lutz, em São Paulo (IAL/SP); e o Laboratório de Vírus Respiratório e Sarampo da Fundação Oswaldo Cruz, no Rio de Janeiro (Fiocruz/RJ), que estão credenciados junto à Organização Mundial da Saúde (OMS) como Centros Nacionais de Influenza (NIC National Influenza Center) $(7,15)$.

Compete às US, numa amostragem por conveniência, encaminhar cinco amostras biológicas de secreção respiratória, por semana epidemiológica (SE), a um dos Lacen; e fazer o registro no Sivep-Gripe tanto dos casos de SG que tiveram amostras coletadas, como da proporção de atendimentos por SG em relação ao número total dos atendimentos. Os Lacen de cada estado realizam o exame de imunofluorescência indireta (IFI) para identificação dos vírus respiratórios - influenza A e B; parainfluenza 1, 2 e 3; adenovírus e vírus respiratório sincicial (VRS) - e, posteriormente, conforme protocolo, encaminham alíquota para o LR de acordo com a área de abrangência, todas as amostras positivas para Influenza $A$, as inconclusivas e 10\% das amostras negativas. Os LR remetem, regularmente, informações e amostras para o CDC. Os registros são verificados e a área técnica de influenza elabora Boletim Epidemiológico mensal, para publicação no sítio da internet da SVS/MS e envio eletrônico para as vigilâncias epidemiológicas estaduais.

\subsubsection{Informações relevantes geradas à vigilância}


O banco de dados obtidos a partir do Sivep-Gripe estava estruturado em consonância com formulário padronizado de registro individual de casos de SG que realizaram coleta de amostra, no período de $1^{\circ}$ de janeiro de 2010 a $1^{\circ}$ de junho de 2013 (SE 1/2010 a SE 23/2013), e apresentava 30.089 registros de SG com coleta de amostras. Não constavam os registros dos dados agregados das US.

Foi observado que, em 2010, havia 27 estados com US participantes; em 2011, 25 estados; em 2012, 24 estados; e, em 2013, 18 estados contribuíram para a vigilância sentinela.

A distribuição dos vírus respiratórios identificados no período pode ser verificada na Figura 2. Os vírus que mais circularam foram o respiratório sincicial e o influenza A. Não foram realizados os exames laboratoriais em aproximadamente $6,7 \%$ das amostras; $20,8 \%$ tiveram resultados inconclusivos e $2,4 \%$ constavam sem informação. Tiveram resultados negativos, cerca de $87,8 \%$ das amostras processadas para todos os vírus. 


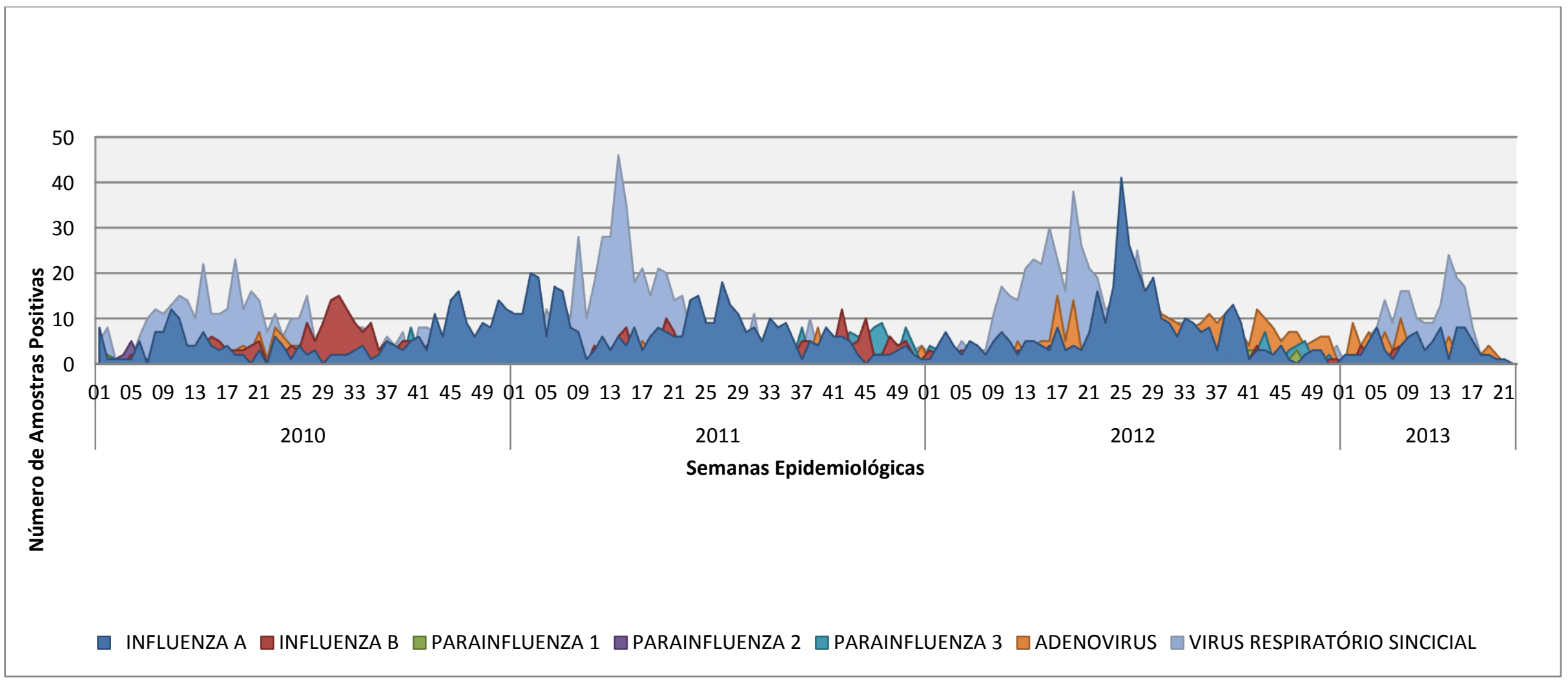

Figura 2 - Distribuição dos vírus respiratórios identificados nas unidades sentinelas de Síndrome Gripal, por semana epidemiológica de início dos sintomas. Sivep-Gripe, Brasil, SE 1/2010 a SE 22/2013 
$\mathrm{Na}$ distribuição dos resultados por faixa etária, pode ser observado que o grupo de crianças de 5 a 14 anos apresentou o maior percentual de positividade para todos os vírus respiratórios (33,5\%), seguido dos menores de 4 anos $(27,0 \%)$ e do grupo de 24 a 59 anos (25,5\%). A faixa dos idosos teve a menor positividade: $4,5 \%$. Entre os menores de 4 anos, o VRS $(44,4 \%)$ e o adenovírus $(38,0 \%)$ foram os mais frequentes. Na faixa entre 5 a 14 anos, os vírus que mais circularam foram o parainfluenza $1(41,9 \%)$, seguido do adenovírus $(40,4 \%)$ e do vírus respiratório sincicial $(37,8 \%)$. Os resultados dos pacientes de 15 a 24 anos apontaram os vírus influenza B (18,5\%) e o influenza A (14,4\%); entre os de 25 a 59 anos, predominaram os vírus influenza $A(44,6 \%)$, influenza B $(43,7 \%)$ e parainfluenza $2(36,0 \%)$. O influenza A (7,2\%) foi o principal vírus encontrado no grupo de 60 anos ou mais (Tabela 1). 
Tabela 1 - Vírus respiratórios identificados nas unidades sentinelas, por região e faixa etária. Sivep-Gripe, Brasil, 2010-2013

\begin{tabular}{|c|c|c|c|c|c|c|c|c|c|c|c|c|c|c|c|c|c|}
\hline \multirow[t]{2}{*}{ Ano } & \multicolumn{2}{|c|}{ Flu A } & \multicolumn{2}{|c|}{ Flu B } & \multicolumn{2}{|c|}{ Para 1} & \multicolumn{2}{|c|}{ Para 2} & \multicolumn{2}{|c|}{ Para 3} & \multicolumn{2}{|c|}{ Adeno } & \multicolumn{2}{|c|}{ VRS } & \multicolumn{2}{|c|}{$\begin{array}{c}\text { Amostras } \\
\text { positivas para } \\
\text { vírus } \\
\text { respiratórios }\end{array}$} & \multirow{2}{*}{$\begin{array}{c}\text { Total de } \\
\text { amostras } \\
\text { coletadas }\end{array}$} \\
\hline & $\mathbf{n}$ & $\%$ & $\mathbf{n}$ & $\%$ & $\mathrm{n}$ & $\%$ & $\mathbf{n}$ & $\%$ & $\mathbf{n}$ & $\%$ & $\mathrm{n}$ & $\%$ & $\mathbf{n}$ & $\%$ & $\mathbf{n}$ & $\%$ & \\
\hline 2010 & 253 & 3,2 & 213 & 2,7 & 71 & 0,9 & 57 & 0,7 & 120 & 1,5 & 147 & 1,8 & 430 & 5,4 & 1.291 & 16,2 & 7.971 \\
\hline 2011 & 376 & 4,1 & 195 & 2,1 & 52 & 0,6 & 39 & 0,4 & 115 & 1,3 & 134 & 1,5 & 538 & 5,8 & 1.449 & 15,7 & 9.215 \\
\hline 2012 & 372 & 3,6 & 89 & 0,9 & 72 & 0,7 & 33 & 0,3 & 88 & 0,8 & 320 & 3,1 & 501 & 4,8 & 1.475 & 14,1 & 10.479 \\
\hline 2013 & 84 & 3,5 & 28 & 1,2 & 8 & 0,3 & 7 & 0,3 & 6 & 0,3 & 83 & 3,4 & 192 & 7,9 & 408 & 16,8 & 2.424 \\
\hline Total & 1.085 & 3,6 & 525 & 1,7 & 203 & 0,7 & 136 & 0,5 & 329 & 1,1 & 684 & 2,3 & 1.661 & 5,5 & 4.623 & 15,4 & 30.089 \\
\hline \multicolumn{18}{|l|}{ Região } \\
\hline Norte & 198 & 18,3 & 72 & 13,7 & 73 & 36,0 & 20 & 14,7 & 66 & 20,1 & 227 & 33,2 & 452 & 27,2 & 1.108 & 24,0 & 6.573 \\
\hline Nordeste & 234 & 21,6 & 156 & 29,7 & 62 & 30,5 & 59 & 43,4 & 104 & 31,6 & 274 & 40,1 & 344 & 20,7 & 1.233 & 26,7 & 7.969 \\
\hline Sudeste & 191 & 17,6 & 95 & 18,1 & 38 & 18,7 & 19 & 14,0 & 101 & 30,7 & 87 & 12,7 & 591 & 35,6 & 1.122 & 24,3 & 8.087 \\
\hline Sul & 309 & 28,5 & 161 & 30,7 & 18 & 8,9 & 30 & 22,1 & 38 & 11,6 & 49 & 7,2 & 156 & 9,4 & 761 & 16,5 & 3.910 \\
\hline Centro-Oeste & 153 & 14,1 & 41 & 7,8 & 12 & 5,9 & 8 & 5,9 & 20 & 6,1 & 47 & 6,9 & 118 & 7,1 & 399 & 8,6 & 3.550 \\
\hline Brasil & 1.085 & 100,0 & 525 & 100,0 & 203 & 100,0 & 136 & 100,0 & 329 & 100,0 & 684 & 100,0 & 1661 & 100,0 & 4.623 & 100,0 & 30.089 \\
\hline \multicolumn{18}{|l|}{ Faixa Etária* } \\
\hline $0-4$ & 104 & 9,6 & 45 & 8,6 & 40 & 19,7 & 17 & 12,5 & 125 & 38,0 & 180 & 26,3 & 738 & 44,4 & 1.249 & 27,0 & 5.285 \\
\hline $5-14$ & 263 & 24,2 & 128 & 24,4 & 85 & 41,9 & 49 & 36,0 & 120 & 36,5 & 276 & 40,4 & 628 & 37,8 & 1.549 & 33,5 & 9.004 \\
\hline $15-24$ & 156 & 14,4 & 97 & 18,5 & 17 & 8,4 & 15 & 11,0 & 14 & 4,3 & 60 & 8,8 & 76 & 4,6 & 435 & 9,4 & 3.547 \\
\hline $25-59$ & 484 & 44,6 & 229 & 43,7 & 50 & 24,6 & 49 & 36,0 & 56 & 17,0 & 135 & 19,7 & 177 & 10,7 & 1.180 & 25,5 & 10.251 \\
\hline$\geq 60$ & 78 & 7,2 & 25 & 4,8 & 11 & 5,4 & 6 & 4,4 & 14 & 4,3 & 33 & 4,8 & 42 & 2,5 & 209 & 4,5 & 1.995 \\
\hline Total & 1.085 & 100,0 & 524 & 100,0 & 203 & 100,0 & 136 & 100,0 & 329 & 100,0 & 684 & 1,8 & 1.661 & 100,0 & 4.622 & 100,0 & 30.082 \\
\hline \multicolumn{18}{|l|}{ Sexo } \\
\hline Masculino & 538 & 3,7 & 272 & 1,9 & 113 & 0,8 & 59 & 0,4 & 171 & 1,2 & 353 & 2,4 & 855 & 5,9 & 2.361 & 16,2 & 14.615 \\
\hline Feminino & 545 & 3,6 & 250 & 1,6 & 90 & 0,6 & 77 & 0,5 & 156 & 1,0 & 325 & 2,1 & 795 & 5,2 & 2.238 & 14,6 & 15.334 \\
\hline S/Informação & 2 & 1,4 & 3 & 2,1 & 0 & 0,0 & 0 & 0,0 & 2 & 1,4 & 6 & 4,3 & 11 & 7,9 & 24 & 17,1 & 140 \\
\hline Total & 1.085 & 0,00 & 525 & 1,74 & 203 & 0,67 & 136 & 0,45 & 329 & 1,09 & 684 & 2,27 & 1.661 & 5,52 & 4.623 & 15,4 & 30.089 \\
\hline
\end{tabular}

Flu A=Influenza A; Flu B=Influenza B; Para 1=Parainfluenza A; Para 2=Parainfluenza 2; Para 3=Parainfluenza 3; Adeno=Adenovírus; VRS=Vírus Respiratório Sincicial 
Pode ser verificado um discreto predomínio de amostras de indivíduos do sexo feminino (51,0\%), principalmente na faixa de 25 a 59 anos (56,8\%), em cada ano do período estudado. O número de amostras foi maior nas faixas de 25 a 59 anos $(34,0 \%)$ e de 5 a 14 anos (29,7\%). Amostras de crianças de 0 a 4 anos constituíam quase 18,0\%; e as de idosos, cerca de 7,0\%, foram a menor percentagem dos espécimes clínicos (Tabela 2).

Tabela 2 - Distribuição das amostras coletadas nas unidades sentinelas para síndrome gripal por faixa etária e sexo. Sivep-Gripe, Brasil, 2010-2013

\begin{tabular}{ccccccccc}
\hline \multirow{2}{*}{$\begin{array}{c}\text { Faixa } \\
\text { Etária* }^{*}\end{array}$} & \multicolumn{2}{c}{ Sexo Masculino } & \multicolumn{2}{c}{ Sexo Feminino } & \multicolumn{2}{c}{ Sexo Ignorado } & \multicolumn{2}{c}{ Total } \\
\cline { 2 - 9 } & $\mathrm{n}$ & $\%$ & $\mathrm{n}$ & $\%$ & $\mathrm{n}$ & $\%$ & $\mathrm{n}$ & $\%$ \\
\hline $0-4$ & 2.889 & 53,7 & 2.404 & 45,1 & 61 & 1,1 & 5.354 & 17,8 \\
$5-14$ & 4.755 & 53,3 & 4.150 & 46,3 & 39 & 0,4 & 8.944 & 29,7 \\
$15-24$ & 1.682 & 47,4 & 1.860 & 52,3 & 9 & 0,2 & 3.551 & 11,8 \\
$25-59$ & 4.406 & 43,0 & 5.811 & 56,7 & 24 & 0,2 & 10.241 & 34,0 \\
$\geq 60$ & 879 & 44,1 & 1.106 & 55,5 & 7 & 0,3 & 1.992 & 6,6 \\
Total & 14.611 & 48,6 & 15.331 & 51,0 & 140 & 0,5 & $30.082^{*}$ & 100,0 \\
\hline
\end{tabular}

*sete registros apresentavam erro no registro da data de nascimento.

A co-infecção identificada foi baixa: 1,2\% (57/4.623). Das amostras positivas para o vírus influenza $A$, houve co-infecção de 3,4\% com o parainfluenza-1. Em relação ao influenza $B$, o maior percentual de co-infecção foi de $5,1 \%$ com o vírus parainfluenza-2. Destacam-se, dentre as 136 amostras positivas para o vírus parainfluenza-2, 5,1\% apresentaram também positividade para o influenza B e 5,1\% para VRS. Dentre os 203 positivos para o vírus parainfluenza-1, 3,4\% estavam também positivos para o influenza A; 3,0\% para parainfluenza-3; e 3,0\% para VRS. Dos 684 positivos para adenovírus, 4,4\% para VRS (Apêndice B).

O espécime clínico obtido por swab combinado (SC) ocorreu em $61,4 \%$ das amostras e, por aspirado de nasofaringe (ANF), em 37,3\%. Amostras obtidas pela combinação das técnicas ( $\mathrm{ANF}+\mathrm{SC}$ ) foram poucas, assim como as para exame sorológico, 15 e 4 amostras, respectivamente, no período. 
No início das atividades de vigilância de influenza era realizada coleta de sangue para sorologia. Esse exame era indicado para aqueles pacientes a quem o serviço teria acesso para realizar coleta de duas amostras de sangue, como, por exemplo, pacientes internados. As coletas seriam realizadas na fase aguda e, outra, 15 dias após, na fase convalescente (7). Na prática, tal metodologia não foi efetivada. No período estudado, de 30.089 amostras, apenas quatro foram coletadas para sorologia: em 2010, duas amostras para sorologia 1 e uma única para sorologia 2; em 2012, uma coleta para sorologia 1.

Cerca de $10 \%$ da informação sobre a qualidade das amostras estavam sem preenchimento. A maioria das amostras - 87,0\% - foi considerada adequada. No entanto, dentre as amostras consideradas de qualidade adequada, em 117 constavam observações que as tornavam inadequadas ao processamento laboratorial. Estavam registradas como conformes cerca de 95\% das amostras oriundas das Regiões Norte e Centro-Oeste, 94\% da Região Sul, 86\% da Região Nordeste e, do Sudeste, 73\%. A Região Sudeste apresentou maior percentual de ausência de informação (22\%) e de registro de amostras inadequadas (5\%) (Tabela 3).

Tabela 3 - Frequência da informação “Qualidade do material” por região. SivepGripe, Brasil, 2010-2013

\begin{tabular}{cccccccccc}
\hline \multirow{2}{*}{$\begin{array}{c}\text { Qualidade da } \\
\text { Amostra }\end{array}$} & \multicolumn{2}{c}{ Adequada } & \multicolumn{2}{c}{ Inadequada } & \multicolumn{2}{c}{ Sem Informação } & \multicolumn{2}{c}{ Total } \\
\cline { 2 - 10 } Região & $\mathrm{n}$ & $\%$ & $\mathrm{n}$ & $\%$ & $\mathrm{n}$ & $\%$ & $\mathrm{n}$ & $\%$ \\
\hline Norte & 6.297 & 95,8 & 148 & 2,3 & 128 & 1,9 & 6.573 & 21,8 \\
Nordeste & 6.892 & 86,5 & 127 & 1,6 & 950 & 11,9 & 7.969 & 26,5 \\
Sudeste & 5.906 & 73,0 & 396 & 4,9 & 1.785 & 22,1 & 8.087 & 26,9 \\
Sul & 3.678 & 94,1 & 129 & 3,3 & 103 & 2,6 & 3.910 & 13,0 \\
Centro-Oeste & 3.391 & 95,5 & 55 & 1,5 & 104 & 2,9 & 3.550 & 11,8 \\
\hline Brasil & 26.164 & 87,0 & 855 & 2,8 & 3.070 & 10,2 & 30.089 & 100 \\
\hline
\end{tabular}

Importante ressaltar que o teste de IFI trata-se um painel que utiliza anticorpos monoclonais para identificar a presença de vírus em células infectadas, conhecido como "painel de vírus respiratórios". Ao verificarmos o campo "Observação Imunofluorescência”, destinado para observações pertinentes sobre o 
teste diagnóstico, campo de preenchimento livre, não obrigatório, foi constatado o registro de alguns resultados de exames realizados por biologia molecular e havia também, o registro de problemas com as amostras. Dentre as 407 observações referentes à qualidade da amostra, 82\% (333/407) registravam a quantidade insuficiente de células para o diagnóstico. Por ser um campo não obrigatório e de registro textual livre, as observações foram agrupadas em sete categorias: 1) Material insuficiente. Ausência ou poucas células; 2) Material coletado acima do tempo preconizado para coleta - com mais de 7, 10 ou 15 dias; 3) Acondicionamento inadequado e material congelado; 4) Amostra com preparo não conforme: lâmina quebrada, material descolado, vazado, sem meio de transporte viral (tubo seco); 5) Amostra enviada para o Lacen fora do prazo: mais de 24 horas após a coleta; 6) Material com sangue e ou muco; 7) Amostra contaminada (Figura 3).

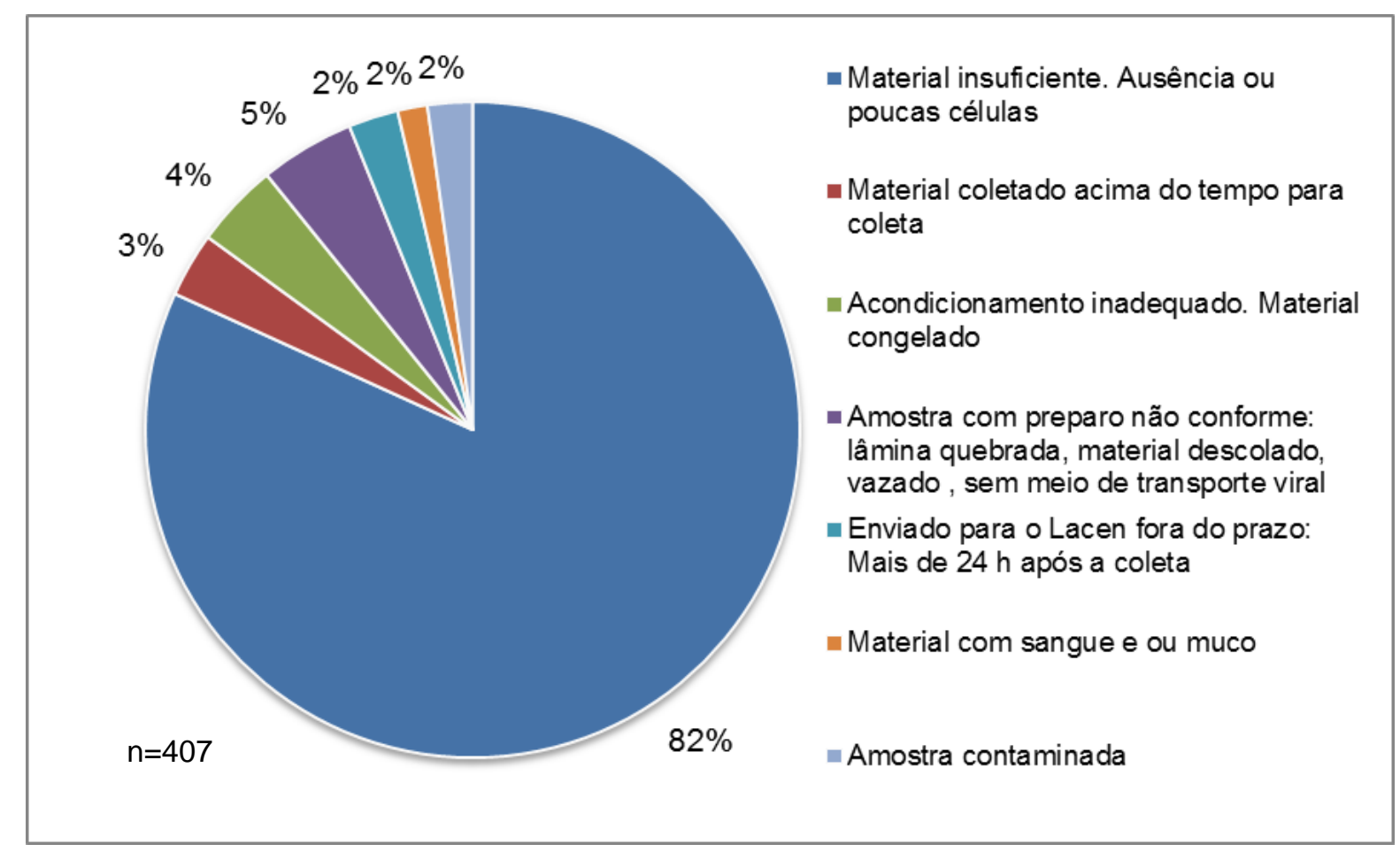

Figura 3 - Observações sobre a qualidade da amostra para imunofluorescência. Sivep-Gripe, Brasil, 2010-2013 


\subsubsection{Utilidade}

A utilidade de um sistema de vigilância está na capacidade de contribuir para o controle e prevenção, além de propiciar o entendimento sobre o impacto em saúde pública de determinado agravo $(13,11)$.

Com base nos seis objetivos estabelecidos para a vigilância de influenza o sistema foi considerado parcialmente útil. Embora o sistema tenha conseguido realizar identificação e monitoramento da circulação dos principais vírus respiratórios no país, a tendência de morbidade e, com isso eventualmente verificar e indicar resposta a situações inusitadas como surtos, seu desempenho foi reduzido. Há que se considerar ainda que por se tratar de sistema passivo de vigilância sentinela o monitoramento da morbidade é de uma parcela da população.

A performance do sistema sofreu interferências de fatores relativos aos atributos aceitabilidade, oportunidade, VPP e representatividade. A baixa aceitabilidade acarretou no número reduzido de amostras, que na maioria dos estados não atingiu a meta estabelecida. Embora seja de conhecimento a publicação de boletim mensal sobre influenza na página da SVS/MS, não foi avaliada a produção e disseminação de informações sobre a doença para os profissionais de saúde dos diferentes níveis envolvidos e para a população.

Acerca do objetivo de avaliação do impacto da vacinação, o sistema contribui com dados que podem ser empregados em estudos, porém são necessárias outras informações não previstas ou insuficientemente preenchidas - como as relacionadas à situação vacinal do paciente (16) - nesse sistema de vigilância.

\subsubsection{Estudo dos atributos qualitativos}

\subsection{Simplicidade}

O fluxo da vigilância sentinela de SG foi considerado simples, de fácil entendimento conforme fluxograma (Figura 1). As US estavam implantadas em serviços de saúde principalmente das capitais estaduais, que constitui um facilitador 
para a comunicação e o transporte das amostras entre a US e o Lacen. Os casos de SG identificados nas US e que tiveram amostras coletadas e encaminhadas ao Lacen, são notificados/registrados pelo profissional de saúde, tendo por base formulário padronizado individual e relacionado ao agregado de casos da US. Após o preenchimento dos dados no Sivep-Gripe a informação se torna acessível aos componentes do sistema como US, secretarias municipais e estaduais, laboratórios e área técnica da SVS/MS. O Sivep-Gripe foi proposto como plataforma on-line, de modo que a informação sobre o agravo ocorresse de forma imediata e simultânea entre os diferentes serviços e instâncias hierárquicas envolvidas na vigilância. $O$ sistema é de acesso restrito a técnicos cadastrados com senha para acesso.

\subsection{Flexibilidade}

A flexibilidade indica a habilidade de um sistema de vigilância adaptar-se facilmente a novas necessidades, em resposta às mudanças na natureza ou na importância de um evento adverso à saúde (13). No período do estudo não houve alterações no fluxo da vigilância nem no Sivep-Gripe. Houve cadastramento de US e implementação de técnicas de biologia molecular no diagnóstico quando o sistema não previa campo específico para inclusão dos resultados. No entanto, os resultados foram lançados no campo "Observação Imunofluorescência" destinado para registro de observações sobre o teste diagnóstico de IFI. O sistema aceitou as modificações de inclusão e ou exclusão de US. Como houve adaptação, o sistema foi considerado flexível.

\subsection{Aceitabilidade}

O atributo aceitabilidade indica 0 quanto os profissionais envolvidos participam do sistema de vigilância. Foi avaliado de modo indireto, pela proporção do grau de preenchimento ou integralidade dos registros das variáveis obrigatórias e essenciais do Sivep-Gripe; e pelo percentual de amostras coletadas nas US. Os critérios de classificação adotados para o sistema ser considerado de boa aceitação 
foram: percentual de preenchimento das variáveis igual ou acima de $85 \%$, e percentual de amostras coletadas igual ou maior de $80 \%$.

O Dicionário de Dados do Sivep-Gripe descreve 61 variáveis, sendo dez campos classificados como obrigatórios, quinze essenciais e três internos; trinta e três não possuem classificação. Houve média de preenchimento de cerca de $86 \%$ para as variáveis obrigatórias e de 93\% para os campos essenciais. Em vista disso, a análise de completitude foi considerada boa (16), o que reflete na boa aceitabilidade.

Em relação ao percentual de amostras, é pactuado que por semana devem ser coletadas cinco amostras por US, sendo aceitável a coleta de no mínimo 80\% (quatro amostras). Foram realizadas pouco mais da metade $(53,3 \%)$ do número preconizado de coletas de amostras de secreção respiratória. Esse parâmetro indicou uma aceitação abaixo do esperado para o país no período (Tabela 4).

Cinco $(18,5 \%)$ estados atingiram a meta estabelecida para coleta de amostras: Acre $(96,9 \%)$, Ceará $(88,5 \%)$, Pernambuco $(87,4 \%)$, Bahia $(83,5 \%)$, Mato Grosso do Sul (81,9\%). O estado de São Paulo, com quase 79\%, praticamente alcançou a estimativa preconizada. Foi verificada inconstância na participação das US, o que pode ser observado pelo registro no Sivep-Gripe do código da unidade de saúde referente ao Cadastro Nacional de Estabelecimentos de Saúde (CNES).

Em 2010 nenhum estado alcançou a meta e o país contabilizou um percentual médio de $31,3 \%$ de amostras coletadas.

Em 2011 superaram a meta 6 (22,2\%) unidades federativas: Acre (210,4\%), Piauí (98,5\%), Ceará (97,5\%), Pernambuco (91,9\%), São Paulo (88,5\%), Mato Grosso do Sul (85,6\%) e o Distrito Federal (85,6\%). Abaixo dos 20\%, constaram Rio de Janeiro (17,4\%), Rio Grande do Norte (14,0\%), Alagoas (13,1\%), Santa Catarina $(12,0 \%)$, Mato Grosso $(7,7 \%)$ e Pará $(0,4 \%)$. Não houve registro no Amapá e na Paraíba.

Ficaram acima dos 80\%, em 2012, 8 (29,6\%) estados: Acre (133,1\%), Ceará $(109,8 \%)$, Pernambuco $(100,4 \%)$, Sergipe $(106,2 \%)$, Bahia $(90,0)$, São Paulo (80,4\%), Rio Grande do Sul (93,5\%), Mato Grosso do Sul (85,8\%). O menor desempenho foi o do Rio Grande do Norte (6,5\%) e os estados do Amapá, Paraíba e Rio de Janeiro não tiveram amostras coletadas. 
Até a semana 22/2013 a meta foi superada por $3(11,1 \%)$ estados. O maior percentual foi observado no Acre $(107,9 \%)$, seguido por Sergipe $(96,4 \%)$ e Mato Grosso do Sul (86,4\%). Não houve participação de 8 (29,6\%) estados: Roraima, Amapá, Rio Grande do Norte, Alagoas, Minas Gerais, Espírito Santo, Rio de Janeiro e Goiás. 
Tabela 4 - Número e percentual de amostras coletadas nas unidades sentinelas de influenza. Sivep-Gripe, Brasil, 2010-2013

\begin{tabular}{|c|c|c|c|c|c|c|c|c|c|c|c|c|c|c|c|c|c|c|c|c|c|c|c|c|c|}
\hline \multirow{3}{*}{ UF } & \multicolumn{5}{|c|}{2010} & \multicolumn{5}{|c|}{2011} & \multicolumn{5}{|c|}{2012} & \multicolumn{5}{|c|}{$2013^{*}$} & \multicolumn{5}{|c|}{$2010-2013^{*}$} \\
\hline & \multirow{2}{*}{$\begin{array}{l}\mathbf{N}^{\circ} \\
\text { US }\end{array}$} & \multicolumn{2}{|c|}{ Amostras } & \multicolumn{2}{|c|}{ Meta } & \multirow{2}{*}{$\begin{array}{l}\mathbf{N}^{\circ} \\
\text { US }\end{array}$} & \multicolumn{2}{|c|}{ Amostras } & \multicolumn{2}{|c|}{ Meta } & \multirow{2}{*}{$\begin{array}{l}\mathbf{N}^{\circ} \\
\text { US }\end{array}$} & \multicolumn{2}{|c|}{ Amostras } & \multicolumn{2}{|c|}{ Meta } & \multirow{2}{*}{$\begin{array}{l}\mathbf{N}^{\circ} \\
\text { US }\end{array}$} & \multicolumn{2}{|c|}{ Amostras } & \multicolumn{2}{|c|}{ Meta } & Med & Amos & stras & $\mathrm{Me}$ & \\
\hline & & $\mathrm{n}$ & $\%$ & $\mathbf{n}$ & $\%$ & & $\mathbf{n}$ & $\%$ & $\mathrm{n}$ & $\%$ & & $n$ & $\%$ & $\mathbf{n}$ & $\%$ & & $\mathbf{n}$ & $\%$ & $\mathbf{n}$ & $\%$ & & $\mathrm{n}$ & $\%$ & $\mathbf{n}$ & $\%$ \\
\hline Rondônia & 3 & 355 & 31.6 & 780 & 45.5 & 2 & 335 & 29.9 & 520 & 64.4 & 2 & 349 & 31.1 & 520 & 67.1 & 2 & 83 & 7.4 & 220 & 37.7 & 2.0 & 1122 & 17.1 & 1780 & 63.0 \\
\hline Acre & 2 & 214 & 9.9 & 520 & 41.2 & 1 & 547 & 25.4 & 260 & 210.4 & 3 & 1038 & 48.2 & 780 & 133.1 & 3 & 356 & 16.5 & 330 & 107.9 & 2.5 & 2155 & 32.8 & 2225 & 96.9 \\
\hline Amazonas & 2 & 155 & 14.1 & 520 & 29.8 & 3 & 271 & 24.6 & 780 & 34.7 & 4 & 550 & 49.9 & 1040 & 52.9 & 2 & 126 & 11.4 & 220 & 57.3 & 2.5 & 1102 & 16.8 & 2225 & 49.5 \\
\hline Roraima & 6 & 405 & 33.5 & 1560 & 26.0 & 3 & 300 & 24.8 & 780 & 38.5 & 3 & 505 & 41.7 & 780 & 64.7 & & & & & & 3.0 & 1210 & 18.4 & 2670 & 45.3 \\
\hline Pará & 2 & 99 & 31.9 & 520 & 19.0 & 1 & 1 & 0.3 & 260 & 0.4 & 1 & 186 & 60.0 & 260 & 71.5 & 1 & 24 & 7.7 & 110 & 21.8 & 1.0 & 310 & 4.7 & 890 & 34.8 \\
\hline Amapá & 1 & 3 & 100.0 & 260 & 1.2 & & & & & & & & & & & & & & & & 1.0 & 3 & 0.0 & 890 & 0.3 \\
\hline Tocantins & 3 & 218 & 32.5 & 780 & 27.9 & 2 & 280 & 41.7 & 520 & 53.8 & 2 & 129 & 19.2 & 520 & 24.8 & 2 & 44 & 6.6 & 220 & 20.0 & 2.0 & 671 & 10.2 & 1780 & 37.7 \\
\hline Norte & 19 & 1449 & 22.0 & 4940 & 29.3 & 12 & 1734 & 26.4 & 3120 & 55.6 & 15 & 2757 & 41.9 & 3900 & 70.7 & 10 & 633 & 9.6 & 1100 & 57.5 & 13.5 & 6573 & 100.0 & 12015 & 54.7 \\
\hline Maranhão & 3 & 205 & 30.0 & 780 & 26.3 & 2 & 230 & 33.7 & 520 & 44.2 & 2 & 163 & 23.9 & 520 & 31.3 & 1 & 85 & 12.4 & 110 & 77.3 & 2.0 & 683 & 8.6 & 1780 & 38.4 \\
\hline Piaui & 3 & 351 & 26.4 & 780 & 45.0 & 2 & 512 & 38.5 & 520 & 98.5 & 2 & 396 & 29.8 & 520 & 76.2 & 1 & 70 & 5.3 & 110 & 63.6 & 2.0 & 1329 & 16.7 & 1780 & 74.7 \\
\hline Ceará & 4 & 466 & 29.6 & 1040 & 44.8 & 2 & 507 & 32.2 & 520 & 97.5 & 2 & 571 & 36.2 & 520 & 109.8 & 1 & 32 & 2.0 & 110 & 29.1 & 2.0 & 1576 & 19.8 & 1780 & 88.5 \\
\hline Rio Grande do Norte & 3 & 111 & 50.9 & 780 & 14.2 & 2 & 73 & 33.5 & 520 & 14.0 & 2 & 34 & 15.6 & 520 & 6.5 & & & & & & 2.0 & 218 & 2.7 & 1780 & 12.2 \\
\hline Paraíba & 1 & 4 & 100.0 & 260 & 1.5 & & & & & & & & & & & & & & & & 1.0 & 4 & 0.1 & 890 & 0.4 \\
\hline Pernambuco & 3 & 385 & 24.7 & 780 & 49.4 & 2 & 478 & 30.7 & 520 & 91.9 & 2 & 522 & 33.5 & 520 & 100.4 & 2 & 171 & 11.0 & 220 & 77.7 & 2.0 & 1556 & 19.5 & 1780 & 87.4 \\
\hline Alagoas & 1 & 71 & 48.6 & 260 & 27.3 & 1 & 34 & 23.3 & 260 & 13.1 & 1 & 41 & 28.1 & 260 & 15.8 & & & & & & 1.0 & 146 & 1.8 & 890 & 16.4 \\
\hline Sergipe & 4 & 552 & 32.2 & 1040 & 53.1 & 3 & 504 & 29.4 & 780 & 64.6 & 2 & 552 & 32.2 & 520 & 106.2 & 1 & 106 & 6.2 & 110 & 96.4 & 2.5 & 1714 & 21.5 & 2225 & 77.0 \\
\hline Bahia & 3 & 240 & 32.3 & 780 & 30.8 & 1 & 202 & 27.2 & 260 & 77.7 & 1 & 234 & 31.5 & 260 & 90.0 & 1 & 67 & 9.0 & 110 & 60.9 & 1.0 & 743 & 9.3 & 890 & 83.5 \\
\hline Nordeste & 25 & 2385 & 29.9 & 6500 & 36.7 & 15 & 2540 & 31.9 & 3900 & 65.1 & 14 & 2513 & 31.5 & 3640 & 69.0 & 7 & 531 & 6.7 & 770 & 69.0 & 14.5 & 7969 & 100.0 & 12905 & 61.8 \\
\hline Minas Gerais & 4 & 111 & 16.5 & 1040 & 10.7 & 3 & 264 & 39.3 & 780 & 33.8 & 3 & 297 & 44.2 & 780 & 38.1 & & & & & & 3.0 & 672 & 8.3 & 2670 & 25.2 \\
\hline Espirito Santo & 1 & 43 & 22.6 & 260 & 16.5 & 1 & 106 & 55.8 & 260 & 40.8 & 1 & 41 & 21.6 & 260 & 15.8 & & & & & & 1.0 & 190 & 2.3 & 890 & 21.3 \\
\hline Rio de Janeiro & 3 & 70 & 34.0 & 780 & 9.0 & 3 & 136 & 66.0 & 780 & 17.4 & & & & & & & & & & & 3.0 & 206 & 2.5 & 2670 & 7.7 \\
\hline São Paulo & 15 & 1991 & 28.4 & 3900 & 51.1 & 10 & 2300 & 32.8 & 2600 & 88.5 & 10 & 2090 & 29.8 & 2600 & 80.4 & 10 & 638 & 9.1 & 1100 & 58.0 & 10.0 & 7019 & 86.8 & 8900 & 78.9 \\
\hline Sudeste & 23 & 2215 & 27.4 & 5980 & 37.0 & 17 & 2806 & 34.7 & 4420 & 63.5 & 14 & 2428 & 30.0 & 3640 & 66.7 & 10 & 638 & 7.9 & 1100 & 58.0 & 15.5 & 8087 & 100.0 & 13795 & 58.6 \\
\hline Paraná & 5 & 395 & 27.8 & 1300 & 30.4 & 6 & 434 & 30.6 & 1560 & 27.8 & 3 & 502 & 35.4 & 780 & 64.4 & 2 & 88 & 6.2 & 220 & 40.0 & 4.0 & 1419 & 36.3 & 3560 & 39.9 \\
\hline Santa Catarina & 6 & 173 & 28.1 & 1560 & 11.1 & 4 & 125 & 20.3 & 1040 & 12.0 & 3 & 283 & 45.9 & 780 & 36.3 & 3 & 35 & 5.7 & 330 & 10.6 & 3.5 & 616 & 15.8 & 3115 & 19.8 \\
\hline Rio Grande do Sul & 6 & 388 & 20.7 & 1560 & 24.9 & 4 & 545 & 29.1 & 1040 & 52.4 & 3 & 729 & 38.9 & 780 & 93.5 & 3 & 213 & 11.4 & 330 & 64.5 & 3.5 & 1875 & 48.0 & 3115 & 60.2 \\
\hline Sul & 17 & 956 & 24.5 & 4420 & 21.6 & 14 & 1104 & 28.2 & 3640 & 30.3 & 9 & 1514 & 38.7 & 2340 & 64.7 & 8 & 336 & 8.6 & 880 & 38.2 & 11.5 & 3910 & 100.0 & 10235 & 38.2 \\
\hline Mato Grosso do Sul & 4 & 378 & 25.9 & 1040 & 36.3 & 2 & 444 & 30.5 & 520 & 85.4 & 2 & 446 & 30.6 & 520 & 85.8 & 2 & 190 & 13.0 & 220 & 86.4 & 2.0 & 1458 & 41.1 & 1780 & 81.9 \\
\hline Mato Grosso & 2 & 69 & 31.9 & 520 & 13.3 & 2 & 40 & 18.5 & 520 & 7.7 & 2 & 91 & 42.1 & 520 & 17.5 & 1 & 16 & 7.4 & 110 & 14.5 & 2.0 & 216 & 6.1 & 1780 & 12.1 \\
\hline Goiás & 3 & 122 & 34.2 & 780 & 15.6 & 2 & 102 & 28.6 & 520 & 19.6 & 1 & 133 & 37.3 & 260 & 51.2 & & & & & & 2.0 & 357 & 10.1 & 1780 & 20.1 \\
\hline Distrito Federal & 5 & 397 & 26.1 & 1300 & 30.5 & 2 & 445 & 29.3 & 520 & 85.6 & 4 & 597 & 39.3 & 1040 & 57.4 & 2 & 80 & 5.3 & 220 & 36.4 & 3.0 & 1519 & 42.8 & 2670 & 56.9 \\
\hline Centro-Oeste & 14 & 966 & 27.2 & 3640 & 26.5 & 8 & 1031 & 29.0 & 2080 & 49.6 & 9 & 1267 & 35.7 & 2340 & 54.1 & 5 & 286 & 8.1 & 550 & 52.0 & 8.5 & 3550 & 100.0 & 7565 & 46.9 \\
\hline Brasil & 98 & 7971 & 26.5 & 25480 & 31.3 & 66 & 9215 & 30.6 & 17160 & 53.7 & 61 & 10479 & 34.8 & 15860 & 66.1 & 40 & 2424 & 8.1 & 4400 & 55.1 & 63.5 & 30089 & 100.0 & 56515 & 53.2 \\
\hline
\end{tabular}

*até a Semana Epidemiológica 22/2013 / № de US = Número de Unidades Sentinelas / Med = № Médio de US 


\subsubsection{Estudo dos atributos quantitativos}

\subsection{Valor Preditivo Positivo}

O valor preditivo positivo (VPP) indica a proporção e casos notificados no sistema que são realmente casos confirmados. Para avaliação do VPP foi verificada a proporção dos casos considerados positivos (com base no resultado do exame de imunofluorescência indireta) entre o total de casos registrados de síndrome gripal que tiveram amostra coletadas para exame laboratorial. A positividade foi considerada insatisfatória em todos os anos do período estudado e para todos os vírus respiratórios, conforme demonstra a Tabela 1.

No período estudado, 2010 a 2013, nas US foram coletadas 30.089 amostras de secreção de nasofaringe de pacientes com síndrome gripal. Dessas amostras, cerca de $15,4 \%$ (4.623) foram positivas para vírus respiratórios, sendo $23,5 \%$ (1085/4623) positivas para o vírus influenza A; 11,4\% (525/4623) influenza B; 4,4\% (203/4623) parainfluenza $1 ; 2,9 \%(136 / 4623)$ parainfluenza 2; 7,1\% (329/4623) parainfluenza 3; adenovírus 14,8\% (684/4623); e 35,9\% (1661/4623) vírus respiratório sincicial. Em relação ao número total de amostras, a positividade encontrada foi de 3,6\% (1.085) para vírus influenza $A ; 1,7 \%$ (525) para influenza $B$; 0,7\% (203) para vírus parainfluenza $1 ; 0,5 \%$ (136) parainfluenza 2; $1,1 \%$ (329) parainfluenza 3; 2,3\% (684) adenovírus; 5,5\% (1.661) vírus respiratório sincicial. Em aproximadamente $7 \%$ das amostras não foram realizados os exames laboratoriais e $20 \%$ tiveram resultados inconclusivos. Foram negativos os resultados de $84,6 \%$ a $89,5 \%$ das amostras processadas para cada um dos vírus respiratório (Tabelas 1 e $6)$.

\subsection{Representatividade}

A representatividade do sistema reflete a capacidade de descrição da ocorrência do evento sanitário ao longo do tempo e sua distribuição na população por lugar e pessoa. Mesmo que para influenza sazonal seja utilizada uma estratégia 
de vigilância sentinela, a identificação da circulação dos vírus deve ser de forma representativa e considerar tempo, lugar e pessoa.

Considerando o parâmetro populacional para implantação da vigilância sentinela de SG preconizado na Portaria MS/2.693/2011 (Quadro 2), foi estimado o número de US. A representatividade foi classificada como insatisfatória.

Tabela 5 - Resultados da imunofluorescência indireta para vírus respiratórios. Sivep-Gripe, Brasil, 2010-2013

\begin{tabular}{|c|c|c|c|c|c|c|c|c|c|c|c|c|}
\hline \multirow{3}{*}{$\stackrel{\circ}{\frac{1}{4}}$} & \multirow{3}{*}{$\begin{array}{l}\text { Total de } \\
\text { Amostras }\end{array}$} & \multirow{3}{*}{ Vírus } & \multicolumn{10}{|c|}{ Resultado da Imunofluorescência Indireta } \\
\hline & & & \multicolumn{2}{|c|}{ Positivo } & \multicolumn{2}{|c|}{ Negativo } & \multicolumn{2}{|c|}{ Inconclusivo } & \multicolumn{2}{|c|}{$\begin{array}{c}\text { Não } \\
\text { realizado }\end{array}$} & \multicolumn{2}{|c|}{$\begin{array}{l}\text { Sem } \\
\text { Informação }\end{array}$} \\
\hline & & & $\mathrm{n}$ & $\%$ & $n$ & $\%$ & $n$ & $\%$ & $\mathbf{n}$ & $\%$ & $\mathbf{n}$ & $\%$ \\
\hline \multirow{6}{*}{ 울 } & \multirow{6}{*}{7.971} & Flu A & 253 & 3,2 & 6.775 & 85,0 & 208 & 2,6 & 704 & 8,8 & 31 & 0,4 \\
\hline & & Flu B & 213 & 2,7 & 6.815 & 85,5 & 209 & 2,6 & 703 & 8,8 & 31 & 0,4 \\
\hline & & Para 1 & 71 & 0,9 & 7.017 & 88,0 & 209 & 2,6 & 643 & 8,1 & 31 & 0,4 \\
\hline & & Para 2 & 57 & 0,7 & 7.034 & 88,2 & 206 & 2,6 & 642 & 8,1 & 32 & 0,4 \\
\hline & & Adeno & 147 & 1,8 & 6.943 & 87,1 & 202 & 2,5 & 642 & 8,1 & 37 & 0,5 \\
\hline & & VRS & 430 & 5,4 & 6.657 & 83,5 & 204 & 2,6 & 643 & 8,1 & 37 & 0,5 \\
\hline \multirow{6}{*}{$\overline{\check{N}}$} & \multirow{6}{*}{9.215} & Flu A & 376 & 4,1 & 7.821 & 84,9 & 245 & & 735 & 8,0 & 38 & 0,4 \\
\hline & & Flu B & 195 & 2,1 & 8.005 & 86,9 & 244 & 2,6 & 733 & 8,0 & 38 & 0,4 \\
\hline & & Para 1 & 52 & 0,6 & 8.167 & 88,6 & 237 & 2,6 & 721 & 7,8 & 38 & 0,4 \\
\hline & & Para 2 & 39 & 0,4 & 8.176 & 88,7 & 240 & 2,6 & 721 & 7,8 & 39 & 0,4 \\
\hline & & Adeno & 134 & 1,5 & 8.078 & 87,7 & 239 & 2,6 & 721 & 7,8 & 43 & 0,5 \\
\hline & & VRS & 538 & 5,8 & 7.674 & 83,3 & 242 & 2,6 & 717 & 7,8 & 44 & 0,5 \\
\hline \multirow{6}{*}{ ָั } & \multirow{6}{*}{10.479} & & 372 & 3,5 & 9.262 & 88 & 39 & & 424 & 4,0 & 23 & 0,2 \\
\hline & & Flu B & 89 & 0,8 & 9.552 & 91,2 & 393 & 3,8 & 422 & 4,0 & 23 & 0,2 \\
\hline & & Para 1 & 72 & 0,7 & 9.575 & 91,4 & 386 & 3,7 & 423 & 4,0 & 23 & 0,2 \\
\hline & & Para 2 & 33 & 0,3 & 9.614 & 91,7 & 388 & 3,7 & 420 & 4,0 & 24 & 0,2 \\
\hline & & Adeno & 320 & 3,1 & 9.320 & 88,9 & 389 & 3,7 & 422 & 4,0 & 28 & 0,3 \\
\hline & & VRS & 501 & 4,8 & 9.139 & 87,2 & 388 & 3,7 & 422 & 4,0 & 29 & 0,3 \\
\hline \multirow{6}{*}{ 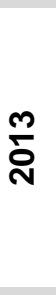 } & \multirow{6}{*}{2.424} & Flu A & 84 & 3,5 & 2.079 & 85,8 & 5 & & 197 & 8,1 & 7 & 0,3 \\
\hline & & Flu B & 28 & 1,2 & 2.138 & 88,2 & 55 & 2,3 & 196 & 8,1 & 7 & 0,3 \\
\hline & & Para 1 & 8 & 0,3 & 2.158 & 89,0 & 55 & 2,3 & 196 & 8,1 & 7 & 0,3 \\
\hline & & Para 2 & 7 & 0,3 & 2.159 & 89,1 & 54 & 2,2 & 197 & 8,1 & 7 & 0,3 \\
\hline & & Adeno & 83 & 3,4 & 2.082 & 85,9 & 57 & 2,4 & 195 & 8,0 & 7 & 0,3 \\
\hline & & VRS & 192 & 7,9 & 1.975 & 81,5 & 54 & 2,2 & 196 & 8,1 & 7 & 0,3 \\
\hline \multirow{6}{*}{ 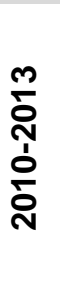 } & \multirow{6}{*}{30.089} & Flu A & 1.085 & 3,6 & 25.937 & 86,2 & 908 & 3,0 & 2060 & 6,8 & 99 & 0,3 \\
\hline & & Flu B & 525 & 1,7 & 26.510 & 88,1 & 901 & 3,0 & 2054 & 6,8 & 99 & 0,3 \\
\hline & & Para 1 & 203 & 0,7 & 26.917 & 89,5 & 887 & 2,9 & 1983 & 6,6 & 99 & 0,3 \\
\hline & & Para 2 & 136 & 0,5 & 26.983 & 89,7 & 888 & 3,0 & 1980 & 6,6 & 102 & 0,3 \\
\hline & & Adeno & 684 & 2,3 & 26.423 & 87,8 & 887 & 2,9 & 1980 & 6,6 & 115 & 0,4 \\
\hline & & VRS & 1.661 & 5,5 & 25.445 & 84,6 & 888 & 3,0 & 1978 & 6,6 & 117 & 0,4 \\
\hline
\end{tabular}


$\mathrm{Na}$ Tabela 6 pode ser verificada a distribuição do número de US notificantes por município, estado, região, extensão territorial, população e densidade demográfica, com base nos dados do Instituto Brasileiro de Geografia e Estatística (IBGE) $(17,18)$.

A comparação do número estimado e do número médio de US existentes indicou que 11 (40\%) capitais estão deficitárias: Manaus, Belém, São Luís, Fortaleza, Recife, Salvador, Belo Horizonte, Rio de Janeiro, São Paulo, Curitiba e Distrito Federal.

Há nas diversas regiões metropolitanas (RM) do país, 27 municípios que tinham mais de 300.000 habitantes em 2010 localizados em RM de capitais estaduais e que deveriam ter US implantadas: na Região Norte, somente Ananindeua/PA (RM de Belém); na Região Nordeste, Caucaia/CE (RM de Fortaleza), Jaboatão dos Guararapes, Olinda e Paulista/PE (na RM de Recife), na região Centro-Oeste, somente Aparecida/GO (RM de Goiânia); na Região Sudeste, Cariacica, Serra e Vila Velha/ES (na RM de Vitória); Betim e Contagem/MG (na RM de Belo Horizonte); Belford Roxo, Duque de Caxias, Niterói, Nova Iguaçu, São Gonçalo e São João de Meriti/RJ (na RM do Rio de Janeiro); e Carapicuíba, Diadema, Guarulhos, Itaquaquecetuba, Mauá, Mogi das Cruzes, Osasco, Santo André e São Bernardo do Campo/SP (na RM de São Paulo). Na região Sul, o município de Canoas faz parte da RM de Porto Alegre e é o único que tinha mais de 300.000 habitantes em 2010 dentre as RM das capitais. Ou seja, dessas 27 cidades, pertencentes a RM de capitais estaduais, 7,4 \% (2/27) delas tem US para influenza sazonal (Quadro 4). 


\begin{tabular}{|c|c|c|c|c|}
\hline Região & Região Metropolitana & Município & $\begin{array}{c}\text { População } \\
\text { em } 2010 \\
\text { (hab.) }\end{array}$ & $\begin{array}{c}\text { № de } \\
\text { US }\end{array}$ \\
\hline \multirow{2}{*}{ Norte } & Belém do Pará/PA & Ananindeua & 471.980 & $1^{*}$ \\
\hline & Manaus/AM & - & - & - \\
\hline \multirow{10}{*}{ Nordeste } & Maceió/AL & - & - & - \\
\hline & Salvador/BA & - & - & - \\
\hline & Fortaleza/CE & Caucaia & 325.441 & 0 \\
\hline & São Luís/MA & - & - & - \\
\hline & João Pessoa/PB & - & - & - \\
\hline & \multirow{3}{*}{ Recife/PE } & Jaboatão dos Guararapes & 644.620 & 0 \\
\hline & & Olinda & 377.779 & 0 \\
\hline & & Paulista & 300.466 & 0 \\
\hline & Natal/RN & - & - & - \\
\hline & Aracajú/SE & - & - & - \\
\hline \multirow{2}{*}{ Centro-Oeste } & Goiânia/GO & Aparecida & 455.657 & 0 \\
\hline & Vale do Rio Cuiabá/GO & - & - & - \\
\hline \multirow{21}{*}{ Sudeste } & \multirow{3}{*}{ Vitória/ES } & Cariacica & 348.738 & 0 \\
\hline & & Serra & 409.267 & 0 \\
\hline & & Vila Velha & 414.586 & 0 \\
\hline & \multirow{2}{*}{ Belo Horizonte/MG } & Betim & 378.089 & 0 \\
\hline & & Contagem & 603.442 & 0 \\
\hline & \multirow{6}{*}{ Rio de Janeiro/RJ } & Belford Roxo & 469.332 & 0 \\
\hline & & Duque de Caxias & 855.048 & 0 \\
\hline & & Niterói & 487.562 & 0 \\
\hline & & Nova Iguaçu & 796.257 & 0 \\
\hline & & São Gonçalo & 999.728 & 0 \\
\hline & & São João de Meriti & 358.673 & 0 \\
\hline & \multirow{9}{*}{ São Paulo/SP } & Carapicuíba & 369.584 & 0 \\
\hline & & Diadema & 386.089 & 0 \\
\hline & & Guarulhos & 1.221 .979 & 1 \\
\hline & & Itaquaquecetuba & 321.770 & 0 \\
\hline & & Mauá & 417.064 & 0 \\
\hline & & Mogi das Cruzes & 387.779 & 0 \\
\hline & & Osasco & 666.740 & 0 \\
\hline & & Santo André & 676.407 & 0 \\
\hline & & São Bernardo do Campo & 765.463 & 0 \\
\hline & Porto Alegre/RS & Canoas & 323.827 & 0 \\
\hline \multicolumn{4}{|c|}{ Total de Unidades Sentinelas } & 2 \\
\hline
\end{tabular}

Quadro 4 - Distribuição de Unidades Sentinelas de síndrome gripal por Região Metropolitana de capital estadual, em municípios com mais de 300 mil habitantes. Brasil, 2010-2013

(-) Não se aplica. Município com menos de 300 mil hab.

${ }^{*}$ Constam apenas 2 coletas em 2010

**322.600 hab. em 2015

Nos estados do Sul, além das duas capitais com mais de 1 milhão de habitantes, Curitiba e Porto Alegre, Florianópolis tinha 421.000 hab. em 2010. Das cidades não pertencentes a regiões metropolitanas (RM), havia 7 municípios com 
mais de 300.000 habitantes em 2010: Londrina, Maringá e Ponta Grossa/PR; Blumenau e Joinville/SC; Caxias do Sul e Pelotas/RS. A rigor, todos esses municípios deveriam ter US, mas somente Caxias do Sul possuía. Para esse parâmetro, 14,3\% (1/7) dos municípios participavam da rede sentinela de SG (Quadro 5).

\begin{tabular}{|c|c|c|c|}
\hline Estado & Município & $\begin{array}{l}\text { População em } 2010 \\
\text { (hab.) }\end{array}$ & № de US \\
\hline \multirow{3}{*}{ Paraná } & Londrina & 506.701 & 0 \\
\hline & Maringá & 357.077 & 0 \\
\hline & Ponta Grossa & 311.611 & 0 \\
\hline \multirow{2}{*}{ Santa Catarina } & Blumenau & 309.011 & 0 \\
\hline & Joinville & 515.288 & 0 \\
\hline \multirow{2}{*}{ Rio Grande do Sul } & Caxias do Sul & 435.564 & 1 \\
\hline & Pelotas & 328.275 & 0 \\
\hline \multicolumn{3}{|c|}{ Total de Unidades Sentinelas } & 1 \\
\hline
\end{tabular}

Quadro 5 - Distribuição de Unidades Sentinelas de síndrome gripal em municípios da Região Sul com mais de 300 mil habitantes

Merecem atenção situações de não adequação do município ao indicador: cidade com mais de 300 mil habitantes que não pertence à RM de capital (Ex. Santos/SP); cidade de RM de capital com mais de 1 milhão de habitantes (Ex. Guarulhos/SP); e cidade de RM, não de capital, com mais de 1 milhão de habitantes (Ex. Campinas/SP, Caxias do Sul/RS). Esses municípios são polos econômicos importantes com intenso fluxo de pessoas, o que favorece a dispersão de vírus respiratórios.

Outra situação são municípios que possuem US, mas não se enquadram não parâmetros como: Foz do Iguaçu/PR, que conta com 1 US e a população, em 2010, era de 256.088 hab.; e Uruguaiana/RS também com 1 US e com 125.435 hab. Já Canoas/RS que não tem US, é duplamente qualificada: é cidade de RM de capital e cidade sulista com mais de 300 mil hab. 
Tabela 6 - Distribuição do número de US por município, estado, região, extensão territorial, população e densidade demográfica (continua)

\begin{tabular}{|c|c|c|c|c|c|c|c|c|c|}
\hline UF / Região & Município & Área (Km2) & $\begin{array}{c}\text { População } \\
2010\end{array}$ & $\begin{array}{c}\mathrm{Hab} / \mathrm{Km} 2 \\
2010\end{array}$ & $\begin{array}{l}\% \text { da } \\
\text { Popul. } \\
\text { Brasil }\end{array}$ & $\begin{array}{c}\text { No } \\
\text { Médio } \\
\text { de US }\end{array}$ & $\begin{array}{c}N^{\circ} \text { Médio } \\
\text { US/Pop. Mun. } \\
\text { por } 100.000 \\
\text { hab }\end{array}$ & $\begin{array}{l}\text { No Médio } \\
\text { US/ Dens. } \\
\text { Pop. }\end{array}$ & $\begin{array}{c}N^{\circ} \text { US } \\
\text { estimado } \\
\text { Portaria }\end{array}$ \\
\hline & \multirow[t]{2}{*}{ Porto Velho } & $34,096.4$ & $428,527.0$ & 12.6 & 0.2 & 2 & 0.5 & 0.2 & \\
\hline Acre & & $164,123.7$ & $733,559.0$ & 4.5 & 0.4 & 2.5 & 0.3 & 0.6 & \\
\hline & \multirow[t]{2}{*}{ Rio Branco } & $8,835.54$ & 336,038 & 38.0 & 0.2 & 1 & 0.3 & 0.0 & \\
\hline Amazonas & & $1,559,148.9$ & $3,483,985.0$ & 2.2 & 1.8 & 2.5 & 0.1 & 1.1 & \\
\hline & \multirow[t]{2}{*}{ Boa Vista } & $5,687.0$ & $284,313.0$ & 50.0 & 0.1 & 1 & 0.4 & 0.0 & \\
\hline Pará & & $1,247,954.3$ & $7,581,051.0$ & 6.1 & 4.0 & 1 & 0.0 & 0.2 & \\
\hline & \multirow[t]{2}{*}{ Belém } & $1,059.5$ & $1,393,399.0$ & 1315.3 & 0.7 & 1 & 0.1 & 0.0 & 2 \\
\hline Amapá & & $142,828.5$ & $669,526.0$ & 4.7 & 0.4 & 1 & 0.1 & 0.2 & \\
\hline & \multirow[t]{2}{*}{ Macapá } & $6,502.12$ & $398,204.0$ & 62.1 & 0.4 & 1 & 0.3 & 0.0 & \\
\hline Tocantins & & $277,720.6$ & $1,383,445.0$ & 5.0 & 0.7 & 2 & 0.1 & 0.4 & \\
\hline & \multirow[t]{2}{*}{ Palmas } & $2,218.94$ & 228,332 & 102.9 & 0.1 & 1 & 0.4 & 0.0 & \\
\hline Região Norte & & $3,853,669.8$ & $15,864,454.0$ & 4.1 & 8.3 & 13.5 & 0.1 & 3.3 & \\
\hline Ceará & Teresina & $148,886.3$ & $8,452,381.0$ & 56.8 & 4.4 & 2 & 0.0 & 0.0 & \\
\hline & \multirow[t]{2}{*}{ Fortaleza } & 314.93 & $2,452,185$ & 7786.4 & 1.3 & 2 & 0.1 & 0.0 & 4 \\
\hline Rio Grande do Norte & & $52,811.1$ & $3,168,027.0$ & 60.0 & 1.7 & 2 & 0.1 & 0.0 & \\
\hline & \multirow[t]{2}{*}{ Natal } & 167.264 & 803,739 & 4805.2 & 0.4 & 2 & 0.2 & 0.0 & 1 \\
\hline Paraíba & & $56,469.7$ & $3,766,528.0$ & 66.7 & 2.0 & 1 & 0.0 & 0.0 & \\
\hline & \multirow[t]{2}{*}{ João Pessoa } & 211.475 & 723,515 & 3421.3 & 0.4 & 1 & 0.1 & 0.0 & 1 \\
\hline Pernambuco & & $98,149.1$ & $8,796,448.0$ & 89.6 & 4.6 & 2 & 0.0 & 0.0 & \\
\hline Alagoas & Recife & $\begin{array}{r}218.435 \\
27,775.0\end{array}$ & $\begin{array}{r}1,537,704 \\
3,120,494.0\end{array}$ & $\begin{array}{r}7039.6 \\
112.3\end{array}$ & $\begin{array}{l}0.8 \\
1.6\end{array}$ & $\begin{array}{l}2 \\
1\end{array}$ & $\begin{array}{l}0.1 \\
0.0\end{array}$ & $\begin{array}{l}0.0 \\
0.0\end{array}$ & 3 \\
\hline & \multirow[t]{2}{*}{ Maceió } & 509.876 & $932,748.0$ & $1,854.1$ & 0.5 & 1 & 0.1 & 0.0 & 1 \\
\hline Sergipe & & $21,918.5$ & $2,068,017.0$ & 94.4 & 1.1 & 2.5 & 0.1 & 0.0 & \\
\hline Bahia & Aracajú & $\begin{array}{r}181.857 \\
564,733.1\end{array}$ & $\begin{array}{r}571,149 \\
14,016,906.0\end{array}$ & $\begin{array}{r}3140.7 \\
24.8\end{array}$ & $\begin{array}{l}0.3 \\
7.3\end{array}$ & $\begin{array}{l}1 \\
1\end{array}$ & $\begin{array}{l}0.2 \\
0.0\end{array}$ & $\begin{array}{l}0.0 \\
0.0\end{array}$ & 1 \\
\hline & Salvador & 692.819 & $2,675,656$ & 3859.4 & 1.4 & 1 & 0.0 & 0.0 & 5 \\
\hline
\end{tabular}

Fonte: Instituto Brasileiro de Geografia e Estatística - IBGE 
Tabela 6 - Distribuição do número de US por município, estado, região, extensão territorial, população e densidade demográfica (continuação)

\begin{tabular}{|c|c|c|c|c|c|c|c|c|c|}
\hline UF / Região & Município & Área (Km2) & $\begin{array}{c}\text { População } \\
2010\end{array}$ & $\begin{array}{c}\mathrm{Hab} / \mathrm{Km} 2 \\
2010\end{array}$ & $\begin{array}{l}\% \text { da } \\
\text { Popul. } \\
\text { Brasil }\end{array}$ & $\begin{array}{l}\text { No } \\
\text { Médio } \\
\text { de US }\end{array}$ & $\begin{array}{c}N^{\circ} \text { Médio } \\
\text { US/Pop. Mun. } \\
\text { por } 100.000 \\
\text { hab }\end{array}$ & $\begin{array}{l}\text { No Médio } \\
\text { US/ Dens. } \\
\text { Pop. }\end{array}$ & $\begin{array}{c}\text { No US } \\
\text { estimado } \\
\text { Portaria }\end{array}$ \\
\hline \multirow[t]{3}{*}{ Minas Gerais } & & $586,519.7$ & $19,597,330.0$ & 33.4 & 10.3 & 3 & 0.0 & 0.1 & \\
\hline & Belo Horizonte & 331.4 & $2,375,151.0$ & 7167.0 & 1.2 & 2 & 0.1 & 0.0 & 4 \\
\hline & Pouso Alegre & 543.068 & 130,615 & 240.5 & 0.1 & 1 & 0.8 & 0.0 & \\
\hline \multirow[t]{2}{*}{ Espírito Santo } & & $46,096.9$ & $3,514,952.0$ & 76.3 & 1.8 & 1 & 0.0 & 0.0 & \\
\hline & Vitória & 98.194 & 327,801 & 3338.3 & 0.2 & 1 & 0.3 & 0.0 & \\
\hline \multirow[t]{2}{*}{ Rio de Janeiro } & & $43,778.0$ & $15,989,929.0$ & 365.2 & 8.4 & 3 & 0.0 & 0.0 & \\
\hline & Rio de Janeiro & $1,197.46$ & $6,320,446$ & 5265.8 & 3.3 & 1 & 0.0 & 0.0 & 6 \\
\hline \multirow[t]{10}{*}{ São Paulo } & & $248,222.4$ & $41,262,199.0$ & 166.3 & 21.6 & 10 & 0.0 & 0.1 & \\
\hline & São Paulo & $1,521.1$ & $11,253,503.0$ & 7398.3 & 5.9 & 2 & 0.0 & 0.0 & 22 \\
\hline & Santos & 280.7 & $419,400.0$ & 1494.3 & 0.2 & 1 & 0.2 & 0.0 & 1 \\
\hline & Guarulhos & 318.7 & $1,221,979.0$ & 3834.5 & 0.6 & 1 & 0.1 & 0.0 & 1 \\
\hline & Campinas & 794.6 & $1,080,113.0$ & 1359.6 & 0.6 & 1 & 0.1 & 0.0 & 1 \\
\hline & Ribeirão Preto & 650.9 & $604,682.0$ & 928.9 & 0.3 & 1 & 0.2 & 0.0 & \\
\hline & São José do Rio Preto & 432.0 & $408,258.0$ & 945.1 & 0.2 & 1 & 0.2 & 0.0 & \\
\hline & Águas de São Pedro & 3.6 & $2,707.0$ & 488.9 & 0.0 & 1 & 36.9 & 0.0 & \\
\hline & Taubaté & 625.0 & $278,686.0$ & 446.0 & 0.1 & 1 & 0.4 & 0.0 & \\
\hline & Sorocaba & 450.4 & $586,625.0$ & 1304.2 & 0.3 & 1 & 0.2 & 0.0 & \\
\hline \multicolumn{2}{|l|}{ Região Sudeste } & $924,617.0$ & $80,364,410.0$ & 86.9 & 42.1 & 15.5 & 0.0 & 0.2 & \\
\hline \multirow[t]{3}{*}{ Paraná } & & $199,307.9$ & $10,444,526.0$ & 52.4 & 5.5 & 3 & 0.0 & 0.1 & \\
\hline & Curitiba & 435.0 & $1,751,907.0$ & 4027.0 & 0.9 & 2 & 0.1 & 0.0 & 3 \\
\hline & Foz do Iguaçu & 617.7 & $256,088.0$ & 414.6 & 0.1 & 1 & 0.4 & 0.0 & \\
\hline \multirow[t]{3}{*}{ Santa Catarina } & & $95,734.0$ & $6,248,436.0$ & 65.3 & 3.3 & 3.5 & 0.1 & 0.1 & \\
\hline & Florianópolis & 675.4 & $421,240.0$ & 623.7 & 0.2 & 3 & 0.7 & 0.0 & 1 \\
\hline & São José & 150.5 & $209,804.0$ & 1376.8 & 0.1 & 2 & 1.0 & 0.0 & \\
\hline \multirow[t]{4}{*}{ Rio Grande do Sul } & & $281,731.4$ & $10,693,929.0$ & 39.8 & 5.6 & 3.5 & 0.0 & 0.1 & \\
\hline & Porto Alegre & 496.7 & $1,409,351.0$ & 2837.5 & 0.7 & 2 & 0.1 & 0.0 & 2 \\
\hline & Caxias do Sul & $1,644.3$ & $435,564.0$ & 264.9 & 0.2 & 1 & 0.2 & 0.0 & 1 \\
\hline & Uruguaiana & $5,715.8$ & $125,435.0$ & 22.0 & 0.1 & 1 & 0.8 & 0.0 & \\
\hline Região Sul & & $586,508.7$ & $27,386,891.0$ & 48.6 & 14.4 & 11.5 & 0.0 & 0.2 & \\
\hline \multirow[t]{2}{*}{ Mato Grosso do Sul } & & $357,145.5$ & $2,449,024.0$ & 6.9 & 1.3 & 2 & 0.1 & 0.3 & \\
\hline & Campo Grande & $8,092.95$ & 786,797 & 97.2 & 0.4 & 2 & 0.3 & 0.0 & 1 \\
\hline \multirow[t]{2}{*}{ Mato Grosso } & & $903,378.3$ & $3,035,122.0$ & 3.4 & 1.6 & 2 & 0.1 & 0.6 & \\
\hline & Cuiabá & $3,495.42$ & 551,098 & 157.7 & 3.1 & 2 & 0.4 & 0.0 & 1 \\
\hline \multirow[t]{2}{*}{ Goiás } & & $340,111.4$ & $6,003,788.0$ & 17.7 & 3.1 & 2 & 0.0 & 0.1 & \\
\hline & Goiânia & 733.116 & $1,302,001$ & 1776.7 & 0.7 & 2 & 0.2 & 0.0 & 2 \\
\hline \multirow[t]{2}{*}{ Distrito Federal } & & $5,780.0$ & $2,570,160.0$ & 444.1 & 1.3 & 3 & 0.1 & 0.0 & \\
\hline & Brasília & $5,780.0$ & $2,570,160$ & 444.7 & 1.3 & 2 & 0.1 & 0.0 & 5 \\
\hline Região Centro-Oeste & $1,606,415.2$ & $1,618,736.7$ & $14,058,094.0$ & 8.8 & 7.4 & 8.5 & 0.1 & 1.0 & \\
\hline BRASIL & $8,515,767.0$ & $8,515,767.0$ & $190,755,799.0$ & 22.4 & 100.0 & 63.5 & 0.0 & 2.8 & \\
\hline
\end{tabular}

Fonte: Instituto Brasileiro de Geografia e Estatística - IBGE 


\subsection{Oportunidade}

Para avaliar a oportunidade, que é o intervalo de tempo transcorrido entre as etapas do sistema de vigilância da influenza, foi calculada a mediana da diferença, em dias, entre: 1) a data dos primeiros sintomas e a da coleta de amostra; 2) a data da coleta de amostra e a da realização do exame laboratorial.

Para monitorar o vírus e sua circulação, os resultados de tipificação do vírus influenza devem ser disponibilizados em tempo oportuno, principalmente por se tratar de doença aguda, com emprego de medidas de controle imediatas. O prazo entre o recebimento da amostra no Lacen e a liberação do resultado, está estimado em 7 dias, no Guia de Vigilância em Saúde vigente (1). Com base nessa estimativa oficial, assumimos que um dia é suficiente para o transporte da amostra até o laboratório e, por via de consequência, consideramos que o tempo de 8 ou mais dias de liberação do resultado é inoportuno.

Os resultados estão demonstrados na Tabela 7. A mediana do intervalo de tempo entre o início dos sintomas e a coleta foi de três dias, conforme preconizado, com variação de 0 a 738 dias. Em todos os estados foi observada uma boa oportunidade, com tempo menor que 5 dias. A boa oportunidade do resultado laboratorial foi evidenciada por mediana de 5 dias com número mínimo e máximo entre 5 a 389 dias. Em cinco estados (18,5\%) a mediana foi maior que 8 dias: Pará 23; Alagoas, 20; Pernambuco, 13; Rio de Janeiro, 10; Paraíba, 9; e Distrito Federal, 9.

\subsection{Sensibilidade}

Um sistema de vigilância sentinela não tem por objetivo a obtenção do universo dos casos da doença. $O$ interesse está no monitoramento das tendências ou estimativas do comportamento da doença em amostras da população. A sensibilidade de um sistema corresponde à sua capacidade de detecção dos casos verdadeiros da doença em uma população. Vale ressaltar que no Brasil não há outros sistemas para vigilância da influenza para poder estimar-se a sensibilidade. 
Tabela 7- Oportunidade da coleta de amostra e do resultado laboratorial: mediana em dias, por estado. Sivep-Gripe, Brasil, 2010-2013*

\begin{tabular}{|c|c|c|c|c|c|c|c|c|c|c|}
\hline \multirow{2}{*}{ UF } & \multicolumn{5}{|c|}{ Oportunidade da Coleta } & \multicolumn{5}{|c|}{ Oportunidade do Resultado } \\
\hline & Med & Min & Máx & $\begin{array}{c}\text { P1 } \\
(25 \%)\end{array}$ & $\begin{array}{c}\text { P3 } \\
(75 \%)\end{array}$ & Med & Min & Máx & $\begin{array}{c}\text { P1 } \\
(25 \%)\end{array}$ & $\begin{array}{c}\text { P3 } \\
(75 \%)\end{array}$ \\
\hline Rondônia & 3 & 3 & 368 & 1 & 3 & 2 & 0 & 8 & 1 & 3 \\
\hline Acre & 3 & 0 & 368 & 2 & 5 & 6 & 0 & 97 & 1 & 8 \\
\hline Amazonas & 2 & 0 & 371 & 1 & 4 & 5 & 0 & 222 & 2 & 6 \\
\hline Roraima & 3 & 0 & 370 & 2 & 4 & 7 & 0 & 367 & 3 & 11 \\
\hline Pará & 3 & 0 & 368 & 1 & 5 & 23 & 0 & 389 & 8 & 56 \\
\hline Amapá & 2 & 1 & 2 & 1 & 2 & 7 & 7 & 7 & 7 & 7 \\
\hline Tocantins & 3 & 0 & 20 & 2 & 3 & 5 & 0 & 37 & 2 & 7 \\
\hline Maranhão & 2 & 0 & 367 & 2 & 3 & 2 & 0 & 15 & 1 & 3 \\
\hline Piauí & 4 & 0 & 308 & 2 & 5 & 8 & 0 & 15 & 4 & 9 \\
\hline Ceará & 2 & 0 & 17 & 1 & 5 & 4 & 0 & 15 & 3 & 7 \\
\hline $\begin{array}{l}\text { Rio Grande do } \\
\text { Norte }\end{array}$ & 2 & 0 & 17 & 1 & 3 & 3 & 0 & 15 & 0 & 6 \\
\hline Paraíba & 3 & 3 & 5 & 3 & 4 & 9 & 5 & 13 & 5 & 13 \\
\hline Pernambuco & 3 & 0 & 735 & 2 & 4 & 13 & 0 & 312 & 8 & 20 \\
\hline Alagoas & 3 & 0 & 7 & 2 & 4 & 20 & 0 & 44 & 9 & 31 \\
\hline Sergipe & 3 & 0 & 369 & 2 & 4 & 7 & 0 & 387 & 1 & 14 \\
\hline Bahia & 2 & 0 & 373 & 1 & 3 & 5 & 0 & 346 & 3 & 8 \\
\hline Minas Gerais & 3 & 0 & 369 & 3 & 4 & 6 & 0 & 29 & 2 & 12 \\
\hline Espírito Santo & 2 & 0 & 39 & 1 & 4 & 1 & 0 & 16 & 0 & 1 \\
\hline Rio de Janeiro & 1 & 0 & 9 & 1 & 2 & 10 & 0 & 112 & 4 & 18 \\
\hline São Paulo & 2 & 0 & 733 & 1 & 4 & 2 & 0 & 126 & 1 & 5 \\
\hline Paraná & 2 & 0 & 374 & 1 & 3 & 2 & 0 & 159 & 2 & 3 \\
\hline Santa Catarina & 3 & 0 & 368 & 2 & 4 & 0 & 0 & 151 & 0 & 1 \\
\hline Rio Grande do Sul & 2 & 0 & 732 & 1 & 4 & 5 & 0 & 378 & 3 & 8 \\
\hline Mato Grosso do Sul & 2 & 0 & 733 & 1 & 3 & 4 & 0 & 161 & 2 & 6 \\
\hline Mato Grosso & 3 & 0 & 738 & 2 & 5 & 0 & 0 & 106 & 0 & 1 \\
\hline Goiás & 2 & 0 & 309 & 2 & 3 & 7 & 1 & 70 & 3 & 10 \\
\hline Distrito Federal & 3 & 0 & 378 & 2 & 4 & 9 & 0 & 347 & 7 & 16 \\
\hline Brasil & 3 & 0 & 738 & 2 & 4 & 4 & 0 & 389 & 2 & 3 \\
\hline
\end{tabular}

* até a SE 22/2013 


\subsubsection{Desempenho da definição de caso}

Para a análise do desempenho da definição de caso de SG foi considerado o indivíduo com febre (aferida ou referida), acompanhada de tosse ou dor de garganta, na ausência de outros diagnósticos, com no máximo cinco dias do início dos sintomas. Foram calculadas a sensibilidade, especificidade e VPP para combinações de sinais e sintomas segundo o resultado de vírus respiratórios. Os resultados estão expressos na Tabela 9.

O resultado laboratorial é fator importante e a sensibilidade e especificidade de qualquer teste para diagnóstico de influenza depende do laboratório e da forma do processamento da amostra, do tipo de espécime coletado e da qualidade da amostra (19). O kit comercial para identificação de vírus respiratórios apresenta alta sensibilidade e especificidade quando amostras clínicas são comparadas para confirmação por cultivo celular (20).

Os sintomas mais frequentes foram tosse $(83,9 \%)$, febre $(78,7 \%)$ e coriza (76,2\%). Dor de garganta estava presente em 43\% dos indivíduos. Foi verificado que, nas amostras coletadas, quase $70 \%$ dos pacientes não apresentou dores musculares e cerca de $60 \%$ das amostras eram de indivíduos sem dor de cabeça. Queixavam-se de artralgia, 16\% dos pacientes. Coriza estava presente em $76 \%$ dos pacientes; dor de ouvido foi verificada em 10\%; e 45\% das amostras coletadas eram de pacientes com obstrução nasal. A maioria dos pacientes $(87 \%)$ não indicou ter outros sinais e sintomas. No sistema não havia alternativa para registro de quais seriam os outros sinais e sintomas (Tabela 8 ). 
Tabela 8 - Frequência da informação dos sintomas. Sivep-Gripe, Brasil, 2010-2013

\begin{tabular}{ccccccccccc}
\hline Ano & \multicolumn{2}{c}{2010} & \multicolumn{2}{c}{2011} & \multicolumn{2}{c}{2012} & \multicolumn{2}{c}{2013} & \multicolumn{2}{c}{ Total } \\
\cline { 2 - 11 } Sintoma & $\mathrm{n}$ & $\%$ & $\mathrm{n}$ & $\%$ & $\mathrm{n}$ & $\%$ & $\mathrm{n}$ & $\%$ & $\mathrm{n}$ & $\%$ \\
\hline Febre & 6.200 & 77,8 & 7.063 & 76,7 & 8.386 & 80,0 & 2.036 & 84,0 & 23.685 & 78,7 \\
Tosse & 6.733 & 84,5 & 7.623 & 82,7 & 8.862 & 84,6 & 2.017 & 83,2 & 25.235 & 83,9 \\
Dor de garganta & 3.283 & 41,2 & 3.987 & 43,3 & 4.520 & 43,1 & 1.084 & 44,7 & 12.874 & 42,8 \\
Dores musculares & 2.563 & 32,2 & 2.960 & 32,1 & 3.053 & 29,1 & 669 & 27,6 & 9.245 & 30,7 \\
Dor de cabeça & 3.255 & 40,8 & 4.044 & 43,9 & 3.919 & 37,4 & 911 & 37,6 & 12.129 & 40,3 \\
Artralgia & 1.357 & 17,0 & 1.608 & 17,5 & 1.573 & 15,0 & 382 & 15,8 & 4.920 & 16,4 \\
Coriza & 6.247 & 78,4 & 7.156 & 77,7 & 7.817 & 74,6 & 1.697 & 70,0 & 22.917 & 76,2 \\
Dor de ouvido & 844 & 10,6 & 975 & 10,6 & 1.152 & 11,0 & 249 & 10,3 & 3.220 & 10,7 \\
Obstrução nasal & 3.910 & 49,1 & 4.269 & 46,3 & 4.482 & 42,8 & 911 & 37,6 & 13.572 & 45,1 \\
Outros Sintomas & 1.087 & 13,6 & 1.062 & 11,5 & 1.346 & 12,8 & 348 & 14,4 & 3843 & 12,8 \\
\hline Total de amostras & 7.971 & 26,5 & 9215 & 30,6 & 10479 & 34,8 & 2424 & 8,1 & 30.089 & 100,0 \\
coletadas & & & & & & & & & & \\
\hline
\end{tabular}

Das 30.089 amostras de pacientes, foram incluídas no estudo de desempenho da definição de caso as coletas realizadas até 5 dias do início dos sintomas. Foram excluídos 9,8\% (2.939) dos registros, totalizando 27.150 registros de resultados.

Febre e tosse, isoladamente, apresentaram a maior sensibilidade $(84,9 \% \mathrm{e}$ $85,8 \%$ respectivamente) e, a combinação dos dois, melhor desempenho para detecção de todos os vírus respiratórios. A combinação de febre, tosse e dor de garganta obteve uma sensibilidade de 39,5\% para deteç̧ão de influenza tipo A e $42 \%$ para o tipo B. Para influenza A e B o VPP se manteve constante e, em média, $4,2 \%$ e $2,1 \%$ respectivamente a maior especificidade foi relacionada a dor de garganta $(59,4 \%)$ para ambos os vírus influenza. O VPP foi baixo para todos os sintomas e resultados laboratoriais. 
Tabela 9 - Desempenho da definição de caso de síndrome gripal. Sivep-Gripe, Brasil, 2010-2013

\begin{tabular}{|c|c|c|c|c|c|c|c|c|c|c|c|c|c|c|c|c|c|c|c|c|c|c|c|c|c|c|c|c|c|c|c|c|c|c|c|c|}
\hline \multirow{3}{*}{$\begin{array}{l}\text { Sinais e } \\
\text { sintomas }\end{array}$} & \multirow[b]{3}{*}{$\mathrm{N}$} & \multicolumn{5}{|c|}{ Influenza A } & \multicolumn{5}{|c|}{ Influenza B } & \multicolumn{5}{|c|}{ Para 1} & \multicolumn{4}{|c|}{ Para 2} & \multicolumn{6}{|c|}{ Para 3} & \multicolumn{5}{|c|}{ Adeno } & \multicolumn{5}{|c|}{ VRS } \\
\hline & & \multicolumn{2}{|c|}{ Sensibilidade } & \multicolumn{2}{|c|}{$\begin{array}{l}\mathrm{Neg}=23338 \\
\text { Especificidade }\end{array}$} & \multirow[t]{2}{*}{ VPP } & \multicolumn{2}{|c|}{$\begin{array}{c}\text { Pos }=486 \\
\text { Sensibilidade }\end{array}$} & \multicolumn{2}{|c|}{$\begin{array}{l}\mathrm{Neg}=23883 \\
\text { Especificidade }\end{array}$} & \multirow[t]{2}{*}{ VPP } & \multicolumn{2}{|c|}{$\begin{array}{c}\text { Pos }=184 \\
\text { Sensibilidade }\end{array}$} & \multicolumn{2}{|c|}{$\begin{array}{l}\mathrm{Neg}=24263 \\
\text { Especificidade }\end{array}$} & \multirow[t]{2}{*}{ VPP } & \multicolumn{2}{|c|}{$\begin{array}{c}\text { Pos }=125 \\
\text { Sensibilidade }\end{array}$} & \multicolumn{2}{|c|}{$\begin{array}{c}\mathrm{Neg}=24320 \\
\text { Especificidade }\end{array}$} & & \multicolumn{2}{|c|}{$\begin{array}{c}\text { Pos }=301 \\
\text { Sensibilidade }\end{array}$} & \multicolumn{2}{|c|}{$\begin{array}{l}\mathrm{Neg}=24131 \\
\text { Especificidade }\end{array}$} & \multirow[t]{2}{*}{ VPP } & \multicolumn{2}{|c|}{$\begin{array}{c}\text { Pos }=609 \\
\text { Sensibilidade }\end{array}$} & \multicolumn{2}{|c|}{$\begin{array}{l}\mathrm{Neg}=23824 \\
\text { Especificidade }\end{array}$} & VPP & $\begin{array}{l}\text { Pos }= \\
\text { Sensibi }\end{array}$ & 1503 & $\begin{array}{l}\text { Neg=2 } \\
\text { Especifi }\end{array}$ & 22931 & VPF \\
\hline & & $\mathrm{n}$ & $\%$ & $\mathrm{n}$ & $\%$ & & $n$ & $\%$ & $\mathrm{n}$ & $\%$ & & $\mathrm{n}$ & $\%$ & $\mathrm{n}$ & $\%$ & & $n$ & $\%$ & $\mathrm{n}$ & $\%$ & & $\mathrm{n}$ & $\%$ & $\mathrm{n}$ & $\%$ & & $\mathrm{n}$ & $\%$ & $\mathrm{n}$ & $\%$ & & $\mathrm{n}$ & $\%$ & $\mathrm{n}$ & $\%$ & \\
\hline Febre & 21468 & 868 & 84.9 & 4985 & 21.4 & 4.0 & 405 & 83.3 & 5059 & 21.2 & 1.9 & 164 & 89.1 & 5139 & 21.2 & 0.8 & 97 & 77.6 & 5131 & 21.1 & 0.5 & 220 & 73.1 & 5074 & 21.0 & 1.0 & 507 & 12.7 & 5053 & 21.2 & 2.4 & 1174 & 78.1 & 4829 & 21.1 & 5.5 \\
\hline $\begin{array}{l}\text { Febre, } \\
\text { tosse e } \\
\text { dor de } \\
\text { garganta }\end{array}$ & 8591 & 404 & 39.5 & 1576 & 6.8 & 4.7 & 204 & 42.0 & 1600 & 6.7 & 2.4 & 59 & 32.1 & 1632 & 6.7 & 0.7 & 43 & 34.4 & 1626 & 6.7 & 0.5 & 64 & 21.3 & 1605 & 6.7 & 0.7 & 184 & 5.6 & 1589 & 6.7 & 2.1 & 314 & 20.9 & 1560 & 6.8 & 3.7 \\
\hline $\begin{array}{l}\text { Febre } \mathrm{e} \\
\text { tosse }\end{array}$ & 18932 & 785 & 76.8 & 1787 & 7.7 & 4.1 & 360 & 74.1 & 1809 & 7.6 & 1.9 & 146 & 79.3 & 1845 & 7.6 & 0.8 & 79 & 63.2 & 1833 & 7.5 & 0.4 & 202 & 67.1 & 1815 & 7.5 & 1.1 & 475 & 10.4 & 1797 & 7.5 & 2.5 & 1091 & 72.6 & 1771 & 7.7 & 5.8 \\
\hline $\begin{array}{l}\text { Febre e } \\
\text { dor de } \\
\text { garganta }\end{array}$ & 9934 & 443 & 43.3 & 3712 & 15.9 & 4.5 & 223 & 45.9 & 3780 & 15.8 & 2.2 & 64 & 34.8 & 3841 & 15.8 & 0.6 & 49 & 39.2 & 3837 & 15.8 & 0.5 & 69 & 22.9 & 3785 & 15.7 & 0.7 & 198 & 6.4 & 3771 & 15.8 & 2.0 & 340 & 22.6 & 3562 & 15.5 & 3.4 \\
\hline $\begin{array}{l}\text { Tosse e } \\
\text { dor de } \\
\text { garganta }\end{array}$ & 9914 & 428 & 41.9 & 2590 & 11.1 & 4.3 & 222 & 45.7 & 2633 & 11.0 & 2.2 & 65 & 35.3 & 2686 & 11.1 & 0.7 & 47 & 37.6 & 2681 & 11.0 & 0.5 & 74 & 24.6 & 2659 & 11.0 & 0.7 & 198 & 6.2 & 2638 & 11.1 & 2.0 & 349 & 23.2 & 2571 & 11.2 & 3.5 \\
\hline $\begin{array}{l}\text { Dor de } \\
\text { garganta }\end{array}$ & 11530 & 469 & 45.9 & 13855 & 59.4 & 4.1 & 245 & 50.4 & 14172 & 59.3 & 2.1 & 70 & 38.0 & 14352 & 59.2 & 0.6 & 59 & 47.2 & 14400 & 59.2 & 0.5 & 82 & 27.2 & 14238 & 59.0 & 0.7 & 216 & 7.8 & 14069 & 59.1 & 1.9 & 378 & 25.1 & 13331 & 58.1 & 3.3 \\
\hline Tosse & 22625 & 877 & 85.8 & 3833 & 16.4 & 3.9 & 400 & 82.3 & 3895 & 16.3 & 1.8 & 160 & 87.0 & 3969 & 16.4 & 0.7 & 91 & 72.8 & 3956 & 16.3 & 0.4 & 249 & 82.7 & 3939 & 16.3 & 1.1 & 524 & 12.0 & 3905 & 16.4 & 2.3 & 1340 & 89.2 & 3831 & 16.7 & 5.9 \\
\hline
\end{tabular}




\subsubsection{Discussão}

Os atributos da vigilância possuem interação entre eles e a interferência em um deles irá refletir em outro. Sistemas simples tendem a ter mais aceitabilidade e, consequentemente, maior oportunidade, representatividade e qualidade dos dados (13).

O sistema de vigilância da influenza, apesar de envolver muitos atores, foi considerado simples. $\mathrm{O}$ atributo simplicidade deve ser princípio norteador de um sistema de vigilância. Sistemas simples, de fácil entendimento e implementação costumam refletir na melhor aceitabilidade pelos profissionais envolvidos, além de menor custo, o que não foi abordado nessa avaliação.

A despeito de ter sido considerada simples, a vigilância da influenza envolve a gestão articulada com atores institucionais que precisam ser sensibilizados em todos os lócus hierárquicos em que se insere. Envolve processos de trabalho diferenciados conforme o local da atividade e natureza da vigilância. É preciso ressaltar a complexidade decorrente da participação de instituições com finalidades diferentes e com diversidades operacionais, como as atividades da rede de assistência médica, de laboratórios, vigilância e saúde pública nas três esferas de governo.

O sistema foi avaliado como flexível por permitir alterações e ou adaptações. Uma nova versão do Sivep-Gripe entrou em funcionamento a partir de $1^{\circ}$ de junho de 2013. Na versão atualizada - que é dividida em módulos conforme as estratégias da vigilância ampliada da influenza e rotinas gerenciais - houve modificações com inclusão e exclusão de campos/variáveis com redução no número, porém maior detalhamento de informações como as socioeconômicas (raça/cor, etnia, escolaridade) e de fatores de risco (comorbidades). Foram acrescentados campos para informação sobre tratamento antiviral. Houve redução dos campos referentes aos sintomas. Foi acrescida a opção de tecido post-mortem em relação ao tipo de amostra clínica coletada e modificações nos espaços destinados para lançamento dos resultados laboratoriais dos testes de IFI e de biologia molecular (pela reação em cadeia da polimerase - PCR) com opções para como Metapneumovírus, Bocavírus, Rinovírus e outros vírus respiratórios, entre outras alterações. 
Sobre 0 atributo aceitabilidade, quanto maior a sensibilização dos profissionais para a importância do agravo, maior é a adesão à vigilância. Em relação ao parâmetro de completitude do preenchimento das variáveis obrigatórias e essenciais, a avaliação foi boa. No entanto, a análise não foi boa no tocante ao percentual de amostras coletadas. O Brasil coletou uma média de $43 \%$ do número de amostras estimadas para o período.

Como possíveis motivos para a baixa aceitação da vigilância da influenza estariam pouca sensibilização dos profissionais para a importância do agravo e da coleta de material biológico; a dificuldade de captação dos casos de SG que atendam a todos os sintomas da definição de caso; e a recusa na autorização da coleta por parte dos pacientes, segundo Skalinski (21). Nesse relatório a autora aponta que a aceitabilidade do sistema poderia ser melhorada com a sensibilização tanto de gestores como dos profissionais das US; investimento em mais pessoal para desenvolver as atividades de vigilância de influenza nas US, municípios e estados; aumento da infraestrutura do serviço; e estabelecimento de rotina para devolução dos dados, resultados, informações e supervisões.

Valor preditivo positivo refere-se à probabilidade de que um resultado positivo do sistema realmente reflita a situação real. O VPP foi considerado baixo: $15,4 \%$ em relação a todos os vírus respiratórios. Para os vírus influenza $A$ e $B$, principais vírus monitorados com objetivo de estudo para composição da vacina, o VPP de 3,6\% e $1,7 \%$, respectivamente, foi classificado como muito baixo. A baixa positividade pode estar relacionada com a observação criteriosa da definição de caso de síndrome gripal para coleta de amostras, pois $21,3 \%$ dos pacientes não tinham febre; $16,1 \%$ não apresentavam tosse, e dor de garganta estava ausente em 57,2\%.

Resultado de VPP insatisfatório de 9,2\% foi encontrado em avaliação do sistema brasileiro de vigilância de influenza nos anos de 2000 a 2004 (22). Em estudo de 2000 a 2007 a positividade foi de 18\%, sendo 7\% para vírus influenza (83\% vírus influenza tipo A e $17 \%$ do tipo de B) (23). VPP de $18 \%$ para todos os vírus respiratórios e de $6 \%$ para os vírus influenza foram relatados para o período de 2005 a 2008 (21,24). O baixo VPP, num sistema de vigilância, pode ser devido a uma maior proporção de casos falsos positivos; reflete, principalmente, a sensibilidade da definição de caso e depende da prevalência da doença na população (quanto maior for a especificidade e a prevalência, maior o VPP). Pode 
indicar que o sistema pode estar captando outros problemas respiratórios. O baixo VPP pode acarretar um aumento de recursos dispendidos - financeiros e humanos na investigação de casos e situações de surtos e epidemias que na verdade não existem (12).

É preciso destacar a importância e valorizar o diagnóstico laboratorial como peça-chave na vigilância da influenza. O objetivo de detecção viral depende: do tipo de espécime coletado; da qualidade da amostra; da técnica empregada; do processamento laboratorial; e da sensibilidade e especificidade do teste diagnóstico. O exame de cultura é o padrão-ouro. A sensibilidade pode variar de $60 \%$ a $90 \%$ e a especificidade é próxima a 100\%. No entanto, é demorado, de 4 a 14 dias. Técnicas mais rápidas de detecção de antígenos virais, como a reação de IFI, apresentam sensibilidade de $80 \%$ e especificidade de $90 \%$. As técnicas de PCR são mais sensíveis do que a imunofluorescência e a cultura, sendo que a metodologia do PCR real-time é mais rápida do que o PCR convencional, além de permitir a quantificação de um único ou de múltiplos patógenos numa mesma amostra $(19,20,25)$.

O não enquadramento adequado da definição de caso na seleção de pacientes para tomada de amostras representa um impacto desnecessário em todas as etapas da vigilância, seja nos serviços de saúde, desde a US, na logística do acondicionamento e transporte da amostra, nos laboratórios, na digitação dos dados no Sivep-Gripe, seja na análise dos dados e produção de informações. Esse impacto reflete-se não só nas atividades inerentes aos serviços, mas também nos custos financeiros da vigilância. Esse é também aspecto da avaliação de serviços de saúde que, embora importante, não foi abordado nesse trabalho.

Falha no cumprimento da definição de caso de SG certamente interferiu no resultado negativo de aproximadamente $88 \%$, em média, dos exames realizados para cada vírus respiratório. O alto percentual de testes negativos pode ser decorrência do não enquadramento adequado na definição de caso; ou por problemas na coleta, armazenamento, transporte e processamento laboratorial das amostras; e ou pelo preenchimento automático como negativo no Sivep-Gripe (16). A positividade dos exames para vírus respiratórios se manteve em todos os anos com uma média percentual de cerca de 15,4\%. Estudo da vigilância da influenza, de 2000 a 2010, demonstrou que, dos pacientes atendidos nas US, 11\% apresentavam SG, e desses, foram tomadas amostras clínicas de $1 \%$ e a positividade foi de $17 \%$ 
(26). O alto percentual de resultados negativos indica fragilidade importante do sistema de vigilância.

$\mathrm{Na}$ definição de caso de influenza, febre é sintoma obrigatório, no entanto $21,0 \%$ de todas as amostras coletadas foram de pacientes sem febre. Problemas no cumprimento da definição de caso de SG foram apontados em trabalhos e relatórios do Programa de Treinamento em Epidemiologia Aplicada aos Serviços do SUS (Episus) realizados nos anos de 2005 a 2008 (21), de 2000 a 2007 (24), de 2000 a 2006 (27) e de 2000 a 2004 (28). Almeida e colaboradores (27) identificaram que $32 \%$ dos registros de SG não atenderam à definição, sendo $24 \%$ casos que não apresentavam febre. A ausência de febre foi constatada em $28 \%$ dos pacientes em estudo que apontou maior sensibilidade (70\%) para a definição que incluía febre e tosse $(22,28)$. Outra avaliação apresentou resultado em que $19 \%$ dos casos de síndrome gripal não registravam febre e $9 \%$ não registravam tosse ou dor de garganta $(21,24)$.

Ajustes nas definições de caso devem ocorrer em função das modificações do cenário epidemiológico. Entretanto, foi observado que as definições de caso constantes em documentos oficiais do MS apresentavam inconsistências (Apêndice A). A padronização é importante, pois dela depende a correta compreensão e tomada de decisão, o que pode interferir na aceitabilidade da vigilância.

Mesmo com limitações o sistema de vigilância tem conseguido identificar a presença e a circulação de vírus respiratórios, a sazonalidade e grupo populacional mais afetado (29). No presente estudo, a intensidade de circulação viral do período pode ser evidenciada pela proporção de vírus respiratórios identificados para o período analisado. Dos resultados positivos para todos os vírus respiratórios no período, a Região Nordeste contribuiu com 26,7\% amostras; $24,3 \%$ foram da região Sudeste, $24,0 \%$ da Norte, $16,5 \%$ da Sul e $8,6 \%$ da Centro-Oeste.

A extensão territorial do Brasil é de 8,5 milhões de $\mathrm{km}^{2}$. São 5.570 municípios distribuídos em 26 estados e o Distrito Federal. De acordo com o Censo Demográfico de 2010 (30), a população brasileira era de 190.755.799 habitantes. Desses, 84,4\% (160.925.792 hab.) residiam em área urbana, como as capitais e grandes áreas metropolitanas onde estão localizadas as US. O país possui grandes diferenças regionais, com características climáticas, sociais e econômicas distintas. 
A cobertura ou distribuição espacial da vigilância de síndrome gripal no país reflete essas desigualdades.

O sistema não tem possibilidade de identificar todos os grupos e subgrupos populacionais em que ocorrem os casos segundo pessoa, tempo e lugar, mesmo com identificação dos vírus respiratórios em todas as regiões brasileiras com a distribuição por sexo e idade dos pacientes. Em relação à distribuição das amostras positivas para todos os vírus respiratórios entre as regiões brasileiras, foram encontrados resultados semelhantes em trabalho publicado em 2013 (26): a Região Nordeste foi a que mais apresentou resultados positivos e a Região Centro-Oeste, o menor número.

Ressalta-se que todas as US de SG são unidades de saúde públicas. Não há US de influenza na rede de assistência privada. Isso deixa de fora da vigilância uma parcela da população, embora a maioria dos atendimentos médicos seja realizada no sistema público de saúde - $75 \%$ da população é atendida exclusivamente pelo SUS - em todas as regiões (31).

A vigilância de síndrome gripal poderia contar com a participação, de forma voluntária, de unidades de serviços e profissionais da rede de saúde privada - por meio de programa, convênio ou parceria específica - para reforçar e ampliar a abrangência do monitoramento da influenza no país. Essa colaboração poderia ser feita com o fornecimento de informações acerca dos atendimentos de SG para a SVS/MS, da mesma forma que ocorre nas US públicas. Poderia, ainda, conforme pactuação, contar com o envio de amostras a serem processadas nos Lacen, mediante cadastro do profissional e ou serviço médico. Esse exemplo de parceria público-privada em relação à influenza ocorre em territórios e países como Austrália $(32,33)$, Hong Kong (34), Cingapura (35). Segundo a OMS (36), existem lacunas geográficas e populacionais, bem como deficiências de expertise, nessas redes de fontes formais de informação na vigilância de doenças infecciosas globais que devem ser retificadas. Como a maioria dessas redes representa o setor público, a própria OMS sugere que sejam desenvolvidos meios de incluir também o setor privado, bem como outras fontes de informações válidas, como laboratórios de pesquisa. 
A procura por atendimento médico é diferente entre as regiões, sendo menor no Norte, Nordeste e Centro-Oeste (61,4\%, 66,3\% e 69,5\%, respectivamente) e maior no Sudeste e Sul $(75,8 \%$ e $73,8 \%$, respectivamente). Buscam mais por serviços médicos: mulheres (78,0\%); pessoas de cor branca $(74,8 \%)$; adultos na faixa etária de 40 a 59 anos (73,5\%) e de 60 anos ou mais (83,5\%); e indivíduos com nível superior completo (37). O uso dos serviços do SUS é diferenciado entre as regiões, sendo predominante nas Regiões Norte e Nordeste (em torno de 70\%) e menor, proporcionalmente, na Região Sudeste (38).

Pelos parâmetros estimados na Portaria/MS/2.693/2011 de repasse financeiro, a representatividade foi considerada insatisfatória: 40\% das capitais apresentavam déficit de US e $78 \%$ das cidades sulistas com mais de 300 mil habitantes, não possuem US de SG.

Para melhorar a representatividade e manter abrangência para identificação dos vírus circulantes e potencial de transmissão, os resultados apontam a necessidade de revisão e ampliação no número e distribuição de US nos municípios populosos de RM de capitais com mais de 500 mil habitantes. Há que se avaliar o impacto da relação US/população na rede laboratorial e o custo-benefício para a vigilância e para a sociedade. Para tanto outro ponto a ser considerado seria a possibilidade de reduzir o número de amostras e ampliar a abrangência da rede sentinela. No parâmetro adotado, algumas cidades, claramente não contam com o número de US necessário em proporção à sua população, a exemplo do município de São Paulo, que deveria contar com 22 unidades.

A oportunidade indica a velocidade dimensionada pelo intervalo de tempo decorrido entre etapas do sistema de vigilância. É um atributo importante, especialmente para sistemas para detecção de tendências ou aumento anormal de doenças infecciosas que necessitem de adoção de medidas preventivas e controle rápido. O sistema foi considerado oportuno nos dois parâmetros observados. A grande variação entre os valores máximo e mínimo pode ser atribuída a falhas na digitação das datas. Em avaliação da qualidade dos registros, a inconsistência contribui com quase $5 \%$ dos registros relativos às datas entre coleta de amostras e realização de exames, e com cerca de $14 \%$ referente à realização do exame de imunofluorescência com mais de quinze dias após a coleta (16). Um 
acompanhamento deve ser realizado nos estados onde a mediana foi acima de 8 dias para o resultado do teste de laboratório.

Estudo da vigilância de influenza realizado entre os anos 2000 a 2004 (28) também constatou coleta oportuna de amostras, com mediana de 3 dias. Os autores verificaram, por meio da diferença em dias entre as datas da liberação dos resultados de IFI e da entrada do dado no Sivep-Gripe, a velocidade em que os laboratórios lançavam os resultados no sistema: mediana de 34 dias, ultrapassando a recomendação de preenchimento semanal. A digitação dos resultados no sistema foi oportuna - 8 dias ou menos - em 27\% (4/15) dos laboratórios avaliados, nesse estudo.

Com resultados semelhantes, a coleta foi considerada oportuna - 5 dias ou menos do início dos sintomas - para 95\% das amostras, em avaliação feita para o período de 2000 a 2006 (27). Outra avaliação feita para o período de 2005 a 2008, foram relatadas medianas de 3 dias tanto para o tempo entre os primeiros sintomas e a coleta, quanto para o tempo entre da coleta e resultado laboratorial. Foram consideradas inoportunas $9 \%$ das amostras coletadas em todo país (21).

Para melhorar a oportunidade devem ser adotadas estratégias para motivar para os participantes da vigilância, seja na coleta de amostras, seja no lançamento e envio dos dados na plataforma. É fundamental que o profissional de saúde se identifique como partícipe da pesquisa epidemiológica.

Muitos fatores afetam o desempenho dos sistemas de vigilância e, portanto, o resultado da avaliação. Um fator primordial é a definição de caso. É importante que a definição de casos seja clara, objetiva e esteja padronizada em todos os documentos do MS, em um mesmo horizonte temporal da vigilância.

Em um estudo de avaliação da definição de caso de influenza, Almeida e colaboradores (27) verificaram que febre foi o sinal com melhor desempenho para SG, com sensibilidade de $87 \%$, especificidade de $24 \%$ e VPP de $8 \%$. A combinação de febre, tosse e dor de garganta obteve sensibilidade de $33 \%$, especificidade de 74\% e VPP de 8\%. Não houve diferença na sensibilidade, especificidade e VPP em relação à oportunidade da coleta entre maior ou igual a 3 dias e menor ou igual a 5 dias. Skalinski et al (21) encontraram resultado semelhante para febre associada a tosse e dor de garganta (39\%). 
Estudos de performance de definição de casos de SG em estratégia sentinela indicaram que a sensibilidade da definição do caso ILI não variou com a idade (27, 39) e a inclusão de febre isoladamente aumentou a detecção de casos em 34\% (39). A vigilância sentinela de influenza busca detectar a circulação viral. A definição de caso adotada possui maior sensibilidade e menor especificidade. Uma definição mais restritiva poderia otimizar o desempenho do sistema com aumento da positividade e redução de recursos (humanos e de capital).

O estudo teve algumas limitações, como não identificar duplicidade, uma vez que a base de dados utilizada era anônima. Não foi possível o cálculo de proporção de síndrome gripal, pois não obtivemos os dados agregados de atendimentos das US.

O sistema de vigilância de influenza, desde a sua implantação, vem sendo aperfeiçoado e tem demonstrado a presença e a circulação viral, mesmo com fragilidades. O número de US e de amostras coletadas é pequeno frente à composição da população brasileira e sua distribuição geográfica. A positividade dos resultados, em torno de 17\%, pode ocorrer tanto por reflexo da seleção de pacientes (definição de caso), dos procedimentos adequados na coleta, armazenamento e envio para o laboratório, bem como pela técnica do diagnóstico. Esses elementos se configuram como pontos críticos para a vigilância e devem ser trabalhados nas supervisões e avaliações de serviço. Há que se melhorar a vigilância, principalmente, no que se refere à representatividade, oportunidade e positividade dos exames, de modo a refinar o conhecimento do impacto da virose e aumentar a capacidade de resposta dos serviços de saúde pública. 


\section{Referências}

1. Brasil. Guia de Vigilância em Saúde. 1 ed.versão eletrônica].Brasília: Ministério da Saúde; 2014.

2. Cox NJ, Subbarao K. Global epidemiology of influenza: Past and present. Annual Review of Medicine 2000;51:407-21.

3. Barros FRd, Daufenbach LZ, Vicente MG, et al. O desafio da influenza: epidemiologia e organização da vigilância no Brasil. Boletim Eletrônico Epidemiológico 2004;19(1):197-225.

4. Brasil. Ministério da Saúde. Portaria ํํ 1.984, de 12 de setembro de 2014. Define a lista nacional de doenças e agravos de notificação compulsória, na forma do Anexo, a serem monitorados por meio da estratégia de vigilância em unidades sentinelas e suas diretrizes. Brasília: Diário Oficial da União, 2014, 15 set p.59.

5. Brasil. Ministério da Saúde. Gabinete do Ministro. Portaria no 2.693, de 17 de novembro de 2011. Estabelece mecanismo de repasse financeiro do Fundo Nacional de Saúde aos Fundos de Saúde do Distrito Federal e Municípios, por meio do Piso Variável de Vigilância e Promoção da Saúde, para implantação, implementação e fortalecimento da Vigilância Epidemiológica da Influenza. Brasília: Diário Oficial da União, 26 abr; 2011.

6. Brasil. Ministério da Saúde. Portaria ํㅜ 183, de 30 de janeiro de 2014. Regulamenta o incentivo financeiro de custeio para implantação e manutenção de ações e serviços públicos estratégicos de vigilância em saúde, previsto no art. 18, inciso I, da Portaria n 1.378/GM/MS, de 9 de julho de 2013, com a definição dos critérios de financiamento, monitoramento e avaliação. Brasília: Diário Oficial da União, 2014.

7. Brasil. Ministério da Saúde. Secretaria de Vigilância em Saúde. Departamento de Vigilância Epidemiológica. Guia de vigilância epidemiológica. 7ª̣ Ed. Brasília: Ministério da Saúde, 2009, (Série A. Normas e Manuais Técnicos).

8. Briand S, Mounts A, Chamberland M. Challenges of global surveillance during an influenza pandemic. Public Health 2011;125(5):247-56. 
9. Merchan-Hamann E, Laguardia J. Reflexões sobre a vigilância epidemiológica: mais além da notificação compulsória. Informe Epidemiológico do SUS 2000;9(3):211-9.

10. Teixeira MG, Risi Junior JB, Costa MCN. Vigilância epidemiológica. In: Rouquayrol MZ, Almeida Filho N, eds. Epidemiologia \& Saúde. Rio de Janeiro: Medsi, 2003:313-43.

11. Klaucke D. Evaluating public health surveillance. In: Teutsch SM, Churchill R, Elliot, eds. Principles and practice of public health surveillance. New York: Oxford University Press, 1994:158-74.

12. Waldman EA. Usos da vigilância e da monitorização em saúde pública. Informe Epidemiológico do SUS 1998;VII(3):7-26.

13. Centers for Disease $C$. Updated guidelines for evaluating public health surveillance systems: Recommendations from the guidelines working group. Morbidity and Mortality Weekly Report 2001;50(RR-13):1-36.

14. Brasil. Doenças infecciosas e parasitárias: guia de bolso. $8^{\mathrm{a}}$ ed. Brasília: Ministério da Saúde; 2010.

15. WHO WHO. Global Influenza Surveillance and Response System (GISRS). 2014. (http://www.who.int/influenza/gisrs_laboratory/en). (Accessed 5 Out 2014).

16. Cantarino L, Merchan-Hamann E. Avaliação da qualidade dos registros do Sistema de Informação da Vigilância Epidemiológica da Gripe, Brasil, 20102013. Dados não publicados 2015.

17. Brasil. Instituto Brasileiro de Geografia e Estatística. IBGE. Área Territorial Brasileira. Consulta por unidade da federação. Disponível em: http://www.ibge.gov.br/home/geociencias/areaterritorial/principal.shtm. Acesso em 6 nov 2015.

18. Brasil. Sinopse do Censo Demográfico 2010. Instituto Brasileiro de Geografia e Estatística. IBGE. Disponível em: http://www.censo2010.ibge.gov.br/sinopse/index.php?dados $=10 \& u f=00$. Acesso em 6 nov. 2015. 
19. Ortiz JR, Sotomayor V, Uez OC, et al. Strategy to Enhance Influenza Surveillance Worldwide. Emerging Infectious Diseases 2009;15(8):1271-8.

20. Millipore M. Light Diagnostics ${ }^{\mathrm{TM}}$ Respiratory Panel Viral Screening and Identification IFA Kit. Qualitative Identification of Adenovirus, Influenza A, Influenza B, Parainfluenza 1, 2, 3, and Respiratory Syncytial Virus in cell culture. United Kingdom: Millipore. Disponível em: http://www.merckmillipore.com/BR/pt/product/LIGHTDIAGNOSTICS\%E2\%84\%A2-Respiratory-Panel-I-Viral-Screening-andIdentification-IFA,MM_NF-3105?bd=1. Acesso em 2 nov.2015.

21. Skalinski LM. Avaliação do sistema de vigilância sentinela da influenza, Brasil, 2005 a 2008. Relatório Programa de Treinamento em Epidemiologia Aplicada aos Serviços do SUS. Brasília: Ministério da Saúde, 2010.

22. Freitas DRC, Daufenbach LZ, Barros FR, et al. Avaliação do sistema de vigilância epidemiológica da influenza no Brasil, 2000 a 2004. 43ํㅡㄹ Congresso da Sociedade Brasileira de Medicina Tropical, Campos do Jordão, 2007.

23. Freitas GD, Daufenbach LZ, Malaguti $R$, et al. Vigilância da influenza no Brasil: descrição da morbimortalidade desde a implantação até 2007. III Encontro do EPISUS, Brasília, 2009.

24. Skalinski LM, Barros ENC, Araújo WN. Avaliação do sistema de vigilância sentinela da influenza, Brasil, 2005 a 2008. IV Encontro Científico do EPISUS, Brasília, 2010.

25 Mello, WA. O papel do diagnóstico laboratorial da influenza. Rev Pan-Amaz Saude. 2010;1(1):191-193.

26. Freitas FTM. Sentinel surveillance of influenza and other respiratory viruses, Brazil, 2000-2010. The Brazilian Journal of Infectious Diseases 2013;17(1):62.

27. Almeida $\mathrm{MAB}$, Araújo GCB, Barros FR, et al. Vigilância da influenza no Brasil: avaliação da definição de caso. $1^{\circ}$ Encontro Científico do Programa de Treinamento em Epidemiologia Aplicada aos Serviços do SUS - EPISUS, Brasília, 2007. 
28. Freitas DRC. Avaliação do sistema de vigilância de influenza no Brasil. Relatório. Programa de Treinamento em Epidemiologia Aplicada aos Serviços do SUS - EPISUS. Brasília: Ministério da Saúde, 2005.

29 Cantarino L, Merchan-Hamann. Influenza in Brazil: surveillance pathways. The Journal of Infection in Developing Countries 2015;9 (no prelo).

30 Brasil. Instituto Brasileiro de Geografia e Estatística. IBGE.

Censo Demográfico 2010. Características da população e dos domicílios.

Resultados do universo. Rio de Janeiro: Ministério do Planejamento, Orçamento e Gestão, 2011.

31 Organização Pan-Americana de Saúde. O perfil do sistema de serviços de saúde no Brasil: monitoração e análise dos processos de mudança. Washington: OPAS, 2008.

32. Parrella A, Dalton C, Pearce,R, Litt JC, Stocks N. ASPREN surveillance system for influenza-like illness - a comparison with FluTracking and the National Notifiable Diseases Surveillance System. Australian Family Physician. 2009; 38(11), 932-936.

33. Barakat A, Ihazmad H, Benkaroum S, Cherkaoui I, Benmamoun A, Youbi M, EI Aouad R. Influenza Surveillance among outpatients and inpatients in Morocco, 1996-2009. PLoS ONE. 2011; 6(9), e24579.

34 Fung, OC. Evaluation of the surveillance system on influenza-like-illness in Hong Kong [dissertation].Hong Kong: University of Hong Kong, 2011.

35 Hishamuddin, P. Evaluation of the Influenza Sentinel Surveillance System in Singapore 2011-2012. Online Journal of Public Health Informatics. 2014; 6(1), e42.

36 WHO. World Health Organization. Global infectious disease surveillance. Fact sheet $\mathrm{n}^{\circ} 200$. Disponível em:

http://www.who.int/mediacentre/factsheets/fs200/en/. Acesso em 11 nov 2015.

37 Brasil. Pesquisa Nacional de Saúde 2013: acesso e utilização dos serviços de saúde, acidentes e violências. Rio de Janeiro: IBGE; 2015. 
38 Porto SM, Uga MAD, Moreira RS. Uma análise da utilização de serviços de saúde por sistema de financiamento: Brasil 1998-2008. 2011;16(9):3795-806.

39 Kasper MR, Wierzba TF, Sovann L, et al. Evaluation of an influenza-like illness case definition in the diagnosis of influenza among patients with acute febrile illness in Cambodia. BMC Infect Dis 2010;10:320. 


\section{CONSIDERAÇÕES FINAIS}

Os principais fatos sobre a influenza sazonal, de acordo com a OMS, podem ser resumidos da seguinte forma: (a) é uma infecção viral aguda que se propaga facilmente de pessoa para pessoa; (b) os vírus da influenza sazonal circulam no mundo inteiro e podem afetar qualquer pessoa de qualquer faixa etária; (c) esses vírus causam epidemias anuais, com pico de ocorrência durante o inverno em regiões temperadas; (d) constitui um sério problema de saúde pública que causa doença grave e morte em populações de alto risco; (e) uma epidemia de influenza pode ter um impacto econômico por meio de perda de produtividade da força de trabalho, além de sobrecarregar os serviços de saúde; (f) a vacinação contra a influenza é a medida mais eficaz para prevenir a infecção; $(\mathrm{g})$ medicamentos antivirais estão disponíveis para o tratamento, no entanto, os vírus da influenza podem desenvolver resistência às drogas (3).

A OMS, em colaboração com parceiros internacionais como o Brasil, monitora a influenza em nível mundial, recomenda composições para a vacina e apoia os esforços de seus países-membros no desenvolvimento de estratégias de prevenção e controle desse agravo. O objetivo comum é fortalecer a capacidade nacional e regional de diagnóstico da influenza, que inclui o monitoramento da susceptibilidade antiviral, respostas a surtos, aumento da cobertura vacinal entre os grupos de risco e a vigilância da doença. Esse último item constitui o foco central deste estudo, que buscou avaliar os atributos do sistema de vigilância epidemiológica da influenza no Brasil, no período de 2010 a 2013.

O primeiro objetivo desse trabalho de pesquisa foi descrever a estrutura sanitária brasileira frente a episódios pandêmicos de influenza. O primeiro artigo aqui apresentado introduz, portanto, um histórico da situação dos serviços de saúde do Brasil diante de ocorrências pandêmicas. Acompanha-se, assim, a evolução da capacidade de diagnóstico, controle e resposta ao agravo.

Durante a pandemia de influenza de 1889 a 1890, por exemplo, o Brasil ainda não tinha uma estrutura sanitária definida para o controle dessa e de muitas outras enfermidades. As atividades de saúde pública eram, nessa época, de caráter emergencial e temporário. A grande virulência da pandemia seguinte, de 1918 a 
1920 (Gripe Espanhola), expôs ainda mais a fragilidade da estrutura sanitária brasileira. A falta de conhecimento científico e de técnicas apropriadas de resposta à influenza impediram que o Estado brasileiro reagisse de modo efetivo no controle dessa epidemia. O Departamento Nacional de Saúde Pública, órgão equivalente ao atual Ministério da Saúde (MS), somente foi criado em janeiro de 1920.

Quando a pandemia de 1957 a 1958 (Gripe Asiática) chega ao Brasil, o país já contava com o Ministério da Saúde, criado em 1953. Nota-se, nesse momento, pelo menos três avanços: a instauração de uma comissão de estudos sobre a gripe com o objetivo de planejar o seu combate; a criação de uma cadeia de laboratórios regionais para identificação do vírus nas capitais dos principais estados; e o estímulo à produção de vacina específica.

Na epidemia de influenza de 1977 a 1978 (Gripe Russa), a estrutura sanitária brasileira estava um pouco mais definida. As ações de vigilância epidemiológica, o Programa Nacional de Imunizações e a notificação compulsória de doenças haviam sido estabelecidos em 1975 pela Lei 6.259.

Cento e dez anos depois da última pandemia do século XIX, o Brasil passa, então, a demonstrar um grau de maturidade técnico-administrativa e sanitária mais avançado. No ano 2000, três anos antes de a Gripe Aviária atingir a Ásia (20032004), ocorre a implantação nacional da vigilância da influenza no Brasil. Entre os objetivos estavam o monitoramento dos vírus da influenza nas regiões brasileiras, a avaliação do impacto da vacinação e a disseminação de informações epidemiológicas. Em 2003, foi constituído o Comitê Técnico para a elaboração do Plano de Preparação para a Pandemia de Influenza no Brasil. Dois anos depois, em 2005, é criado o Grupo Executivo Interministerial (GEI) para contribuir para implantação do Plano de Contingência Brasileiro para a Pandemia de Influenza.

Durante a pandemia de 2009, o MS criou o Gabinete Permanente de Emergência de Saúde Pública, no Centro de Informações Estratégicas e Resposta em Vigilância em Saúde (CIEVS). Houve investimento em ações de detecção de casos suspeitos, com agilização dos fluxos de envio de amostras e liberação dos resultados laboratoriais. Foram estabelecidos protocolos de notificação e sistemas on-line de informação. Ocorrem, também, a intensificação das medidas sanitárias em portos, aeroportos e fronteiras, o aumento da difusão de informação e a 
ampliação da capacidade nacional de produção de vacina específica. Percebe-se, então, que a cada onda pandêmica novas medidas e ações de prevenção e controle da influenza foram aos poucos sendo adotadas, contribuindo, assim, para o aperfeiçoamento da própria estrutura sanitária brasileira.

A descrição da implantação e estruturação da vigilância em si da influenza no Brasil, outro objetivo deste estudo, foi apresentada no segundo artigo. O texto destaca a vigilância virológica, o papel dos laboratórios de diagnóstico e como tem sido a ampliação de suas ações para melhorar a detecção e resposta rápida ao agravo. $\mathrm{O}$ modelo instituído corresponde à vigilância sentinela complementada pela notificação universal de Síndrome Respiratória Aguda Grave; pela investigação de surtos, óbitos e eventos incomuns; e pelo monitoramento de hospitalização e mortalidade numa vigilância ampliada.

No entanto, a vigilância epidemiológica da influenza precisa ser exercida à luz de uma série de princípios éticos. As questões éticas presentes nas práticas diárias de vigilância demandam processos reflexivos aprofundados e discussões específicas mais qualificadas. Essas indagações éticas relacionadas à vigilância da influenza foram feitas no terceiro artigo e atendem a mais um dos objetivos deste estudo. Uma gama de conceitos bioéticos, de direitos humanos, de direito à saúde, de saúde pública e de ética foi considerada. As reflexões propostas enfocam os princípios da bioética, relacionando-os às características das ações de vigilância direcionadas aos participantes da pesquisa de circulação de vírus respiratórios.

O trabalho de avaliação em saúde apresentado no quarto artigo examinou a qualidade da informação dos registros de síndrome gripal do Sistema de Informação de Vigilância Epidemiológica da Gripe (Sivep-Gripe), no período de 2010 a 2013, em âmbito nacional. A descrição dos dados e a qualidade dos seus registros - que constituiu mais um dos objetivos deste estudo -, foi realizada nas seguintes dimensões: clareza metodológica, completitude e inconsistências. Entre os resultados, pode-se destacar que a clareza metodológica foi avaliada como ruim. Por outro lado, a completitude dos campos teve boa avaliação para variáveis obrigatórias e essenciais, embora considerada baixa para alguns campos de relevância para a vigilância. O estudo aponta para a necessidade de avaliações sistemáticas para qualificação dos dados e fortalecimento da vigilância do agravo. 
O quinto e último artigo complementa essa análise ao descrever e avaliar os atributos do sistema de vigilância epidemiológica de influenza no mesmo período de 2010 a 2013. O estudo abordou os atributos qualitativos (simplicidade, flexibilidade e aceitabilidade) e quantitativos (valor preditivo positivo, oportunidade e representatividade). Com base nos objetivos estabelecidos para a vigilância de influenza, o sistema foi considerado parcialmente útil. Os atributos da vigilância possuem interação entre eles e a interferência em um deles irá refletir em outro. $O$ sistema de vigilância da influenza, apesar de envolver muitos atores, foi considerado simples. $O$ atributo simplicidade deve ser considerado como princípio norteador de um sistema de vigilância. A facilidade de entendimento e implementação costuma refletir na melhor aceitabilidade pelos profissionais envolvidos. O sistema foi avaliado, também, como flexível por permitir alterações e ou adaptações, mas apresenta fragilidades. O número de US e de amostras coletadas, por exemplo, é pequeno frente à composição da população brasileira e sua distribuição geográfica. Como resultado, o estudo aponta para a necessidade de se melhorar a vigilância, principalmente, no que se refere à representatividade, oportunidade e positividade dos exames, de modo a refinar o conhecimento do impacto da virose e aumentar a capacidade de resposta dos serviços de saúde pública.

Além disso, as estratégias globais para tratar doenças imunopreveníveis têm reconhecido a importância de estabelecer a carga local da doença (efeitos, gravidade, quantidade de doença e os custos) como um primeiro passo para decisões sobre vacinas.

A motivação dos diferentes atores envolvidos na vigilância da influenza - rede de assistência, rede laboratorial, da vigilância - é fundamental para melhorar a adesão dos profissionais de saúde nos serviços e a qualidade dos dados do Sistema de Informação. O estímulo pode ser por meio de capacitações regulares, retorno de dados e resultados, de forma que o profissional se identifique como participante da pesquisa de identificação dos vírus respiratórios circulantes. As supervisões técnicas periódicas devem ser estrategicamente planejadas com base nas avaliações realizadas de modo a direcionar os esforços nas soluções de falhas pontuais.

Como recomendação, periodicamente, também deve ser realizada a avaliação dos custos por estado e região, como preconizado na Portaria 183/2014 (26), além da análise dos dados e do funcionamento do sistema. É importante 
verificar o impacto financeiro que tanto o agravo influenza bem como sua vigilância representam nos recursos do MS. Esse aspecto é importante para definição de prioridades estratégicas para o investimento e monitoramento do sistema de vigilância de influenza.

O presente estudo demonstrou a importância da vigilância da influenza e que atenção deve ser dada no acompanhamento das suas diferentes etapas. Avaliações constantes devem ser realizadas para identificar e corrigir problemas e melhorar o desempenho do sistema de vigilância, num processo contínuo de aperfeiçoamento. 


\section{Referências}

1. Cox NJ, Subbarao K. Global epidemiology of influenza: Past and present. Annual Review of Medicine 2000;51:407-21.

2. Brasil. Doenças infecciosas e parasitárias: guia de bolso. 8ª Edição Rev. ed. Brasília: Ministério da Saúde; 2010.

3. Influenza (Seasonal). Genebra: World Health Organization-WHO; 2014. (http://www.who.int/mediacentre/factsheets/fs211/en/). (Accessed 6 nov 2015).

4. Brasil. Pesquisa Nacional de Saúde 2013: acesso e utilização dos serviços de saúde, acidentes e violências. Rio de Janeiro: IBGE; 2015.

5. Brasil. Lei no 6.259 de 30 de outubro de 1975. Dispõe sobre a organização das ações de Vigilância Epidemiológica, sobre o Programa Nacional de Imunizações, estabelece normas relativas à notificação compulsória de doenças, e dá outras providências. Brasília: Diário Oficial da União, 1975.

6. Brasil. Decreto $n^{\circ}$ 78.231, de 12 de agosto de 1976. Regulamenta a Lei $n^{\circ}$ 6.259, de 30 de outubro de 1975, que dispõe sobre a organização das ações de Vigilância Epidemiológica, sobre o Programa Nacional de Imunizações, estabelece normas relativas à notificação compulsória de doenças, e dá outras providências. Brasília: Diário Oficial da União, 1976.

7. Brasil. Lei no 8.080, de 19 de setembro de 1990. Dispõe sobre as condições para a promoção, proteção e recuperação da saúde, a organização e o funcionamento dos serviços correspondentes e dá outras providências. Brasília: Diário Oficial da União, Seção 1, 1990 [publ 20 de set 1990].

8. Brasil. Decreto no 7.508, de 28 de junho de 2011. Brasília: Diário Oficial da União, 2011.

9. Brasil. Ministério da Saúde. Secretaria de Vigilância em Saúde. Departamento de Vigilância Epidemiológica. Guia de vigilância epidemiológica. Brasília: Ministério da Saúde, 2009, (Série A. Normas e Manuais Técnicos no. 7ª̣ Edição).

10. Waldman E. O controle das doenças infecciosas emergentes e a segurança sanitária. Revista de Direito Sanitário 2000;1(1):89-106. 
11. Thacker SB. Historical development. In: Teutsch SM, R CE, eds. Principles and practice of public health surveillance. New York: Oxford University Press, 1994:317.

12. Centers for Disease C. Updated guidelines for evaluating public health surveillance systems: Recommendations from the guidelines working group. Morbidity and Mortality Weekly Report 2001;50(RR-13):1-36.

13. Klaucke D. Evaluating public health surveillance. In: Teutsch SM, Churchill R, Elliot, eds. Principles and practice of public health surveillance. New York: Oxford University Press, 1994:158-74.

14. Fischmann A. Vigilância epidemiológica. In: Rouquayrol MZ, ed. Epidemiologia \& saúde. Rio de Janeiro: Medsi, 1988:319-41.

15. Waldman EA. Usos da vigilância e da monitorização em saúde pública. Informe Epidemiológico do SUS 1998;VII(3):7-26.

16. Duarte EC, Schneider MC, Paes-Sousa R, et al. Epidemiologia das desigualdades em saúde no Brasil: um estudo exploratório. Brasília: Organização Pan-Americana da Saúde; 2002.

17. Reis POI, Betine Pinto Moehlecke, Souza LRO, Yokota RTC, et al. Monitoramento da síndrome gripal em adultos nas capitais do Brasil e no Distrito Federal por meio de inquérito telefônico. Revista Brasileira de Epidemiologia 2011;14(1 Supl):115-24.

18. Brasil. Guia de Vigilância em Saúde. 1a edição [Versão eletrônica]. Brasília: Ministério da Saúde; 2014.

19. Jesus R, Guimarães RP, Bergamo R, et al. Sistema Gerenciador de Ambiente Laboratorial: relato de experiência de uma ferramenta transformadora para a gestão laboratorial e vigilância em saúde. Epidemiologia e Serviços de Saúde 2013;22(3):525-9.

20. Barros FRd, Daufenbach LZ, Vicente MG, et al. O desafio da influenza: epidemiologia e organização da vigilância no Brasil. Boletim Eletrônico Epidemiológico 2004;19(1):197-225. 
21. Freitas FTM. Sentinel surveillance of influenza and other respiratory viruses, Brazil, 2000-2010.(Original article)(Report). The Brazilian Journal of Infectious Diseases 2013;17(1):62.

22. Brasil. Conselho Nacional de Saúde - CONASS. Situação atual do Sistema de Informações de Agravos de Notificação - SINAN. Nota Técnica no 45, de 29 de outubro de 2013. Brasília, 2013.

23. Brasil. Presidência da República. Lei oㅜ 12.527, de 18 de novembro de 2011. Regula o acesso a informações previsto no inciso XXXIII do art. $5^{\circ}$, no inciso II do $\S 3^{\circ}$ do art. 37 e no $\S 2^{\circ}$ do art. 216 da Constituição Federal; altera a Lei no 8.112, de 11 de dezembro de 1990; revoga a Lei no 11.111, de 5 de maio de 2005, e dispositivos da Lei no 8.159, de 8 de janeiro de 1991; e dá outras providências Brasília: Diário Oficial da União, Brasília, 18 de novembro de 2011. Edição extra, 2011:1-4.

24. Brasil. Ministério da Saúde. Portaria no 1.583, de 19 de Julho de 2012. Dispõe, no âmbito do Ministério da Saúde e entidades a ele vinculadas, sobre a execução da Lei no 12.527, de 18 de novembro de 2011, que versa sobre a lei de Acesso à Informação, e do Decreto № 7.724, de 16 de maio de 2012, que a regulamenta. Brasília: Diário Oficial da União 2012; 20 jul.

25. Brasil. Conselho Nacional de Saúde. Resolução № 466, de 12 de dezembro de 2012. Aprovar as diretrizes e normas regulamentadoras de pesquisa envolvendo seres humanos. Brasília: Diário Oficial da União, no 112, 13 jun. 2013. Seção 1 , 2012.

26. Brasil. Ministério da Saúde. Portaria o 183, de 30 de janeiro de 2014. Regulamenta o incentivo financeiro de custeio para implantação e manutenção de ações e serviços públicos estratégicos de vigilância em saúde, previsto no art. 18, inciso I, da Portaria no 1.378/GM/MS, de 9 de julho de 2013, com a definição dos critérios de financiamento, monitoramento e avaliação. Brasília: Diário Oficial da União, 2014. 


\section{APÊNDICE A - DEFINIÇÃO DE CASO DE SÍNDROME GRIPAL EM DOCUMENTOS DO MINISTÉRIO DA SAÚDE, 2009-2013}

\section{Guia de Vigilância Epidemiológica - 7ª̣ Edição, 2009}

"like illness, ILI ou flu like".

Indivíduo com doença aguda (com duração máxima de 5 dias), apresentando febre (ainda que referida) e pelo menos um sintoma respiratório (tosse ou dor de garganta), na ausência de outros diagnósticos. Abrange as seguintes infecções respiratórias agudas, com seus respectivos CID: J00 (todos) - Nasofaringite aguda (resfriado comum); J02.9 - Faringite aguda não especificada; J03.9 - Amigdalite aguda não especificada; J04.0 - Laringite aguda; J04.1 - Traqueíte aguda; J04.2 - Laringotraqueíte aguda; J06 (todos) - Infecção aguda das vias aéreas superiores e não especificadas; J10 (todos) - Influenza devido a vírus influenza identificado; e J11 (todos) - Influenza devida a vírus influenza não identificado.

Doenças Infecciosas e Parasitárias: Guia de Bolso. 8ª Edição revisada, 2010

"like illness, ILI ou flu like". Indivíduo com doença aguda (duração máxima de 5 dias) apresentando febre (ainda que referida) e tosse ou dor de garganta na ausência de outros diagnósticos.

Protocolo de Vigilância Epidemiológica da Influenza Pandêmica (H1N1) 2009 Notificação, Investigação e Monitoramento, 2010.

"Indivíduo com doença aguda (com duração máxima de cinco dias), apresentando febre (ainda que referida) acompanhada de tosse ou dor de garganta, na ausência de outros diagnósticos", e abrange as seguintes infecções respiratórias agudas com seus respectivos CID:

J00 Nasofaringite aguda (resfriado comum)

J02.9 Faringite aguda não especificada

J03.9 Amigdalite aguda não especificada

J04.0 Laringite aguda

J04.1 Traqueite aguda

J04.2 Laringotraqueite aguda

J06 Infecção aguda das vias aéreas superiores de localizações múltiplas e não especificadas"

Informe Técnico de Influenza - Edição nำ, janeiro de 2012

"Indivíduo que apresentou febre acompanhada de tosse ou dor de garganta"

\section{Protocolo de Tratamento de Influenza - 2013}

"Indivíduo que apresente febre de início súbito, mesmo que referida, acompanhada de tosse ou dor de garganta e pelo menos um dos seguintes sintomas: cefaleia, mialgia ou artralgia, na ausência de outro diagnóstico específico. Em crianças com menos de dois anos de idade, considera-se também como caso de síndrome gripal: febre de início súbito (mesmo que referida) e sintomas respiratórios (tosse, coriza e obstrução nasal), na ausência de outro diagnóstico específico". 
APÊNDICE B - CO-INFECÇÃO IDENTIFICADA POR IMUNOFLUORESCÊNCIA INDIRETA PARA VÍRUS RESPIRATÓRIOS. SIVEP-GRIPE, BRASIL, 2010-2013

\begin{tabular}{|c|c|c|c|c|c|c|c|c|c|c|c|c|c|c|c|}
\hline \multirow{2}{*}{\multicolumn{2}{|c|}{ Infecção }} & \multicolumn{14}{|c|}{ Co-infecção } \\
\hline & & \multicolumn{2}{|c|}{ Influenza A } & \multicolumn{2}{|c|}{ Influenza B } & \multicolumn{2}{|c|}{ Para 1} & \multicolumn{2}{|c|}{ Para 2} & \multicolumn{2}{|c|}{ Para 3} & \multicolumn{2}{|c|}{ Adeno } & \multicolumn{2}{|c|}{ VRS } \\
\hline & $\mathrm{N}$ & $\mathrm{n}$ & $\%$ & $n$ & $\%$ & $n$ & $\%$ & $n$ & $\%$ & $n$ & $\%$ & $\mathrm{n}$ & $\%$ & $n$ & $\%$ \\
\hline Influenza A & 1085 & 0 & 0,0 & 4 & 0,4 & 7 & 0,6 & 3 & 0,3 & 5 & 0,5 & 15 & 1,4 & 23 & 2,1 \\
\hline Influenza B & 525 & 4 & 0,8 & 0 & 0,0 & 3 & 0,6 & 7 & 1,3 & 3 & 0,6 & 8 & 1,5 & 14 & 2,7 \\
\hline Para 1 & 203 & 7 & 3,4 & 3 & 1,5 & 0 & 0,0 & 2 & 1,0 & 6 & 3,0 & 5 & 2,5 & 6 & 3,0 \\
\hline Para 2 & 136 & 3 & 2,2 & 7 & 5,1 & 2 & 1,5 & 0 & 0,0 & 3 & 2,2 & 3 & 2,2 & 7 & 5,1 \\
\hline Para 3 & 329 & 5 & 1,5 & 3 & 0,9 & 6 & 1,8 & 3 & 0,9 & 0 & 0,0 & 7 & 2,1 & 5 & 1,5 \\
\hline Adeno & 684 & 15 & 2,2 & 8 & 1,2 & 5 & 0,7 & 3 & 0,4 & 7 & 1,0 & 0 & 0,0 & 30 & 4,4 \\
\hline VRS & 1661 & 23 & 1,4 & 14 & 0,8 & 6 & 0,4 & 7 & 0,4 & 5 & 0,3 & 30 & 1,8 & 0 & 0,0 \\
\hline Total & 4623 & 57 & 1,2 & 39 & 0,8 & 29 & 0,6 & 25 & 0,5 & 29 & 0,6 & 68 & 1,5 & 85 & 1,8 \\
\hline
\end{tabular}


ANEXOS

\section{ANEXO A - PARECER DO COMITÊ DE ÉTICA DA FACULDADE DE CIÊNCIAS DA SAÚDE DA UNIVERSIDADE DE BRASÍLIA (continua)}

FACULDADE DE CIÊNCIAS DA
SAÚDE DA UNIVERSIDADE DE Platorforma
BnB
BRASÍLIA - CEP/FS-UNB

\section{PARECER CONSUBSTANCIADO DO CEP}

\section{DADOS DO PROJETO DE PESQUISA}

Título da Pesquisa: Capacidade de alerta e resposta: um estudo dos atributos do sistema de vigilância epidemiológica da influenza no Brasil

Pesquisador: Ligia Maria Cantarino da Costa

Área Temática:

Versão: 3

CAAE: 27907114.8 .0000 .0030

Instituição Proponente: Faculdade de Ciências da Saúde da Universidade de Brasília

Patrocinador Principal: Financiamento Próprio

\section{DADOS DO PARECER}

Número do Parecer: 1.267.137

Apresentação do Projeto:

Resumo:

"A influenza ou gripe talvez seja a infecção que causou mais doenças e mortes até a atualidade. Doença aguda do sistema respiratório causada pelo vírus influenza tem alta capacidade de transmissão e distribuição global. A influenza é uma preocupação das autoridades sanitárias mundiais pelas repercussões na morbimortalidade, pelo elevado potencial de transmissão e gravidade devido à sua capacidade de variações antigênicas. No Brasil a vigilância da influenza é composta pela vigilância sentinela de síndrome gripal e pelas vigilâncias sentinela e universal de síndrome respiratória aguda grave. Os objetivos são a identificação dos vírus respiratórios circulantes para contribuir com os estudos sobre a composição da vacina; colaborar no monitoramento da demanda de atendimento médico; monitorar os casos graves hospitalizados e óbitos para identificar o

comportamento da influenza no país para orientar a tomada de decisão e adoção de novas estratégias de controle. As avaliações de sistemas de vigilância epidemiológica devem ser periódicas para assegurar seu monitoramento e que fragilidades detectadas no possam ser objeto de recomendações para superação. Cada sistema de vigilância possui características ou atributos que contribuem diretamente para a sua capacidade de cumprir seus objetivos específicos e são

\footnotetext{
Endereço: Faculdade de Ciências da Saúde - Campus Darcy Ribeiro

Bairro: Asa Norte CEP: $70.910-900$

UF: DF Município: BRASILIA

Telefone: (61)3107-1947

E-mail: cepfsunb@gmail.com
} 


\section{ANEXO A - PARECER DO COMITÊ DE ÉTICA DA FACULDADE DE CIÊNCIAS DA SAÚDE DA UNIVERSIDADE DE BRASÍLIA (continuação)}

FACULDADE DE CIÊNCIAS DA
SAÚDE DA UNIVERSIDADE DE Plotoforma
BnBasíliA - CEP/FS-UNB

Continuação do Parecer: 1.267.137

utilizados para as avaliações. São quatro atributos qualitativos: sensibilidade, valor preditivo positivo, representatividade e oportunidade e três atributos quantitativos: simplicidade, flexibilidade e aceitabilidade. O propósito deste estudo é avaliar os atributos do sistema de vigilância epidemiológica da influenza no Brasil utilizando a metodologia de avaliação de atributos quantitativos e qualitativos de sistemas de vigilância preconizados pelo Centers for Disease Control and Prevention-CDC. Será um estudo descritivo, de avaliação de sistemas de vigilância em saúde pública que terá como fonte, banco de dados secundários não nominado, sem qualquer identificação dos indivíduos - proveniente das notificações registradas nos anos 2012 e 2013 no Sistema Nacional de Agravos de Notificação - SINAN".

Metodologia: estudo descritivo de avaliação de sistemas de vigilância em saúde pública. Será realizada a descrição do propósito e da operação do sistema de vigilância de influenza, bem como das notificações registradas no SINAN.

- realização de consulta à legislação, a documentos de trabalho e materiais diversos, como as Notas Técnicas e Informes Epidemiológicos da Secretaria de Vigilância em Saúde;

- estudo do sistema de vigilância de influenza.

O período escolhido para o estudo será entre os anos de 2012 e 2013, devido a alteração da vigilância da gripe no país após a implementação da Portaria 2.693/2011.

Será utilizado como fonte, banco de dados secundários proveniente do Sistema Nacional de Agravos de Notificação - SINAN - nos anos 2012 e 2013 (dos campos existentes na Ficha de Notificação Individual, serão selecionados aqueles de interesse para análise, com base no estudo).

\section{Objetivo da Pesquisa:}

Objetivo da pesquisa:

Objetivo Principal: "Avaliar os atributos do sistema de vigilância epidemiológica da influenza nos anos de 2012 e 2013".

Objetivos específicos: "1. Descrever o atributo oportunidade do sistema de vigilância epidemiológica de influenza nas diferentes etapas da investigação epidemiológica nos anos de 2012 e 2013; 2. Descrever os atributos sensibilidade, representatividade e o valor preditivo positivo do sistema de vigilância epidemiológica de influenza nos anos de 2012 e 2013; 3. Descrever os atributos simplicidade, flexibilidade e a aceitabilidade do sistema de vigilância epidemiológica de influenza nos anos de 2012 e 2013; 4. Avaliar os atributos e propor recomendações para aperfeiçoamento do sistema de vigilância de influenza".

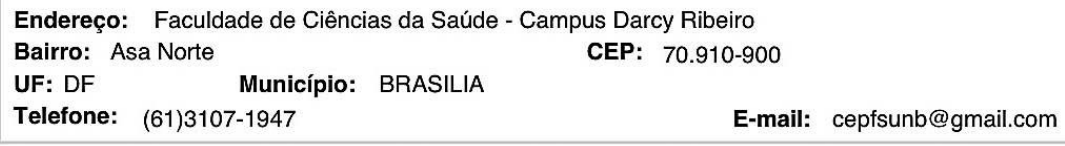




\section{ANEXO A - PARECER DO COMITÊ DE ÉTICA DA FACULDADE DE CIÊNCIAS DA SAÚDE DA UNIVERSIDADE DE BRASÍLIA (continuação)}

FACULDADE DE CIÊNCIAS DA
SAÚDE DA UNIVERSIDADE DE Platoforma
BnBASÍLIA - CEP/FS-UNB

Continuação do Parecer: 1.267.137

Hipóteses: "O estudo e avaliação dos atributos da vigilância trará subsídios para verificar o equilíbrio do sistema da vigilância influenza no Brasil”.

\section{Avaliação dos Riscos e Benefícios:}

Avaliação de riscos e benefícios: "Não há riscos envolvidos na pesquisa ou na aplicação dos instrumentos do estudo. A pesquisa está baseada em dados secundários, de bancos não nominados. Observação: o número da amostra não faz referência a número de indivíduos recrutados e sim ao número de casos oriundos de notificação registrados nos bancos de dados utilizados".

Benefícios: "O estudo trará benefícios diretos para os gestores da vigilância pelo conhecimento e avaliação dos atributos do sistema e, indireto, para a sociedade pelo papel fundamental da vigilância no monitoramento e planejamento de ações de controle na eventualidade de surtos e epidemias".

\section{Comentários e Considerações sobre a Pesquisa:}

Os pesquisadores responderam adequadamente à solicitação deste CEP, conforme elencado no último ponto do parecer postado em 05 de setembro de 2015 (Considerações finais a critério do CEP), enviando carta resposta, com as devidas informações e apontamentos necessário para a análise do projeto.

Os pesquisadores realizaram a adequação de todos os documentos que compõe o processo, com a atualização do período do estudo e banco de dados. Também foram apresentados documentos que apresentam a autorização para a utilização dos bancos de dados elencados na Emenda 1.

\section{Considerações sobre os Termos de apresentação obrigatória:}

Documentos que compõem o processo + EMENDA 1:

1. Informações básicas do Projeto: "PB_INFORMAÇÕES_BÁSICAS_DO_PROJETO_563551_E1.pdf”, postado em 04/08/2015. Cronograma da pesquisa encontra-se desatualizado. Com a solicitação realizada na Emenda, faz-se necessário a revisão do mesmo;

2. Outros: "Emenda_agosto 2015.pdf", postado em 04/08/2015. Documento devidamente assinado pela pesquisadora responsável pelo estudo;

3. Informações básicas do Projeto: "PB_INFORMAÇÕES_BÁSICAS_DO_PROJETO_279071.pdf", postado em 24/02/2014. Já avaliado por este CEP;

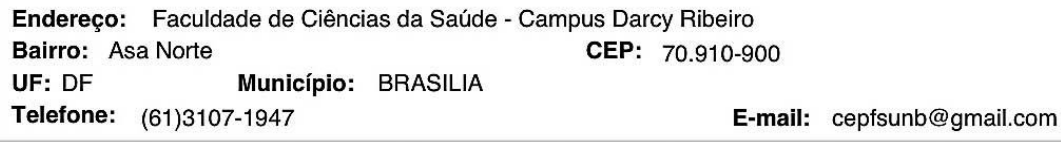




\section{ANEXO A - PARECER DO COMITÊ DE ÉTICA DA FACULDADE DE CIÊNCIAS DA SAÚDE DA UNIVERSIDADE DE BRASÍLIA (continuação)}

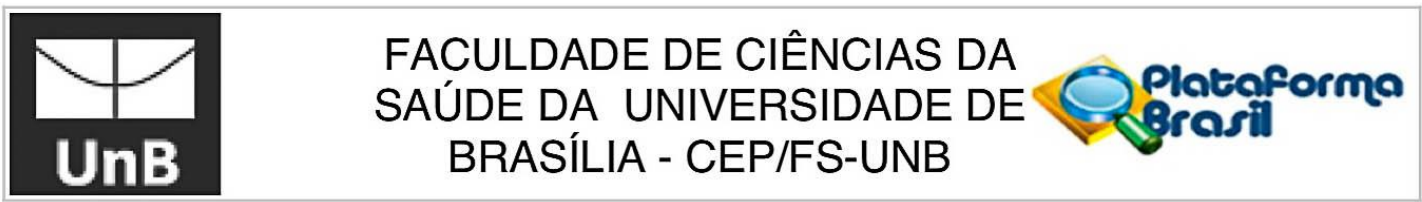

Continuação do Parecer: 1.267.137

4. Outros: "Orientação acesso ao banco de dados influenza.pdf", postado em 24/02/2014. Já avaliado por este CEP;

5. Informações básicas do Projeto: "PB_INFORMAÇÕES_BÁSICAS_DO_PROJETO_279071.pdf”, postado em 24/02/2014. Já avaliado por este CEP;

6. Outros: "Edgar Hamann_Lattes.pdf", postado em 24/02/2014. Já avaliado por este CEP;

7. Outros: "Ligia Catarino_Lattes.pdf”, postado em 24/02/2014. Já avaliado por este CEP;

8. Outros: “Justificativa_autorização banco de dados_ligia.pdf, postado em 24/02/2014. Já avaliado por este CEP;

9. Informações básicas do Projeto: "PB_INFORMAÇÕES_BÁSICAS_DO_PROJETO_279071.pdf”, postado em 24/02/2014. Já avaliado por este CEP;

10. Folha de rosto: "Folha de rosto_Ligia_2014.pdf”, postada em 24/02/2014. Já avaliado por este CEP;

11. Outros: “CEP_dispensa do TCLE.pdf”, postada em 22/02/2014. Já avaliado por este CEP;

12.Outros: "CEP_Termo de Ciência da Instituição Co-participante.pdf", postada em 22/02/2014. Já avaliado por este CEP;

13. Outros: “CEP_Carta de Apresentação.pdf”, postada em 22/02/2014. Já avaliado por este CEP;

14. Projeto Detalhado/Brochura Investigador: "Projeto-Doutorado_Ligia Catarino 14-02-22.pdf”, postada em 22/02/2014. Já avaliado por este CEP;

Documentos acrescentados ao projeto após Parecer $n^{\circ} 1.215 .940$, emitido em 05/09/2015

1. Informações Básicas do Projeto: "PB_INFORMAÇÕES_BÁSICAS_563551_E1.pdf”, postado em 08/09/2015. Documento foi atualizado;

2. Outros: "AutorizaçãoB_dados.pdf", postado em 08/09/2015. Comprovação da autorização de uso de banco de dados;

3. Outros: "AutorizaçãoA_dados.pdf", postado em 08/09/2015. Comprovação da autorização de uso de banco de dados;

4. Outros: “Resposta_Parecer_agosto_2015.pdf”, postado em 08/09/2015. Documento devidamente redigido e assinado.

Recomendações:

Não se aplica

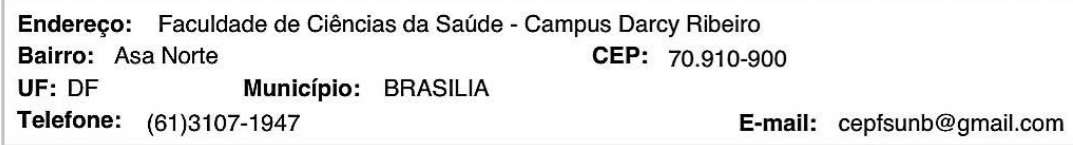




\section{ANEXO A - PARECER DO COMITÊ DE ÉTICA DA FACULDADE DE CIÊNCIAS DA SAÚDE DA UNIVERSIDADE DE BRASÍLIA (continuação)}

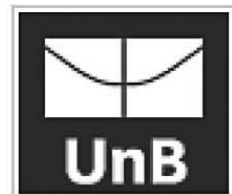

\section{FACULDADE DE CIÊNCIAS DA SAÚDE DA UNIVERSIDADE DE BRASÍLIA - CEP/FS-UNB}

Continuação do Parecer: 1.267.137

Conclusões ou Pendências e Lista de Inadequações:

ANÁLISE DAS RESPOSTAS ÀS PENDÊNCIAS APONTADOS NO PARECER NO. 1.215.940 DE 05/09/2015:

1. Solicita-se adequar na Plataforma Brasil a versão atual do projeto e o projeto detalhado com as solicitações de modificação/inclusão realizadas na Emenda 1: a) Quanto às fontes de dados; b) quanto ao período do estudo - revisão do cronograma.

Apresentar dois documentos com modificações/marcações e com as mesmas incorporadas.

Modificação do Projeto Detalhado e da Plataforma Brasil realizadas. PENDÊNCIA ATENDIDA;

2. Solicita-se apresentar termo de autorização para acesso aos dados do Sistema de Vigilância Epidemiológica da Gripe (SIVEP-Gripe) e do Sistema Gerenciador de Ambiente Laboratorial (GAL) do SINAN. Anexada documentação (autorização) solicitada. PENDÊNCIA ATENDIDA.

Protocolo de pesquisa em conformidade com a Resolução CNS 466/2012 e Complementares.

Considerações Finais a critério do CEP:

Em acordo com a Resolução 466/12 CNS, ítens X.1.- 3.b. e XI.2.d, os pesquisadores responsáveis deverão apresentar relatórios parcial semestral e final do projeto de pesquisa, contados a partir da data de aprovação do protocolo de pesquisa.

Este parecer foi elaborado baseado nos documentos abaixo relacionados:

\begin{tabular}{|l|l|c|l|c|}
\hline \multicolumn{1}{|c|}{ Tipo Documento } & \multicolumn{1}{|c|}{ Arquivo } & Postagem & \multicolumn{1}{c|}{ Autor } & Situação \\
\hline $\begin{array}{l}\text { Informações Básicas } \\
\text { do Projeto }\end{array}$ & $\begin{array}{l}\text { PB_INFORMAÇÕES_BÁSICAS_563551 } \\
\text { E1.pdf }\end{array}$ & $\begin{array}{c}08 / 09 / 2015 \\
15: 56: 46\end{array}$ & Aceito \\
\hline Outros & AutorizacaoB_dados.pdf & $\begin{array}{c}08 / 09 / 2015 \\
15: 52: 05\end{array}$ & $\begin{array}{l}\text { Ligia Maria Cantarino } \\
\text { da Costa }\end{array}$ & Aceito \\
& & $\begin{array}{c}08 / 09 / 2015 \\
15: 51: 23\end{array}$ & $\begin{array}{l}\text { Ligia Maria Cantarino } \\
\text { da Costa }\end{array}$ & Aceito \\
\hline Outros & AutorizacaoA_dados.pdf & $08 / 09 / 2015$ \\
& & $\begin{array}{l}\text { Ligia Maria Cantarino } \\
\text { da Costa }\end{array}$ & Aceito \\
\hline Outros & Resposta_Parecer_agosto_2015.pdf & $08 / 09 / 2015$ & $\begin{array}{l}\text { Ligia Maria Cantarino } \\
\text { da Costa }\end{array}$ & Aceito \\
\hline $\begin{array}{l}\text { Projeto Detalhado / } \\
\text { Brochura } \\
\text { Investigador }\end{array}$ & Projeto_corrigido_2015.pdf & $15: 00: 14$ & \\
\hline Outros & & $04 / 08 / 2015$ & & Aceito \\
\hline Outros & Emenda_agosto 2015.pdf & $24 / 02 / 2014$ & & Aceito \\
\hline
\end{tabular}

Endereço: Faculdade de Ciências da Saúde - Campus Darcy Ribeiro

Bairro: Asa Norte

UF: DF

Município: BRASILIA

CEP: $70.910-900$

Telefone: (61)3107-1947

E-mail: cepfsunb@gmail.com 


\section{ANEXO A - PARECER DO COMITÊ DE ÉTICA DA FACULDADE DE CIÊNCIAS DA SAÚDE DA UNIVERSIDADE DE BRASÍLIA (continuação)}

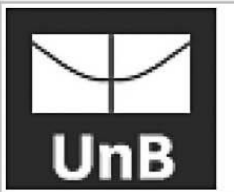

\section{FACULDADE DE CIÊNCIAS DA SAÚDE DA UNIVERSIDADE DE BRASÍLIA - CEP/FS-UNB}

Continuação do Parecer: 1.267.137

\begin{tabular}{|c|c|c|c|}
\hline Outros & dados Influenza.pdf & $16: 31: 57$ & Aceito \\
\hline Outros & Edgar Hamann_Lattes.pdf & $\begin{array}{c}24 / 02 / 2014 \\
16: 22: 31\end{array}$ & Aceito \\
\hline Outros & Ligia Cantarino_Lattes.pdf & $\begin{array}{c}24 / 02 / 2014 \\
16: 18: 31 \\
\end{array}$ & Aceito \\
\hline Outros & $\begin{array}{l}\text { Justificativa_autorização banco de } \\
\text { dados_ligia.pdf }\end{array}$ & $\begin{array}{c}24 / 02 / 2014 \\
16: 17: 38 \\
\end{array}$ & Aceito \\
\hline Folha de Rosto & Folha de Rosto_Ligia_2014.pdf & $\begin{array}{c}24 / 02 / 2014 \\
11: 45: 51 \\
\end{array}$ & Aceito \\
\hline Outros & CEP_dispensa do TCLE.pdf & $\begin{array}{c}22 / 02 / 2014 \\
20: 51: 00\end{array}$ & Aceito \\
\hline Outros & $\begin{array}{l}\text { CEP_Termo de Ciência da Instituição } \\
\text { Co-participante.pdf }\end{array}$ & $\begin{array}{c}22 / 02 / 2014 \\
20: 48: 13 \\
\end{array}$ & Aceito \\
\hline Outros & CEP_Carta de Apresentação.pdf & $\begin{array}{c}22 / 02 / 2014 \\
20: 47: 04\end{array}$ & Aceito \\
\hline
\end{tabular}

Situação do Parecer:

Aprovado

Necessita Apreciação da CONEP:

Não

BRASILIA, 07 de Outubro de 2015
Assinado por:
Marie Togashi
(Coordenador) 


\section{ANEXO B - SEGUNDO ARTIGO - INFLUENZA NO BRASIL: CAMINHOS DA VIGILÂNCIA - CARTA DE ACEITE PARA PUBLICAÇÃO NO THE JOURNAL OF INFECTION IN DEVELOPING COUNTRIES}

03/08/2015

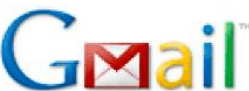

Gmail - [JIDC] Editor Decision - ID\#7135 - ID\#7135

Ligia Maria Cantarino da Costa <ligiacantarino@gmail.com>

\section{[JIDC] Editor Decision - ID\#7135 - ID\#7135}

Dr Sojan abraham <sojan.abraham@ttuhsc.edu>

3 de agosto de 2015 18:25

Para: Ligia Cantarino <ligiacantarino@gmail.com>

Cc: Edgar Merchan-Hamann <merchan.hamann@gmail.com>

Ligia Cantarino:

We have reached a decision regarding your submission to The Journal of Infection in Developing Countries, "Influenza in Brazil: surveillance pathways".

Our decision is to accept the manuscript for publication

Dr Sojan abraham

Texas Tech University,

Phone 9152154245

sojan.abraham@ttuhsc.edu

The Journal of Infection in Developing Countries

http://www.jidc.org/

The Journal of Infection in Developing Countries is a non-profit

organization that operates solely on funding from grants and donations.

Please consider making a donation, or ask your institution to make a

donation to JIDC, so that we may continue to communicate the rich scientific

discoveries of developing nations! 


\title{
ANEXO C - SEGUNDO ARTIGO - "INFLUENZA IN BRAZIL: SURVEILLANCE \\ PATHWAYS". VERSÃO FINAL DO TEXTO APROVADO PARA PUBLICAÇÃO PELA \\ REVISTA THE JOURNAL OF INFECTION IN DEVELOPING COUNTRIES
}

\section{Influenza in Brazil: surveillance pathways}

\author{
Ligia Cantarino $^{1}$, Edgar Merchan-Hamann ${ }^{2}$ \\ ${ }^{1}$ Faculty of Agronomy and Veterinary Medicine - University of Brasília, Brasília, DF, Brazil \\ ${ }^{2}$ Faculty of Health Sciences - University of Brasília, Brasília, DF, Brazil
}

\section{Corresponding author}

Ligia Cantarino

Faculdade de Agronomia e Medicina Veterinária

Universidade de Brasília - UnB

Campus Darcy Ribeiro, Instituto Central de Ciências, Caixa Postal 4508

70.910-900 - Brasília - DF - Brasil

Tel: + 556131077565

Fax: + 556131077118

Email: ligiacantarino@unb.br

Running title: Influenza in Brazil: surveillance pathways

Keywords: influenza; epidemiological surveillance; public health

\begin{abstract}
Influenza is a viral disease of global concern that has demanded the attention of health authorities. Since 1947, as a preventive measure, the World Health Organization monitors viral circulation to define the annual vaccine through a worldwide network of laboratories. This article presents the structuring of influenza surveillance in Brazil and highlights virological surveillance and the role of diagnostic laboratories as well as the expansion of actions to improve detection and expedite responses. The model set corresponds to sentinel surveillance complemented by the universal notification of severe acute respiratory syndrome investigating outbreaks, deaths, and unusual events and monitoring hospitalization and mortality in an expanded surveillance. In this review, we address
\end{abstract}


aspects of influenza surveillance in animals, the need for interagency integration, and the sharing of information in many surveillance systems.

\section{INTRODUCTION}

Influenza ("flu") is a respiratory disease of worldwide distribution that is caused by the influenza virus Myxovirus influenzae, which belongs to the Orthomyxoviridae family and includes viruses $\mathrm{A}, \mathrm{B}$, and $\mathrm{C}$. The antigenic variations of the virus comprise an important immunological escape mechanism that favors the infection of new susceptible hosts. These factors, along with high transmissibility and zoonotic and pandemic potential, make the challenge of its prevention and control an increasing problem with a recognized importance in public health $[1,2]$.

This viral infection has been considered as a multifaceted disease throughout history. Flu is a common disease with a benign clinical course and known seasonality that may lead to severe and fatal medical conditions. Pandemics such as those that occurred in the past - the Spanish flu (1918-20), Asian flu (1957-60), and Hong Kong flu (1968-72) - caused millions of deaths. In the pandemic episode of 2009, the H1N1 virus rapidly spread among humans and had high morbidity rates [3,4,5].

Depending on the pandemic potential and clinical manifestation severity, influenza presents different problems from the public health perspective that require specific surveillance and control [6]. In fact, the worldwide surveillance of this disease is recommended [7].

Given the threats of flu pandemic, the importance of this disease has motivated this narrative review in which we present the structure of surveillance of human influenza in Brazil as well as a brief overview of surveillance aspects in animals.

\section{Global surveillance}

Since 1947, the World Health Organization (WHO) has been monitoring the activity of the influenza virus through a network of laboratories for viral identification, which was initially named as 
Global Influenza Surveillance Network (GISN). In 2011, the name of this network was changed to Global Influenza Surveillance and Response System (GISRS). Its objective is to follow the evolution of influenza viruses and provide information to support the WHO's recommendations for laboratory diagnostics, vaccines, antiviral susceptibility and risk assessment, in addition to establish a mechanism of global alert of the emergence of viruses with pandemic potential $[2,8]$.

The objectives of influenza virological surveillance are to: identify viral circulation - types and subtypes - as well as its correlation with regional and global patterns; describe antigenic and genetic features; monitor antiviral sensibility; understand the correlation between a viral strain and its severity; and provide information and samples for the selection of virus candidates for the production of vaccines [7].

The GISRS is composed of six Collaborating Centers (CCs) of the WHO and 141 institutions of viral disease diagnosis in 111 member states of the WHO. The diagnosis laboratories are known as National Influenza Centers (NICs) [8]. The organization of this laboratory system assigns the NICs of each country as responsible for collecting clinical specimens, isolating, and sending viral samples of interest to the CCs. In addition to the antigenic and genetic characterization of the viruses, the CCs have the purpose of providing training and developing guidelines for laboratory techniques, quality control, and assessment of standardized procedures throughout the network. For technique standardization and unification, the protocols and common reagents are provided by the WHO through the Centers for Disease Control (CDC) to the NICs [2].

Brazil, part of the GISRS, has three WHO-accredited NIC laboratories: the Virology Laboratory of the Evandro Chagas Institute in Pará (IEC/PA); the Respiratory Virus Laboratory of the Adolfo Lutz Institute in São Paulo (IAL/SP); and the Respiratory Virus and Measles Laboratory of the Oswaldo Cruz Foundation in Rio de Janeiro (Fiocruz/RJ). The first two laboratories are recognized by the National System of Public Health Laboratories (Sislab) as regional references, while the latter is considered a national reference for influenza in Brazil $[9,10]$. 
In addition to viral surveillance, since 1950 a global standardized system has been improving the monitoring activities of influenza virus with the following specific objectives: describing the seasonality of influenza in each country; signaling the start of the influenza season; establishing and monitoring the trends of influenza-like illness (ILI) and severe acute respiratory syndrome (SARS). This information is important since it provides data on the disease burden and the impact of influenza compared to other diseases; it assists in the identification and monitoring of high-risk groups and annual changes in severity, and factors in specify priorities for the utilization of resources [7].

\section{Surveillance of human influenza in Brazil}

In Brazil, the surveillance of influenza started in the 1990s with the identification of the circulating viruses in some parts of the country and in outbreak situations [11]. Based on the sentinel surveillance system of virus circulation developed in Paris, France, and started in October of 1984 by the Groupe Regional d'Observation de la Grippe (GROG) [12], in 1995, the GROG Flu Monitoring Group was created in Brazil by some public and private health services from the Southern and Southeastern regions. The goal was to systematize information about the circulation of respiratory viruses in Brazil, the influenza virus in particular. In 2000, the Brazilian GROG was renamed the VigiGripe Project, part of the VigiVirus Project. This group was associated with the Federal University of São Paulo in a joint effort with the Enteric and Respiratory Virus Department of the IAL/SP $[11,13,14]$. The epidemiological surveillance of influenza was nationally implemented in 2000 based in Sentinel Units (SUs) and the use of indirect morbidity and mortality associated data [9]. At this time, the epidemiological surveillance was performed by the National Centre of Epidemiology (Cenepi) of Ministry of Health, which structured the technical team in coordination with the state offices of health and the laboratories of respiratory viruses of the IAL/SP, IEC/PA, and Fiocruz/RJ, which were accredited as reference centers by the WHO [11]. Therefore, a set of specific and ongoing actions was introduced to elucidate the behavior of influenza and allow the introduction of appropriate, timely, and effective preventive measures [9,10]. 
The implemented surveillance system aimed to: monitor the circulation of influenza virus strains and morbidity trends; evaluate the impact of vaccination; respond to unusual situations; and produce information about the disease. To select at least one SU per state, the following specific criteria were adopted: the real interest of the unit in participating in the epidemiological surveillance work; its situation as a care center regarding consultation demands for general practice or pediatrics; the minimum requirements for staff and structural resources; preferable close location to the laboratory; and good managerial performance. Each SU should record the proportion of consultations due to ILI compared to the total number of consultations and send five biological samples of respiratory secretions each week to one of the 27 Central Laboratories of Public Health (Lacen) [9].

The surveillance of influenza has been able to identify the circulating respiratory viruses as well as their seasonality and high-risk populations. In a study of the Brazilian surveillance of influenza performed in 2000-2010 [10], a total of 29,318,698 patient consultations were recorded in the SUs, of which $3,291,949(11 \%)$ were due to ILI. Of these, 37,120 (1\%) had samples of nasopharyngeal secretions collected for respiratory virus detection. Of the 6,421 (17\%) positive results, 1,690 (26\%) were positive for influenza A, 567 (9\%) for influenza B, 277 (4\%) for parainfluenza 1,571 (9\%) for parainfluenza 2,589 (9\%) for parainfluenza 3,742 (12\%) for adenovirus, and 1,985 (31\%) for respiratory syncytial virus.

In 2003, strengthening of the influenza surveillance was driven by the outbreaks in the Asian region and some European countries of an avian influenza (AI) virus with high pathogenicity (A/H5N1), which led to episodes of severe disease and mortality $[1,2,15]$. This situation generated worldwide concern and, in Brazil, several organizations were mobilized to discuss strategies that led to Brazil's Contingency Plan to Confront an Influenza Pandemic, which was presented and discussed in an international seminar in Rio de Janeiro in November 2005. This collective effort placed influenza on the agenda of the national policy of public health [11].

With the approval of the review of the International Health Regulations (IHR) by the World Health Assembly in 2005, the signatory countries also reviewed their monitoring structures and 
processes, surveillance, and responses to Public Health Emergencies of International Concern (PHEIC), and committed to developing the capability to respond to those emergencies $[2,14]$.

With regard to the notification of outbreaks or death, human influenza became part of the list of the national mandatory notifiable diseases in July 2005 [16]. Human influenza by new subtype (pandemic) was included in February 2006 [17]. The ordinance GM/MS No. 104, January 25, 2011, in addition to defining the terminologies according to the IHR 2005, changed the nomenclature of human influenza by new subtype as mandatory and immediate notification, and classified human influenza as a mandatory notifiable disease in SUs [18]. According to the current regulations, Ordinance GM/MS No. 1271 created on June 6, 2014, it is registered as human influenza provided by a new viral subtype [19].

The regulation of the Operational directives of the Pacts for Life and Management, by Ordinance GM/MS No. 699 created March 30, 2006 also contributed to the strengthening of influenza surveillance. Prerogatives of the transfer of federal funds were agreed to strengthen the capacity to respond to influenza among other emerging and endemic diseases. The national goal for 2006 established the implementation of SUs and the Information System of Epidemiological Surveillance of Influenza Virus in Brazil (Sivep-Gripe) in $100 \%$ of the capitals. The defined indicator for monitoring and evaluation was the system participation rate: number of epidemiological weeks reported divided by the total of epidemiological weeks during that period multiplied by 100 . Having the financial investments targeting qualification, training, and supervision and the acquisition of supplies and laboratory and computer equipment, the surveillance of influenza was gradually implemented and expanded throughout the country [20].

\section{Surveillance in 2009: pandemic year}

When the pandemic of 2009 was announced, in April, the national surveillance of influenza had a structured program in $60 \mathrm{SUs}$, which facilitated the monitoring of the recommended measures, 
which, even with shortcomings - problems with the system and dissemination of information showed an increase in infection by the A/H1N1 2009 virus among other respiratory viruses [21].

During the pandemic, with a sustained transmission in the country declared on August 16, 2009, only cases of SARS were placed under surveillance with notification, hospitalization, and laboratory research according to WHO recommendations. There were changes in the undertaken surveillance that went from a universal notification to a notification of death and SARS cases with laboratory confirmation of pandemic influenza infections [6]. This strategy contributed to the subsequent addition of SARS sentinel surveillance.

The end of the pandemic was declared on August 10, 2010 by the WHO. The worldwide disease activity returned to seasonal levels. In Brazil, the Southern and Southeastern regions were the most affected (66.2 and 9.7 cases/100,000 habitants, respectively), while the incidence of SARS per pandemic influenza was 14.5 cases/100,000 habitants. Children of less than 2 years old (22 cases/100,000 habitants) and young people 20-29 years old (16 cases/100,000 habitants) were the most affected age groups [6]. After stabilizing the epidemiological occurrence of influenza, the management experience acquired through the pandemic event, public awareness for health issues, and WHO recommendations led to governmental understanding of the need to review and adjust the surveillance strategy.

\section{Current surveillance of influenza in Brazil}

To improve and expand the surveillance of influenza, a mechanism of financial transfer was established by opt-in from the Brazil's National Health Fund to the Health Fund of the Federal District and Municipalities by GM/MS Ordinance No. 2693 on November 17, 2011 [22]. In this instrument, while seeking the minimum representativeness of viral circulation in all Brazilian states, for both severe and mild cases, the capitals and larger municipalities of the metropolitan regions were defined as sentinels, while the SU selection criteria were reviewed. This financial funding incentive for 
implementation and maintenance measures and strategic public health surveillance services was regulated by Ordinance GM/MS No. 183 on January 30, 2014 [23], which also established the financing, monitoring, and evaluation criteria.

Different strategies are employed in an expanded surveillance of influenza: sentinel surveillance of ILI and SARS; universal surveillance of SARS complemented by the monitoring of hospitalization and death by pneumonia according to the International Classification of Diseases and Related Health Problems (ICD-10) from J9 to J18; and the investigation of outbreaks, deaths, and unusual events of suspected influenza (Figure 1). The case definitions considered were: for ILI, individual with fever (including reported fever) accompanied by cough or sore throat and symptom onset within the last 7 days; and for SARS, individual hospitalized with fever, including reported fever, accompanied by cough, sore throat, and dyspnea as well as the signs of oxygen saturation < $95 \%$, respiratory distress, or increased respiratory rate [6].

The SUs record ILI consultations and aggregate data by epidemiological week (proportion of suspected ILI cases of the total number of consultations) and are committed to collecting five clinical samples per week to reach the minimum of $80 \%$ of the weekly goal for material collection. In due course, they register the weekly aggregate in the Sivep-Gripe by genre and age of the ILI consultations and the total number of consultations in the SU in at least $90 \%$ of the epidemiological weeks of the year. The GM/MS Ordinance No. 2693, created November 17, 2011, recommends this protocol and that the sentinel surveillance of SARS should be performed in the intensive care unit with monitoring of the aggregate surveillance for each epidemiological week by the ICD-10 of J09-J18. The aggregated Sivep-Gripe data about the hospitalization registered weekly are from at least $90 \%$ of the year's epidemiological weeks. Samples of at least $80 \%$ of the notified SARS cases are collected and sent to the Lacen. The registration of the universal (and immediate) notification of SARS is performed in the Influenza module of the of Notifiable Diseases Information System (Sinan), with records of outbreak investigation, deaths, and uncommon events suspected for influenza in the outbreak-specific component (Sinan-NET) and the monitoring of the hospitalization and mortality by the ICD-10 in 
J09-J18 in the Hospitalization Information System (HIS) and Mortality Information System (MIS), respectively [22].

The SU number increased across the country with the financial transfer strategy adopted in 2011. In 2009, there were 60 active SUs; in March 2014, there were 221. Despite the increase in number, these were not equally distributed across the country: the Northern region had 22 for ILI and 11 for SARS; the Northeastern region had 28 for ILI and 17 for SARS; the Southeastern region had 36 for ILI and 10 for SARS; the Southern region had 40 for ILI and 41 for SARS; and the Midwestern region had 11 for ILI and five for SARS [24].

\section{Laboratorial diagnosis in surveillance}

The diagnosis of influenza in Brazil follows the recommended WHO methodology with clinical specimens being tested for influenza A and B by indirect immunofluorescence (IIF) or by classical molecular techniques in real time. Positive samples are selected for virus isolation and genetic and antigenic characterization according to the standardized protocol from the CDC. Isolation of the influenza virus (in eggs or cells derived from the epithelium of the canine kidney - MDCK Madin-Darby canine kidney cells) is also performed [6].

Diagnosis depends on collected clinical sample quality, appropriate transportation and storage, and following of the biosafety guidelines. The clinical specimens can be obtained by nasal, nasopharyngeal, oral, or combined nasal + oral swabs, nasopharyngeal aspirate, or a nasal, bronchial, or tracheal wash. The samples should be collected preferably between the third and fifth days after symptom onset (acute disease stage) [9,25] being currently accepted, until the seventh day [6].

\section{Laboratory network}

To structure the surveillance of influenza, it was necessary to organize a laboratory diagnosis network, a mandatory infrastructure for the surveillance's efficiency. The National Influenza Diagnostic Network, one of the specific sub-networks that compose the National Epidemiological 
Surveillance Network, is part of the Sislab and acts under the scope of the Lacen and the three WHOaccredited NIC laboratories.

Clinical samples belonging to ILI and SARS cases are directed to the Lacens of each state for analysis of the detection of respiratory viruses: influenza $\mathrm{A}$ and $\mathrm{B}$; parainfluenza 1,2 , and 3 ; adenovirus; and syncytial virus. All of the samples with inconclusive results, all that are positive for influenza A and $10 \%$ of the negative are sent to one of the three NICs for quality control testing. In addition, the positive samples are also subjected to virus characterization, sequencing, and antiviral resistance testing [10].

Current laboratory analyses use molecular biology methodologies such as real-time reverse transcription polymerase chain reaction (RT-PCR). The laboratories that use this methodology direct $100 \%$ of samples that are positive for influenza A with no sub-type identification or inconclusive (regardless of the cycle threshold $[\mathrm{Ct}]$ ) and the positive samples with a $\mathrm{Ct} \leq 30$ according to seasonality to Reference Laboratories (RL) for complementary analysis. For ILI, $20 \%$ of the positive samples from poultry and swine workers and from outbreaks are sent. For SARS, 20\% of the positive samples during the seasonal period as well as all of the positive samples from outside that period should be sent. Samples from patients with SARS who are 2-65 years old or have been hospitalized for more than 10 days while taking oseltamivir phosphate should be referred to the RLs. Samples from patients who are 2-65 years old who died of SARS, had a recent history of flu vaccination, or used oseltamivir phosphate up until 2 days after symptom onset should also be sent to the RLs. In the Lacens that do not make a molecular diagnosis, the clinical material should be processed by IIF and the laboratory should send $100 \%$ of both the positive samples and the inconclusive ones [6].

Results and virus strains are periodically sent to the CDC for complementary analysis of the circulating viruses in Brazil, these are also forwarded to the WHO's Expert Meetings to support the formulation of a vaccine for the Southern Hemisphere [10]. 


\section{Vaccination as a preventive measure}

Immunization against influenza is recognized as an important control strategy. Used worldwide since 1945 , the vaccine composition changes periodically as a result of viral monitoring. Since 1977, the trivalent vaccine has included strains from influenza viruses A/H3N2, A/H1N1 and B. In 2004, with the co-circulation of the Victoria and Yamagata lineages of the influenza B virus, a study was initiated to develop a tetravalent composition [26]. In November 2014, in Brazil, the registration of the tetravalent influenza vaccine (fragmented, inactivated) [27], which consists of two strains of the virus influenza B in addition to the influenza A strains, was approved by ANVISA, the Brazilian Health Surveillance Agency.

Global influenza virological surveillance was an important factor in the WHO's adoption of specific recommendations for the composition of the annual influenza vaccine for the Southern Hemisphere in September 1998. Since then, the vaccine composition recommendation is performed twice yearly, in February for the Northern Hemisphere (from November to April) and in September for the Southern Hemisphere (from May to October). For the equatorial regions, the epidemiological data are considered to indicate the most appropriate composition - that from February or that from September [28].

In Brazil, the implementation of vaccination against influenza preceded the measures of epidemiologic surveillance [11]; in 1999, it was included in the National Immunization Program with annual national campaigns aimed at people who are 65 years old or more $[11,13]$ to protect high-risk groups such as the elderly and chronically ill from influenza complications.

In 2000, the age was reduced to people 60 years old and more. Gradually, other priority groups were also included; for the campaign in 2014 , with a target group of 49.6 million people, the indication was for people aged 60 years of age or more, health workers, native indigenous people, children 6 months to 5 years old, pregnant women, women up to 45 days after giving birth, people with chronic non-communicable diseases and other special clinical conditions, and inmates and 
employees of the prison system. The vaccine is available for people with special clinical conditions with a medical prescription at the Special Immunobiological Reference Centers [29].

\section{Information systems}

To follow the surveillance strategies for this disease, online information is used in different HIS: the Sivep-Gripe uses sentinel surveillance data, while the Sinan uses SARS universal surveillance data of aggravated morbidity, mortality, and case fatality [6] in addition to the HIS and MIS. The system Laboratory Environment Manager is also a tool for monitoring and controlling laboratory tests that are essential to the management and monitoring of the programs [30]. FluNet is also relevant since it is the international web-based platform of GISRS for the sharing of data and communication since 1996 [8].

\section{Aspects of flu surveillance in animals}

In 1963, WHO developed an informal program to coordinate studies on the relevance of animal influenza to humans that have contributed to the evidence of transmission between species. The importance of these investigations led to the designation of a specific $\mathrm{CC}$ for research on the ecology of animal influenza, in Memphis, TN, USA, that remains active today [8].

In 2005, the World Organization for Animal Health (OIE) and the Food and Agriculture Organization of the United Nations (FAO) established the OFFLU (OIE/FAO Network of Expertise on Animal Influenza), a global network of information about animal influenza that is available at http://www.offlu.net. OFFLU promotes cooperation between experts in animal and human health in addition to providing support and coordination of worldwide efforts to prevent, detect, and control animal influenza [31,32].

Studies on the human-animal interface have been important both to understanding the role of the animals in the virus transmission chain and surveillance activities, especially those regarding highly pathogenic AI. The influenza A virus is present in many mammalian and avian species. 
Phylogenetic studies have demonstrated species-specific viral lineages that cause highly contagious infections in animals with a significant economic impact. From the perspective of human health, the highest risk comes from swine and poultry for their role as a source of new flu viruses that are able to cause pandemics. Swine can be infected with viruses of both avian and human origin; therefore, they have a higher capability to promote viral rearrangements [33].

The influenza in poultry produces evident clinical signs (neurological and respiratory problems, limited mobility, edema on the chest and legs, and depression) and high mortality rates [33]. In swine, however, the disease manifests as clinical symptoms that tend to be mild or subclinical with high transmissibility, high morbidity, and low mortality. This may favor the viral circulation without detection; therefore, control measures cannot be implemented to interrupt transmission and dissemination. This may contribute to the maintenance of the circulation of different viral strains and, therefore, rearrangement opportunities [34].

In equine, the disease is caused by two viral subtypes - H7N7 and H3N8 - that can also cross the species barrier and have already been identified in respiratory diseases in dogs, swine, and people due to occupational exposure [33].

The pandemic influenza virus of 2009 was described in both domestic and non-domestic animals, such as in giant pandas in China [35] and swine in Brazil [36,37] and in other countries such as Australia, India, Sri Lanka, Colombia, and Cameroon [38]. Many studies emphasize the importance of knowledge about animal influenza to the disease in humans. However, despite the extensive scientific literature on the ecological and molecular properties of the influenza virus in animals, there is no comprehensive international surveillance system $[32,39]$.

The surveillance of influenza in farm animals is crucial; in Brazil, it is performed by the Ministry of Agriculture, Livestock, and Food Supply (MAPA). Most of the attention is given to the AI because, in addition to the issues regarding its transmission to humans with severe and deadly cases, poultry production is economically relevant and Brazil is a major worldwide producer and exporter of 
poultry meat. This poultry profile was consolidated in the early 2000s [40], a period of highly pathogenic AI outbreaks $[1,2,15,41]$.

MAPA instituted a national passive surveillance program that supported all suspected AI cases and actively monitored migratory bird sites, as well as commercial and subsistence poultry flocks, and sent material for laboratory diagnosis. This diagnosis follows the OIE regulations, both for the collection and transport (blood, tracheal swab, and cloacal swab) and the employed methodologies, and is performed in the official MAPA network with the National Agricultural Laboratory (Lanagro), Campinas, São Paulo, as the reference laboratory for poultry diseases [42]. To date, no highly pathogenic AI virus has been identified in Brazil; however, several lowly pathogenic virus strains were described by Mota et al. (2013) [40], Rajão et al. (2013) [36] Araujo et al. (2014) [43], among others.

The OIE maintains a list with the mandatory notifiable diseases updated annually. This list includes both AI and equine influenza, but not swine influenza [44]. In addition to the AI, confirmed cases of equine influenza (horses, donkeys and mules) and swine influenza are to be mandatorily notified to MAPA, with registration in the monthly reports, according to the Normative Instruction MAPA No. 50, September $24^{\text {th }}$ of 2013 [45].

The use of avian influenza vaccine for poultry is prohibited in Brazil [42]. There is no recommended vaccination for swine according to the National Swine Health Program, instituted by the Normative Instruction MAPA No. 47 on June 18, 2004 [46], although a commercial vaccine is available. The National Equine Health Program instituted by Normative Instruction MAPA No. 17 on May 8, 2008 does not refer vaccination [47]. However, the Service Instruction MAPA No. 17, November 16, 2001 [48] refers to vaccination as a health measure in the occurrence of an equine influenza outbreak. The indication is for primary vaccination with two doses at a 4-6-week interval and a booster every 6 months after that. Foals should be vaccinated after 4 months of age, while competition animals should be vaccinated every 3-4 months [49]. 
Veterinary surveillance information is registered in the National Animal Health Information System (SIZ), which belongs to the Brazilian System for Surveillance and Veterinary Emergencies (SisBraVet). The MAPA's Department of Animal Health is responsible for the maintenance and management of the SIZ based on the list of the notifiable diseases in Brazil and of the OIE. Data of the World Animal Health Information System (WAHIS) is available on the OIE website via the World Animal Health Information Database (WAHID). The Continental Epidemiological Surveillance System (SivCont), another monitoring tool, was developed in 2004 by the Pan American Foot-andMouth Disease Center (Panaftosa), for the logging and analysis of data and information on syndrome surveillance events in which, by the end of 2010, included avian respiratory and neurological syndrome [50].

MAPA monitors the epidemiological situation of avian influenza worldwide and has improved the health measures and requirements in the country's entry points to protect and preserve the health status of the Brazilian poultry flocks [51]. However, there is little knowledge on the circulating influenza viruses in animals in Brazil, especially in swine, and a single infection seems to have become endemic in livestock throughout the country after introduction of the pandemic virus [37].

\section{CONSIDERATIONS}

Despite the intention of approaching the structuring of the Brazilian surveillance of influenza, effectiveness studies, system performance, information systems qualification, and integration of surveillance from the aspects of human and animal are issues that require further and deeper analysis. This description has focused the interventions of the official influenza surveillance network - human or animal - through continued and systematic measures as required by epidemiological surveillance while avoiding encompassing the valuable research work conducted by research teams from educational and research institutions on this subject. The approach to the official influenza surveillance network, although brief, does not ignore the importance of the sectors involved in it. 
The investment in the improvement of the surveillance of human and animal influenza in Brazil is worth mentioning. Strategic differences should be considered since the surveillance is passive in animals, while the base of epidemiological surveillance of human influenza follows the sentinel model.

Since 2000, the structure has been chiseled according to the epidemiological and political settings, and the system is able to demonstrate the presence and circulation of viruses, even with limitations. The number of SUs and collected samples is small compared to the composition of the Brazilian population as well as its geographical distribution. The positive results of $17 \%$ may be due to the patient selection (case definition), adequate collection procedures, storage and transport to the laboratory, and diagnostic technique. These elements are configured as critical points for surveillance and should be improved through supervision and public health service evaluations. It is necessary to improve surveillance, mainly with regard to the representativeness, opportunity, and test positivity, to refine knowledge of the impact of the viruses and increase response capacity of the public health services.

Nelson \& Vincent [38] emphasize the biases - of the sample, time, and space - in the surveillance of influenza in humans and swine given that the imbalance of the surveillance activities affects the understanding of viral ecology. The authors state the necessity of intensifying the surveillance of influenza in swine, especially in countries that have large populations of these animals, and with reduced surveillance such as in Brazil, Vietnam, and Russia. The bias issue can be extrapolated to other animal species.

Brazil, a major producer of swine and poultry, needs to improve surveillance and communication among the involved governmental organizations. Due to the characteristics of the disease in swine and to confer a greater representation of the research of circulating viruses, both healthy and unhealthy animals should be considered for sample collections as suggested by Henningson et al [34]. 
It is important to emphasize the necessary investment in the laboratory diagnostic network since the provision of supplies, professional and technical staff, and adequate and appropriate infrastructure are critical to the establishment of new sensitive and effective methodologies. Investing in human resources at different levels of participation is an indisputable factor in the undeniable improvement that it provides to the health services.

Given its high infectivity and dissemination, influenza is a complex health problem that demands exceptional emergency measures even in the event of low lethality. The prevention and control of influenza are impossible without a permanent monitoring of the human and animal influenza viruses. The circulation of the virus in animals can represent a risk for both public health and animal health.

It is necessary to promote studies and surveillance in animals; therefore, the legal instruments of human and animal health should be more objective and consistent within a single health approach. It is essential to improve the interface and the sharing of information as well as to optimize resources among government agencies, to establish information flows, and build friendly platforms and technological ambience (merging, layers of geographic information systems) to provide subsidies for joint decision making.

To maintain the alert regarding influenza, it is also essential to invest in health education - a major task of the public health organizations - as well as the production of disease-related information to provide continuous education to the public as well as health professionals. Influenza is a permanent worldwide challenge for veterinary and public health authorities.

\section{ACKNOWLEDGEMENTS}

We wish to thank Dr. Wildo Navegantes de Araújo, Professor at University of Brasilia, and Denise Mancini, Technical Analyst of Social Policies at Brazil's Ministry of Health, for their critical reviews. 


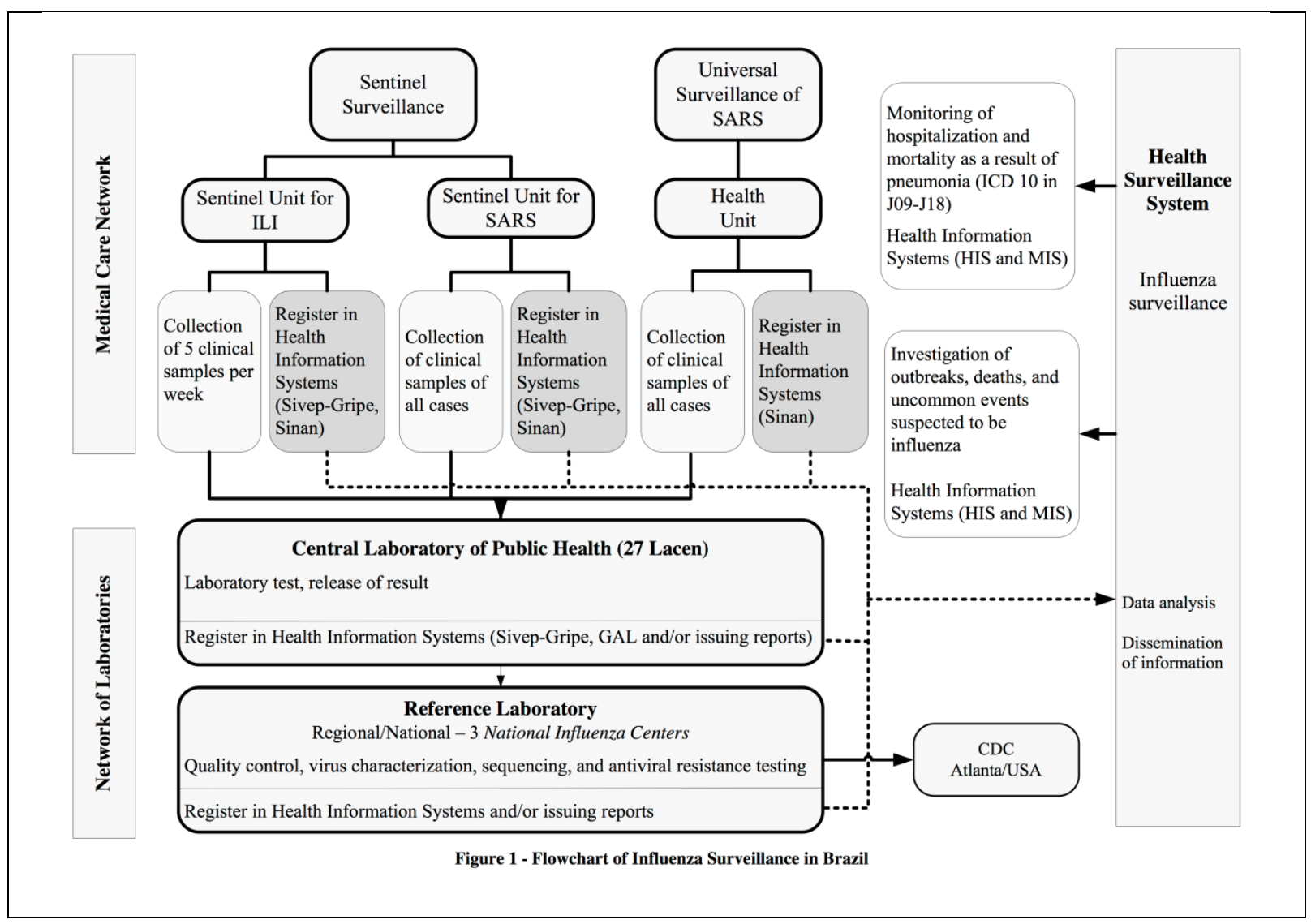




\section{REFERENCES}

Zambon M (2014) Influenza and other emerging respiratory viruses. Medicine 42: 4551.

Jerigan DB, Cox NJ (2013) Human influenza: one health, one world. In: Webster RG, Monto As, Braciale TJ, Lamb RA, editors. Textbook of influenza. 2th edition. Oxford: Wiley Blackwell. 3-19.

Cox NJ, Subbarao K (2000) Global epidemiology of influenza: past and present. Annu Rev Med 51: 407-421.

Monto AS, Webster RG (2013) Human pandemic: history and lessons learned. In: Webster RG, Monto AS, Braciale TJ, Lamb RA, editors. Textbook of influenza. 2th edititon. Oxford: Wiley Blackwell. 20-33.

Potter CW (2001) A history of influenza. J Appl Microbiol 91: 572-579.

Brasil. Secretaria de Vigilância em Saúde. Departamento de Vigilância Epidemiológica (2014) Influenza. In: Guia de Vigilância em Saúde. 1th edition. Brasília: Ministério da Saúde. 13-39.

World Health Organization (WHO) (2013) Global epidemiological surveillance standards for influenza. Switzerland: WHO Press 84p.

World Health Organization (WHO). Global Influenza Surveillance and Response System (GISRS). Available: http://www.who.int/influenza/gisrs_laboratory/en. Acessed 5 November. 2014.

Barros FR, Daufenbach LZ, Vicente MG, Soares MS, Siqueira M, Carmo EH (2004) O desafio da influenza: epidemiologia e organização da vigilância no Brasil. Boletim Eletrônico Epidemiológico da Secretaria de Vigilância em Saúde, 19: 197-225.

Freitas FTM (2013) Sentinel surveillance of influenza and other respiratory viruses, Brazil, 2000-2010. Braz J Infect Dis 17: 62-68.

Luna EJ (2011) Vigilância epidemiológica da influenza no Brasil - onde estamos? In: Kfouri RÁ, Berezin EN, editors. Atualização em vírus respiratórios. 1th edition. São Paulo: Guinom Propaganda \& Comunicação. 15-20.

Dab W Quenel P, Cohen JM, Hannoun C (1991) A new influenza surveillance system in France - TheIle-de-France GROG.2. Validity of indicators (1984-1989). Eur J Epidemiol 7: 579-587.

Forleo-Neto E, Halker E, Santos VJ, Paiva TM, Toniolo-Neto J (2003) Influenza. Rev Soc Bras Med Trop 36: 267-274.

Carmo EH. O regulamento sanitário internacional e as oportunidades para fortalecimento do sistema de vigilância em saúde. Recife: Portal DSS Nordeste; 30 abr. 2013. Available: $<$ http://dssbr.org/site/opinioes/o-regulamento-sanitariointernacional-e-as-oportunidades-para-fortalecimento-do-sistema-de-vigilancia-emsaude>. Acessed 29 November 2014. 

Dis 49: 317-327.

Brasil. Ministério da Saúde. Secretaria de Vigilância em Saúde. Portaria n 33, de 14 de julho de 2005. Inclui doenças à relação de notificação compulsória, define agravos de notificação imediata e a relação dos resultados laboratoriais que devem ser notificados pelos Laboratórios de Referência Nacional ou Regional. Available: http://bvsms.saude.gov.br/bvs/saudelegis/svs/2005/prt0033_14_07_2005.html.

Acessed 5 February 2015.

Brasil. Ministério da Saúde. Secretaria de Vigilância em Saúde. Portaria n 5, de 21 de fevereiro de 2006. Inclui doenças na relação nacional de notificação compulsória, define doenças de notificação imediata, relação dos resultados laboratoriais que devem ser notificados pelos Laboratórios de Referência Nacional ou Regional e normas para notificação de casos. Available: http://bvsms.saude.gov.br/bvs/saudelegis/svs/2006/prt0005_21_02_2006_comp.html. Acessed 5 February 2015.

Brasil. Ministério da Saúde. Gabinete do Ministro. Portaria n 104, de 25 de janeiro de 2011. Define as terminologias adotadas em legislação nacional, conforme o disposto no Regulamento Sanitário Internacional 2005 (RSI 2005), a relação de doenças, agravos e eventos em saúde pública de notificação compulsória em todo o território nacional e estabelece fluxo, critérios, responsabilidades e atribuições aos profissionais e serviços de saúde. Available: http://bvsms.saude.gov.br/bvs/saudelegis/gm/2011/prt0104_25_01_2011.html.

Acessed 5 February 2015

Brasil. Ministério da Saúde. Gabinete do Ministro. Portaria n 1.271, de 6 de junho de 2014. Define a Lista Nacional de Notificação Compulsória de doenças, agravos e eventos de saúde pública nos serviços de saúde públicos e privados em todo o território nacional, nos termos do anexo, e dá outras providências. Available: http://bvsms.saude.gov.br/bvs/saudelegis/gm/2014/prt1271_06_06_2014.html.

Acessed 5 February 2015.

Brasil. Ministério da Saúde (2006) Portaria n 699, de 30 de março de 2006. Regulamenta as Diretrizes Operacionais dos Pactos Pela Vida e de Gestão. Diário Oficial da União, Brasília, 3 abr. p. 49-67. Seção 1. Available: http://www.saude.pr.gov.br/arquivos/File/CIB/LEGIS/PortGM_699_30marco_2006.p df. Acessed 13 March 2015.

Oliveira WK, Carmo EH, Penna GO, Kuchenbecker RS, Santos HB, Araujo WN et al (2009) Pandemic H1N1 influenza in Brazil: Analysis of the first 34,506 notified cases of influenza-like illness with severe acute respiratory infection (SARI). Euro Surveill 14: 19382.

Brasil. Ministério da Saúde. Gabinete do Ministro. Portaria n 2.693, de 17 de novembro de 2011. Estabelece mecanismo de repasse financeiro do Fundo Nacional de Saúde aos Fundos de Saúde do Distrito Federal e Municípios, por meio do Piso Variável de Vigilância e Promoção da Saúde, para implantação, implementação e fortalecimento da Vigilância Epidemiológica da Influenza. Diário Oficial da União, 
Brasília, p.81-82, 18 nov. 2011. Seção 1. Republicada no DOU. Brasília, 26 abr 2012. p.37-38. Seção 1.

Brasil. Ministério da Saúde. Gabinete do Ministro. Portaria n 183, de 30 de janeiro de 2014. Regulamenta o incentivo financeiro de custeio para implantação e manutenção de ações e serviços públicos estratégicos de vigilância em saúde, previsto no art. 18, inciso I, da Portaria n 1.378/GM/MS, de 9 de julho de 2013, com a definição dos critérios de financiamento, monitoramento e avaliação. Diário Oficial da União, Brasília, 31 jan 2014. p.59, Seção 1.

Brasil.Ministério da Saúde. Secretaria de Vigilância em Saúde. Influenza: monitoramento até a semana epidemiológica 5 de 2014. Boletim epidemiológico. Brasília, DF: Ministério da Saúde, 2014. Available: http://portalsaude.saude.gov.br/images/pdf/2014/maio/28/2boletim-influenza-se052014.pdf. Acessed 5 February 2015.

WHO (2011) World Health Organization. WHO global influenza surveillance network: manual for the laboratory diagnosis and virological surveillance of influenza. Geneva: WHO Press 137p.

Keitel WA, Neuzil KM, Treanor J (2013) Immunogenicity, efficacy of inactivated/live virus seasonal and pandemic vaccines. In: Webster RG, Monto As, Braciale TJ, Lamb RA, editors. Textbook of influenza. 2th edition. Oxford: Wiley Blackwell. 313-326.

Brasil. Agência Nacional de Vigilância Sanitária. Resolução-RE n 4319 de 31 de outubro de 2014.Brasília, DF: Diário Oficial da União de 3 nov 2014.

WHO (1998) World Health Organization. Recommendation for the composition of influenza virus vaccines for use in 1999. Wkly Epidemiol Rec 73: 305-308.

Brasil. Ministério da Saúde. Secretaria de Vigilância em Saúde. Coordenação-Geral do Programa Nacional de Imunizações.Campanha Nacional de Vacinação Contra a influenza 2014. Informe Técnico. Brasília: Ministério da Saúde, 2014.Available: http://www.sbim.org.br/wp-content/uploads/2014/04/Informe_Campanha_Influenza_-25_03_2014.pdf. Acessed 13 March 2015.

Jesus R, Guimarães RP, Bergamo R, Santos LCF, Matta ASD, Paula-Júnior FJ (2013) Sistema Gerenciador de Ambiente Laboratorial: relato de experiência de uma ferramenta transformadora para a gestão laboratorial e vigilância em saúde. Epidemiol Serv Saúde 22: 525-529.

Edwards S (2006) OFFLU network on avian influenza. Emerg Infect Diseases 12: $1287-1288$.

Vincent A, Awada L, Brown I, Chen H, Claes F, Dauphin G, Donis R, Culhane M, Hamilton K, LewisN, Mumford E, Nguyen T, Parchariyanon S, Pasick J, Pavade G, Pereda A, Peiris M, Saito T, Swenson S, Van Reeth K, Webby R, Wong F, CiacciZanella J (2014) Review of influenza A virus in swine worldwide: a call for increased surveillance and research. Zoonoses Public Health 61: 4-17.

Alexander DJ, Brown IH (2000) Recent zoonoses caused by influenza A viruses. Rev Sci Tech OIE 19: 197-225. 
Henningson JN, Rajão DS, Kitikoon P, Lorussoc A, Culhaned MR, Lewise NS, Anderson TK, Vincent AL (2015) Comparative virulence of wild-type H1N1pdm09 influenza A isolates in swine. Vet Microbiol 176: 40-49.

Li D, Zhu L, Cui H, Ling S, Fan S, Yu Z, Zhou Y, Wang T, Qian J, Xia X, Xu Z, Gao $\mathrm{Y}$, Wang C (2014) Influenza A (H1N1)pdm09 virus infection in giant pandas, China. Emerg Infect Dis 20: 480-483.

Rajão DS, et al (2013) Genetic characterization of influenza virus circulating in Brazilian pigs during 2009 and 2010 reveals a high prevalence of the pandemic H1N1 subtype. Influenza Other Respir Viruses 7: 783-790.

Schaefer R, Zanella JRC, Brentano L, Vincent AL, Ritterbusch GA, Silveira S, Caron, L, Mores N (2011) Isolation and characterization of a pandemic H1N1 influenza virus in pigs in Brazil. Pesqui Vet Bras 31: 761-767.

Nelson MI, Vincent AL (2015) Reverse zoonosis of influenza to swine: new perspectives on the human-animal interface. Trends Microbiol 23: 142-153.

Webster RG (2002) The importance of animal influenza for human disease. Vaccine 20: S16-S20.

Mota MA, Lima FA, Oliveira PFN, Guimarães MP (2013) Ações de vigilância para influenza aviária desenvolvida no Brasil, no período de 2004 e 2007. Arq Bras Med Vet Zootec 65: 1265-1273.

WHO (2005) World Health Organization. Evolution of H5N1 Avian Influenza Viruses in Asia. Emerg Infect Diseases 11: 1515-1521.

Brasil. Ministério da Agricultura, Pecuária e Abastecimento. Secretaria de Defesa Agropecuária. Departamento de Saúde Animal. Plano de contingência para influenza aviária e doença de Newcastle. 2013 a. 59p. Available: <http://www.agricultura.gov.br/arq_editor/file/PNSA/Plano\%20de\%20Conting\%C3\% AAncia\%20-\%20Vers\%C3\%A3o\%201_4.pdf>. Acessed 11 October 2014.

Araujo J, Azevedo-Júnior SM, Gaidet N, Hurtado RF, Walker D, Thomazelli LM, Ometto T, Seixas MMM, Rodrigues R, Galindo DB, Silva ACS, Rodrigues AMM, Bomfim LL, Mota MA, Larrazábal ME, Branco JO, Serafini P, Neto IS, Franks J, Webby RJ, Webster RG, Durigon EL (2014) Avian Influenza Virus (H11N9) in Migratory Shorebirds Wintering in the Amazon Region, Brazil. Plos One 9: e110141.

World Organization for Animal Health (OIE). OIE listed disease, 2014. Available: <http://www.oie.int/animal-health-in-the-world/oie-listed-diseases-2014>. Acessed 15 December 2014.

Brasil.Ministério da Agricultura, Pecuária e Abastecimento. Instrução Normativa n 50, de 24 de Setembro de 2013. Estabelece a relação das doenças de notificação obrigatória ao serviço veterinário oficial. Brasília, DF: Diário Oficial da União 25 Set 2013, p47. Seção 1.

Brasil.Ministério da Agricultura, Pecuária e Abastecimento. Secretaria de Defesa Agropecuária. Instrução Normativa n 47, de 18 de junho de 2004. Aprova o Regulamento Técnico de Programa Nacional de Sanidade Suídea - PNSS, na forma do 
anexo a esta Instrução Normativa. Brasília, DF: Diário Oficial da União de 23 jun 2004, p64. Seção 1. Available: http://extranet.agricultura.gov.br/sislegisconsulta/consultarLegislacao.do?operacao=visualizar\&id=7938.Acessed 15 December 2014.

Brasil.Ministério da Agricultura, Pecuária e Abastecimento. Secretaria de Defesa Agropecuária. Instrução Normativa n 17, de 8 de maio de 2008. Institui o Programa Nacional de Sanidade dos Equíídeos - PNSE, no âmbito do Ministério da Agricultura, Pecuária e Abastecimento. Brasília, DF:Diário Oficial da União de 9 mai 2008, p27.Seção $1.1 \quad$ http://extranet.agricultura.gov.br/sislegisconsulta/consultarLegislacao.do?operacao=visualizar\&id=18609.. Acessed 15 December 2014.

Brasil.Ministério da Agricultura, Pecuária e Abastecimento. Secretaria de Defesa Agropecuária. Departamento de Defesa Animal. Instrução de Serviço n 17, de 16 de novembro de 2001. Brasília, 2001.

Brasil.Ministério da Agricultura, Pecuária e Abastecimento. Sanidade Animal. de vacinação. 2014.

Available: <http://www.agricultura.gov.br/animal/sanidade-animal/calendario-de-vacinacao>. Acessed 11 October 2014.

Brasil.Ministério da Agricultura, Pecuária e Abastecimento. Secretaria de Defesa Agropecuária. Manual do Sistema Nacional de Informação Zoossanitária - SIZ. 2nd edition. Brasília: Ministério da Agricultura 2013. 40p. Available: $<$ http://www.agricultura.gov.br/arq_editor/file/Manual\%20SIZ/Manual_SIZ _09_12_2013.pdf>. Acessed 11 October 2014.

Brasil.Ministério da Agricultura, Pecuária e Abastecimento. Mapa monitora situação da gripe aviária pelo mundo. Assessoria de Comunicação Social. Notícias, $11 \mathrm{fev}$ 2015. Gripe Aviária.

Available:http://www.agricultura.gov.br/comunicacao/noticias/2015/02/mapamonitora-situacao-da-gripe-aviaria-pelo-mundo. Acessed 4 de March 2015. 


\title{
ANEXO D - TERCEIRO ARTIGO - "PENSAR A ÉTICA NA VIGILÂNCIA DE INFLUENZA?” - VERSÃO FINAL FORMATADA PARA PUBLICAÇÃO NA REVISTA BIOÉTICA (CONTINUA)
}

\author{
Pensar a ética na vigilância da influenza? \\ Ligia Cantarino ', Edgar Merchan-Hamann ${ }^{2}$
}

\begin{abstract}
Resumo
A vigilância epidemiológica, importante na indicação e execução de políticas de saúde pública e nas tomadas de decisão, constitui um elo entre os serviços de saúde e a pesquisa. Nesse contexto, as questões éticas presentes nas práticas diárias de vigilância demandam processos reflexivos aprofundados e discussões específicas mais qualificadas. Para a elaboração deste ensaio reflexivo, tomaram-se algumas indagações éticas relacionadas à vigilância da influenza, confrontando-as com uma gama de conceitos bioéticos, de direitos humanos, de direito à saúde, de saúde pública e de ética. As reflexões propostas enfocam os princípios da bioética, relacionando-os às características das ações de vigilância direcionadas aos participantes da pesquisa de circulação de vírus respiratórios.

Palavras-chave: Ética. Bioética. Vigilância epidemiológica. Influenza humana.

Resumen

¿Pensar la ética en la vigilancia de la gripe?

La vigilancia epidemiológica, importante en la indicación e implementación de políticas de salud pública y toma de decisión, constituye una conexión entre los servicios de salud y la investigación. En este contexto, las cuestiones éticas presentes en las prácticas diarias de vigilancia requieren procesos reflexivos profundos y discusiones específicas más calificadas. Para el presente ensayo de reflexión se consideran algunas indagaciones éticas relacionadas con la vigilancia ejercida a la influenza, abordándolas frente a una gama de conceptos bioéticos, de derechos humanos, del derecho a la salud, de salud pública y de ética. Las reflexiones propuestas abordan los principios de la bioética relacionándolos con las características de las acciones de vigilancia dirigidas a los participantes de la investigación de circulación de virus respiratorios.

Palabras-clave: Ética. Bioética. Vigilancia epidemiológica. Gripe humana.

Abstract

To think about ethics in influenza surveillance?

Epidemiological surveillance, important in the indication and implementation of public health policies and decision-making, constitutes a link between health services and research. In this context, the ethical issues found in daily surveillance practices require in-depth reflective processes and specific qualified discussions. Some ethical questions related to influenza surveillance were considered for the elaboration of this reflective essay. Those questions were held up against a range of bioethical, human rights, right to health, public health and ethics' concepts. The proposed reflections address the principles of bioethics, relating them to the characteristics of surveillance actions directed to the participants of the survey on respiratory viruses circulation. Keywords: Ethics. Bioethics. Epidemiological surveillance. Influenza, human.
\end{abstract}




\section{ANEXO D - TERCEIRO ARTIGO - "PENSAR A ÉTICA NA VIGILÂNCIA DE INFLUENZA?” - VERSÃO FINAL FORMATADA PARA PUBLICAÇÃO NA REVISTA BIOÉTICA (CONTINUAÇÃO)}

A influenza, ou gripe, é uma doença viral aguda do sistema respiratório, de rápida disseminação e distribuição global. Um indivíduo pode contrair gripe várias vezes ao longo de sua vida, e sua maior gravidade verifica-se nos grupos de risco, como idosos, crianças, imunodeprimidos, cardiopatas e pneumopatas. Na perspectiva de saúde pública, essa virose constitui-se em diferentes problemas que requerem cuidados específicos de vigilância e controle, haja vista a gravidade de suas manifestações clínicas e de seu potencial pandêmico e zoonótico ${ }^{1-3}$

A influenza causa preocupação às autoridades sanitárias mundiais por suas repercussões na morbimortalidade, sua similaridade com pneumonias atípicas de elevado poder de transmissão e gravidade, bem como pela probabilidade de aparecimento e disseminação de cepas com potencial pandêmi$\mathrm{co}^{4}$. Por causa dessas características, a virose é alvo desde 1947, de programa mundial de vigilância, atualmente denominado Sistema Global de Vigilância e Resposta à Influenza (Global Influenza Surveillance and Response System - GISRS), criado pela Organização Mundial da Saúde (OMS) ${ }^{5}$.

No ano 2000, o governo brasileiro, por intermédio do Ministério da Saúde (MS), introduziu a vigilância da influenza em âmbito nacional. A vigilância está calcada em unidades-sentinelas e no monitoramento de dados indiretos de morbidade e mortalidade associados à influenza. São considerados os registros dos atendimentos por síndrome gripal e a circulação dos vírus, que são os agentes etiológicos de infecções agudas do sistema respiratório. A vigilância de vírus respiratórios tem como objetivo conhecer as cepas em circulação no Brasil, responder a situações inusitadas, avaliar o impacto da vacinação, acompanhar a tendência da morbimortalidade, além de produzir e disseminar informações epidemiológicas com vistas ao fortalecimento da vigilância por meio da elaboração de planos de contingência para o enfrentamento de situações pandêmicas ${ }^{1}$.

A vigilância epidemiológica tem papel importante na indicação e execução de políticas de saúde pública e nas tomadas de decisão. Em um conceito ampliado, a vigilância epidemiológica funciona como elo entre os serviços de saúde e a pesquisa ${ }^{6}$. Já o papel da pesquisa na vigilância em saúde é fundamental para a construção do conhecimento e elucidação de situações sanitárias. A pesquisa em saúde pública e a investigação em serviços de saúde estão imbricadas e, embora tenham diferentes abordagens em relação à pesquisa acadêmica tradicional, os aspectos éticos em comum devem ser considerados.
A necessidade de vigilância da influenza é indiscutivel. No entanto, algumas questões éticas demandam reflexão. $\mathrm{O}$ objetivo deste artigo é fazer uma reflexão sobre aspectos da ação permanente de vigilância de vírus respiratórios, parte fundamental da vigilância da influenza sob o olhar da bioética.

Práticas, orientações e normas de vigilância

O Brasil pertence à rede mundial de vigilância da influenza com a participação de três laboratórios credenciados pela OMS, como centros nacionais de referência para influenza (National Influenza Center - NIC). As informações geradas por essa rede são analisadas e discutidas anualmente em reunião na sede da OMS, que, entre outras tomadas de decisão, indica as composições das vacinas a serem empregadas no ano seguinte.

Para situar a vigilância da influenza no contexto mais abrangente das atividades da vigilância à saúde, convém esclarecer que há formas diferentes de monitorar os eventos. $\mathrm{O}$ enfoque tradicional, centrado na doença e conhecido como vigilância universal, fundamenta-se na notificação compulsória e é chamado de vigilância passiva. No entanto, abordagens alternativas têm sido preconizadas nos últimos anos, focalizando outros momentos do evento, ou dos ciclos biológicos, o que implica a promoção de ações diversificadas, denominadas vigilância ativa. Nessa abordagem, incluem-se as estratégias de vigilância-sentinela.

Na vigilância-sentinela da influenza, são tomadas amostras de pacientes com sintomatologia de síndrome gripal que buscaram atendimento médico nas unidades de saúde, mesmo que a queixa principal desses pacientes não se relacione com a síndrome. Preconiza-se uma amostragem por conveniência, e as unidades de saúde devem coletar amostras de cinco pacientes por semana, todas as semanas do ano. Assim, amostras são tomadas após triagem e rápida entrevista com os cidadãos presentes na sala de espera, desde que eles confirmem serem portadores de sinais clínicos compativeis com síndrome gripal. As amostras são, em ordem de preferência: 1) aspirado de nasofaringe, ou 2) swab combinado (nasal e oral), obtido até cinco dias do início do aparecimento dos sintomas (fase aguda da doença) ${ }^{1}$. Essas amostras são encaminhadas para os laboratórios da rede de vigilância da influenza e não para diagnóstico atrelado ao atendimento do paciente. 


\section{ANEXO D - TERCEIRO ARTIGO - "PENSAR A ÉTICA NA VIGILÂNCIA DE INFLUENZA?” - VERSÃO FINAL FORMATADA PARA PUBLICAÇÃO NA REVISTA BIOÉTICA (CONTINUAÇÃO)}

Pensar a ética na vigilância da influenza?

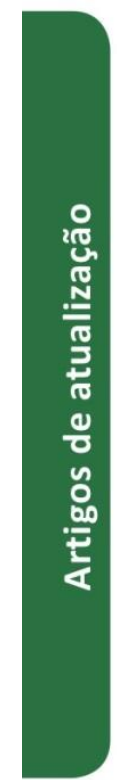

Quanto à forma de abordagem e aos cuidados ou aspectos éticos relativos aos pacientes, sujeitos participantes da pesquisa viral, encontra-se referência sobre o tema no "Guia de vigilância epidemiológica" do $\mathrm{MS}^{1}$ (página 23 ), expressa pela afirmação de que a notificação tem de ser sigilosa, só podendo ser divulgada fora do âmbito médico-sanitário em caso de risco para a comunidade, respeitando-se o direito de anonimato dos cidadãos. Na Portaria MS 2.693/2011 ${ }^{7}$, que trata do repasse de recursos para introdução, execução e fortalecimento da vigilância epidemiológica da influenza, não há alusão aos aspectos éticos.

Na prática da vigilância do agravo, documentos normativos não são observados em sua integralidade, a exemplo da orientação aos pacientes sobre as amostras biológicas, fluxo laboratorial e resultados. A Portaria 788/2002, expedida pela Secretaria de Assistência à Saúde (SAS) do MS, preconiza que entre as principais funções de um posto de coleta estão o atendimento e orientação de pacientes para a coleta, identificação e recebimento de materiais biológicos, bem como o armazenamento adequado dos fluidos biológicos para posterior transporte, liberação e entrega de laudo ${ }^{8}$. Nesse sentido, a Portaria SAS 787/2002, além de estabelecer parâmetros básicos e normas técnicas para a organização da rede de laboratórios clínicos, recomenda a identificação correta das amostras, sistema de transporte eficiente e em acondicionamento adequado, bem como fluxo claro de encaminhamento de laudos de exames para os postos de coleta e/ou unidade de origem dos pacientes, de forma segura e confiável, visando garantir que o paciente tenha acesso ao resultado oportunamente ${ }^{9}$.

Também reforça esse cuidado a Resolução 302/2005 da Diretoria Colegiada da Agência Nacional de Vigilância Sanitária (Anvisa), destinada à regulamentação técnica para o funcionamento de laboratórios clínicos, e aplicável a todos os serviços públicos ou privados que realizam atividades laboratoriais na área de análises clínicas, patologia clínica e citologia. De acordo com essa normativa, a unidade de coleta de amostras e o laboratório devem atender aos processos operacionais previstos e, entre outras atribuições, devem disponibilizar ao paciente ou responsável instruções escritas e ou verbais, em linguagem acessivel, orientando sobre $o$ preparo e coleta de amostras tendo como objetivo $o$ entendimento do paciente ${ }^{10}$. Além disso, a resolução determina que o paciente ambulatorial ou seu responsável deve receber um comprovante de atendimento contendo número de registro, nome completo do paciente, data do atendimento, data prevista de entrega do laudo, relação de exames solicitados e dados para contato com o laboratório.

No entanto, a despeito da existência dessas normativas orientadoras, persiste a situação em que o paciente não sabe qual laboratório processará sua amostra, não recebe comprovante para acompanhamento da análise laboratorial de sua amostra biológica, e tampouco recebe o resultado da análise. Uma vez realizada a coleta da amostra clínica, é dever do serviço público (ou privado) garantir a identificação, o acondicionamento e envio adequado e oportuno dessa amostra para análise laboratorial. Do mesmo modo, devem-se assegurar o processamento da amostra no prazo estabelecido e a entrega dos resultados laboratoriais aos pacientes de forma individualizada (para cada paciente, um laudo). $\mathrm{Na}$ prática da vigilância, o que se observa é que os resultados das análises laboratoriais são divulgados, de modo agregado, por semana epidemiológica, no "Boletim Epidemiológico de Influenza", disponível no site da Secretaria de Vigilância em Saúde do MS.

Nas atividades de vigilância da influenza, no momento da coleta na unidade de saúde, o consentimento ou assentimento para a investigação viral é informado oralmente pelo paciente, após receber breve explicação. Não existe o assentimento livre e esclarecido, assim como não há assinatura formalizada de um documento análogo ao termo de consentimento livre e esclarecido (TCLE), como no caso das pesquisas científicas, ou uma gravação da manifestação de aceite. Também inexiste qualquer outra evidência inequívoca de que a informação foi correta e oportunamente repassada pelo profissional de saúde e entendida pelo paciente. $E$, como se sabe, para que haja um consentimento esclarecido a informação revelada deve ser compreendida, não sendo suficiente que a pessoa seja mera recepto$r a{ }^{11}$. Não há aqui uma sugestão de formalização documental, mas sim o questionamento quanto à informação e à comunicação adequada aos sujeitos da pesquisa. Procedimentos formais, mero cumprimento de determinações burocráticas desprovidas de reflexão e escolha consciente ${ }^{12}$ não contribuem para o respeito aos direitos do cidadão participante da pesquisa.

Na pesquisa em vigilância, mesmo com base em um entendimento diferenciado, à luz da Resolução 466/2012 ${ }^{13}$ do Conselho Nacional de Saúde (CNS), que dispõe sobre as diretrizes e normas regulamentadoras de pesquisas envolvendo seres humanos, os pacientes participantes da investigação viral, sujeitos da pesquisa, podem ser considerados 


\section{ANEXO D - TERCEIRO ARTIGO - "PENSAR A ÉTICA NA VIGILÂNCIA DE INFLUENZA?” - VERSÃO FINAL FORMATADA PARA PUBLICAÇÃO NA REVISTA BIOÉTICA (CONTINUAÇÃO)}

vulneráveis. Ou ainda, os pacientes podem ser reputados como vulnerados, dada sua condição de vida, inclusive seu estado de saúde ${ }^{14}$. Afinal, esses pacientes buscaram uma unidade de saúde para atendimento médico não necessariamente por problemas respiratórios, e, na triagem, foram interpelados por um profissional de saúde com vista à realização de coleta de material para exame pelo fato de aquele serviço médico pertencer à rede-sentinela para influenza.

Embora em seus efeitos individuais e sociais a pesquisa de vírus respiratórios seja altamente relevante e benéfica, uma vez que trará proveito direto ou indireto, imediato ou posterior, auferido pelo participante e/ou sua comunidade em decorrência de sua participação na pesquisa, os participantes devem ser esclarecidos sobre a natureza da pesquisa, seus objetivos, métodos, benefícios previstos, potenciais riscos e o incômodo que esta possa lhes acarretar, na medida de sua compreensão e respeitados em suas singularidades, conforme preconiza a Resolução CNS 466/2012 ${ }^{13}$.

Não se propõe aqui a utilização da Resolução CNS 466/2012 ${ }^{13}$ para subsidiar aspectos acerca da ética na vigilância epidemiológica da influenza. A pesquisa biomédica acadêmica tem características diferentes da investigação ou pesquisa em vigilância em saúde; no entanto, faz-se necessário observar as práticas de vigilância. É notório que a tomada de decisões em epidemiologia envolve ao mesmo tempo conhecimentos técnicos e a reflexão sobre questões importantes para o serviço de saúde pública. Do mesmo modo, as relações entre ética e epidemiologia desdobram-se entre compromisso político e prática nos serviços de saúde, passando pela produção de conhecimentos. Além do compromisso político ou da relevância social dos conhecimentos e intervenções, é fundamental destacar a necessidade de eleger prioridades para indivíduos na sociedade. A isso se somam as questões relativas à ética nas pesquisas envolvendo seres humanos e aos conceitos de risco e vulnerabilidade, que levantam a questão do consentimento informado $\mathrm{e}$ do retorno dos resultados à sociedade ${ }^{12}$ - retorno esse aqui discutido tanto como resultado individual quanto como benefício da pesquisa à coletividade.

Embora os princípios individuais não se apliquem à saúde pública nem às pesquisas epidemiológicas, é importante a observação de normas e condutas que considerem as particularidades dos grupos e populações. Nas pesquisas epidemiológicas, mesmo com o compromisso de aquisição e aplicação de conhecimentos científicos para a ma- nutenção e restauração da saúde pública, os direitos individuais devem ser respeitados ${ }^{15}$

Definir critérios e parâmetros para condutas éticas na pesquisa epidemiológica é preocupação constante dos estudiosos e pesquisadores da área, cujos temas de discussão constam de documentos internacionais dirigidos a epidemiologistas, como os seguintes exemplos, mencionados por Coughlin ${ }^{16}$ : as "International Ethical Guidelines for Epidemiological Studies", elaboradas pelo Conselho Internacional de Organizações de Ciências Médicas (Cioms) em colaboração com a OMS, e editadas em 1991; as "Ethics Guidelines", do American College of Epidemiology (ACE), publicadas no ano 2000; e as orientações da "HIPAA privacy rule and public health guidance", de 2003, do Centers for Diseases Control and Prevention $(C D C)$.

Dos direitos

Considerando que a estratégia da vigilância deve fundamentar-se no conceito de cidadão como sujeito de direitos, é vital estabelecer instrumentos que protejam a saúde do indivíduo integrado ao seu grupo populacional, reconhecido como igual em seus direitos, mesmo quando defende posições ou valores socioculturais diferenciados. É assaz relevante que a ética esteja estreitamente vinculada às práticas de saúde pública, uma vez que os aspectos éticos estão circunscritos apenas ao âmbito técnico, legal ou administrativo. As interferências éticas, sejam diretas ou indiretas, podem afetar as pessoas em suas tomadas de decisão ${ }^{17}$.

De acordo com documento da OMS ${ }^{18}$ que discute soluções para a influenza pandêmica, os direitos humanos são garantias legais universais destinadas a proteger os indivíduos e grupos contra ações que afrontam as liberdades fundamentais ou a dignidade humana. Uma das características mais importantes desse documento, o consenso internacional acerca das garantias que indivíduos e povos devem usufruir no âmbito da saúde foi ratificado pelos governos dos países signatários, que, dessa forma, se comprometem em aplicar as normas internacionais em contexto local. Assim, tanto por força de lei na dimensão nacional quanto em decorrência de consenso moral entre os países, os direitos humanos não podem ser renegados ou retirados.

O direito à saúde é exigência primária do direito à vida ${ }^{19}$. Em grande medida, a construção do direito à saúde decorre da crescente urbanização que sobreveio à industrialização a partir do século 


\title{
ANEXO D - TERCEIRO ARTIGO - "PENSAR A ÉTICA NA VIGILÂNCIA DE INFLUENZA?” - VERSÃO FINAL FORMATADA PARA PUBLICAÇÃO NA REVISTA BIOÉTICA (CONTINUAÇÃO)
}

\author{
Pensar a ética na vigilância da influenza?
}

XIX, bem como do fato-definido por lei-de a saúde ter passado a ser responsabilidade do Estado ${ }^{20}$. Do mesmo modo, a vigilância epidemiológica é função do Estado, devendo constituir pré-requisito na elaboração de programas de saúde e instrumento de avaliação do impacto de sua execução. Os sistemas de vigilância de doenças ou agravos devem ser objeto de avaliações frequentes e além de adaptações às mudanças necessárias, de forma a garantir bom desempenho, com qualidade, eficácia, eficiência e efetividade de suas ações. Só assim será possível evidenciar a situação epidemiológica do problema, as tendências, o impacto das medidas de controle, bem como propor novas ações. $\mathrm{O}$ sistema de vigilância epidemiológica mantém-se eficiente quando seu funcionamento é aferido regularmente, com vistas a ajustes oportunos ${ }^{21}$.

Cabe, portanto, avaliar a pesquisa epidemiológica em função do bem coletivo, mas com olhar de respeito pelos direitos do indivíduo. $\mathrm{O}$ avanço da saúde pública tem se pautado pela incorporação de atribuições e responsabilidades, por parte do Estado, com base na consideração de que os direitos coletivos, e mesmo os direitos sociais difusos, se definem como condição inexorável da cidadania. As ações de controle sanitário têm origem no conjunto de medidas que as sociedades estabelecem no decorrer do tempo, com o intuito de impedir ou diminuir riscos e danos à saúde da população. As relações entre saúde pública e direitos humanos permeiam os aspectos políticos, programas e práticas da saúde pública. É indispensável, portanto, buscar o equilíbrio entre o bem coletivo e os direitos individuais 22 .

\section{Dos princípios bioéticos}

A bioética pode ser definida como ética voltada para a sobrevivência humana, uma vez que abrange temas sociais e ambientais, além dos conflitos biomédicos e biotecnológicos ${ }^{23}$. O campo constitui-se em disciplina comprometida não só com a moral na área da saúde e da doença dos seres humanos e dos animais, mas também com a reflexão e discussão dos conflitos éticos por ela apontados, e que sempre estiveram presentes ao longo da história da sociedade humana ${ }^{24}$.

A Declaração Universal sobre Bioética e Direitos Humanos ${ }^{25}$ significou uma nova fase para o campo da bioética, que abandonou os estreitos limites da clínica e da pesquisa para consolidar-se como disciplina sob o marco dos direitos humanos.
O documento traz inúmeros princípios: a dignidade humana e os direitos humanos; benefício e dano; autonomia e responsabilidade individual; consentimento; indivíduos sem capacidade de consentir; respeito pela vulnerabilidade humana e pela integridade individual; privacidade e confidencialidade; igualdade, justiça e equidade; não discriminação e não estigmatização; respeito pela diversidade cultural e pelo pluralismo; solidariedade e cooperação; responsabilidade social e saúde; compartilhamento de benefícios; proteção das gerações futuras; proteção do meio ambiente, da biosfera e da biodiversidade.

No Brasil, a motivação ética é vista por princípios semelhantes entre si: a) respeito pelas pessoas, seja na obtenção de um TCLE, seja na confidencialidade e na proteção dos que são incapazes de tomar decisões; b) beneficência ou não causar dano (não maleficência), maximizando benefícios e reduzindo riscos; c) justiça distributiva, com balanço favorável do risco-benefício e seleção equitativa de pacientes, aspectos decorrentes de desenhos adequados ao estudo e da qualificação dos pesquisadores e equipe. Essa motivação foi discutida em estudo de Novaes e colaboradores ${ }^{26}$, e seus princípios são regulamentados pela Resolução 466/2012 ${ }^{13}$ do Conselho Nacional de Saúde.

Os desafios bioéticos com enfoque na saúde coletiva merecem reflexão crítica em temas essenciais como: saúde global e bioética global, justiça social e equidade em saúde, fatores de vulnerabilidade nos paises mais desfavorecidos, respeito pela autonomia cultural dos povos, responsabilidade face à solidariedade e cooperação entre as nações, o universalismo versus relativismo ético face à dignidade humana ${ }^{27}$.

Considerando as transformações vivenciadas pela sociedade, há que pensar em bioética orientada pelo respeito e incentivo à liberdade individual na tomada de decisão, somados aos princípios da solidariedade, justiça, equidade e responsabilidade, reforçando a necessidade de proteção dos menos favorecidos ou vulneráveis. É preciso pensar em um fazer bioético capaz de auxiliar na busca de soluções equilibradas entre liberdades individuais e interesses coletivos ${ }^{28}$.

Os princípios bioéticos devem ser observados até mesmo na interdependência entre vigilância e pesquisa em saúde. As interfaces presentes nas atividades de vigilância da influenza devem ser minuciosas, de modo a orientar e pontuar a tomada de decisão quanto às ações de serviço, que devem priorizar o respeito ao cidadão. A ética da vida deve 


\section{ANEXO D - TERCEIRO ARTIGO - "PENSAR A ÉTICA NA VIGILÂNCIA DE INFLUENZA?" - VERSÃO FINAL FORMATADA PARA PUBLICAÇÃO NA REVISTA BIOÉTICA (CONTINUAÇÃO)}

nortear as ações de vigilância, uma vez que elas se voltam para o coletivo, com o propósito de garantir, por parte do Estado, direitos dos cidadãos.

\section{Considerações finais}

Este ensaio traz algumas reflexões a partir da perspectiva da ética na vigilância da influenza. O que se observa é que os serviços e os profissionais de saúde não têm manifestado interesse explícito por mudanças no sistema, ao mesmo tempo que os pacientes participantes não se mostram preocupados com a obtenção dos resultados diagnósticos nem com o andamento da pesquisa.

As considerações acerca do redimensionamento das ações de vigilância incluíram, como ponto de partida, o fato de constituírem dever de Estado e de atingirem a coletividade. Em parte, essas reflexões ocorreram no período de descentralização da vigilância e no momento em que se percebeu que a vigilância tradicional - passiva, baseada na notificação compulsória - era insuficiente e, com frequência, pouco oportuna ${ }^{6}$. Tal fato reforçou a necessidade de inovar as formas de vigilância mediante a introdução de estratégias de vigilância-sentinela ativa, impactando o próprio conceito de vigilância. Ao mesmo tempo, vem se enfatizando o papel da pesquisa tanto de forma induzida e pontual (ad hoc), para elucidação de eventos relevantes à vigilância em saúde, quanto de modo seriado e permanente, a fim de acompanhar estrategicamente a evolução de agravos e práticas ou hábitos de risco. Tais investigações podem ser realizadas, quer pelo próprio serviço de saúde, quer por entidades acadêmicas e institutos de pesquisa. Na pesquisa epidemiológica, em geral, há importantes considerações éticas ${ }^{15,16}$. É relevante ponderar que a interface e a profunda ligação entre a pesquisa epidemiológica e as práticas de vigilância implicam novos desafios no enfrentamento dos aspectos éticos, e, dada sua relevância social e política, deve-se levar em conta sua relação com o cuidado ou a assistência em saúde.

Questões relacionadas à ética muitas vezes passam despercebidas pelos serviços e profissionais de vigilância em saúde; consequentemente, não são contempladas em seus programas e protocolos. Aspectos éticos na condução da vigilância da influenza são importantes e devem ser observados, como qualquer outro fator necessário para essa gestão.

São de interesse para estudo mais aprofundado as condutas adotadas no momento da tomada de amostras, as explicações oportunas e necessárias sobre o uso do material biológico obtido, bem como o dever e o direito relacionados ao resultado das análises laboratoriais. Outras questões relativas aos planos de contingência também devem ser verificadas na perspectiva da ética, como as medidas de restrição da liberdade (quarentenas), o uso de medicamentos antivirais e de vacinas (racionar ou racionalizar?), o acesso ao sistema de saúde e a seus recursos físicos, o risco e o desgaste impostos aos profissionais de saúde e suas responsabilidades, além da comunicação do risco e o papel da imprensa.

É necessário que direitos e responsabilidades sejam discutidos a partir do enfoque educativo, nos espaços de educação continuada ${ }^{29}$ e nos treinamentos em serviço e supervisões técnicas. Na produção do conhecimento epidemiológico, as questões éticas em pesquisas envolvendo seres humanos, bem como o significado social do risco e da vulnerabilidade, são importantes aspectos de reflexão para o norteamento das práticas de vigilância epidemiológica.

Aqui foram retratados alguns pontos acerca da vigilância-sentinela da influenza como um exercício de reflexão. As preocupações éticas são indispensáveis nas práticas corriqueiras da vigilância. Como direitos de todo cidadão-paciente, a obtenção de informações claras sobre o encaminhamento laboratorial da amostra no momento da coleta e a comunicação adequada dos resultados dos exames são exemplos de situações que precisam ser revistas no âmbito dos serviços de saúde. Além disso, há que levar em conta a criação e adesão a rotinas pautadas pela ética na relação com aqueles que participam dos estudos. Tais preocupações deveriam estar previstas nas orientações e guias de vigilância e em regulamentos éticos voltados para a pesquisa em vigilância de saúde pública.

\section{Referências}

1. Brasil. Ministério da Saúde. Secretaria de Vigilância em Saúde. Departamento de Vigilância Epidemiológica. Guia de vigilância epidemiológica. 7ạ ed. Brasilia: Ministério da Saúde; 2009. (Série A. Normas e Manuais Técnicos).

2. Jerigan D, Cox NJ. Human influenza: one health, one world. In: Webster RG, Monto AS, Braciale TJ, Lamb RA, editors. Textbook of influenza. $2^{\text {a }}$ ed. Oxford, UK: Wiley Blackwell; 2013. p. 3-19. 


\section{ANEXO D - TERCEIRO ARTIGO - "PENSAR A ÉTICA NA VIGILÂNCIA DE INFLUENZA?” - VERSÃO FINAL FORMATADA PARA PUBLICAÇÃO NA REVISTA BIOÉTICA (CONTINUAÇÃO)}

3. Zambon M. Influenza and other emerging respiratory viruses. Medicine. 2014;42(1):45-51.

4. Barros FR, Daufenbach LZ, Vicente MG, Soares MS, Siqueira M, Carmo EH. O desafio da influenza: epidemiologia e organização da vigilância no Brasil. Bol Eletr Epidemiol. [Internet]. 2004 [acesso 20 fev 2014];4(1):2-6. Disponivel: http://bvsms.saude.gov.br/bvs/periodicos/boletim_ eletronico_epi_ano04_n01.pdf

5. World Health Organization. Global Influenza Surveillance and Response System (GISRS). [Internet]. 2014 [acesso 20 fev 2014]. Disponivel: http://www.who.int/influenza/giss__laboratory/en

6. Hamann EM, Laguardia J. Reflections on epidemiological surveillance: beyond notifiable diseases. Inf Epidemiol SUS. [Internet]. 2000 set;9(3):211-9.

7. Brasil. Ministério da Saúde. Portaria no 2.693, de 17 de novembro de 2011, republicada em 26 de abril de 2012. Estabelece mecanismo de repasse financeiro do Fundo Nacional de Saúde aos Fundos de Saúde do Distrito Federal e Municípios, por meio do Piso Variável de Vigilância e Promoção da Saúde, para implantação, implementação e fortalecimento da Vigilância Epidemiológica da Influenza. Diário Oficial da União. Brasília, no 81, p. 37-8, 26 abr 2012. Seção 1

8. Brasil. Ministério da Saúde. Secretaria de Assistência à Saúde. Portaria no 788 , de 23 de outubro de 2002. Institui Manual de Apoio aos Gestores do Sistema Único de Saúde - SUS, para a organização dos Postos de Coleta da Rede de Laboratórios Clínicos. Diário Oficial da União. Brasília, no 207, p. 156-8, 24 out 2002. Seção 1.

9. Brasil. Ministério da Saúde. Secretaria de Assistência à Saúde. Portaria no 787, de 23 de outubro de 2002. Institui Manual de Apoio aos Gestores do SUS para organização da Rede de Laboratórios Clínicos. Diário Oficial da União. Brasília, no 207, p. 142-56, 24 out 2002. Seção 1

10. Brasil. Ministério da Saúde. Agência Nacional de Vigilância Sanitária. Resolução no 302, de 13 de outubro de 2005. Dispõe sobre Regulamento Técnico para funcionamento de Laboratórios Clínicos. [Internet]. 2005 [acesso 20 maio 2014]. Disponível: http://bvsms.saude.gov.br/bvs/ saudelegis/anvisa/2005/res0302_13_10_2005.html

11. Fortes PAC. Reflexões sobre a bioética e o consentimento esclarecido. Bioética. 1994;2(2):129-35 p.131.

12. Barata RB. Ética e epidemiologia. Hist Cienc Saúde-Manguinhos. [Internet]. 2005 set-dez [acesso 19 ago 2015];12(3):735-53. Disponivel: http://www.scielo.br/pdf/hcsm/v12n3/06.pdf

13. Brasil. Ministério da Saúde. Conselho Nacional de Saúde. Resolução $n=466$, de 12 de dezembro de 2012. Aprova as diretrizes e normas regulamentadoras de pesquisas envolvendo seres humanos. Diário Oficial da União. Brasilia, no 112, p. 59-62, 13 jun. 2013. Seção 1.

14. Schramm FR. A saúde é um direito ou um dever? Autocrítica da saúde pública. Rev Bras Bioét. 2006;2(2):187-200.

15. Barata RB. Ethics in epidemiological research. Ciênc Saúde Coletiva. 2008 mar-abr;13(2):453-8.

16. Coughlin SS. Ethical issues in epidemiologic research and public health practice. Emerg Themes Epidemiol. [Internet]. 2006 out [acesso 1 ago 2015];3:16. DOI: 10.1186/1742-7622-3-16

17. Fortes PAC. Vigilância sanitária, ética e construção da cidadania. In: De Seta MH, Pepe VLE, Oliveira GO, organizadores. Gestão e vigilância sanitária: modos atuais do pensar e fazer. Rio de Janeiro: Fiocruz; 2006. p. 61-9.

18. World Health Organization. Ethical considerations in developing a public health response to pandemic influenza. [Internet]. Geneva: WHO Press, 2007 [acesso 20 maio 2014]. Disponivel: http://www.who.int/csr/resources/publications/WHO_CDS_EPR_GIP_2007_2c.pdf

19. Garrafa V, Oselka G, Diniz D. Saúde pública, bioética e equidade. Bioética. 1997;5(1):27-33.

20. Dallari SG. A bioética e a saúde pública. In: Ferreira SI, Costa GO, Garrafa V, coordenadores. Iniciação à bioética. Brasilia: Conselho Federal de Medicina; 1998. p. 205-16.

21. Teixeira MG, Junior, JBR, Costa MCN. Vigilância epidemiológica. In: Rouquayrol MZ, organizador. Epidemiologia \& saúde. 6å ed. Rio de Janeiro: Medsi; 2003. p. 313-43.

22. Mann J. Saúde pública e direitos humanos. Physis. 1996;6(1-2):135-45.

23. Potter VR. Bioethics: bridge to the future. Englewood Cliffs, NJ: Prentice-Hall; 1971.

24. Diniz D, Guilhem D. O que é bioética. São Paulo: Brasiliense; 2002. (Primeiros Passos).

25. Organização das Nações Unidas para a Educação, a Ciência e a Cultura. Declaração Universal sobre Bioética e Direitos Humanos. [Internet]. Paris: Unesco; 2006 [acesso 15 fev 2014]. Disponivel: http://unesdoc.unesco.org/images/0014/001461/146180por.pdf

26. Novaes MRCG, Guilhem D, Lolas F. Dez anos de experiência do Comitê de Ética em Pesquisa da Secretaria de Saúde do Distrito Federal, Brasil. Acta Bioeth. 2008;14(2):185-92.

27. Meireles ACP. Venenos de Deus, remédios do diabo - uma análise bioética da obra de Mia Couto. Rev Bras Bioét. 2009;5(1-4):9-23. p.23.

28. Fortes PAC. A bioética em um mundo em transformação. Rev. bioét. (Impr.). 2011;19(2):319-27.

29. Vidal SV, Motta LCS, Gomes AP, Siqueira-Batista R. Problemas bioéticos na Estratégia Saúde da Família: reflexões necessárias. Rev. bioét. (Impr.). 2014;22(2):347-57.

Participação dos autores

Ligia Cantarino e Edgar Merchan-Hamann trabalharam conjuntamente em todas as etapas de elaboração do texto original deste artigo.

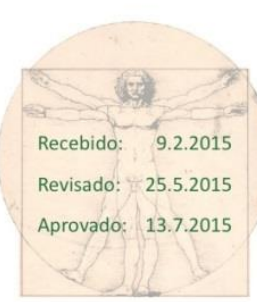




\section{ANEXO E - FICHA DE ENCAMINHAMENTO DE AMOSTRAS PARA PESQUISA DE VÍRUS RESPIRATÓRIOS (INFLUENZA SAZONAL)}

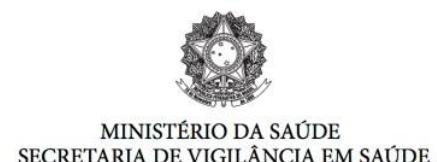

SECRETARIA DE VIGILÂNCIA EM SAỨDE

VIGILÂNCIA EPIDEMIOLÓGICA DA INFLUENZA FORMULÁRIO CLÍNICO LABORATORIAL

SENTINELA:

LABORATÓRIO:

Nome:

Município de Residência:

Vacinado contra Influenza:（ ）Sim （ ） Não

UF:

Data Nascimento: Outro País:

Data Início Sintomas:

\section{SINAIS E SINTOMAS}
( ) Febre
( ) Tosse
( ) Dor Garganta
( ) Dor Muscular
( ) Dor Cabeça
( ) Artralgia
( ) Coriza
( ) Dor Ouvido
( ) Obstrução Nasal

Outros sintomas:

Data Coleta da Amostra: 1

RESERVADO PARA LABORATÓRIO

$\mathrm{N}^{\circ}$ Registro: Espécime: ( ) ANF

( ) Swab Combinado

Sorologia ( ) 1 ( ) 2

Qualidade do Material: （ ) Adequado

( ) Inadequado

\begin{tabular}{|l|l|l|l|l|}
\hline \multicolumn{1}{|c|}{ RESULTADOS IF } & Negativo & Positivo & Inconclusivo & Observações \\
\hline Influenza A & & & & \\
\hline Influenza B & & & & \\
\hline Parainfluenza 1 & & & & \\
\hline Parainfluenza 2 & & & & \\
\hline Parainfluenza 3 & & & & \\
\hline Adenovírus & & & & \\
\hline Vírus Respiratório Sincicial & & & & \\
\hline
\end{tabular}

Data do Resultado: ___ Retorno do Resultado à Sentinela:___________ Responsável: 


\section{ANEXO F - FICHA DE DADOS AGREGADOS DA VIGILÂNCIA EPIDEMIOLÓGICA DA}

INFLUENZA SAZONAL

MINISTÉRIO DA SAÚDE

SECRETARIA DE VIGILÂNCIA EM SAÚDE

VIGILÂNCIA EPIDEMIOLÓGICA DA INFLUENZA

Unidade Sentinela:

Município:

Responsável:

Semana de UF:

\begin{tabular}{|c|c|c|}
\hline \multirow{2}{*}{$\begin{array}{l}\text { Faixa Etária } \\
\text { (em anos) }\end{array}$} & \multicolumn{2}{|c|}{ Número de Consultas } \\
\hline & Sindrome Gripal & Total \\
\hline 0 a 4 & & \\
\hline 5 a 14 & & \\
\hline 15 a 24 & & \\
\hline 25 a 55 & & \\
\hline 60 a 64 & & \\
\hline$\geq 65$ & & \\
\hline Idade ignorada & & \\
\hline Total & & \\
\hline
\end{tabular}


ANEXO G - DICIONÁRIO DE DADOS DO SIVEP-GRIPE (continua)

\section{Dicionário de Dados, versão antiga do SIVEP-Gripe}

FICHA DE REGISTRO INDIVIDUAL - CASOS DE SÍNDROME GRIPAL QUE REALIZARAM COLETA DE AMOSTRA

Este documento tem como finalidade descrever as variáveis exportadas para o banco de dados em DBF.

CAMPO OBRIGATÓRIO é aquele cuja ausência de dado impossibilita a inclusão do registro no sistema.

CAMPO ESSENCIAL é aquele que, apesar de não ser obrigatório, registra dado necessário à investigação do caso ou ao cálculo de indicador epidemiológico

ou operacional.

CAMPO INTERNO é aquele que apesar de não constar na ficha, é preenchido automaticamente pelo sistema, não aparece no display da tela e é persistido no banco de dados.

\begin{tabular}{|c|c|c|c|c|c|}
\hline Nome do campo & Tipo & Categoria & Descrição & Caracteristicas & DBF \\
\hline Registro do LACEN & Varchar2(10) & & $\begin{array}{l}\text { Número do registro no } \\
\text { Laboratório Central do Estado } \\
\text { (LACEN). }\end{array}$ & Campo Chave & REG_LAB \\
\hline Unidade Sentinela & Varchar2(7) & & $\begin{array}{l}\text { Unidade Sentinela que realizou o } \\
\text { atendimento e coleta de amostra } \\
\text { do caso. } \\
\\
\text { Obs: As unidades sentinelas } \\
\text { IPAMB e FUNDACCÃO RUBEN } \\
\text { BERTA foram atribuidos CO_CNES } \\
\text { O000001 e } 0000002 \text {, } \\
\text { respectivamente. }\end{array}$ & Campo Obrigatório & COD_UNID \\
\hline UF & Varchar2(2) & $\begin{array}{l}\text { Tabela com código e siglas das UF } \\
\text { padronizados pelo IBGE. }\end{array}$ & $\begin{array}{l}\text { Unidade Federativa onde está } \\
\text { localizada a Unidade } \\
\text { Sentinela que realizou a coleta. }\end{array}$ & $\begin{array}{l}\text { Campo Interno, preenchido a partir } \\
\text { do campo Sentinela. }\end{array}$ & COD_UF \\
\hline $\begin{array}{l}\text { Município } \\
\text { Código (IBGE) }\end{array}$ & Varchar2(6) & $\begin{array}{l}\text { Tabela com código e nomes dos } \\
\text { Municípios padronizados pelo IBGE }\end{array}$ & $\begin{array}{l}\text { Município onde está localizada a } \\
\text { Unidade Sentinela que realizou a } \\
\text { coleta. }\end{array}$ & $\begin{array}{l}\text { Campo Interno, preenchido a partir } \\
\text { do campo Sentinela. }\end{array}$ & COD_MUNIC \\
\hline
\end{tabular}


ANEXO G - DICIONÁRIO DE DADOS DO SIVEP-GRIPE (continuação)

\begin{tabular}{|c|c|c|c|c|c|}
\hline Laboratório & Varchar2(7) & & $\begin{array}{l}\text { Laboratório responsável pela } \\
\text { liberação do resultado do teste } \\
\text { diagnóstico (IFI) da amostra do } \\
\text { paciente. }\end{array}$ & Campo Obrigatório & LABORATO \\
\hline Nome & Varchar2(70) & & $\begin{array}{l}\text { Nome completo do paciente (sem } \\
\text { abreviações) }\end{array}$ & Campo Obrigatório & NOME_PAC \\
\hline Sexo & Varchar2(1) & $\begin{array}{l}\text { 1-Masculino } \\
\text { 2-Feminino } \\
\text { 9-Ignorado }\end{array}$ & Sexo do paciente. & Campo Obrigatório & SEXo \\
\hline Data de nascimento & $\begin{array}{c}\text { Data } \\
\text { DD/MM/AAAA }\end{array}$ & & Data de nascimento do paciente. & Campo Obrigatório & DT_NASC \\
\hline Idade & Varchar2(3) & & & $\begin{array}{l}\text { Campo Obrigatório } \\
\text { O campo idade é calculado e } \\
\text { preenchido automaticamente pelo } \\
\text { sistema: considerando o intervalo } \\
\text { entre a data de nascimento e a data } \\
\text { atual. }\end{array}$ & IDADE \\
\hline Idade/Tipo & Varchar2(1) & $\begin{array}{l}\text { 1-Dia } \\
\text { 2-Mês } \\
\text { 3-Ano }\end{array}$ & & $\begin{array}{l}\text { Campo Obrigatório } \\
\text { Se digitado a data de nascimento, o } \\
\text { campo Idade/Tipo é } \\
\text { calculado e preenchido } \\
\text { automaticamente pelo sistema: } \\
\text { considerando o intervalo entre a } \\
\text { data de nascimento e a data atual. }\end{array}$ & TP_IDADE \\
\hline Idade/Tipo + Idade & Varchar2(4) & & & $\begin{array}{l}\text { Campo Interno, calculado a partir do } \\
\text { campo Idade/Tipo + campo Idade. } \\
\text { Ex: } \\
2009 \text { - nove meses } \\
3018 \text { - dezoito anos }\end{array}$ & COD_IDADE \\
\hline UF & Varchar2(2) & $\begin{array}{l}\text { Tabela com siglas das UF padronizados } \\
\text { pelo IBGE. }\end{array}$ & $\begin{array}{l}\text { Unidade Federativa de residência } \\
\text { do paciente. }\end{array}$ & Campo Essencial & COD_UFRES \\
\hline Município & $\operatorname{Varchar2(7)}$ & $\begin{array}{l}\text { Tabela nome dos Municíios } \\
\text { padronizados pelo IBGE. }\end{array}$ & $\begin{array}{l}\text { Município de residência do } \\
\text { paciente. }\end{array}$ & Campo Essencial & COD_MUNRES \\
\hline Pais (se residente fora do Brasil) & Varchar2(3) & Tabela com código e nome dos Países. & País de residência do paciente. & $\begin{array}{l}\text { Campo Essencial } \\
\text { Para a exportação de base antiga } \\
\text { considerar sempre o código do pais } \\
\text { Brasil (1). }\end{array}$ & COD_PAIS \\
\hline
\end{tabular}


ANEXO G - DICIONÁRIO DE DADOS DO SIVEP-GRIPE (continuação)

\begin{tabular}{|c|c|c|c|c|c|}
\hline Vacinado contra Influenza? & Varchar2(1) & $\begin{array}{l}\text { 1-Sim } \\
\text { 2-Não }\end{array}$ & $\begin{array}{l}\text { Informar se o paciente foi } \\
\text { vacinado contra influenza, após } \\
\text { verificar a documentação / } \\
\text { caderneta. } \\
\text { Caso o paciente não tiver a } \\
\text { caderneta, direcionar a pergunta } \\
\text { para ele ou responsável e } \\
\text { preencher o campo com o código } \\
\text { correspondente a resposta. } \\
\end{array}$ & $\begin{array}{l}\text { Campo automaticamente preenchido } \\
\text { pelo sistema com a opção "Não". } \\
\text { Permite alteração. }\end{array}$ & VACINA \\
\hline Mês da última vacina & Varchar2(2) & $\begin{array}{l}\text { 01-Janeiro } \\
\text { 02-Fevereiro } \\
\text { 03-Marce } \\
\text { 04-Abril } \\
\text { 05-Maio } \\
\text { 06-Junho } \\
\text { 06-Juho } \\
\text { 08-Agosto } \\
\text { 09-Setembro } \\
\text { 10-Outubro } \\
\text { 11-Novembro } \\
\text { 12-Dezembro }\end{array}$ & $\begin{array}{l}\text { Mês da última vacina contra gripe } \\
\text { que o paciente tomou. }\end{array}$ & $\begin{array}{l}\text { Habilitado se campo Vacinado contra } \\
\text { Influenza for igual a } 1 .\end{array}$ & M_VACINA \\
\hline Ano da última vacina & Varchar2(4) & & $\begin{array}{l}\text { Ano da última vacina contra gripe } \\
\text { que o paciente tomou. }\end{array}$ & $\begin{array}{l}\text { Habilitado se campo Vacinado contra } \\
\text { Influenza for igual a } 1 .\end{array}$ & A_VACINA \\
\hline Data do Início dos Sintomas & $\begin{array}{c}\text { Date } \\
\text { DD/MM/AAAA }\end{array}$ & & Data do início dos sintomas. & Campo Obrigatório & DT_PRISINT \\
\hline $\begin{array}{l}\text { Semana Epidemiológica do Início dos } \\
\text { Sintomas }\end{array}$ & $\begin{array}{c}\text { Varchar2(6) } \\
\text { SSAAAA }\end{array}$ & & $\begin{array}{l}\text { Semana Epidemiológica do início } \\
\text { dos sintomas. }\end{array}$ & $\begin{array}{l}\text { Campo Interno, calculado a partir da } \\
\text { data dos Primeiros Sintomas. }\end{array}$ & SE_PRISINT \\
\hline Sinais e Sintomas/Febre & Varchar2(1) & \begin{tabular}{|l} 
1-Sim \\
2-Não
\end{tabular} & Paciente apresentou febre? & Campo Essencial & FEBRE \\
\hline Sinais e Sintomas/Tosse & $\operatorname{Varchar} 2(1)$ & $\begin{array}{l}\text { 1-Sim } \\
\text { 2-Não }\end{array}$ & Paciente apresentou tosse? & Campo Essencial & TOSSE \\
\hline Sinais e Sintomas/Dor de Garganta & Varchar2(1) & $\begin{array}{l}\text { 1-Sim } \\
\text { 2-Não }\end{array}$ & $\begin{array}{l}\text { Paciente apresentou dor de } \\
\text { garganta? }\end{array}$ & Campo Essencial & DOR_GARGAN \\
\hline Sinais e Sintomas/Dores Musculares & Varchar2(1) & $\begin{array}{l}\text { 1-Sim } \\
\text { 2-Não }\end{array}$ & $\begin{array}{l}\text { Paciente apresentou dores } \\
\text { musculares? }\end{array}$ & Campo Essencial & DOR_MUSCUL \\
\hline Sinais e Sintomas/Dor de Cabeça & Varchar2(1) & $\mid \begin{array}{l}\text { 1-Sim } \\
\text { 2-Nẫo }\end{array}$ & $\begin{array}{l}\text { Paciente apresentou dor de } \\
\text { cabeça? }\end{array}$ & Campo Essencial & DOR_CABECA \\
\hline Sinais e Sintomas/Artralgia & Varchar2(1) & $\mid \begin{array}{l}\text { 1-Sim } \\
\text { 2-Não }\end{array}$ & $\begin{array}{l}\text { Paciente apresentou Artralgia } \\
\text { (dor nas articulaçôes)? }\end{array}$ & Campo Essencial & ARTRALGIA \\
\hline Sinais e Sintomas/Coriza & Varchar2(1) & 1-Sim & Paciente apresentou Coriza? & Campo Essencial & CORIZA \\
\hline
\end{tabular}


ANEXO G - DICIONÁRIO DE DADOS DO SIVEP-GRIPE (continuação)

\begin{tabular}{|c|c|c|c|c|c|}
\hline & & 2-Não & & & \\
\hline Sinais e Sintomas/Dor de ouvido & Varchar2(1) & $\begin{array}{l}\text { 1-Sim } \\
\text { 2-Năo }\end{array}$ & $\begin{array}{l}\text { Paciente apresentou dor de } \\
\text { ouvido? }\end{array}$ & Campo Essencial & DOR_OUVID \\
\hline Sinais e Sintomas/Obstrução Nasal & Varchar2(1) & | & $\begin{array}{l}\text { Paciente apresentou obstrução } \\
\text { nasal? }\end{array}$ & Campo Essencial & OBS_NASAL \\
\hline Outros Sintomas & Varchar2(50) & & $\begin{array}{l}\text { Listar outros sinais e sintomas } \\
\text { apresentados pelo paciente. }\end{array}$ & Campo Essencial & OUT_SINT \\
\hline Data da Coleta & $\begin{array}{l}\text { Date } \\
\text { DD/MM/AAAA }\end{array}$ & & \begin{tabular}{|l} 
Data da coleta da amostra para \\
realização do teste diagnóstico.
\end{tabular} & Campo Obrigatório & DT_COLETA \\
\hline Semana Epidemiológica da coleta & $\begin{array}{l}\text { Varchar2(6) } \\
\text { SSAAAA }\end{array}$ & & $\begin{array}{l}\text { Semana Epidemiológica da coleta } \\
\text { da amostra para realizaçăo do } \\
\text { teste diagnóstico. }\end{array}$ & $\begin{array}{l}\text { Campo Interno, calculado a partir da } \\
\text { data da coleta. }\end{array}$ & SE_COLETA \\
\hline Natureza da Investigação & $\operatorname{Varchar2(1)}$ & $\begin{array}{l}\text { 1-Caso Esporádico } \\
\text { 2-Surto } \\
\text { 3-Epidemia }\end{array}$ & & $\begin{array}{l}\text { Campo automaticamente preenchido } \\
\text { pelo sistema com a opção "Caso } \\
\text { Esporádico". } \\
\text { Permite alteração. }\end{array}$ & NATU_INVES \\
\hline Natureza do Espécime & Varchar2(1) & $\begin{array}{l}\text { 1-ANF-Aspirado de nasofaringeo } \\
\text { 2-SC-Swab Combinado } \\
\text { 3-ANF e SC } \\
\text { 4-Sorologia } 1 \\
\text { 5-Sorologia } 2\end{array}$ & $\begin{array}{l}\text { Natureza do espécime da amostra } \\
\text { clínica. }\end{array}$ & & NATU_ESPEC \\
\hline Qualidade do Material & Varchar2(1) & $\begin{array}{l}\text { 1-Adequado } \\
\text { 2-Inadequado }\end{array}$ & $\begin{array}{l}\text { Qualidade do material da amostra } \\
\text { clíica para realizaçăo do teste } \\
\text { diagnóstico. }\end{array}$ & & QUALI_MAT \\
\hline IF Influenza A & Varchar2(1) & $\begin{array}{l}\text { 1-Positivo } \\
\text { 2-Negativo } \\
\text { 3-Inconclusivo } \\
\text { 4-Năo Realizado } \\
\text { 9-Ignorado }\end{array}$ & $\begin{array}{l}\text { Resultado diagnóstico da IFI para } \\
\text { Influenza A. }\end{array}$ & $\begin{array}{l}\text { Campo automaticamente preenchido } \\
\text { pelo sistema com a opção } \\
\text { "Negativo". } \\
\text { Permite alteração. }\end{array}$ & IFI_FLUA \\
\hline IF Influenza B & Varchar2(1) & $\begin{array}{l}\text { 1-Positivo } \\
\text { 2-Negativo } \\
\text { 3-Inconclusivo } \\
\text { 4-Não Realizado } \\
\text { 9-Ignorado }\end{array}$ & $\begin{array}{l}\text { Resultado diagnóstico da IFI para } \\
\text { Influenza B. }\end{array}$ & $\begin{array}{l}\text { Campo automaticamente preenchido } \\
\text { pelo sistema com a opção } \\
\text { "Negativo". } \\
\text { Permite alteração. }\end{array}$ & IFI_FLUB \\
\hline IF Parainfluenza 1 & Varchar2(1) & $\begin{array}{l}\text { 1-Positivo } \\
\text { 2-Negativo } \\
\text { 3-Inconclusivo } \\
\text { 4-Não Realizado } \\
\text { 9-Ignorado }\end{array}$ & $\begin{array}{l}\text { Resultado diagnóstico da IFI para } \\
\text { Parainfluenza } 1 .\end{array}$ & $\begin{array}{l}\text { Campo automaticamente preenchido } \\
\text { plo sistema com a opção } \\
\text { "Negativo". }\end{array}$ & IFI_PARA1 \\
\hline
\end{tabular}


ANEXO G - DICIONÁRIO DE DADOS DO SIVEP-GRIPE (continuação)

\begin{tabular}{|c|c|c|c|c|c|}
\hline & & & & Permite alteração. & \\
\hline IF Parainfluenza 2 & Varchar2(1) & $\begin{array}{l}\text { 1-Positivo } \\
\text { 2-Negativo } \\
\text { 3-Inconclusivo } \\
\text { 4-Não Realizado } \\
\text { 9-Ignorado }\end{array}$ & $\begin{array}{l}\text { Resultado diagnóstico da IFI para } \\
\text { Parainfluenza } 2 .\end{array}$ & $\begin{array}{l}\text { Campo automaticamente preenchido } \\
\text { pelo sistema com a opção } \\
\text { "Negativo". } \\
\text { Permite alteração. }\end{array}$ & IFI_PARA2 \\
\hline IF Parainfluenza 3 & Varchar2(1) & $\begin{array}{l}\text { 1-Positivo } \\
\text { 2-Negativo } \\
\text { 3-Inconclusivo } \\
\text { 4-Não Realizado } \\
\text { 9-Ignorado }\end{array}$ & $\begin{array}{l}\text { Resultado diagnóstico da IFI para } \\
\text { Parainfluenza } 3 .\end{array}$ & $\begin{array}{l}\text { Campo automaticamente preenchido } \\
\text { pelo sistema com a opção } \\
\text { "Negativo". } \\
\text { Permite alteração. }\end{array}$ & IFI_PARA3 \\
\hline IF Adenovírus & Varchar2(1) & $\begin{array}{l}\text { 1-Positivo } \\
\text { 2-Negativo } \\
\text { 3-Inconclusivo } \\
\text { 4-Não Realizado } \\
\text { 9-Ignorado }\end{array}$ & $\begin{array}{l}\text { Resultado diagnóstico da IFI para } \\
\text { Adenovirus. }\end{array}$ & $\begin{array}{l}\text { Campo automaticamente preenchido } \\
\text { pelo sistema com a opç̃ô } \\
\text { "Negativo". } \\
\text { Permite alteração. }\end{array}$ & IFI_ADENO \\
\hline IF VRS & Varchar2(1) & $\begin{array}{l}\text { 1-Positivo } \\
\text { 2-Negativo } \\
\text { 3-IIconclusivo } \\
\text { 4-Não Realizado } \\
\text { 9-Ignorado }\end{array}$ & $\begin{array}{l}\text { Resultado diagnóstico da IFI para } \\
\text { Virus Sincicial Respiratório. }\end{array}$ & $\begin{array}{l}\begin{array}{l}\text { Campo automaticamente preenchido } \\
\text { pelo sistema com a opção } \\
\text { "Negativo". } \\
\text { Permite alteração. }\end{array} \\
\end{array}$ & IFI_VRS \\
\hline Observação Imunofluorescência & Varchar2(250) & & $\begin{array}{l}\text { Outras observaç̃os sobre o teste } \\
\text { diagnóstico de } \\
\text { Imunofluorescência consideradas } \\
\text { pertinentes. }\end{array}$ & & OBSERVA_IF \\
\hline Data da realização do exame & $\begin{array}{c}\text { Date } \\
\text { DD/MM/AAAA }\end{array}$ & & $\begin{array}{l}\text { Data em que o exame foi } \\
\text { realizado. }\end{array}$ & Campo Essencial & DT_IFI \\
\hline Registro do LR & Varchar2(10) & & $\begin{array}{l}\text { Número do registro no } \\
\text { Laboratório de Referência (NIC). }\end{array}$ & Campo Chave & REG_NIC \\
\hline $\begin{array}{l}\text { Imunofluorescência Cultura - IF Influenza } \\
\text { A }\end{array}$ & Varchar2(1) & $\begin{array}{l}\text { 1-Positivo } \\
\text { 2-Negativo } \\
\text { 3-IInconclusivo } \\
\text { 4-Não Realizado } \\
\text { 9-lgnorado }\end{array}$ & $\begin{array}{l}\text { Resultado diagnóstico da IFI para } \\
\text { Influenza A. }\end{array}$ & $\begin{array}{l}\text { Campo automaticamente preenchido } \\
\text { pelo sistema com a opção } \\
\text { "Negativo". } \\
\text { Permite alteração. }\end{array}$ & CULT_FLUA \\
\hline $\begin{array}{l}\text { Imunofluorescência Cultura - IF Influenza } \\
\text { B }\end{array}$ & Varchar2(1) & $\begin{array}{l}\text { 1-Positivo } \\
\text { 2-Negativo } \\
\text { 3-IIconclusivo } \\
\text { 4-Não Realizado } \\
\text { 9-lgnorado }\end{array}$ & $\begin{array}{l}\text { Resultado diagnóstico da IFI para } \\
\text { Influenza B. }\end{array}$ & $\begin{array}{l}\text { Campo automaticamente preenchido } \\
\text { pelo sistema com a opção } \\
\text { "Negativo". } \\
\text { Permite alteração. }\end{array}$ & CULT_FLUB \\
\hline
\end{tabular}

Página 5 
ANEXO G - DICIONÁRIO DE DADOS DO SIVEP-GRIPE (continuação)

\begin{tabular}{|c|c|c|c|c|c|}
\hline $\begin{array}{l}\text { Imunofluorescência Cultura - IF } \\
\text { Parainfluenza } 1\end{array}$ & Varchar2(1) & $\begin{array}{l}\text { 1-Positivo } \\
\text { 2-Negativo } \\
\text { 3-Inconclusivo } \\
\text { 4-Não Realizado } \\
\text { 9-Ignorado }\end{array}$ & $\begin{array}{l}\text { Resultado diagnóstico da IFI para } \\
\text { Parainfluenza } 1 .\end{array}$ & $\begin{array}{l}\text { Campo automaticamente preenchido } \\
\text { pelo sistema com a opção } \\
\text { "Negativo". } \\
\text { Permite alteração. } \\
\end{array}$ & CULT_PARA1 \\
\hline $\begin{array}{l}\text { Imunofluorescência Cultura - IF } \\
\text { Parainfluenza 2 }\end{array}$ & Varchar2(1) & $\begin{array}{l}\text { 1-Positivo } \\
\text { 2-Negativo } \\
\text { 3-Inconclusivo } \\
\text { 4-Não Realizado } \\
\text { 9-Ignorado }\end{array}$ & $\begin{array}{l}\text { Resultado diagnóstico da IFI para } \\
\text { Parainfluenza } 2 .\end{array}$ & $\begin{array}{l}\text { Campo automaticamente preenchido } \\
\text { pelo sistema com a opção } \\
\text { "Negativo". } \\
\text { Permite alteração. }\end{array}$ & CULT_PARA2 \\
\hline $\begin{array}{l}\text { Imunofluorescência Cultura - IF } \\
\text { Parainfluenza } 3\end{array}$ & Varchar2(1) & $\begin{array}{l}\text { 1-Positivo } \\
\text { 2-Negativo } \\
\text { 3-Inconclusivo } \\
\text { 4-Não Realizado } \\
\text { 9-Ignorado }\end{array}$ & $\begin{array}{l}\text { Resultado diagnóstico da IFI para } \\
\text { Parainfluenza } 3 .\end{array}$ & $\begin{array}{l}\text { Campo automaticamente preenchido } \\
\text { pelo sistema com a opção } \\
\text { "Negativo". } \\
\text { Permite alteração. }\end{array}$ & CULT_PARA3 \\
\hline $\begin{array}{l}\text { Imunofluorescência Cultura - IF } \\
\text { Adenovirus }\end{array}$ & Varchar2(1) & $\begin{array}{l}\text { 1-Positivo } \\
\text { 2-Negativo } \\
\text { 3-Inconclusivo } \\
\text { 4-Não Realizado } \\
\text { 9-Ignorado }\end{array}$ & $\begin{array}{l}\text { Resultado diagnóstico da IFI para } \\
\text { Adenovírus. }\end{array}$ & $\begin{array}{l}\text { Campo automaticamente preenchido } \\
\text { pelo sistema com a opção } \\
\text { "Negativo”. } \\
\text { Permite alteração. }\end{array}$ & CULT_ADENO \\
\hline Imunofluorescência Cultura - IF VRS & Varchar2(1) & $\begin{array}{l}\text { 1-Positivo } \\
\text { 2-Negativo } \\
\text { 3-Inconclusivo } \\
\text { 4-Não Realizado } \\
\text { 9-Ignorado }\end{array}$ & \begin{tabular}{|l} 
Resultado diagnóstico da IFI para \\
Virus Sincicial respiratório (VRS).
\end{tabular} & $\begin{array}{l}\text { Campo automaticamente preenchido } \\
\text { pelo sistema com a opção } \\
\text { "Negativo". } \\
\text { Permite alteração. }\end{array}$ & CULT_VRS \\
\hline Data da realização do exame & $\begin{array}{l}\text { Data } \\
\text { DD/MM/AAAA }\end{array}$ & & $\begin{array}{l}\text { Data em que a cultura foi } \\
\text { realizado. }\end{array}$ & Campo Essencial & DT_CULTURA \\
\hline Dados da Cultura / Resultado Influenza A & $\operatorname{Varchar2(1)}$ & $\begin{array}{l}\text { 1-Positivo } \\
\text { 2--egativo } \\
\text { 3-Inconclusivo }\end{array}$ & & $\begin{array}{l}\text { Campo automaticamente preenchido } \\
\text { pelo sistema com a opção } \\
\text { "Negativo”. } \\
\text { Permite alteração. } \\
\end{array}$ & D_FLUA_RES \\
\hline Dados da Cultura / Influenza A / H & Varchar2(2) & Tabela com as opções de 1 a 16. & $\begin{array}{l}\text { Subtipo } \mathrm{H} \text { (hemaglutinina) para } \\
\text { Influenza A. }\end{array}$ & & FLUA_H \\
\hline Dados da Cultura / Influenza A / N & Varchar2(1) & Tabela com as opções de 1 a 9. & $\begin{array}{l}\text { Subtipo N (neuraminidase) para } \\
\text { Influenza A. }\end{array}$ & & FLUA_N \\
\hline $\begin{array}{l}\text { Dados da Cultura / Influenza A / } \\
\text { Caracterização do vírus }\end{array}$ & Varchar2(2) & $\begin{array}{l}\text { (A/Caracterização/No/Ano) } \\
01 \text { - A(H1N1)/2009 pandêmica } \\
02 \text { - A/AGUAN DONG/25/93 }\end{array}$ & & $\begin{array}{l}\text { Campo automaticamente preenchido } \\
\text { pelo sistema com a opção } \\
\text { "Isolamento". }\end{array}$ & FLUA_CARAC \\
\hline
\end{tabular}


ANEXO G - DICIONÁRIO DE DADOS DO SIVEP-GRIPE (continuação)

\begin{tabular}{|c|c|c|c|c|c|}
\hline & & 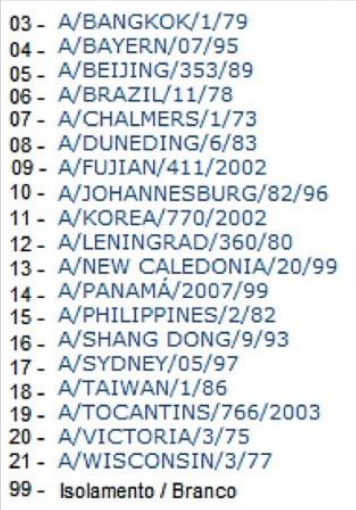 & & Permite alteração. & \\
\hline Dados da Cultura / Resultado Influenza B & Varchar2(1) & $\begin{array}{l}\text { 1-Positivo } \\
\text { 2--Negativo } \\
\text { 3-Inconclusivo }\end{array}$ & & $\begin{array}{l}\text { Campo automaticamente preenchido } \\
\text { pelo sistema com a opção } \\
\text { "Negativo". } \\
\text { Permite alteração. }\end{array}$ & D_FLUB_RES \\
\hline $\begin{array}{l}\text { Dados da Cultura / Influenza B / } \\
\text { Caracterização do vírus }\end{array}$ & Varchar2(2) & 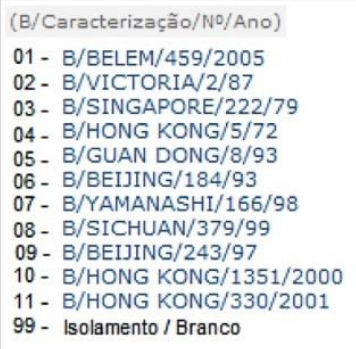 & & $\begin{array}{l}\text { Campo automaticamente preenchido } \\
\text { pelo sistema com a opção } \\
\text { "Isolamento". } \\
\text { Permite alteração. }\end{array}$ & FLUB_CARAC \\
\hline Outros & Varchar2 (30) & & $\begin{array}{l}\text { Listar outros resultados da } \\
\text { cultura. }\end{array}$ & & OUT_CULT \\
\hline
\end{tabular}


ANEXO G- DICIONÁRIO DE DADOS DO SIVEP-GRIPE (continuação)

\begin{tabular}{|l|l|l|l|l|l|}
\hline observação cultura & Varchar2(250) & & $\begin{array}{l}\text { Outras observaç̄es sobre a } \\
\text { cultura consideradas pertinentes. }\end{array}$ & & OBSERVA_C \\
\hline Data do Resultado & $\begin{array}{c}\text { Data } \\
\text { DDIMMAAA }\end{array}$ & & Data do resultado do exame. & Campo Obrigatório & DT_CuITUR \\
\hline
\end{tabular}


ANEXO H - PORTARIA MS № 2.693, DE 17 DE NOVEMBRO DE 2011* (continua)

$\mathrm{N}^{\circ} 81$, quinta-feira, 26 de abril de 2012

Ministério da Previdência Social GABINETE DO MINISTRO

PORTARIA N² 170, DE 25 DE ABRIL DE 2012 Altera a Portaria MPS/GM no 519 , de 24 de
agosto de 2011, que dispōe sobre as appli-
caçōes dos recursos financeiros dos Regi-
mes Próprios de Previdencia Social insti-
túdos pela União, Estados, Distrito Federal
e Municípios.

O MINISTRO DE ESTADO DA PREVIDÊNCIA SOCIAL no uso das atribuiçôes que lhe confere o art. 87, parágrafo único,
inciso II, da Constituiçăo e tendo em vista o disposto no inciso IV do art. $6^{\circ}$ da Lei no 9.717 , de 27 de novembro de 1998 , resolve: Art. $1^{\circ}$ Os art. $1^{\circ}, 3^{\circ}, 6^{\circ}$ e $9^{\circ}$ da Portaria MPS/GM no 519 ,

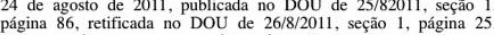
passam a vigorar com as seguintes alteraçōes:
"Art. $1^{\circ} \mathrm{A}$ Uniẫo, os Estados, o Distrito Federal e os $\mathrm{M}$ nicípios, em relação a seus Regimes Próprios de Previdência Socia de que trata a Resolução do Conselho Monetário Nacional - CMN que dispōe sobre a a aplicacãa dos dec mursos dos RPPS, mediante o
envio à Secretaria de Politicas de Previdência Social - SPPS, do

$\S 2^{\circ} \mathrm{O}$ envio do DPIN de que trata o caput somente oconcrerá
por via eletrônica, conforme estipulado pela SPPS letrônica, conforme estipulado pela SPPS. "Art. $3^{\circ}$ A União, os Estados, o Distrito Federal e os Mu-
nicípios deverão observar na gestato dos recursos de seus RPPS as
seguintes obrigaçōes, além daquelas previstas na Resoluçẫo do CMN que dispōe sobre a aplicação dos recursos dos RPPS:

I - na gestão por entidade autorizada e credenciada, realiza
processo seletivo e submetê-lo à instância superior de delibear endo como critérios, no mínimo, a solidez patrimonial da entidade. compatibilidade desta com o volume de recursos e a experiência
positiva no exercício da atividade de administração de recursos de positiva
terceiros;

IX - na gestão própria, antes da realização de qualquer ope-
ssegurar que as instituicōes escolhidas para receber as applraçăo, assegurar que as instituicô̄es escolhidas para receber as apl-
caçōes tenham sido objeto de prévio cadastramento caçōes tenham sido objeto de prévio cadastramento.
$\S 1^{\circ}$ Para o cadastramento referido no inciso IX deste artigo deverão ser observados, e formalmente atestados pelo representante
legal do RPPS, no mínimo, quesitos como: a) atos de registro ou autorização para funcionamento ex-
pedido pelo Banco Central do Brasil ou Comissão de Valores Mobiliários ou órgão competente;
b) observacão de elevado padrão ético de conduta rações realizadas no mercado financeiro e ausência de restriçōes que a critério do Banco Central do Brasil, da Comissão de Valores Mo-
biliários ou de outros órgâos competentes desaconselhem um rebiliários ou de outros órgãos competentes desaconselhem um re-
lacionamento seguro. dastramento previsto no inciso IX deste artigo tecaira sobre a figur gestor e do administrador do fundo." (NR)

\$ $3^{\circ} \mathrm{A}$ inexistência de recursos do RPPS deverá ser in a SPPS, pelo ente federativo, por meio do DPIN." (NR) "Art. $9^{\circ} \mathrm{A}$ SPPS e a Empresa de Tecnologia e Informaçōes
da Previdência Social - DATAPREV adotarão as medidas necesśrias à implementação das disposiçóes desta Portaria." (NR) Art $2^{\circ} \mathrm{A}$ Portaria MPS/GM $\mathrm{n}^{\circ} 519$, de 24 de agost
passa a yigorar acrescida dos seguintes art. $3^{\circ}-\mathrm{A}$ e $3^{\circ}-\mathrm{B}$ :

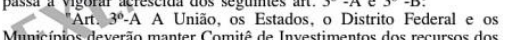
Municíípios deverão manter Comite de Investimentos dos recursos dos
seus respectivos RPPS, como órgão auxiliar no processo decisório seus respectivos RPPS, como órgão auxiliar no processo decisório
quanto à execução da politica de investimentos, cujas decisōes serão registradas em ata.
$\$ 1^{\circ}$ Compete ao ente federativo estabelecer em ato normativo a estrutura, composição e funcionamento do Comitê de Investimentos previsto no caput, respeitada a exigência de que seu
membros mantenham vínculo com o RPPS, na forma definida no $\$ 4$ membros $\mathrm{r}$
do art. $2^{\circ}$.

$\$ 2^{\circ}$ A implantação do Comitê de Investimentos previsto no
caput será exigida após decorridos 180 (cento e oitenta dias) da caput será exigida após decorridos 180 (cento e oitenta dias) da
publicação desta portaria, sendo facultativa para os RPS cujos recursos nâo atingirem o limite definido no art. $6^{\circ}$, enquanto mantida essa condiçāo.".
"Art. 30- B As aplicaçôes ou resgates dos recursos dos RPPS deverão ser acompanhadas do formulário APR - Autorização de Aplicaçăo e Resgate, conforme modelo e instruçôes de preenchimento
disponibilizados no endereço eletrônico do MPS na rede mundial de computadores internet (www.previdencia.gov.br)

Parágrafo único. A utilização do formulário APR mencio-
nado no caput seŕ́ exigida nado no caput será exigida após decorridos 60 (sessenta) dias
publicação desta Portaria." blicação.

GARIBALDI ALVES FILHO
Diário Oficial da Uniāo - Seção 1

ISSN 1677-7042

37 . INSTITUTO NACIONAL DO SEGURO SOCIAL RESOLUÇãO No 196, DE 25 DE ABRIL DE 2012 Estabelece procedimentos a serem adotados
para Avaliacão Médico-Pericial relaciona-
dos à aposentadoria especial.

FUNDAMENTAÇ̃̃O LEGAL

Lei $\mathrm{n}^{\circ} 8.213$, de 24 de julho de 1991 ;
Decreto $\mathrm{n}^{\circ} 3.048$, de 6 de maio de 199

Decreto $\mathrm{n}^{\circ} 4.082$, de 18 de novembro de 2003 .

2010.

O PRESIDENTE DO INSTITUTO NACIONAL DO SE-

GURO SOCIAL - INSS, no uso da competência que the foi conferida necessidade de uniformizar os procedimentos para Avaliação MédicoPericial para a concessão de aposentadoria especial, resolve:

Art. $1^{\circ}$ Ficam aprovados os procedimentos para a Avaliação
Médico-Pericial para a concessão de aposentadoria especial, na forma Médico-Pericial para a concessão de aposentadoria especial, na forma

Resoluçấo serão objeto de Despacho Decisório, de competência do Diretor de Saúde do Trabalhador - DIRSAT.
$\$ 2^{\circ} \mathrm{O}$ Anexo será publicado no Boletim de Serviço.

$\S 2^{\circ} \mathrm{O}$ Anexo será publicado no Boletim de Serviço.
Art. $2^{\circ}$ Esta Resolução entra em vigor na data da sua $\mathrm{p}$ de setembro de 1999.

MAURO LUCIANO HAUSCHILD

Ministério da Saúde

GABINETE DO MINISTRO

PORTARIA N².693, DE 17 DE NOVEMBRO DE 2011\% Estabelece mecanismo de repassse financei-
ro do Fundo Nacional de Saudd aos Fundos
de Saúde Estaduais, do Ditstrito Federal e
Municípios, por meio do Piso Variável de Municípios, por meo do Piso Variável de
Vigilância e Promoçã̃o da Saúde, para implantação implementação e fortalecimento
da Vigiầncia Epidemiológica da Influen-

O MINISTRO DE ESTADO DA SAÚDE, no uso das atribuiçōes que the conferem os incisos I e II do parágrafo único do artigo 87 da Constituição, e
Considerando a Portaria $n^{\circ} 3.252 / \mathrm{GM} / \mathrm{MS}$, de 22 de deZembro de 2009 , que aprova as diretrizes para execução e finan-
ciamento das açōes de Vigiância em Saúde pela Uniâo, Estados. Distrito Federal e Municíipios e edá outras providencicias; Considerando a Portaria Conjunta $\mathrm{n}^{\circ} 1 / \mathrm{SE} / \mathrm{SVS} / \mathrm{MS}$, de 11 de
de 2010, que define os yalores anuais do Componente de marco de 2010, que define os valores anuais do Componente de
Vigilância e Promoção da Saúde, relativos aos recursos federais destinados ao Piso Fixo de Vigilância e Promoção da Saúde e Piso Variável de Vigilância e Promocãa da Saúde, de cada Estado;
Considerando a Portaria n ${ }^{\circ}$ 104/GM/MS, de 25 de jane 2011, que define as terminologias adotadas em legislaçâa nacional, conforme o disposto no Regulamento Sanitário Intermacional 2005 de notificacão compulsória em todo o território nacional e estabelece fluxo, critérios, responsabilidades e atribuiçốes aos profissionais e serviços de saúde; e

Considerando a necessidade de identificação da circulação fluenza Sazonal para o Hemisfério Sul; para o isolamento de esfluenzza sazonal para o Hemisfério Sul; para o isolamento de es-
pécimes virais e seu devido envio ao Centro Colaborador de Influenza para as Américas da Organização Mundial da Saúde (OMS) para a identificação do vírus respiratórios de acordo com a pato-
genicidade e virulência em cada perído sazonal, visando a orientaç̃̃ erapêutica de acordo com o agente; para garantir representatividade mínima da circulação viral em todos os estados do país, tanto em casos graves/leves; para a identificaçāo inusitada e precoce de novo lógica da Influenza, resolve:

Art. $1^{\circ}$ Estabelece mecanismo de repasse financeiro do Fundo Nacional de Saúde (FNS) aos Fundos de Saúde dos Estados, do Distrito Federal e de Municííios, por meio do Piso Variável de Vi-

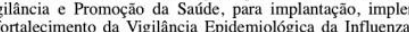

Art. $2^{\circ}$ Definir como sítios sentinelas de atuaçáo da Vigilância Epidemiológica da Influenza as capitais e cidades de região metropolitana de capitais, com populaçáo igual ou superior a 300.000 população igual ou superior a 300.000 mil habitantes independentes de pertencer à região metropolitana.
$\& 1^{\circ}$ As Unidades Sentinelas de Vigilância de Síndrome Gri$\S 1^{\circ}$ As Unidades Sentinelas de Vigilância de Síndrome Gri-
pal (SG) existentes em Municípios que não obedecem ao critério definido neste artigo serão mantidas, desde que atendam às espe-
$\$ 2^{\circ}$ As Unidades Sentinelas de Vigilância de Síndrome Gri-
pal (SG) existentes nos demais Municíios que não obedecem ao critério definido neste artigo, nem ao criterio definido no $\S 1^{\circ}$ deste artigo serão mantidas, desde que assumam o compromisso do cum-
primento das metas estabelecidas no art. 13 .
Art. $3^{\circ} \mathrm{O}$ recebimento do incentivo à Vigilância EpidemioArt. $3^{\circ} \mathrm{O}$ recebimento do incentivo à Vigilância Epidemio-
lógica da Influenza será por meio de adesão. do Termo de Adesão, constante no anexo I a esta Portaria, e submetido à Comissão Intergestores Bipartite $(\mathrm{CIB})$, para pactuação e homologação com posterior encaminhamento, em até 90 (noventa) dias contados da data de publicação desta Portaria, à Secretaria de
Vigilância em Saúde (SVS) para publicacãa da portaria de autorização de repasse do incentivo, considerando sob qual gestâo o estabelecimento se encontra.

Art. $4^{\circ}$ Nas capitais do país e nos Municípios da Região Sul plementadaça a Vigiâância 300 mil habitantes serão implantadas ou imtrês componentes: a Vigilância de Síndrome Respiratória Aguda Gra-
ve (SRAG), a Vigilância de Síndrome Gripal (SG) e a notificaçăo de J09 a J18. Parágrafo único. Para definiçāo de SRAG e de SG deverá ser
adotado o Manual de Vigilância Epidemiológica do Ministério da Saúde em vigência.
Art. $5^{\circ}$ Nos Municípios com população $>$ que 300 mil habitantes de região metropolitana das capitais de outras regiôes do paiśs serão implantadas ou implementadas a vigilância de Sindrome Gripal
(SG) e a notificą̧ão de internaçôs por CID J09 a J18. (SG) e a notificação de internaçōes por CID Jo9 a J18.
Art. $6^{\circ}$ Em caráter excepcional os Estados poderão solicitar a
inclusão de Unidades de Vigilâneia Sentinela de Influenza, encaminhando proposta a ser analisada pela SVS. \& $1^{\circ} \mathrm{A}$ Secretarias Estaduais deverăo encaminhar proposta
pactuada na CIB, papresentando a justificativa epidemiológica e aten-
dendo as condiçoes de adesăo de que trata esta portaria. $\S 2^{\circ}$ As propostas devem ser encaminhadas em até 90 (no-
venta) dias após a republicação desta Portaria, à SVS para publicaçăo da portaria de autorizaçāo de repasse do incentro, considerando sob Atr. $7^{\circ}$ A Vigilância de SRAGG será implantada/implemen-
tada em Unidades de Terapia Intensiva - UTI, definidas de acordo com a população, conforme o anexo II.
Art. $8^{\circ} \mathrm{A}$ Vigilância de SG será implantada ou implementada

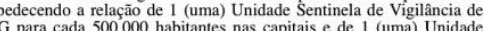
SG para cada 500.000 habitantes nas capitais e de 1 (uma) Unidade
Sentinela de Vigiância de SG em municípios com população $>$
300.000 habitantes da região sul e das regiōes metropolitanas de capitais das demais regiōes.
colion

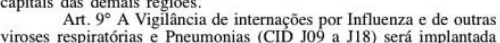
viroses respiratórias e Pneumonias (CID J09 a J18) será implantada ou implementada com a exigência de notificaçăa agregada semanal de
internação por estes CID e deve ser compilada por meio da captação pitalares (AIH) emitidas pelos municípios semanalmente.
Art. 10. Mantém-se o critério de notificação universal de Art. 10. Mantém-se o critério de notificação universal de
todos os casos de SRAG que sejam um evento inusitado, devendo ser
notificados em 24 horas e incluádos no Sinan web Influenza, com a devida coleta de material e envio para o LACEN.
Art. 11 . Os critérios para implantaçâo/implementação da Vigilância Epidemiológica da Influenza são:
$\S 1^{\circ}$ Para a Vigilância da SRAG, apresentar proposta onde conste: I - o número de internaçōes pelos CID de J09 a J18 respectivamente no ano de 2010 no Município e esssas UTI;
II - a escolha dos servicos deve procurar abranger apro-
ximadamente $10 \%$ dos leitos de UTI existentes no Município e que atendam preferencialmente todas as faixas etárias;
III - o número de UTT públicas e privadas vinculadas ou não o SUS existente no Município bem como o respectivo número de leitos em cada serviço;
IV - o número de UTI com o número de leitos públicos e privados vinculados ou não ao SUS do Município, que comporão a Vigiância da -os Municípios que não tiverem UTI privadas vinculadas ou nâo ao SUS podem incluir outra UTI pública;

VI - o Município deve se comprometer a notificar e in-
vestigar $80 \%$ dos casos de SRAG das UTI inclúídas na Vigilância da o sistema de Influenza online; e
VII - o Município deve se comprometer a fazer informe semanal do número de internaçōes por CID 509 a J18, nas UTI participantes (alimentação de sistema informatizado de planilha se$90 \%$ das semanas do ano.
$\& 2^{\circ}$ Para a Vigilância da SG, apresentar proposta onde consI - implantação ou implementação de unidade de Vigilância
da SG, nas capitais, a cada intervalo populacional de 500.000 habitantes; II - as cidades com população > de 300.000 habitantes da região sul e das regiôes metropolitanas das capitais das demais re-
giôes devem implantar 1 (uma) unidade de Vigilância da SG: III - as Unidades Sentinelas de Vigilancia da SG devem ter atendimento para todas as faixas etárias;
IV - os serviços eleitos para serem sítios de Vigilância da SG, devem ser unidades de urgência/emergência (Pronto Socorro, Pronto Atendimento ou Unidade de Pronto Atendimento); $\mathrm{V}$ - as unidades de Vigilância da SG devem informar pro-
porçấo de SG sobre o total de atendimentos realizados pelo serviço de ência/emergência;

Este documento pode ser verificado no endereço eletrônico http://www.in.govbr/autenticidadehtml, Documento assinado digitalmente conforme MP n⿳⺈ 2.200-2 de 24/08/2001, que institui pelo código 0001201204260003 Infraestrutura de Chaves Públicas Brasileira - ICP-Brasi. 
ANEXO H - PORTARIA MS № 2.693, DE 17 DE NOVEMBRO DE 2011* (continuação)

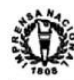

38

ISSN 1677-7042

Diário Oficial da Uniāo - Seção 1

$\mathrm{N}^{\circ} 81$, quinta-feira, 26 de abril de 2012

VI - as unidades de Vigilância da SG devem coletar 5 (cinco) amostras por semana e coletar todas as semanas;
VII - as unidades devem atingir, no mínimo, $80 \%$ de notificação e coleta de material da meta semanal, por Semana Epi-

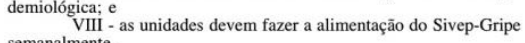
semanalmente.
$\S 3^{\circ}$ Para a notificação de internaçōes por CID J09 a J18 a capitais e cidades com populacão > 300.000 habitantes da região su notificar de forma agregada, semanalmente as internacôos por CID J09 a J18 digitadas no Sistema de Informação de Hospitalizaçāo (SIH). Art. 12. Os valores de repasse do Incentivo de Vigilância Epidemiológica da Influenza para Estados, Di

Art. 13. Os insumos laboratoriais necessários para a realização da técnica de Imunofluorescência (IFI) e rt - PCR em tempo real, para diagnóstico de vírus influenza e outros vírus respira
serão disponibilizados aos LACEN, pelo Ministério da Saúde. Art. 14. O recebimento do incentivo financeiro por parte do
Distrito Federal e Municíios implica no compromisso do cumprimento das metas:
$\$ 1^{\circ}$ Para a Vigilância da SRAG:

1 notificação de no mínimo $80 \%$ dos casos de SRAC intermados nos -serviços escolhidos, com o devido envio de amostra aos LACEN e digitação no sistema de Influenza web; e

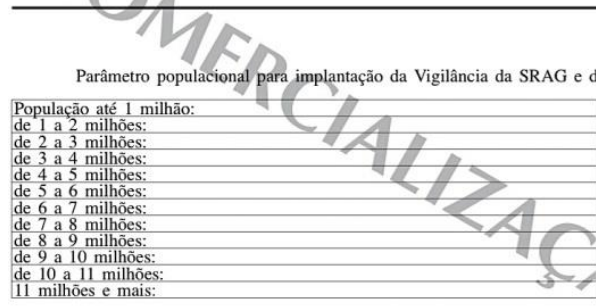

II - notificaçāo semanal do número de internaçōes por CID
J09 a J18, nas UTI participantes com regularidade de $90 \%$ das semanas Epidemiológicas.
$\$ 2^{\circ}$ Para a Vigilância

\$ $2^{\circ}$ Para a Vigilância da SG: material por Semana Epidemiológica (SE);
II - ter informaçăo da proporçâo de atendimentos por SG, em relação ao total de atençimentos no servaiço;
III - notificação de casos de $\mathrm{SG}$ em no ano; $\mathrm{e}$

IV - alimentação do Sivep-Gripe.
$\S 3^{\circ}$ Para a Vigilância de internaçes por CID J09 a J18 informar o total de internaçóes na planilila de notorificacãa agregada, das semanas Art. 15. As metas definidas no artigo anterior e seus pa-
rágrafos serâo monitoradas e avaliadas formalmente a cada seis meses rágrafos serão monitoradas e avaliadas formalmente a cada seis meses na suspensão do repasse deste incentivo.
Art. 16 . O Crédito orçamentário de que trata esta Portaria, Art. 16. O Crédito orçamentário de que trata esta Portaria,
correrá por conta do orcamento do Ministério da Saúde, devendo correrá por conta do orçamento do Ministério da Saude, devendo
onerar o Programa de Trabalho - $10.305 .1444 .20 \mathrm{AL}$ - Incentivo Fi-
nanceiro aos Estados, Distrito Federal e Municípios para a Vigilância nanceiro aos Estados, Distrito Federal e Municípios para a Vigilância
em Saúde. em Saúde. Art. 17. Esta Portaria entra em vigor na data de sua pu-
blicação.

ALEXANDRE ROCHA SANTOS PADILHA

ANEXO II
ANEXO I

TERMO DE ADESÃO

A Secretaria Estadual/Municipal de Saúde de:

, representada

por seu Secretário (a):

vem, por meio deste, oficializar o compromisso de adesão conforme a proposta da Portaria GM/MS n ${ }^{\circ}$ de de de 2011, passando a realizar a Vigilância de internações por CID J09 a J18; SRAG; e

Vigilância de Síndrome Respiratória Aguda Grave -

() Vigilância Sentinela de Síndrome Gripal - SG ( ).

A adesão ao fortalecimento da Vigilância Epidemiológica da Influenza implicará no desenvolvimento das atividades propostas e no cumprimento das metas estabelecidas na referida Portaria.

Atenciosamente,

Secretário Estadual/Municipal de Saúde Data: ___ _ _ _ _

*A cada intervalo populacional de 500.000 habitantes deve-se implantar 01 unidade de Vigilância da SG ANEXO III

Incentivo para implantação da Vigilâncià Ampliada de Influenza
putais, e municípios com população $>300$ mil habitantes da Regiầo Sul

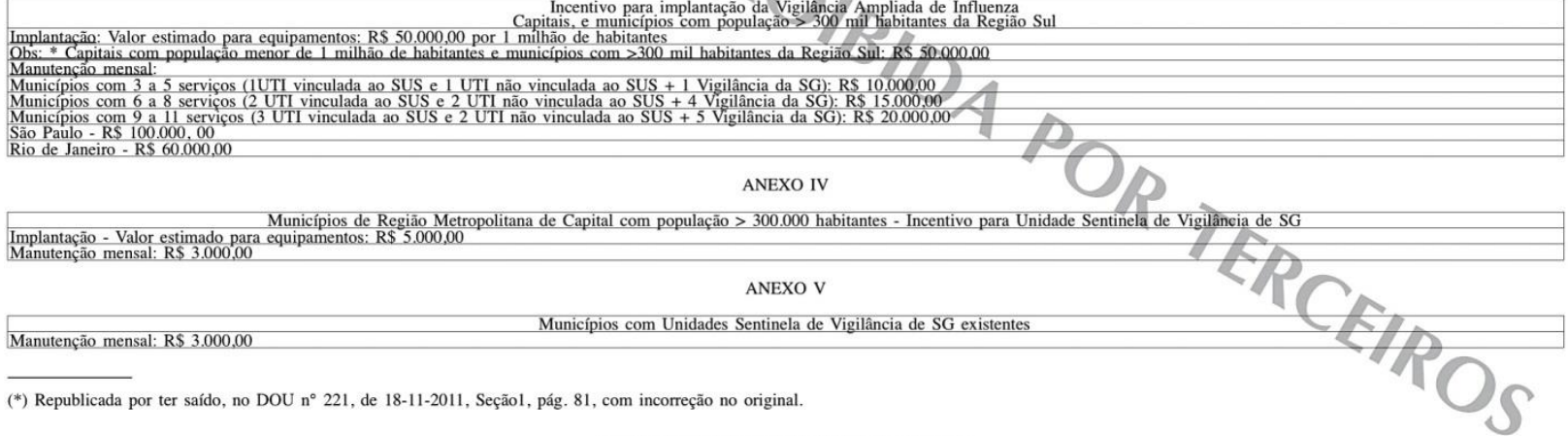

(*) Republicada por ter sádo, no DOU n 221, de 18-11-2011, Seçãol, pág. 81, com incorreção no original.

PORTARIA N"794, DE 25 DE ABRIL DE 2012

Estabelece recursos a serem incorporados ao Teto Financeiro Anual de Média e Alta Complexidade do Estado do Paraná e do Munićípio de Apucarana (PR)

O MINISTRO DE ESTADO DA SAÚDE, no uso da atribuição que lhe conferem os incisos I e II do parágrafo único do art. 87 da Constituição, e serviços de urgências $24 \mathrm{~h}$ da Rede de Atenção às Urgências, em conformidade com o Política Nacional de Atenção às Urgênecias;

Considerando que o Município recebeu o repasse das 3 (três) parcelas referentes aos incentivos financeiros para investimento; e
Considerando a visita técnica realizada pela Secretaria de Atenção à Saúde - Departamento de Atenção Especializada/Coordenação-Geral de Urgência e Emergência no Município de Apucarana (PR), no dia 15 de março de 2012, resolve: Art.
do Município de Apucarana (PR), na forma do anexo a esta Portaria.

Parágrafo unico. Os recursos serão destinados ao custeio e à manutenção da Unidade de Pronto Atendimento (UPA) Porte II no Município de Apucarana (PR)

Art. $3^{\circ}$ Os recursos financeiros, objeto desta Portaria, correrão por conta do orçamento do Ministério da Saúde, devendo onerar o Programa de Trabalho 10.302.2015.8585 - Atenção à Saúde da População para Art. $4^{\circ}$ Me Media e Alta Complexidade.

ALEXANDRE ROCHA SANTOS PADILHA

ANEXO

\begin{tabular}{|l|c|c|c|c|}
\hline \multicolumn{1}{|c|}{ Município } & UPA II & Valor Anual & CNES & Proposta/SISPAG \\
\hline Apucarana UPA 24h & 1 & 2.100 .000000 & 6972497 & $02575.748000 / 1090-01$ \\
\hline TOTAL & & $2.100 .000,00$ & \\
\hline
\end{tabular}

Este documento pode ser verificado no endereço eletrônico http://www.in.govbrautenticidadehtml, pelo código 00012012042600038

Documento assinado digitalmente conforme MP $\mathrm{n}^{9} 2.200-2$ de 24/08/2001, que institui a Infraestrutura de Chaves Públicas Brasileira - ICP-Brasil. 